UNIVERSIDADE DE SÃO PAULO

FACULDADE DE FILOSOFIA, LETRAS E CIÊNCIAS HUMANAS

DEPARTAMENTO DE GEOGRAFIA

PROGRAMA DE PÓS-GRADUAÇÃO EM GEOGRAFIA FÍSICA

ISABEL BARBOSA DOS ANJOS

ANÁLISE DE INTERNAÇÕES POR DOENÇAS DO APARELHO RESPIRATÓRIO, PACIENTES RESIDENTES EM MARINGÁ-PR: RELAÇÕES COM O ESPAÇO URBANO E A VARIABILIDADE CLIMÁTICA.

VERSÃO REVISADA

São Paulo

2011 
UNIVERSIDADE DE SÃO PAULO

FACULDADE DE FILOSOFIA, LETRAS E CIÊNCIAS HUMANAS

DEPARTAMENTO DE GEOGRAFIA

PROGRAMA DE PÓS-GRADUAÇÃO EM GEOGRAFIA FÍSICA

\section{ANÁLISE DE INTERNAÇÕES POR DOENÇAS DO APARELHO RESPIRATÓRIO, PACIENTES RESIDENTES EM MARINGÁ-PR: RELAÇÕES COM O ESPAÇO URBANO E A VARIABILIDADE CLIMÁTICA.}

ISABEL BARBOSA DOS ANJOS

Tese apresentada ao Programa de Pós Graduação em Geografia Física, do Departamento de Geografia da Faculdade de Filosofia, Letras e Ciências Humanas da Universidade de São Paulo, para a obtenção do título de doutor em Geografia.

Área de concentração: Geografia Física.

Orientador: Prof. Dr. Gil Sodero de Toledo

Co-orientação: Prof. ${ }^{a}$ Dr ${ }^{a}$. Maria Eugênia Moreira Costa Ferreira

VERSÃO REVISADA

São Paulo

2011 


\section{FOLHA DE APROVAÇÃO}

Isabel Barbosa dos Anjos

Análise de internações por doenças do Aparelho Respiratório, pacientes residentes em Maringá-PR: Relações com o espaço urbano e a variabilidade climática.

Aprovado em:

Banca Examinadora

Prof. Dr. Emerson Galvani (Presidente) Universidade de São Paulo - USP

Prof $^{\mathrm{a}}$ Dr ${ }^{\mathrm{a}}$. Maria Eugênia Moreira Costa Ferreira

Universidade Estadual de Maringá - UEM

Prof. Dr. José Tadeu Garcia Tommaselli

Universidade Estadual de São Paulo (UNESP - Presidente Prudente)

Prof. Dr. Hélio Silveira

Universidade Estadual de Maringá - UEM

Prof. Dr. Victor de Assunção Borsato

Faculdade Estadual de Ciências e Letras de Campo Mourão

São Paulo

2011 


\section{DEDICATÓRIA}

Aos Anjos de minha vida: Antonio Barbosa dos Anjos, Maria Minervina dos Anjos (meus pais) e ao meu Anjo da Guarda: Natanael. 


\section{AGRADECIMENTOS}

Primeiramente a Deus, pela vida, saúde, discernimento, pela família, os amigos e todos os dons que Ele me deu.

Ao professor doutor Gil sodero de Toledo, Universidade de São Paulo por ter-me aprovado nesse Programa e pela orientação.

A professora doutora Maria Eugenia Moreira Costa Ferreira, Universidade Estadual de Maringá, pela orientação.

A professora doutora Ligia Viseu Barroso e ao professor doutor Emerson Galvani Universidade de São Paulo, pela colaboração.

Ao professor doutor Victor de Assunção Borsato, Faculdade de Jandaia do Sul e a professora doutora Leonor Marcon da Silveira, Universidade Estadual de Maringá, pela contribuição.

Aos colegas de trabalho, da Estação Climatológica Principal de Maringá, Edson Carlos Martins, Elia Crespi Vasconcelos e Marilene Avancini e a Sonia Maria da Silva, pelo apoio.

A Secretaria Regional de Saúde, pela permissão das informações cedidas e a Márcia com prestativa explicação, auxiliou-me nos primeiros passos, de como extrair as informações necessárias contidas nas Autorizações de Internações Hospitalares $(\mathrm{AlH})$.

Especial agradecimento ao professor doutor Jonas Teixeira Nery, Universidade Estadual de São Paulo (UNESP-Ourinhos), que um dia acreditou em minha capacidade e incentivou-me a continuar. Acredito que, sem o seu apoio no passado, jamais conseguiria concluir essa tese, hoje. Muito obrigada de coração.

A todos, que de forma indireta ajudaram-me na conclusão desta tese. 
[...] talvez não tenhamos conseguido fazer o melhor, mas lutamos para que $o$ melhor fosse feito [...] Não somos o que deveríamos ser, mas somos o que iremos ser. Mas graças a Deus, não somos o que éramos (Martin Luther King). 


\section{SUMÁRIO}

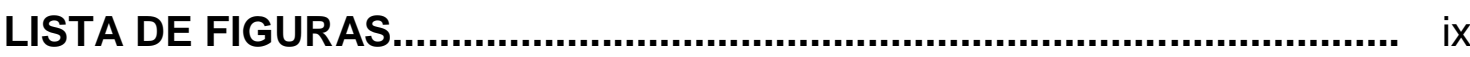

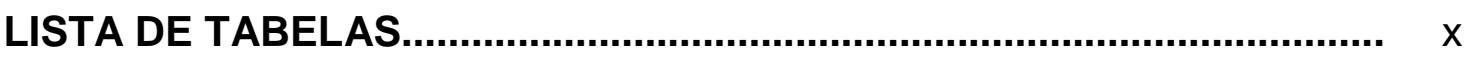

LISTA DE APÊNDICES....................................................................... xiii

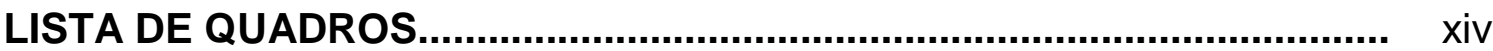

LISTA DE ABREVIATURAS.............................................................. xiv

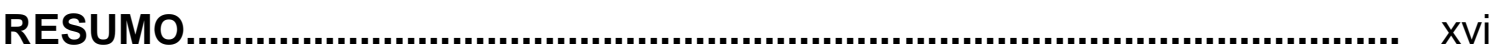

ABSTRACT

RESUMEN........................................................................................ xviii

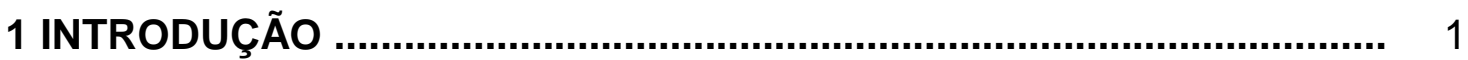

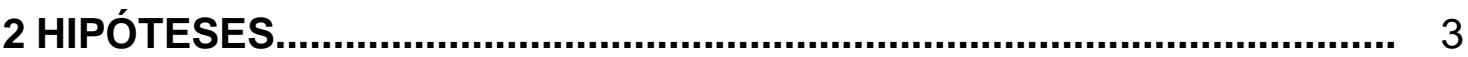

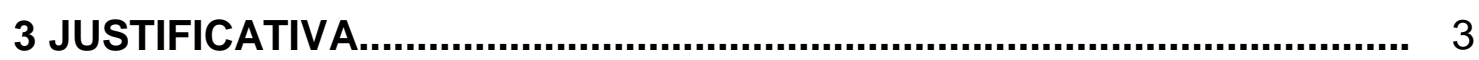

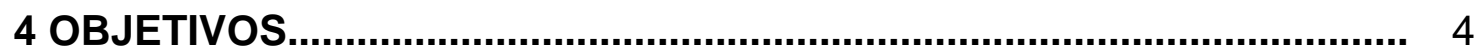

4.1 OBJETIVOS ESPECÍFICOS........................................................... 4

5 REVISÃO DE LITERATURA …...................................................... 5

5.1 A SAÚDE NO BRASIL............................................................... 5

5.2 GEOGRAFIA MÉDICA E GEOGRAFIA DA SAÚDE............................ 9

5.3 ESTUDOS DO CLIMA RELACIONADOS À SAÚDE............................. 12

5.4 ESTUDOS DO CLIMA RELACIONADOS A DOENÇAS
RESPIRATÓRIAS

5.5 CONFORTO TÉRMICO HUMANO.................................................... 18

5.6 A QUESTÃO ESPACIAL NA SAÚDE................................................ 22

5.7 O APARELHO RESPIRATÓRIO................................................... 23

6 CLIMATOLOGIA DA REGIÃO SUL DO BRASIL................................... 24

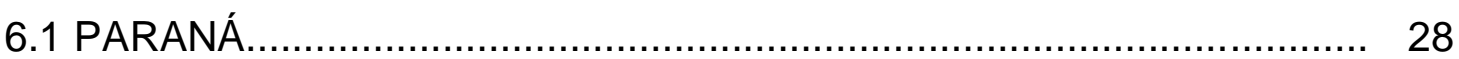

6.2 CARACTERIZAÇÃO DA ÁREA DE ESTUDO - MARINGÁ................... 29

6.2.1 ASPECTOS FÍSICOS DE MARINGÁ.......................................... 36

6.2.2 ASPECTOS DA SAÚDE EM MARINGÁ..................................... 42

7 PROCEDIMENTOS METODOLÓGICOS................................................. 46

7.1 PROCEDIMENTOS ESTATÍSTICOS............................................... 50

8 RESULTADOS E DISCUSSÕES.......................................................... 54

8.1 GRUPO DE CAUSAS, CATEGORIA, SEXO E FAIXA ETÁRIA........... 54

8.2 INTERNAÇÕES POR DOENÇAS RESPIRATÓRIAS E O ESPAÇO URBANO 
8.2.1 POPULAÇÃO POR ZONAS MUNICIPAIS................................ 63

8.2.2 INTERNAÇÕES POR ZONAS MUNICIPAIS............................ 66

8.2.3 COEFICIENTE DE INCIDÊNCIA POR ZONAS MUNICIPAIS..... 66

8.2.4 ÓBITOS POR ZONAS MUNICIPAIS....................................... 69

8.2.5 MÉDIAS E AMPLITUDES DE INTERNAÇÕES, PARA O PERÍODO DE ESTUDO............................................... 70

8.2.6 SÍNTESE DOS RESULTADOS DE INTERNAÇÕES POR GRUPO DE CAUSAS, SEXO E FAIXA ETÁRIA....................... 72

8.3 INTERNAÇÕES POR DOENÇAS RESPIRATÓRIAS RELACIONADA COM A VARIABILIDADE CLIMÁTICA ......................................... 74

8.3.1 ANÁLISE RÍTMICA........................................................... 77

8.3.2 ANÁLISE DE CONFORTO TÉRMICO (DE HORA EM HORA)... 89

8.3.3 ANÁLISE DE CONFORTO TÉRMICO (MÉDIA DIÁRIA)............ 99

8.3.4 ANÁLISE DE CONFORTO TÉRMICO PARA O PERÍODO DE ESTUDO.

8.3.5 ANÁLISE DE REGRESSÃO MÚLTIPLA

8.3.6 SÍNTESE DOS RESULTADOS DE INTERNAÇÕES

RELACIONADA COM A VARIABILIDADE CLIMÁTICA............. 118

9 CONSIDERAÇÕES FINAIS............................................................ 122

10 REFERÊNCIAS BIBLIOGRÁFICAS................................................ 126

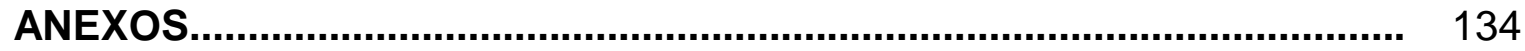

APÊNDICES A: Registros mensais de internações e óbitos.................... 136

APÊNDICES B: Cálculos do índice de conforto térmico............................ 137 


\section{LISTA DE FIGURAS}

Figura 1: Localização da área de estudo.............................................. 30

Figura 1A: Organização do espaço urbano de Maringá-PR.......................... 33

Figura 1B: Base cartográfica do Município de Maringá-PR …………........... 34

Figura 1C: Base cartográfica da área urbana de Maringá-PR...................... 35

Figura 1D: Hipsometria do Município de Maringá-PR................................ 36

Figura 2: Comportamento da precipitação pluvial e temperatura, período: 1976-2007.

Figura 3: Número absoluto de internações por doenças respiratórias, conforme o grupo de causas e sexo. Maringá-PR, 2000-2007.....

Figura 4: Número absoluto de internações por doenças respiratórias, por sexo, para cada faixa etária. Maringá-PR, 2000-2007

Figura 5: Percentual de óbitos por doenças respiratórias, para cada faixa etária. Maringá-PR, 2000-2007............................................... 60

Figura 6: Respectivas Zonas Municipais de Maringá-PR............................ 62

Figura 7: $\quad$ População por Zonas Municipais. Maringá-PR............................ 64

Figura 8: Número absoluto de internações, por Zonas Municipais. Maringá-PR, 2000-2007.................................................. 65

Figura 9: Coeficiente de incidência, por Zonas Municipais. Maringá-PR, 2000-2007.

Figura 10: Média mensais da pressão atmosférica $(\mathrm{hPa})$, precipitação pluvial $(\mathrm{mm})$, umidade relativa do ar (\%), temperatura máxima, mínima e média $\left({ }^{\circ} \mathrm{C}\right)$. Número absoluto de registros de internações por doenças respiratórias. Maringá-PR, 20002007

Figura 11: Análise rítmica: das informações meteorológicas e o número absoluto dos registros de internações por doenças respiratórias, em janeiro de 2000. Maringá-PR.

Figura 12: Análise rítmica: das informações meteorológicas e o número absoluto dos registros de internações por doenças respiratórias, em julho de 2000. Maringá-PR

Figura 13: Análise rítmica: das informações meteorológicas e o número absoluto dos registros de internações por doenças respiratórias, em janeiro de 2003. Maringá-PR.

Figura 14: Análise rítmica: das informações meteorológicas e o número absoluto dos registros de internações por doenças respiratórias, em junho de 2003. Maringá-PR.

Figura15: Análise rítmica: das informações meteorológicas e o número absoluto dos registros de internações por doenças respiratórias, 
em janeiro de 2007. Maringá-PR

Figura 16: Análise rítmica: das informações meteorológicas e o número absoluto dos registros de internações por doenças respiratórias, em junho de 2007. Maringá-PR.

Figura 17: Variação diária da temperatura do ar, da umidade relativa do ar e da Temperatura Efetiva (TE), das massas de ar atuantes e as internações (DRs), em janeiro de 2000. Maringá-PR.

Figura 18: Variação diária da temperatura do ar, da umidade relativa do ar e da Temperatura Efetiva (TE), das massas de ar atuantes e as internações (DRs), em julho de 2000. Maringá-PR

Figura 19: Variação diária da temperatura do ar, da umidade relativa do ar e da temperatura efetiva (TE), das massas de ar atuantes e as internações (DRs), em janeiro de 2003. Maringá-PR

Figura 20: Variação diária da temperatura do ar, da umidade relativa do ar e da temperatura efetiva (TE), das massas de ar atuantes e as internações (DRs), em junho de 2003. Maringá-PR

Figura 21: Variação diária da temperatura do ar, da umidade relativa do ar e da temperatura efetiva (TE), das massas de ar atuantes e as internações (DRs), em janeiro de 2007. Maringá-PR.

Figura 22: Variação da diária da temperatura do ar, da umidade relativa do ar e da temperatura efetiva, (TE), das massas de ar atuantes e as internações (DRs), em junho de 2007. Maringá-PR.

\section{LISTA DE TABELAS}

Tabela 1: Censos realizados no Município de Maringá: 1950-2000

Tabela 2: Comparativo do Índice de Desenvolvimento Humano Municipal (IDH-M), 2000: 1) Esperança de vida ao nascer (em anos); 2) Taxa de alfabetização de adultos (\%); 3) Taxa bruta de frequência escolar (\%); 4) Renda per capita em (R\$); 5) Índice de longevidade (IDHM-L); 6) Índice de Educação (IDHM-E); 7) Índice de Renda (IDHM-R); 8) Índice de Desenvolvimento Humano Municipal (IDH-M); 9) Classificação na UF; 10) Classificação Nacional

Tabela 3: Média dos principais atributos do clima, em Maringá-PR, período: 1976-2007.

Tabela 4: Dias de Geadas com as respectivas temperaturas mínimas registradas, Maringá-PR, período: 1976-2007.

Tabela 5: Internações por grupo de causas (CID-10) em Maringá-PR, no 
período de 2000-2007

Tabela 6: Percentual das internações por grupo de causas e faixa etária, CID-10 (por local de residência - Maringá-PR) em 2007.

Tabela 7: Grupos de causas das internações e óbitos, por doenças respiratórias, em número absoluto e percentual. Maringá-PR, 2000-2007.

Tabela 8: Internações por doenças respiratórias, com o grupo de causas e as categorias. Maringá-PR. 2000-2007

Tabela 9: Número absoluto das internações por doenças respiratórias por faixa etária, Maringá-PR, para cada ano: 2000-2007.

Tabela 10: Número absoluto das internações por doenças respiratórias, por faixa etária, o coeficiente de incidência (100.000 hab.), a probabilidade e a população estimada. Maringá-PR. 20002007.

Tabela 11: Número absoluto de óbitos por doenças respiratórias, por Zonas Municipais. Maringá-PR. 2000-2007.

Tabela 12: Médias mensais de internações e óbitos para Maringá-PR. 20002007.

Tabela 12A: Amplitudes de internações por doenças respiratórias, em relação com a média do período: 2000-2007. Maringá-PR.

Tabela 13: Síntese do número absoluto da população, das internações, do coeficiente de incidência e a probabilidade de riscos, por Zonas Municipais

Tabela 14: Variação sazonal: Primavera; verão; Outono; Inverno, referente à temperatura (máxima mínima e média), precipitação pluvial, umidade relativa do ar e as doenças respiratórias para MaringáPR. 2000-2007

Tabela 15: Média de temperatura do Termômetro de bulbo seco (Ts), temperatura do Termômetro de bulbo úmido $(\mathrm{Tu})$, umidade relativa do ar (UR), temperatura efetiva (TE), sistema atmosférico, sensação térmica e o número absoluto de internações por doenças respiratórias. Janeiro de 2000.

Tabela 15A: Média de temperatura do termômetro de bulbo seco (Ts), temperatura do Termômetro de bulbo úmido $(\mathrm{Tu})$, umidade relativa do ar (UR), temperatura efetiva (TE), sistema atmosférico, sensação térmica e o número absoluto de internações por doenças respiratórias. Julho de 2000.

Tabela 16: Média de temperatura do Termômetro de bulbo seco (Ts), temperatura do Termômetro de bulbo úmido $(\mathrm{Tu})$, umidade relativa do ar (UR), temperatura efetiva (TE), sistema atmosférico, sensação térmica e o número absoluto de internações por doenças respiratórias. Janeiro de 2003.

Tabela 16A: Média de temperatura do termômetro de bulbo seco (Ts), 
temperatura do termômetro de bulbo úmido $(\mathrm{Tu})$, umidade relativa do ar (UR), temperatura efetiva (TE), sistema atmosférico, sensação térmica e o número absoluto de internações por doenças respiratórias. Junho de 2003.

Tabela 17: Média de temperatura do termômetro de bulbo seco (Ts), temperatura do termômetro de bulbo úmido $(\mathrm{Tu})$, umidade relativa do ar (UR), temperatura efetiva (TE), sistema atmosférico, sensação térmica e o número absoluto de internações por doenças respiratórias. Janeiro de 2007.

Tabela 17A: Média de temperatura do termômetro de bulbo seco (Ts), temperatura do termômetro de bulbo úmido $(\mathrm{Tu})$, umidade relativa do ar (UR), temperatura efetiva (TE), sistema atmosférico, sensação térmica e o número absoluto de internações por doenças respiratórias. Junho de 2007.

Tabela 18: Médias mensais de temperatura do termômetro de bulbo seco (Ts), temperatura do termômetro de bulbo úmido (Tu), umidade relativa do ar (UR), temperatura efetiva (TE) e a sensação térmica, para 09h00min, 2000-2007.

Tabela 19: Médias mensais de temperatura do termômetro de bulbo seco (Ts), temperatura do termômetro de bulbo úmido (Tu), umidade relativa do ar (UR), temperatura efetiva (TE) e a sensação térmica, para 15h00min, 2000-2007

Tabela 20: Médias mensais de temperatura do termômetro de bulbo seco (Ts), temperatura do termômetro de bulbo úmido $(\mathrm{Tu})$, umidade relativa do ar (UR), temperatura efetiva (TE) e a sensação térmica, para $21 \mathrm{~h} 00 \mathrm{~min}, 2000-2007$.

Tabela 21: Resumo da análise de regressão múltipla, como variáveis independentes: as temperaturas máxima $\left({ }^{\circ} \mathrm{C}\right)$, mínima $\left({ }^{\circ} \mathrm{C}\right)$, média $\left({ }^{\circ} \mathrm{C}\right)$ e a temperatura efetiva $\left({ }^{\circ} \mathrm{C}\right)$, umidade relativa do ar $(\%)$, precipitação pluvial $(\mathrm{mm})$. Variável dependente: o número absoluto das internações por doenças respiratórias. Janeiro de 2000

Tabela 22: Resumo da análise de regressão múltipla, como variáveis independentes: as temperaturas máxima $\left({ }^{\circ} \mathrm{C}\right)$, mínima $\left({ }^{\circ} \mathrm{C}\right)$, média $\left({ }^{\circ} \mathrm{C}\right)$ e a temperatura efetiva $\left({ }^{\circ} \mathrm{C}\right)$, umidade relativa do ar (\%), precipitação pluvial $(\mathrm{mm})$. Variável dependente: o número absoluto das internações por doenças respiratórias. Julho de 2000

Tabela 23: Resumo da análise de regressão múltipla, como variáveis independentes: as temperaturas máxima $\left({ }^{\circ} \mathrm{C}\right)$, mínima $\left({ }^{\circ} \mathrm{C}\right)$, média $\left({ }^{\circ} \mathrm{C}\right)$ e a temperatura efetiva $\left({ }^{\circ} \mathrm{C}\right)$, a umidade relativa do ar (\%), precipitação pluvial $(\mathrm{mm})$. Variável dependente: o número absoluto das internações por doenças respiratórias. Janeiro de 2003

Tabela 24: Resumo da análise de regressão múltipla, como variáveis independentes: as temperaturas máxima $\left({ }^{\circ} \mathrm{C}\right)$, mínima $\left({ }^{\circ} \mathrm{C}\right)$, média 
$\left({ }^{\circ} \mathrm{C}\right)$ e a temperatura efetiva, $\left({ }^{\circ} \mathrm{C}\right)$, a umidade relativa do ar (\%), precipitação pluvial $(\mathrm{mm})$. Variável dependente: o número absoluto das internações por doenças respiratórias. Junho de 2003

Tabela 25: Resumo da análise de regressão múltipla, como variáveis independentes: as temperaturas máxima $\left({ }^{\circ} \mathrm{C}\right)$, mínima $\left({ }^{\circ} \mathrm{C}\right)$, média $\left({ }^{\circ} \mathrm{C}\right)$ e a temperatura efetiva, $\left({ }^{\circ} \mathrm{C}\right)$, a umidade relativa do ar (\%), precipitação pluvial $(\mathrm{mm})$. Variável dependente: o número absoluto das internações por doenças respiratórias. Janeiro de 2007

Tabela 26: Resumo da análise de regressão múltipla, como variáveis independentes: as temperaturas máxima $\left({ }^{\circ} \mathrm{C}\right)$, mínima $\left({ }^{\circ} \mathrm{C}\right)$, média (ํ) e a temperatura efetiva, ( $\left.{ }^{\circ} \mathrm{C}\right)$, a umidade relativa do ar (\%), precipitação pluvial $(\mathrm{mm})$. Variável dependente: o número absoluto das internações por doenças respiratórias. Junho de 2007

\section{LISTA DE APÊNDICES}

Tabela A.1: Registros mensais de internações por doenças respiratórias, (AlH-SUS). Maringá, 2000-2007.

Tabela A.2: Registros mensais de óbitos por doenças respiratórias, $(\mathrm{AlH}-$ SUS). Maringá, 2000-2007.

Tabela B.1: Resultados da Temperatura Efetiva (TE), para o dia e hora: janeiro de 2000

Tabela B.2: Resultados da Temperatura Efetiva (TE), para o dia e hora: julho de 2000.

Tabela B.3: Resultados da Temperatura Efetiva (TE), para o dia e hora: janeiro de 2003.

Tabela B.4: Resultados da Temperatura Efetiva (TE), para o dia e hora: junho de 2003

Tabela B.5: Resultados da Temperatura Efetiva (TE), para o dia e hora: janeiro de 2007

Tabela B.6: Resultados da Temperatura Efetiva (TE), para o dia e hora: junho de 2007. 


\section{LISTAS DE QUADROS}

Quadro 1: Manifestações Fisiopsicológicas do homem pela ação dos elementos climáticos........................................................... 14

Quadro 2: Temperatura efetiva e sensações térmicas............................... 20

\section{LISTA DE SIGLAS E ABREVIATURAS}

AlH - Autorização de Informação Hospitalar.

CID -10 - Classificação Internacional de Doenças, 10ª Revisão.

DATASUS - Departamento de Informática e Informação do Sistema Único de Saúde.

ECPM - Estação Climatológica Principal de Maringá.

J00-J99 - Doenças Respiratórias

J00-J06 - Infecções agudas das vias aéreas superiores (J00-J06);

J10-J18 - Influenza [gripe] e pneumonia

J20-J22 - Outras infecções agudas das vias aéreas inferiores

J30-J39 - Outras doenças das vias aéreas superiores

J40-J47 - Doenças crônicas das vias aéreas inferiores

J95-J99 - Outras doenças do aparelho respiratório

IAPAR - Instituto Agronômico do Paraná

IBGE - Instituto Brasileiro de Geografia e Estatística.

IDH - E - Índice de Desenvolvimento Humano - Educação.

IDH - R - Índice de Desenvolvimento Humano - Renda.

IDH - M - Índice de Desenvolvimento Humano - Municipal.

IDH - L - Índice de Desenvolvimento Humano - Longevidade.

INAMPS - Instituto Nacional de Assistência Médica da Previdência Social. 
INPE - Instituto Nacional de Pesquisas Espaciais

INMET - Instituto Nacional de Meteorologia.

INPS - Instituto Nacional de Previdência Social.

IPARDES - Instituto Paranaense de Desenvolvimento Humano.

IVAS - Infecção das Vias Aéreas Superiores.

MCC - Complexos Convectivos de Mesoescala.

mEc - massa Equatorial continental.

mPa - massa Polar atlântica.

mTc - massa Tropical continental.

mTa - massa Tropical atlântica.

OMS - Organização Mundial de Saúde.

OPA - Organização Pan - Americana.

PSF - Programa Saúde da Família.

SAMDU - Serviço de Assistência Médica e Domiciliar de Urgência.

SEDUH - Secretaria de Desenvolvimento e Habitação de Maringá.

SF - Sistema Frontal.

SIAB - Sistema de Informação da Atenção Básica.

SIG - Sistema de Informação Geográfica

SIH - Sistema de Informações Hospitalares.

SIH-SUS - Sistema de Informações Hospitalares do SUS

SRS - Secretaria Regional de Saúde

SUS - Sistema Único de Saúde.

TE - Temperatura Efetiva.

UBS - Unidade Básica de Saúde

UR - Umidade relativa do ar.

ZCAS - Zonas de Convergência do Atlântico Sul. 


\title{
RESUMO
}

\begin{abstract}
ANJOS. Isabel, B. Análise de internações por doenças do aparelho respiratório, pacientes residentes em Maringá-PR: relações com o espaço urbano e a variabilidade climática. 2011. 142 f. Tese (Doutorado). Faculdade de Filosofia, Letras e Ciências Humanas, Universidade de São Paulo, São Paulo, 2011.
\end{abstract}

O objetivo deste estudo foi analisar o número absoluto das internações por doenças do aparelho respiratório (J00-J99), em pacientes residentes em Maringá, localizada ao norte do Paraná-Brasil, com latitude $23^{\circ} 30 \mathrm{~S}$ e longitude $52^{\circ} 00 \mathrm{~W}$, com altitude entre 542 a 600 metros acima do nível do mar. Trata-se de um estudo ecológico de séries temporais, para o período compreendido entre 2000 a 2007. Foram selecionados alguns itens, como: infecções agudas das vias aéreas superiores, influenza \{gripe\} e pneumonias, outras infecções agudas das vias aéreas inferiores, outras doenças das vias aéreas superiores, doenças crônicas das vias aéreas inferiores e outras doenças do aparelho respiratório. Primeiramente, as internações foram analisadas por grupo de causas, categoria, sexo, faixa etária, Zonas Municipais e em seguida, relacionada com as informações climáticas, através da climatologia dinâmica e parâmetros estatísticos. Os resultados mostraram 18.339 registros de internações e 736 registros de óbitos, para o período de estudo. As Zonas Municipais densamente populosas destacaram com maior registros de ocorrências. A faixa etária entre 0-4, 60-69 e mais de 70 anos, apresentaram grande vulnerabilidade a essa doença. A maior quantidade encontrada foi para 0 sexo masculino, com $54,7 \%$ dos casos e o sexo feminino com 45,3\%. A maior predominância foi por influenza \{gripe\} e pneumonias, sendo responsável por 59,0\% das internações. Foi verificada menor intensidade de internações em janeiro e maior para junho e julho, devido a vários fatores, como: diminuição da precipitação pluvial, a atuação mais ativa da massa Polar atlântica $(\mathrm{mPa})$, que provoca quedas bruscas de temperatura e umidade relativa do ar. Com base nas investigações realizadas, foi observada correlação significativa entre os controles climáticos e as internações por doenças respiratórias, em Maringá.

Palavra-chave: Maringá, clima, temperatura, saúde, doenças respiratórias. 


\begin{abstract}
ANJOS. Isabel, B. Analyzis of hospitalizations due to diseases in the respiratory system, patients living in Maringá-PR: statement with the space pulite and climatic variability. 2011. 142 f. Tese (Doutorado). Faculdade de Filosofia, Letras e Ciências Humanas, Universidade de São Paulo, São Paulo, 2011.
\end{abstract}

This study was carried out to analyze hospitalizations due to diseases in the respiratory system (J00-J99) of patients living in Maringá, located in the north part of Paraná-Brazil, at latitude $23^{\circ} 30 \mathrm{~S}$ and longitude $52^{\circ} 00 \mathrm{~W}$ at an altitude between 542 to 600 meters above sea level. This is an ecological study in time series from 2000 to 2007. Was selected some tems, such as acute upper airway infections, influenza $\{f l u\}$, and pneumonia, other acute lower airway infections, other upper airway diseases, chronic lower respiratory diseases, and other diseases of the respiratory tract. First, of hospitalizations was analyzed by group of cause, sex, age groups, Municipal Zones and then it was verified in related with the information climatic, from the dynamics climatologic and statistical parameters. The results showed 18.339 records of hospitalizations and 736 records of deaths during this period of study. More densely populated Municipal Zones had of greater register of occurrences. The age group between 0-4 years, 60-69 and above 70 years had greater vulnerability to this disease. There were more cases for the masculine gender with $54,7 \%$ than for the feminine gender with $45,3 \%$. The highest prevalence was influenza $\{$ flu\} and pneumonia, accounting for $59 \%$ of these hospitalizations. Was verified less intensity of hospitalizations in january and greater for june and july, due to several factors such as: reduced rainfall, as the Polar Atlantic Mass (PAM) being more active, which causes the sudden drops in temperature and relative humidity in the air. Based on investigations, it was observed correlation significant between climatic control and the hospitalizations by respiratory problems, in Maringá.

Keyword: Maringá, climate, temperature, health, respiratory diseases. 


\section{RESUMEN}

ANJOS. Isabel, B. Análisis de las internaciones por enfermedades del sistema respiratorio, pacientes residentes en Maringá-PR: relación con el espacio urbano y la variabilidad climática. 2011. 142 f. Tese (Doutorado). Faculdade de Filosofia, Letras e Ciências Humanas, Universidade de São Paulo, São Paulo, 2011.

El objetivo de este estudio fue analizar las internaciones en los hospitales, debido a enfermedades del sistema respiratorio (J00-J99), pacientes residentes en Maringá, ciudad ubicada al norte del Estado de Paraná-Brasil, con latitud 2330 S y longitud $52^{\circ} 00 \mathrm{~W}$, con altitud 542 a 600 metros sobre el nivel de mar. Se trata de un estudio ecológico, de series temporales, para el período entre 2000 a 2007. Fueron seleccionados algunos ítems, como: infecciones agudas de las vías aéreas superiores, influenza \{gripe\} y pneumonias, otras infecciones aguda de las vías aéreas inferiores, otras enfermedades de las vías aéreas superiores, enfermedades crónicas de las vías aéreas inferiores y otras del sistema respiratorio. Primero, la cantidad de internaciones fue analizada por grupo de la causas, categoría, sexo, niveles de edad, Zonas en el censo y posteriormente con relación con la información del clima, por médio de la climatología dinâmica y parámetro estadístico. E resultados mostraron 18.339 registros de internaciones y 736 registros de muertes, para el período de la estudio. Las zonas incluidas en el censo de gran densidad poblacional se destacaron con el mayor registro de ocurrencia. El segmento de edad de 0-4, 60-69 y con más de 70 años, presentó mayor vulnerabilidad para esa enfermedad. La mayor cantidad encontrada fue del sexo masculino, con $54,7 \%$ de los casos y del sexo femenino con 45,3\%. La mayor predominancia fue por influenza \{gripe\} y pneumonías, siendo responsable por 59,0\% de estas internaciones. Fue verificada bajas intensidad de internaciones en enero y mayor en junio y julio, debido a varios factores, como: diminución de las lluvias, la mayor actividad de la Masa Polar Atlántica $(\mathrm{mPa})$, que provoca bruscas bajas en la temperatura y humedad relativa del aire. Con base en las investigaciones hechas, fue observado correlación significativa entre los control climáticos y internaciones por enfermedades respiratórias, en Maringá.

Descriptores: Maringá, clima, temperatura, salud, enfermedades respiratórias. 


\section{INTRODUÇÃO}

Entende-se por variabilidade climática a inconstância observada durante um certo período de tempo, tratando-se de um ciclo periódico, que podem ser sazonal, anual, interanual. Essas variações ocasionais, são propícias para o aumento de algumas doenças que variam conforme as estações do ano.

Nos períodos de outono e inverno, ocorrem diferenciações nas condições do tempo atmosférico, muito rápidas, devido à atuação mais frequente da massa de ar Polar ( $\mathrm{mPa}$ ), logo após a passagem de um sistema frontal, provocando a queda de temperatura, facilitando a ocorrência de alguns problemas de saúde, em virtude do organismo humano levar algum tempo para acostumar-se a essa mudança.

Desta forma, os problemas respiratórios aumentam em períodos climáticos favoráveis, à ocorrência de agravos. Alguns estudos realizados apontaram principalmente a temperatura e a umidade relativa do ar, como causa de efeitos diretos e indiretos na saúde humana.

Segundo Mendonça (2001, p. 23) desde Hipócrates, século V a. C., na sua célebre obra Ares, Águas e Lugares, a preocupação de estudiosos com a influência do clima sobre o organismo dos homens vem sendo observada e registrada.

Em relação aos problemas respiratórios, são encontradas pesquisas que relatam aumentos significativos nos meses de outono e de inverno, como Nadal e Vide (1999), Castro (2000), Mendonça, Bórax e Paula (2000), Pitton (2000), Lima (2000), Bejarán (2001), Zem (2004) e Barros (2006).

A produção cientifica referente à temática, embora associe as enfermidades com as condições do tempo atmosférico, reportam-se também em relacionar a poluição do ar com as doenças respiratórias, como Sobral (1988), Castro (2000), Pitton (2003), Coelho-Zanotti (2007) e Braga et al., (2007).

Todos esses autores encontraram respostas do clima, quando relacionadas aos problemas respiratórios. Grande parte destas produções utilizaram principalmente, a temperatura e umidade relativa do ar, com aplicação de modelos estatísticos como forma de predição e apontaram para a importância de analisar a saúde do ser humano sem ignorar os controles climáticos.

Nessa perspectiva, analisou as doenças respiratórias em Maringá-Paraná, no período de 2000 a 2007, juntamente com as informações meteorológicas. Visto que, 
é comum evidenciar na região considerável aumento de problemas respiratórios, principalmente entre os meses de junho, julho e agosto.

Não foram exploradas todas as possibilidades existentes, tendo em vista os inúmeros fatores, que podem ser considerados para que um indivíduo venha a ser acometido por complicações respiratórias. Esse fato vai desde uma predisposição genética, ou crônica. Também não foram envolvidas: a poluição, embora este item de certa forma contribua para agravos respiratórios; nem as condições de moradias ou de trabalho; as aglomerações em ambientes de creches e escolas, ônibus. Pois perderia o foco da pesquisa, que procurou analisar as condições atmosféricas relacionadas com o número de registros de internações.

Também não abordou todas as causas de internações por doenças respiratórias, julgou-se que, algumas delas não estão relacionadas direta ou indiretamente com as condições atmosféricas, sendo desnecessárias para análise, como as: doenças pulmonares devidas a agentes externos (J60-J70); outras doenças respiratórias que afetam principalmente o interstício (J80-J84); afecções necróticas e superativas das vias aéreas inferiores (J85-J86); outras doenças da pleura (J90-J94).

Foram analisadas aqueles casos de internações que aparentemente estão relacionadas com os aspectos climáticos, como as: infecções agudas das vias aéreas superiores (J00-J06); influenza \{gripe\} e pneumonias (J10-J18); outras infecções agudas das vias aéreas inferiores (J20-J22); outras doenças das vias aéreas superiores (J30-J39); doenças crônicas das vias aéreas inferiores (J40-J47); e outras doenças do aparelho respiratório (J95-J99).

Essa tese abordou dois focos diferenciados, no primeiro seguimento identificou-se o número absoluto de internações por Zonas Municipais, procurando apontar dentro do espaço urbano, qual o local em que a ocorrência das internações seria mais destacada.

O segundo seguimento abrangeu as questões do aspecto climático de Maringá, observando as possíveis relações com os registros de internações, para o período de estudo e para identificar de acordo com a sazonalidade, ou seja, em determinadas épocas do ano diferentes, utilizou-se do mês que apresentou mais e aquele que apresentou menos internações, dentro do período estudado, sendo então composto por janeiro e julho de 2000, janeiro e junho de 2003 e janeiro e junho de 2007. 
Tais abordagens, vem de encontro aos interesses da Geografia da Saúde, com destaque ao papel da Geografia, no desenvolvimento de linhas de pesquisas direcionadas ao homem, a natureza, a saúde e o meio ambiente, que procura identificar e avaliar, as mais variadas causas e riscos de populações expostas à contrair doenças em geral.

Assim, visa colaborar com apontamentos importantes, despertando para o surgimento de debates e considerações essenciais, na prevenção relacionadas à saúde e doença.

\section{HIPÓTESES}

Com base nos referenciais bibliográficos, conceituais metodológicos e teóricos, a hipótese levantada nesse trabalho é que:

- É possível apontar um perfil de internações por problemas respiratórios através das Zonas Municipais, em Maringá;

- A variação do tempo atmosférico pode favorecer ao aumento das doenças respiratórias, em determinadas épocas do ano, nesta cidade;

- O desconforto térmico, pode ser considerado subsídio importante para ser associado com o surgimento e agravos de problemas respiratórios, em linhas gerais a sensação de conforto ou de desconforto é sentido devido a condição da temperatura e da umidade relativa do ar.

- Previsão com apontamentos de períodos críticos, para a gestão de saúde.

\section{JUSTIFICATIVA}

Estudar o espaço urbano e a variação do tempo atmosférico e sua relação com as doenças respiratórias, tem como finalidade facilitar a melhor compreensão e entendimento, na questão da saúde. Como em Maringá, ocorre o aumento de 
problemas respiratórios durante o período de outono e inverno, pensou-se em analisar esse fato junto com as informações meteorológicas.

A população da área urbana conta $97,5 \%$ dos habitantes do municipio, eliminou-se a população da área rural, com 2,5\% da população, pois com a utilização de referenciais das internações através do CEP do paciente internado, tornou-se impossivel agregar o espaço rural, no qual, utiliza-se a Caixa Postal.

Foram utilizadas os dados de internações da Secretaria Regional de Saúde de Maringá (SRS), devido a facilidade de obter as informações de internações por doenças respiratórias, sendo encontradas inúmeras dificuldades nos Postos de Saúde, para a coleta de consultas, bem como, nos órgãos privados. Limitou-se ao período de 2000 até 2007, devido à extensão de informações, contidas nas Autorização de Internações Hospitalares do Sistema Único de Saúde (AIH-SUS).

Essa pesquisa é somente de cunho técnico computadorizado, no qual foram utilizadas as informações arquivadas referente ao clima e as internações, não foram realizadas entrevistas a pacientes, mas contém reflexões que certamente auxiliarão na área da saúde e a outros pesquisadores, na incessante busca de aprimorar as pesquisas voltadas ao clima e ao homem, de modo geral. Desta forma, essa tese será de grande importância para a região estudada.

\section{OBJETIVOS}

O objetivo geral foi analisar o número absoluto de internações por problemas respiratórios, em pacientes residentes em Maringá-Paraná, através das Zonas Municipais e as informações meteorológicas, para o período compreendido de janeiro de 2000 a dezembro de 2007.

\subsection{OBJETIVOS ESPECÍFICOS}

1) Verificar dentre as causas de internações por doenças respiratórias, quais são mais destacadas;

2) Analisar o número absoluto de internações e óbitos, por sexo e por faixa etária; 
3) Identificar quais Zonas Municipais apresentam maior abrangência de internações e de óbitos;

4) Analisar a variação dos atributos climáticos, como a temperatura máxima, mínima e média, umidade relativa do ar, precipitação pluvial, pressão atmosférica e relacioná-las com o aumento dos registros de internações;

5) Verificar de acordo com a sazonalidade qual o período propício para os aumentos de problemas respiratórios;

5) Analisar a temperatura efetiva e verificar a possível relação com a quantidade de internações;

6) Investigar a correlação existente entre as variáveis climáticas e as internações através de método estatístico;

7) Fornecer subsídios para colaborar com os responsáveis na área da saúde.

\section{REVISÃO DE LITERATURA}

\subsection{A SAÚDE NO BRASIL}

O Instituto Nacional de Previdência Social (INPS) foi oficialmente implantado em 2 de janeiro de 1967, mas já havia debates sobre a reforma do sistema de saúde, desde 1960. Reunindo então os Institutos de Aposentadorias e Pensões, o

serviço de Assistência Médica e Domiciliar de Urgência (SAMDU) e a Superintendência dos serviços de Reabilitação da Previdência Social.

Este sistema previdenciário foi se tornando cada vez mais complexo, desde o ponto de vista administrativo até o financeiro, dentro da estrutura do INPS, que acabou levando à criação de uma estrutura própria administrativa, o Instituto Nacional de Assistência Médica da Previdência Social o (INAMPS) em 1978.

Segundo Perehouskei (2005) a dinâmica do setor de saúde no Brasil será pautada desde a crise da Previdência Social na década de 70, cuja prática centravase na medicina curativa e assistencialista: 
Posteriormente passa a ampliar a cobertura de seguridade a diversas classes de trabalhadores, permitindo espaços para a ocorrência de intensas corrupções no setor, até os dias atuais. [...] Nesse contexto, foram elaboradas pelo governo, algumas tentativas de organização dos diversos setores de saúde no intuito de minimizar os problemas estabelecidos, como por exemplo, a criação do MPAS, INPS, INAMPS, LBA, FUNABEM, DATAPREV, IAPAS, entre outros. Esses diversos setores estreitamente vinculados tinham o papel de controle em relação aos contratos privados estabelecidos para atender a demanda, bem como, executar ações de saúde de interesse coletivo, que se definem como campo de atuação do Ministério da Saúde e também proporcionar 0 atendimento médico assistencial individualizado, que se configura como ação do Ministério da Previdência e Assistência Social. Entretanto, esses objetivos aumentaram consideravelmente os gastos da Previdência e no final da década de 1970, marcada pelo fim do 'milagre econômico' que representou um intenso período de industrialização e êxodo rural no País, trouxe como consequência, uma crise generalizada: baixos salários e crescimento da demanda para a assistência a saúde (PEREHOUSKEI, 2005, p. 9).

O período de 1980 a 1990 foi marcado pela transformação do regime da ditadura militar e a instauração da democracia no País, isto resultou também num marco inaugural de um novo tempo nessa questão da saúde brasileira. $\mathrm{Na} \mathrm{8^{a }}$ Conferência Nacional de Saúde realizada em 1986, foram discutidas diversas propostas que passaram a constituir o Projeto de Reforma Sanitária Brasileira e o financiamento do setor.

Esses temas desdobravam-se em um conjunto de diretivas centrais que alimentaram o intenso debate travado até a aprovação da Constituição de 1988, estabelecendo a saúde como direito de todos e dever do Estado, resultando assim no nascimento do Sistema Único de Saúde (SUS).

Polignano (2005) fez um relato da história das políticas de saúde no Brasil e apontou o Capítulo VIII da Ordem Social e na secção II, referente à saúde, no qual está definido no artigo 196:

\footnotetext{
A saúde é direito de todos e dever do Estado, garantindo mediante políticas sociais e econômicas, que visem à redução do risco de doença e de outros agravos e ao acesso universal e igualitário às ações e serviços para a sua promoção, proteção e recuperação (POLIGNANO, 2005, p. 6).
}

Noronha, Lima e Machado (2006, p. 46), apresentaram um complemento sobre o Sistema Único de Saúde (SUS): 
A implementação do SUS inicia-se nos primeiros anos da década de 90, após a promulgação das leis federais da saúde (8.080 e 8.142 de 1990) e de várias portarias emitidas pelo Ministério da Saúde como instrumentos de regulamentação do sistema. Posteriormente, reformulam-se os papéis e funções dos entes governamentais na gestão de unidades e do sistema de saúde, adotam-se novos critérios de distribuição e transferência de recursos, criam-se e ampliam-se as instâncias colegiadas de negociação, integração e decisão, evolvendo a participação dos gestores, prestadores, profissionais de saúde e usuários.

O SUS realiza vários serviços na saúde pública, como transplante de órgãos, distribuição de medicamentos para todos os pacientes com Aids e, outra estratégia como a Saúde da Família, que acompanha 90 milhões de pessoas. Programação Nacional de Imunizações - PNI, com 30 milhões de atendimento ao ano.

Desta forma, o SUS é destinado a toda a população e corresponde à única possibilidade de atenção à saúde, para mais de 140 milhões de brasileiros com baixos rendimentos, empregos precários ou desempregados. Este órgão tem natureza pública, sendo integrado por serviços dos Municípios, Estados e União, além dos contratos filantrópicos e lucrativos.

Nesse aspecto, reflete Paim (2006, p. 25):

A atenção à saúde, como expressão do cuidado às pessoas, individualmente e coletivamente, sofre as influências desses arranjos de organização, gestão e financiamento, além da disponibilidade da infraestrutura de recursos. Esses recursos apresentam uma distribuição desigual entre estratos sociais e entre regiões, Estados e Municípios, áreas urbanas e rurais e nas cidades entre periferia e centro.

O Manual de orientações Técnicas de 2006, acrescenta que, com o advento do SUS, surgiu também a necessidade de estabelecer um sistema único de informações assistenciais para subsidiar os gestores no planejamento, controle e avaliação das ações de saúde.

Nesse sentido, o Ministério da Saúde, por meio da Portaria GM/MS nํ. 896/90, determinou ao Instituto Nacional de Assistência Médica e Previdência Social/INAMPS a implantação do Sistema de Informação Hospitalar SIH/SUS a partir de agosto de 1990. [...] e a partir de abril de 2006, após capacitação das Secretarias Estaduais e Municipais de Saúde e Distrito Federal realizada pela Coordenação Geral de Sistemas de Informação/ Departamento de Regulação Avaliação e Controle/SAS/MS e da Coordenadoria Geral de Informação 
Hospitalar/Departamento de Informática do SUS/DATASUS/MS, foi implantada no país o processo de descentralização do SIH/SUS. (BRASIL, 2006, p. 13).

No Brasil, o órgão responsável pelo controle de morbidades é o Sistema de Informações Hospitalares, pertencente ao SUS (SIH-SUS), tendo como base a Autorização de Internação Hospitalar $(\mathrm{AlH})$, que é de preenchimento obrigatório para a internação de pacientes para que seja recebido o pagamento referente a tais internações. Essas internações pagas pelo Sistema Único de Saúde, segundo estimativas, é algo em torno de $80 \%$ do total de internações do País.

O Sistema de Informações Hospitalares (SIH) é um importante instrumento de informação para orientar o gestor na tomada de decisões relacionadas ao planejamento das ações de saúde, inclusive para a Vigilância em Saúde.

Este sistema de informação, desde que corretamente preenchido a morbidade/mortalidade hospitalar no Município ou do Estado, está refletida através da Classificação Internacional de Doenças - CID, registrado na AIH (Autorização de Internações Hospitalares), servindo por sua vez como indicador da atenção ambulatorial. O desempenho e as condições sanitárias do estabelecimento podem ser avaliados a partir das taxas de óbitos e infecção hospitalar.

Sobre as causas de internações no Brasil, a Organização Pan-Americana de Saúde (1998, p. 10) relatou:

A morbidade geral apresentada no sistema de informação hospitalar, segundo os grupos de causas mostra que $22,8 \%$ dos atendidos correspondem às causas ligadas a gravidez e parto, 15,9\% devido a causas respiratórias, $10,6 \%$ por causas circulatórias, 9,4\% por doenças infecciosas e parasitárias, $8,4 \%$ por causas geniturinárias, $7,5 \%$ por causas digestivas e $7,5 \%$ devido a causas externas.

Ocorrem os maiores registros de internações por doenças respiratórias, predominantemente para o sexo masculino. Rouquayrol, Filho $(1999$, p. 12) apresentaram a possível justificativa:

Para as doenças do aparelho respiratório parece haver uma maior incidência entre homens quando comparados com mulheres, sejam pela maior exposição masculina às influências do clima, atividades ao ar livre, seja pelas condições de trabalho ou mesmo pelo modo de vida ou hábitos. 
Para Rouquayrol, Filho (1999) isso não explica satisfatoriamente o caso, pois de maneira semelhante, esse fato ocorre também em menores de um ano e em crianças de modo geral.

As doenças respiratórias apresentaram de 1979-1995, entre as principais causas de morte no Brasil, como apontaram Mello Jorge, Gotlieb (2000, p. 35):

Sendo a taxa masculina um pouco mais elevada que a feminina, principalmente representadas pelas broncopneumonias, bronquite e asma, ocorrendo em geral, em menores de cinco anos. Nos idosos as internações referem-se a enfisema e obstrução crônica das vias respiratórias.

Continuando os estudos sobre a saúde no Brasil Mello Jorge, Gotlieb e Laurenti (2001, p. 89), apresentaram uma relação, sobre a faixa etária mais acometida por problemas respiratórios:

Entre 1996 a 1999, as crianças de um a quatro anos a principal causa de morte foi por doenças respiratórias, em torno de $(22,8 \%)$, sobressaindo em relação a outras causas, destacando principalmente a pneumonia. Já as crianças de cinco a nove anos aparecem como sendo a quarta causa de morte. Para a faixa etária entre sessenta anos ou mais, as doenças do aparelho respiratório constituem-se em terceira causa de morte, apontando com grande frequência por broncopneumonia e pneumonias.

\subsection{GEOGRAFIA MÉDICA E GEOGRAFIA DA SAÚDE}

O conhecimento da geografia médica teve sua origem nos princípios da civilização, ainda que sua estruturação como ciência tenha se consolidado por volta dos séculos XVIII e XIX, quando vários pesquisadores passaram a abordar conceitos sobre ambiente e saúde em suas pesquisas.

Ferreira (2001) num curso aplicado no Departamento de Geografia denominado de "Tópicos de Geografia Médica, relata alguns fatos importantes ${ }^{1 "}$. A

\footnotetext{
${ }^{1}$ No inicio do século XX a Geografia Médica foi quase abandonada, pois com a descoberta da penicilina parecia ser capaz de erradicar a maior parte das doenças infecciosas prevalentes em determinados ambientes, especialmente em zonas tropicais. Nessa época, os esforços concentravam-se mais no combate ao agente etiológico do que controle ambiental. Conforme foi se comprovando que os antibióticos e os biocidas não eram capazes de eliminar os agentes causadores das doenças, voltou-se novamente a preocupação com os aspectos ambientais.
} 
maior parte desses trabalhos foram escritos em alemão e francês, sendo poucos traduzidos para o inglês.

Dentro do contexto geopolítico e atendendo as necessidades da expansão capitalista nas regiões Norte e Centro-Oeste, empreendida pelos governos militares em 1972, foi publicada a obra de Lacaz, Baruzzi e Siqueira, em Introdução à geografia médica do Brasil.

A obra destes autores pretendiam constituir um trabalho de interligação entre a Medicina e a Geografia, ainda assim essa obra não chegou a integrar os conhecimentos médicos e geógrafos, pois abordava as relações entre doença e o ambiente de modo separado.

Sendo analisados individualmente fatores geográficos físicos e humanos, tais como relevo, clima, vegetação, fauna, população, habitação rural e urbana, bem como a migração, de qualquer forma, essa publicação estabeleceu uma ponte entre a epidemiologia e a geografia, de maneira a enfatizar a importância de estudos geográficos para a compreensão das patologias infecciosas em geral e parasitárias.

Abordando os conceitos sobre a Geografia Médica, Lacaz, Baruzzi e Siqueira (1972, p. 1) consideraram que:

Geografia médica é a disciplina que estuda a geografia das doenças,
isto é, a patologia à luz dos conhecimentos geográficos. Conhecida
também como Patologia geográfica. Geopatologia ou Medicina
geográfica, se constitui em um ramo da Geografia Humana
(Antropogeografia), ou, então da Biogeografia. A Geografia Médica
nasceu com Hipócrates e, portanto, com a própria história da
medicina, quando em 480 a.C., aproximadamente publicou sua
famosa obra 'Dos Ares, das Águas e dos Lugares', onde o grande
mestre de Cós mostrava a influência dos fatores ambientais no
aparecimento das doenças, em geral.

Lacaz, Baruzzi e Siqueira citaram alguns dos importantes nomes, como João de Barros Barreto, Carlos Chagas e de Afrânio Peixoto, como médicos sanitaristas que muito contribuíram para as questões de saúde.

Em 1907 Peixoto publicou um trabalho que tratava da relação entre clima e doenças no Brasil, abordando os ciclos epidemiológicos. Em 1938, publicou a obra Clima e Saúde, abordando questões sobre meteoropatologia relacionando o clima e as variações sazonais, com casos de morbidez, epidemias e endemias.

Verificou-se, então, que a Geografia Médica teve, desde sua origem, fins utilitários ou práticos, tanto econômicos, quanto políticos: 
De modo geral, salvo raras exceções, como por exemplo, a obra de Josué de Castro, ela esteve ligada a interesses de classes sociais dominantes ou ao capitalismo do Estado e servia de instrumentos para facilitar a ocupação e dominação de outras áreas. Nos EUA e países europeus servia ela aos interesses do colonialismo e, no Brasil, aos capitalistas aliados ao Estado desenvolvimentista. Portanto esteve quase sempre vinculada ao movimento de expansão do capitalismo. De inicio tinha um enfoque ambientalista ou até determinista, mais tarde, os fatores sociais vão ser levantados como adjuvantes na etiologia das doenças (SOBRAL, 1988, p. 27).

Logo, a Geografia da Saúde desponta na década de 1970, sugerida então, como uma nova organização da Geografia Humana, veio para colaborar com um novo espaço de estudos geográficos. Para Rojas (1998):

Apesar de que ainda assombra em alguns contextos institucionais, a relação entre as Ciências Geográficas e as Ciências da Saúde, existe uma ampla documentação que argumenta esta articulação desde os tempos mais remotos do ser humano [...]. A Geografia Médica ou da Saúde, frequentemente se divide em dois principais campos de investigação: a Nosogeografia ou Geografia Médica tradicional, encarregada da identificação e análise de padrões de distribuição espacial de enfermidades e a Geografia da gestão de saúde, ocupada na distribuição e planejamento de componentes de infraestruturas, de recursos humanos e de Sistema de atenção Médica (ROJAS, 1998, p. 702-703).

Para Rojas (1998), a fome juntamente com a miséria, a desnutrição, a insalubridade, a desesperança, a tristeza, a contaminação do ar, das águas, das terras e tanto outros males definem os espaços que se constroem e se reconfiguram permanentemente. Assim identificar e revelar estes espaços humanos são possibilidades de melhorar a efetividade e a qualidade das ações em saúde, sendo de responsabilidade e de urgência.

Perehouskei (2005, p. 23) também considerou que os estudos em Geografia Médica voltados para a melhoria das condições de saúde da sociedade intensificamse principalmente a partir de 1982, quando iniciaram alguns encontros sobre Geografia da Saúde. Tais estudos apontavam para uma abordagem mais crítica, com trabalhos científicos que buscavam realmente atender as necessidades da coletividade.

A Geografia da Saúde é o amadurecimento das discussões e estudos desenvolvidos no âmbito da Geografia Médica de outras épocas, hoje com outra visão, mais ampla, planejada e direcionada para ações de prevenção. 
Segundo Barros (2006) é preciso ressaltar que até o inicio do século $X X$ os trabalhos de Geografia Médica eram feitos por médicos, sob o foco da medicina e utilizando a geografia apenas como ciência auxiliar e a cartografia como instrumento, acrescentando:

Os vários anos de pesquisa em Geografia Médica no Brasil
culminaram em dezembro de 2003 , no 1 o Simpósio de Geografia da
Saúde, sob a organização do Departamento de Geografia da
Universidade Estadual Paulista do Campus de Presidente Prudente-
SP. O evento, que ressaltou a retomada do interesse por parte dos
geógrafos pela temática em questão, contou ainda com a
participação dos médicos e epidemiologistas brasileiros e de alguns
países da América Latina, além de fomentar a reflexão e a discussão
sobre os aspectos teóricos desse campo da geografia (BARROS,
2006, p. 34).

No ano de 2005, o Simpósio Nacional de Geografia da Saúde, sediado na cidade de Rio de Janeiro, pôde contar com a contribuição de diversos profissionais da saúde, em nível nacional, como também a integração com pesquisadores da Geografia da Saúde de Portugal (SOUZA, 2007, p. 40).

Com novos encontros ocorridos em Curitiba em 2007 e Uberlândia em 2009, sempre com a mesma perspectiva de análise, envolvendo os fatores ambientais, sociais e debates preventivos.

\subsection{ESTUDOS DO CLIMA RELACIONADOS Á SAÚDE}

As relações entre o clima e a saúde são reconhecidas desde a antiguidade, por Hipócrates em sua célebre obra: dos Ares, das Águas e dos Lugares, que associou as alterações no meio ambiente assim como as variáveis climáticas como causa de infecções e de surgimento de várias doenças.

Conforme Barros (2006, p. 10) Hipócrates organizou as doenças endêmicas (presente em dada população e as epidêmicas, aquelas que aparecem com mais ou menos frequência em determinadas épocas do ano ou condições).

Hipócrates teria vivido entre 460 a 370 a. C, dotado de notável espírito de observação, conhecendo, profundamente o ser humano e exercendo a atividade 
médica, descreveu numerosas doenças, recebeu o codinome de "o pai da medicina" (SOUZA, 2007, p. 34).

Conforme a concepção da época havia certo exagero, com visão determinista levada ao extremo. Segundo Sodré (1979) a forma inicial do determinismo esteve ligada à relação entre o homem e o clima. Escreveu Hipócrates:

Se os asiáticos são hesitantes, sem coragem e de caráter menos belicoso e mais doce do que os europeus, é preciso procurar a essencial causa disso na natureza das estações. Já para Aristóteles os habitantes das regiões frias são cheios de coragem e feitos para a liberdade. Aos asiáticos falta energia, assim são feitos para o despotismo e para a escravidão (SODRÉ, 1979, p. 37-38).

No século XVIII, Montesquieu (1979, p. 201) fortaleceu essa concepção, argumentando:

Tem-se mais vigor nos climas frios, mais coragem, mais conhecimento de sua superioridade, menos desejo de vingança, mais segurança e mais franqueza, menos política, menos malícia [...]. Os povos das regiões quentes são tímidos como os anciões, os das regiões frias são corajosos como os jovens [...].

Já com outra percepção, Lacaz, Barruzzi e Siqueira, (1972, p. 24), observaram:

[...] O clima e os fatores geográficos ou físicos interferem de modo decisivo sobre os germes produtores de infecções, bem como sobre os agentes animados de sua difusão. Os germes patogênicos experimentam a ação do clima e, assim, variam de virulência e de capacidade morbígena, também o organismo humano é influenciado pelos mesmos fatores mesológicos que determinam desvios e adaptações no metabolismo normal e, igualmente, alteram e regulam os processos fisiopatológicos, nos quais se expressam as resistências funcionais à agressão parasitária.

Para Sorre (1984) o clima condiciona as atividades de um complexo vivo, no qual entram os vegetais, os animais e o próprio homem. Sorre elaborou um modelo esquemático apontando como ocorre a ação dos elementos climáticos em relação ao homem, conforme apresentado no Quadro 1.

Conforme Sorre (1984, p. 51) o clima, atuando de forma indireta acaba sendo o pano de fundo para a ocorrência de diversos tipos de doenças, apesar de poucas vezes agir sozinho. 
Quadro 1: Manifestações Fisiopsicológicas do homem pela ação dos elementos climáticos.

\begin{tabular}{|c|c|c|}
\hline $\begin{array}{l}\text { ELEMENTOS } \\
\text { CLIMÁTICOS }\end{array}$ & $\begin{array}{l}\text { CONDIÇÕES } \\
\text { LIMITANTES }\end{array}$ & $\begin{array}{l}\text { MANIFESTAÇÕES } \\
\text { FISIOLÓGICAS }\end{array}$ \\
\hline $\begin{array}{l}\text { Altitude (Pressão } \\
\text { Atmosférica) }\end{array}$ & $\begin{array}{l}\text { Limite máximo: } \\
8.000 \mathrm{~m} \text {. }\end{array}$ & $\begin{array}{l}\text { - Mal das montanhas (dor de cabeça, fadiga, } \\
\text { alteração sensorial, depressão intelectual, } \\
\text { indiferença, sono, descoordenação de } \\
\text { movimentos, perda de memória). Redução das } \\
\text { faculdades físicas e mentais. Tristeza, apatia. }\end{array}$ \\
\hline $\begin{array}{c}\text { Radiação } \\
\text { (Associada à } \\
\text { luminosidade) }\end{array}$ & $60^{\circ}$ e $70^{\circ}$ Latitude & $\begin{array}{l}\text { - Alta radiação/luminosidade: esgotamento } \\
\text { nervoso, perturbações mentais, irritação, } \\
\text { síndrome físicopsíquica "golpe de sol" } \\
\text { (sunstroke), euforia. Baixa radiação/luminosidade: } \\
\text { deficiências orgânicas, raquitismo, depressão, } \\
\text { debilidade mental. }\end{array}$ \\
\hline Higrotermia & $\begin{array}{l}\text { Limite Variável. } \\
\text { Ótimo fisiológico } \\
15^{\circ}-16^{\circ} \\
60 \% \text { UR }\end{array}$ & $\begin{array}{l}\text { - Diminuição da capacidade respiratória (para } \\
\text { europeus nos trópicos). Hiperpnéia térmica (entre } \\
\text { negros). Cansaço e esgotamento (brancos). }\end{array}$ \\
\hline $\begin{array}{c}\text { Vento e Eletricidade } \\
\text { Atmosférica }\end{array}$ & & $\begin{array}{l}\text { - Morbidez, cansaço e abatimento. Debilidade do } \\
\text { tônus nervoso, depressão, hipersensibilidade, } \\
\text { irritabilidade. Desidratação, dessecação do } \\
\text { aparelho tegumentar. Excitação nervosa, } \\
\text { alucinações, delírio. Palpitações, dispnéia, dores } \\
\text { de cabeça, nevralgia. }\end{array}$ \\
\hline
\end{tabular}

Fonte: Sorre (1984, p. 42).

Segundo Ayoade (1986) o clima desempenha algum papel na incidência de certas doenças que atacam o homem. Em primeiro lugar afeta a resistência do corpo humano a algumas doenças.

O clima influencia a propagação e difusão de alguns organismos patogênicos ou de seus hospedeiros. Temperaturas extremamente baixas diminuem a resistência do corpo humano à infecção. A neblina associada a poluentes está frequentemente relacionada com o aumento das doenças respiratórias. Similarmente o ar seco e carregado de pó tende a tornar as vias respiratórias mais suscetíveis às infecções (AYOADE, 1986, p. 291).

Conforme Rouquayrol, Filho (1999, p. 98) o clima é o resultado de toda a variedade de fenômenos meteorológicos específicos que caracterizam a situação da atmosfera em uma região delimitada da superfície terrestre.

Esses autores apontaram os fatores climáticos que mais de perto influenciam as biocenoses e, portanto os seres vivos, implicados no processo de transmissão de doença são: a temperatura do ar, a umidade relativa e a precipitação pluviométrica.

O clima é, enquanto componente do meio natural, um dos principais fatores a influenciar os diferentes tipos de adaptações do homem na superfície do planeta, podendo influenciá-la positiva ou negativamente (MENDONÇA, 2001, p. 23). 
Conforme Mendonça (2001, p.160) a relação clima-homem foi tratada com rigor, na qual o determinismo era categórico em moldar e explicar os fatos. Essa relação observada com característica científica, voltada ao comportamento humano constitui-se na atualidade com outra visão.

Muitas barreiras foram vencidas, as pesquisas estão voltadas para a compreensão entre o clima e a saúde, de maneira abrangente, com vários focos de abordagens. Como Yan (2000) que analisou a influência do clima na mortalidade humana em Hong Kong, entre 1980 a 1994, por problemas relacionados a tumores, circulatórios e respiratórios, verificando que o clima tem efeito importante sobre a mortalidade e certas faixas etárias são mais suscetíveis.

Dessai (2002) analisou o calor associado com o stress e o aumento da mortalidade em Lisboa, no período de 1980 a 1998, incluindo as doenças cardiovasculares, cânceres, respiratórias e isquêmicas. Utilizou-se de modelos estatísticos de previsão, concluindo que durante o verão, ocorrem relação com o stress e mortes por doenças cardiovasculares e cânceres.

Braga, Zanobetti e Schwartz (2002) verificaram o efeito do clima e a mortalidade por doenças respiratórias e cardiovasculares, em doze cidades dos Estados Unidos, notaram que as temperaturas altas favorecem ao aumento de problemas cardiovasculares e temperaturas baixas favorecem ao aumento principalmente pneumonias.

Davis et al., (2003) observaram a mortalidade em geral no verão nos Estados Unidos, analisando por décadas, de 1960 a 1970, e depois de 1980 a 1990, verificaram que em dias de temperatura alta independente do período, a média de mortalidade mostrou-se elevada na maioria das cidades.

Dushoff et al., (2006) estudaram a mortalidade por diversas causas nos Estados Unidos, entre 1979 a 2001, utilizaram-se da temperatura média e de modelos de regressão, concluíram que, o vírus Influenza, é uma importante causa de excesso por mortes sazonais, naquele País.

Para analisar as admissões hospitalares por doenças respiratórias, crises renais, circulatórias e fraturas do fêmur em Veneto - Itália, durante uma onda de calor ocorridas em 2002 e 2003, Mastrangelo et al., (2007), utilizaram informações relacionadas com a umidade e a temperatura simultaneamente, através de um modelo de regressão. Esses autores perceberam que as pessoas idosas foram hospitalizadas por doenças cardiovasculares e respiratórias. 
A produção cientifica referente à temática, embora associe as enfermidades com as condições do tempo atmosférico, reportam-se também em relacionar a poluição do ar com as doenças respiratórias, como Sobral (1988) que retratou os efeitos da poluição do ar na manifestação de doenças respiratórias em crianças em São Paulo, sendo um dos estudos pioneiros referente aos impactos causados na saúde devido a poluição.

Castro (2000) analisou os poluentes atmosféricos no espaço urbano de Rio Claro-SP, juntamente com as variações climáticas, associando com as doenças relacionadas ao aparelho respiratório, para os meses de junho a agosto de 1995, 1996 e 1997. Observou que a estabilidade causada pelas massas de ar polar tropicalizada e pela tropical atlântica aumentam a morbidade e mortalidade por afecções respiratórias.

Pitton (2003), encontrou relação com a poluição e as doenças respiratórias em Piracicaba-SP. Coelho-Zanotti (2007) estudou as internações por doenças respiratórias de 1997 a 2000, em crianças de zero a treze anos, na cidade de São Paulo, a partir dos dados de poluição do ar e índices biometeorológicos. Observou que estes fatores possuem relação com as internações.

Braga et al., (2007) estudaram os efeitos agudos da poluição do ar por material particulado inalável, a temperatura e a umidade, sobre os atendimentos em pronto-socorro por doenças respiratórias e cardiovasculares de pessoas moradoras em Itabira-MG. Verificando que estes itens interferem na ocorrência das causas de morbidade, naquela cidade.

\subsection{ESTUDOS DO CLIMA RELACIONADOS A DOENÇAS RESPIRATÓRIAS}

Sobre esse tópico, Nadal e Vide (1999, p. 467), constataram:

O impacto das temperaturas diárias sobre a saúde e especificamente sobre a mortalidade registrada nos últimos anos em Barcelona, não oferece dúvidas, os efeitos negativos das temperaturas, são evidentes no aumento de falecimentos por infecções cardiovasculares quanto respiratórias, assim como no total de mortes registradas.

Para Abreu, Ferreira (1999) existe uma relação clara entre as doenças respiratórias e as condições meteorológicas, acrescentaram: 
A relação entre o número de casos de doenças respiratórias que acontecem ao longo do ano e a temperatura do ar é inversamente proporcional, ou seja, à medida que a temperatura do ar diminui, ocorrem aumento do número de casos de internações e atendimentos nos hospitais, em Belo Horizonte-MG, que concentram nas estações de outono e inverno (ABREU, FERREIRA, 1999, p. 11).

Pitton (2000) em pesquisa realizada em Cordeirópolis e Santa Gertrudes-SP, percebeu a possibilidade das infecções respiratórias serem mais sensíveis e mais comuns e, às vezes fatais, em tipos de tempo que prevalecem nos meses de outono-inverno, com a maior incidência por gripe, asma e bronquite.

Mendonça, Bórax e Paula (2000) analisaram a incidência de doença respiratória, como a Infecção das Vias Aéreas Superiores (IVAS), na população infantil em Curitiba e perceberam a existência do número de casos mais expressivo no ano de 1996, principalmente nos períodos com domínio da massa Polar atlântica $(\mathrm{mPa})$.

Bejarán (2001) num trabalho realizado entre 1996/98, para Buenos Aires, utilizou-se de análise de regressão múltipla juntamente com ajustes polinomiais. Observou que, com a chegada do período frio, aumentam os problemas das vias respiratórias altas e as infecções cardiovasculares.

Lima (2000, p. 56) constatou que, baixas temperaturas associaram-se a aumento de admissões hospitalares por doenças respiratórias agudas, de crianças até dois anos de idade, residentes no Município de Maringá.

$\mathrm{Na}$ Argentina Rusticucci, Bettolli e Angeles (2002, p. 43) analisaram, num hospital as internações referentes a problemas respiratórios, cardiovasculares, digestivos, infecções, geniturinário, alérgicos, relacionando-os com a temperatura máxima, mínima, umidade relativa e pressão atmosférica, entre o período de inverno e de verão. Concluindo que no inverno as condições atmosféricas, possui relação com as doenças alérgicas e respiratórias.

Zem (2004), analisou as doenças respiratórias na população infantil da cidade de São José dos Pinhais/PR, para o ano de 2000, utilizando-se da análise rítmica, organizadas em trimestres. Esse autor, verificou que no primeiro e terceiro trimestres, ou, verão e primavera, os números de registros de internações são amenizadas, concluindo: 
números perfazem $64,5 \%$ dos registros do ano todo. Com esses números, pode-se evidenciar que as maiores incidências ocorreram nas épocas mais frias do ano, ou seja, no outono e inverno (ZEM, 2004, p. 126).

Barros (2006) estudou a ocorrência de doenças respiratórias e os tipos de tempo, através da análise rítmica, em Brasília-DF, durante o período de outono e inverno de 2003, 2004, 2005, concluindo:

Ocorre aumento nos atendimentos em pronto-socorro por doenças respiratórias, quando há diminuição da umidade relativa do ar, redução da precipitação, da temperatura, com o aumento da amplitude térmica, típicos dos tempos seco de outono e seco de inverno, exercendo clara influência sobre o aumento das doenças das vias aéreas (BARROS, 2006, p. 115).

Souza (2007) analisou as influências dos fatores climáticos urbanos na incidência de casos de doenças do aparelho respiratório, no período de 2000-2007, em Presidente Prudente, constatando:

Num estudo de caso direcionado a cidade de Presidente Prudente (localizada no Extremo Oeste Paulista, possui uma variabilidade climática marcada por verões chuvosos e temperaturas altas e inverno seco de temperatura amena) as análises mensais, tanto meteorológicas quanto respiratórias demonstraram correlações. Período de estiagem prolongadas, oscilações e quedas de temperatura e umidade relativa, na maioria das vezes, abaixo de $60 \%$, estiveram presentes nos momentos em que houve aumento do número de casos de internações, por agravos respiratórios (SOUZA, 2007, p. 171).

Os efeitos do clima e do tempo atmosférico sobre a saúde humana ainda não são bem compreendidos. Conforme Pitton e Domingos (2004, p. 79) no entanto, há uma quantidade considerável de estudos evidenciando que as mudanças climáticas cíclicas influenciam os ritmos biológicos, os quais interferem em todas as atividades e funções humanas.

\subsection{CONFORTO TÉRMICO HUMANO}


Segundo Maia, Gonçalvez (2002, p. 305) a biometeorologia humana tem baseado seus estudos em índices térmicos empíricos, incorporando geralmente, dois ou três parâmetros que são relacionados com sensações humanas de conforto e desconforto.

Existem dois índices mais utilizados, como o índice térmicos empíricos de desconforto de THOM (1959) e o índice de wind-chill de SIMPLE (1945) (MAIA, GONÇALVEZ, 2002, p. 305).

O conforto térmico engloba componentes termodinâmicas, conforme Monteiro (2003, p. 24) que se expressam através do calor, ventilação e umidade, nos referenciais básicos a essa noção. É um filtro perceptivo bastante significativo, pois afeta a todos permanentemente.

Vários são os fatores que proporcionam as condições de conforto térmico, levando em conta, a função da atividade desenvolvida pelo indivíduo, bem como a sua vestimenta. Segundo Frota, Schiffer (2003, p. 25) além disso, devem ser consideradas outras variáveis, como sexo, idade, biotipo, hábitos alimentares, etc.

Os primeiros estudos acerca da influência das condições termo-higrométricas, foram desenvolvidas pela Comissão Americana da Ventilação. Os índices de conforto térmico foram desenvolvidos com base em diferentes aspectos do conforto e podem ser classificados em:

Índices biofísicos - que se baseiam nas trocas de calor entre o corpo e o ambiente, correlacionando os elementos do conforto com as trocas que dão origem a esses elementos;

Índices fisiológicos - que se baseiam nas reações fisiológicas originadas por condições conhecidas de temperatura seca do ar, temperatura radiante média, umidade do ar e velocidade do vento; Índices subjetivos - que se baseiam nas sensações subjetivas de conforto experimentadas em condições em que os elementos de conforto térmico variam (FROTA, SCHIFFER, 2003, p. 26).

Para caracterizar a sensação de bem estar ocasionada por um ambiente, em função de sua temperatura, umidade e deslocamento do ar adota-se o conceito de temperatura efetiva, que está relacionada com as condições de despesa mínima de energia do organismo, que se verifica quando o mesmo não tem de lutar contra o frio ou o calor (COSTA, 1974, p. 207).

Essas condições, ditas de neutralidade térmica, dependem dos mesmos fatores que influem sobre o metabolismo, de modo que, na realidade, não podemos 
falar de uma temperatura efetiva de máximo conforto, mas sim de uma zona de conforto (COSTA, 1974, p. 207).

Segundo Azevedo (2010, p. 31) vários autores tem elaborado equações matemáticas, mais ou menos complexas, envolvendo duas ou mais variáveis meteorológicas que se relacionam, dependendo do meio e finalidade de estudo.

Os índices visam identificar limites fisiológicos de sensibilidade a influência dos vários parâmetros, mediante o comportamento do organismo perante as variações desses parâmetros (AZEVEDO, 2010, p. 31).

Um exemplo clássico é o índice de Temperatura Efetiva (TE) fornecida por Thom (1959), segundo Funari (2006, p. 37) esse índice é também chamado de "índice de desconforto", de E. C. Thom, é o mais conhecido e utilizado, principalmente por urbanistas e arquitetos, para o planejamento urbano.

Conforme Ayoade (1986, p. 65) esse índice é encontrado pela equação da temperatura do bulbo seco e de bulbo úmido, medidas em ${ }^{\circ} \mathrm{C}$, é algumas vezes denominada de índice de desconforto ou índice de temperatura-umidade.

Garcia (1996) disponibiliza as sensações do corpo aos distintos valores de temperatura efetiva, conforme o Quadro 2.

Quadro 2: Temperatura efetiva e sensações térmicas.

\begin{tabular}{||c|c|c|l||}
\hline \hline TEMPERATURA & \multicolumn{2}{|c||}{ SENSAÇÃOO } & \multicolumn{1}{c||}{ RESPOSTA } \\
\hline EFETIVA & TÉRMICA & CONFORTO & \multicolumn{1}{c||}{ FISICA } \\
\hline $40^{\circ} \mathrm{C}$ & Muito quente & Muito incômodo & Problema de regulação. \\
\hline $35^{\circ} \mathrm{C}$ & Quente & - & $\begin{array}{l}\text { Aumento da tensão, por transpiração e } \\
\text { aumento do fluxo sangǘneo. }\end{array}$ \\
\hline $30^{\circ} \mathrm{C}$ & Temperado & - & $\begin{array}{l}\text { Regulação normal por transpiração e } \\
\text { troca vascular. }\end{array}$ \\
\hline $25^{\circ} \mathrm{C}$ & Neutro & Cômodo & Regulação vascular. \\
\hline $20^{\circ} \mathrm{C}$ & $\begin{array}{c}\text { Ligeiramente } \\
\text { fresco }\end{array}$ & $\begin{array}{c}\text { Ligeiramente } \\
\text { incômodo }\end{array}$ & Aumento de perdas por calor seco. \\
\hline $15^{\circ} \mathrm{C}$ & Frio & Incômodo & Vasocontrição nas mãos e pés. \\
\hline $10^{\circ} \mathrm{C}$ & Muito frio & - & Estremecimento \\
\hline
\end{tabular}

Fonte: Garcia (1996, p. 207).

Conforme Garcia (1996) a existência de um equilíbrio térmico, não indica necessariamente confortabilidade, posto que, pode alcançar condições de mal estar por efeito dos mecanismos auto-reguladores. Acrescentando ainda:

O corpo humano tem internamente uma temperatura que varia entre 36,5 e $37^{\circ} \mathrm{C}$, o equilíbrio térmico do corpo consiste em manter a temperatura dentro dessa média, se a temperatura aumenta ou 
diminui pode provocar lesões graves, de tal modo que entre 40 e $45^{\circ} \mathrm{C}$ produz complicações de circulação e acima de 41 e $42^{\circ} \mathrm{C}$ pode um indivíduo chegar ao estado de coma ou colapso total (GARCIA, 1996, p. 200).

Estudos já efetuados mostraram que a sensibilidade do organismo humano, relacionados com a variabilidade climática, os níveis de poluição, (assim como os índices de conforto térmico), muitas vezes podem colaborar para o desencadeamento de alguns problemas de saúde, como as doenças cardiovasculares e as respiratórias.

Braum (2003) analisou os índices de conforto térmico nos estudos relacionados a doenças cardiovasculares na cidade de São Paulo e definiu:

Os resultados obtidos neste estudo são muito claros no sentido de mostrar uma nítida associação entre mortalidade por doenças cardiovasculres e poluição atmosférica e variáveis meteorológicas (ou situações sinóticas) incluindo-se os índices do conforto (BRAUM, 2003, p. 148).

Coelho-Zanotti (2007) estudou as internações por doenças respiratórias de 1997 a 2000, em crianças de zero a treze anos, referente a cidade de São Paulo e concluiu:

[...] De acordo com a análise feita podemos afirmar que os poluentes, os índices de conforto térmico e as variáveis meteorológicas apresentam uma relação de causa e efeito nas internações por Afecções das Vias Aéreas Superiores, (AVAS), Afecções das Vias Aéreas Inferiores (AVAI) e Influenza e Pneumonia (IP) (COELHO-ZANOTTI, 2007, p. 161).

Silva (2010) observou os problemas respiratórios, em crianças menores de cinco anos e circulatórios e respiratórios, em adultos com mais de sessenta anos, no setor Sul/Sudeste de São Paulo. Acrescentando:

Os resultados mostraram associação entre a morbidade e as variáveis climáticas e o índice de conforto, no setor Sul/Sudeste, porém de forma diferenciada nos grupos etários e de doenças, indicando que os efeitos do clima sobre a saúde são diversos e específicos. As condições de desconforto para o frio e a alta amplitude térmica, consistiram em fatores mais agravantes para 0 desencadeamento das doenças (SILVA, 2010, p. 189). 


\subsection{A QUESTÃO ESPACIAL NA SAÚDE}

Segundo Carvalho, Pina e Santos (2000, p. 19) a urbanização tem sido um fator predominante no estabelecimento humano em escala mundial, as cidades têm sido estudadas em termos da ecologia urbana das doenças, poluição, superpopulação, estresse e pobreza que afetam a saúde humana.

Nesse processo de estudo para as cidades, as análises espaciais dos eventos e agravos de saúde possibilitam o diagnóstico preciso das condições sanitárias da população. O conhecimento através da análise espacial permite então melhor diagnóstico, execução de ações e avaliação de intervenções dirigidas à prevenção e ao controle dos danos a saúde.

A utilização de mapas para representar um determinado caso, sempre esteve relacionada a assuntos de saúde pública. Um exemplo muito interessante é o de John Snow, que analisou a distribuição da epidemia da cólera, entre 1849 e 1854, na região de Soho, em Londres (BRODY et al., 2000).

Em sua publicação On the Mode of Communication of Cholera in London, 1855, Snow elaborou um mapa de distribuição dessa doença, marcando os locais de 83 óbitos por cólera, apontando uma estreita ligação entre os casos de cólera e as fontes de fornecimento de água da Rua Broad, identificando a companhia de Southwark Vauxhall como fonte da doença.

Em Maringá-PR, Fonzar, Soares e Santil (2002), utilizaram da técnica de mapeamento, para representar três principais causas de morte nesta cidade, no ano de 1996, sendo as doenças cardiovasculares, neoplasias e causas externas.

Segundo Fonzar (2003, p. 14) com a identificação de áreas geográficas e de seus fenômenos, é possível apontar grupos da população que apresenta maior risco de adoecer ou morrer prematuramente e que, portanto, precisam de maior atenção, seja preventiva, curativa ou de promoção à saúde.

Para definir a mortalidade por causas externas em Maringá-PR, Fonzar (2003), utilizou-se da construção de mapas temáticos e enfatizou:

- É preciso compreender o ambiente urbano enquanto espaços antagônicos que está ligado ao próprio processo de construção da cidade, ou seja, à criação do próprio espaço urbano, do "ambiente" nos quais as pessoas vivem, circulam e morrem, sendo espaço de 
conflitos e desigualdades, de inclusão e exclusão, portanto multidimensional;

- É nessa perspectiva que a Geografia e a Saúde têm que espacializar e analisar os fenômenos e ou agravos, eventos de saúde e, que muitas vezes o objeto de análise ultrapassa a dimensão dessas ciências necessitando a inclusão de outros saberes como da antropologia, psicologia, sociologia, história, engenharia, direito, entre outros (FONZAR, 2003, p. 157).

Segundo Queiroz (2003, p. 9) a visualização espacial de diferentes aspectos, isto é a presença de mapas, é fator fundamental no planejamento. Porém estes mapas devem ser concisos, legíveis, apresentando simbologias que facilitem a apreensão da informação.

A elaboração de mapas para identificar um caso analisado, facilita a amostra e permite indicar onde um determinado problema está em atuação, por esse motivo, em pesquisas geográficas e em eventos de saúde os mapas são extremamente utilizados.

\subsection{O APARELHO RESPIRATÓRIO}

O aparelho respiratório é formado pelo Trato Respiratório Superior, que compreende os órgãos localizados fora da caixa torácica, com espaços interconectados, com o nariz externo, a cavidade nasal ou fossas nasais, seios paranasais, laringe, nasofaringe, parte superior da traquéia. $E$ pelo Trato Respiratório Inferior, que consiste em órgãos localizados na cavidade torácica, começando na laringe e continuam para o tórax com a parte inferior da traquéia, brônquios, bronquíolos e alvéolos.

Conforme a Classificação Internacional de doenças respiratórias CID-10 (1997, p. 499) as doenças respiratórias compreende os seguintes agrupamentos: Infecções agudas das vias aéreas superiores; influenza \{gripe\} e pneumonia; outras infecções agudas das vias aéreas inferiores; outras doenças das vias aéreas superiores; doenças crônicas das vias aéreas inferiores; doenças pulmonares devidas a agentes externos; outras doenças respiratórias que afetam principalmente o interstício; afecções necróticas e superativas das vias aéreas inferiores; outras doenças da pleura; outras doenças do aparelho respiratório. 
Mcphee, Ganong (2007), Apud CORRÊA (2010, p.41/42) as principais doenças do aparelho respiratório podem ser assim resumidas:

- o resfriado comum pode ser causado por vários tipos de vírus e atinge principalmente o nariz, os seios paranasais e a faringe:

- a rinite refere-se à inflamação da membrana do nariz, devido a reações alérgicas, geralmente acontece na infância e na juventude. Fatores genéticos são importantes para o seu aparecimento, mas fatores ambientais podem desencadeá-la;

- a asma é uma doença inflamatória crônica na qual o indivíduo apresenta uma sensibilidade acentuada nas vias aéreas inferiores, com dificuldades de respiração e apresenta como sintomas, entre outros, aperto no peito e tosse. É resultado dos fatores genéticos e, principalmente, exposição ambiental;

- a bronquite caracteriza-se pela inflamação e inchaço dos brônquios. Quando as membranas mucosas que revestem esses tubos inflamam, as glândulas mucosas nas membranas se expandem e liberam o muco. Os brônquios, já estreitados pelo inchaço, ficam mais obstruídos pelo excesso de muco. Esse muco deve ser eliminado para manter a árvore respiratória livre para a passagem normal do ar até os pulmões;

- a enfisema tem como característica a obstrução completa dos bronquíolos, com aumento da resistência à passagem de ar, principalmente durante a expirações. Essa doença acomete principalmente os fumantes;

- a pneumonia constitui-se em um processo inflamatório dos pulmões, podem acometer a região dos alvéolos pulmonares, local que desembocam as ramificações terminais dos brônquios, são provocadas pela ação de um agente irritante, como: bactérias, fungos ou reações alérgicas no espaço alveolar.

\section{CLIMATOLOGIA DA REGIÃO SUL DO BRASIL}

Segundo a definição do clima por HANN (1903) apud FUNARI (2006, p. 22) "clima é o conjunto dos fenômenos meteorológicos, que caracterizam a condição média da atmosfera em cada lugar da Terra". 
Sorre (1984) "definiu o clima de um determinado local como sendo a série dos estados da atmosfera, em sua sucessão habitual. Cada tempo se define por uma combinação de elementos do clima".

O estudo do clima baseia-se na observação de como os tipos de tempo se apresentam em um determinado lugar, de acordo com a atuação direta de frentes e de massas de ar (SORRE, 1984, P. 32).

Podem-se destacar como elementos importantes para o estudo do clima as temperaturas, a umidade relativa do ar, a precipitação, a queda de neve, a incidência de luz solar, a velocidade do vento, a pressão atmosférica e as freqüências dos diferentes tipos de massas de ar (SORRE, 1984, p. 32).

As massas de ar são também muito importantes no estudo de tempo e do clima, porque influenciam diretamente na área na qual predominam, assim, as características meteorológicas de uma massa de ar dependem de suas características higrotérmicas e da distribuição vertical desses elementos.

Monteiro (1968) ao analisar a circulação atmosférica na América do Sul, caracterizou das principais massas de ar predominantes no Brasil, salientando aquelas que tem participação mais ativa na região Sul, como:

- A massa Tropical atlântica (Ta) individualiza-se no anticiclone semifixo do Atlântico Sul. Por suas propriedades na fonte é uma massa quente, úmida e com tendência a estabilidade pela subsidência superior daquela célula oceânica de altas pressões dinâmicas. Graças ao sistema de emissão contra-horário daquele anticiclone austral, têm grande poder de penetração para o interior do continente. As regiões Este, Sul e Centro-Oeste são frequentemente dominadas por esta massa, cujas trajetórias, em que pêse a flutuação latitudinal e proximidade ou afastamento de sua fonte, variam do leste para nordeste. Sua atividade é constante o ano inteiro.

- A massa Polar atlântica $(\mathrm{Pa})$ de atividade mais no inverno, graças aos efeitos que produz, apresenta participação de realce na circulação regional. Essa massa fria tem sua fonte sobre o Atlântico, não longe do continente, na latitude da Patagônia. Resulta do acúmulo do ar polar que, em turbilhões, para aí se dirige. A orientação meridiana da cordilheira andina cria duas massas: a $\mathrm{Pa}$, que se fez referência e a Polar pacífica (Pp), as quais, tendo a mesma gênese, estão intimamente relacionadas [...].

- A massa Equatorial continental (Ec) tem sua fonte na planície amazônica. É uma célula de divergência dos alísios - doldrum - que tende a manter-se durante todo 0 ano naquela zona. Trata-se de uma massa quente, de elevada umidade específica [...]. No verão austral, atraída pelos sistemas depressionários (térmicos e dinâmicos) do interior do continente, tende a avançar do NW, ora 
para SE, ora para ESSE, de acordo com a posição da Frente Polar Atlântica [...].

- A massa Tropical continental (Tc) de ocorrência bem menos conspícua, tem uma participação complementar. Sua individualização é mais restrita ao verão quando a depressão do Chaco, dinamizada pela Frente Polar Atlântica, se superpõe uma bolsa de ar frio (circulação superior). Assim o ar quente e seco da planície central do continente, dotado de subsidência superior pela importação de ar frio, torna-se dotado de movimento divergente, uma das condições básicas para a individualização de massas de ar. Apesar disto, muito frequentemente, durante as outras estações do ano, notam-se, nas cartas sinóticas brasileiras, referências a Tc. Muitas vezes esta sinalização se refere a uma massa polar já velha, bastante modificada, que no interior do continente, se tornou bem mais quente e mais seca [...] (MONTEIRO, 1968, p. 122-123).

Conforme Varejão-Silva (2001) por questões relacionadas à circulação geral da atmosfera, as massas de ar frequentemente abandonam a região de origem, conduzindo consigo as propriedades lá adquiridas. Em relação a esses deslocamentos das massas, argumentou:

No trajeto, podem causar profundas alterações nas condições prevalecentes do tempo, das áreas aonde chegam, à medida que também vão se modificando em suas características originais [...]. Quando uma massa de ar se desloca sobre uma região mais quente (sendo, portanto, classificada como fria), a camada atmosférica que está em contato direto com a superfície é aquecida por condução, gerando instabilidade [...]. Uma massa de ar é dita quente quando se desloca sobre uma área relativamente mais fria. Nessas circunstâncias, o ar quente perde gradualmente calor, por condução, devido ao contato com a superfície terrestre subjacente, que está mais fria (VAREJÃO-SILVA, 2001, p. 419-420).

Um sistema frontal é caracterizado pela transição entre massas de ar diferentes. Segundo Ayoade (1986, p. 103) essas frentes variam de 80 a 240 quilômetros de largura. As mudanças nos elementos do tempo são muito mais rápidas através das frentes do que no interior das próprias massas de ar.

Vários trabalhos foram pioneiros e contribuíram para o entendimento do clima no Brasil, como de Monteiro (1968), Monteiro (1969), Serra (1975), Nimer (1979). Esses autores analisaram a circulação atmosférica, com a participação das massas de ar predominantes, levando com consideração a situação de relevos e latitudes.

Nimer (1979, p. 259) ao estudar a climatologia da Região Sul do Brasil a definiu como sendo uma região das mais uniformes e de maior grau de unidade climática, sendo expressa pelo predomínio do clima mesotérmico, superúmido, sem 
estação seca e sua unidade pelo ritmo climático característico de regiões temperadas.

Conforme Nimer (1979) a sua uniformidade e unidade são dadas pelos fatores climáticos dinâmicos, pois o Sul do Brasil é uma região de passagem da frente polar, o que a torna constantemente sujeita as bruscas mudanças de tempo pelas sucessivas invasões de tais fenômenos em qualquer estação do ano:

[...] Confere nesta região uma importante oscilação térmica ao longo do ano, geralmente seu inverno é frio e verão quente. Apenas o Norte do Paraná e o litoral do Paraná e Santa Catarina possuem inverno ameno. Em quase todo o território regional existe pelo menos um mês com temperatura média inferior a $15^{\circ} \mathrm{C}$ (NIMER, 1979, p. 259).

Monteiro (1968, p. 146) quando analisou o quadro geral das temperaturas do Brasil, salientou que na região Sul, o traçado das isolinhas, referente à média das máximas e mínimas, reflete a influência exercida pelos aquecimentos e resfriamentos que se produzem através das correntes perturbadas das massas intertropicais (ondas de Calor) e extratropicais (ondas de frio) sob a influência da latitude.

Ocorrem outros sistemas que interagem na região Sul, são os Complexos Convectivos de Mesoescala (CCM), atuantes principalmente na primavera e verão, além das Zonas de Convergência do Atlântico Sul (ZCAS), com atuação a partir de setembro/outubro estendendo-se até março/abril (NERY, 2006, p. 62).

Conforme Nery (2006, p. 65) as ZCAS ocorrem principalmente sobre o Brasil central, com seu eixo estendendo-se de noroeste a sudeste, fundamentais na explicação das chuvas de verão, em grande parte da região Sul, dependendo do ano pode até mesmo atingir toda essa região.

Segundo Berezuk e Santa'nna Neto (2006, p. 13) a ZCAS constitui-se, portanto, como uma extensa área de intensa nebulosidade e chuvas geralmente possuindo de 2000 a $2500 \mathrm{~km}$ de extensão.

Sobre os Complexos Convectivos de Mesoescala (CCM) comuns na primavera, Britto, Barletta e Mendonça (2006, p. 40) são sistemas que se formam no período noturno sobre o norte da Argentina e sul do Paraguai e deslocam-se rapidamente atingindo o noroeste da região Sul, com intensa precipitação pluvial. 
A formação dos Complexos Convectivos de Mesoescala, está também muitas vezes relacionada a uma pré-formação de ZCAS. A própria formação desses complexos convectivos está relacionada à influência de calor e umidade província da ação do Sistema Equatorial Continental (BEREZUK, SANTA'NNA NETO, 2006, p. 20).

Portanto, os Complexos Convectivos de Mesoescala, são aglomerados de nuvens que se formam devido à condições locais favoráveis, como a temperatura, relevo, pressão, umidade, provocando chuvas fortes e de curta duração, normalmente essas chuvas associadas a este fenômeno ocorrem de forma isolada.

\subsection{PARANÁ}

O Paraná situa-se na região Sul do Brasil, entre $22^{\circ} 29^{\prime} 33^{\prime \prime}$ e $26^{\circ} 42^{\prime} 59^{\prime \prime}$ latitude Sul, $48^{\circ}$ 02'24" e 54 37'38" longitude Oeste, abrangendo uma área de $201.000 \mathrm{~km}^{2}$.

Maack (1981) destacou cinco grandes unidades físico-geográficas em função da diversidade das paisagens naturais, denominadas de "grandes paisagens e subzonas naturais". São elas: Planície Litorânea, Serra do Mar, Primeiro Planalto, Segundo Planalto, denominado também de planalto de Ponta Grossa, Terceiro Planalto ou planalto de Guarapuava.

O Terceiro Planalto é o maior compartimento morfoestrutural do Estado do Paraná, abrange uma área de, aproximadamente, $135.000 \mathrm{~km}^{2}$, apresenta-se dividida em vários blocos. Para fazer esta subdivisão, Maack (1981) levou em consideração à rede de drenagem dividindo-a em cinco subunidades: Planalto de Cambará e São Jerônimo da Serra, Apucarana, Campo Mourão, Guarapuava e Palmas.

Enfocando o aspecto climático, notamos que, sob o território do Paraná se revezam: a) correntes perturbadas do sul com massas polares frias e secas em descontinuidade frontal; b) correntes marítimas de leste, tépidas e úmidas; e c) correntes de oeste, quentes e úmidas provindas do centro térmico de baixa pressão do Chaco (TROPPMAIR,1990, p. 67). 
No inverno dominam as massas polares com baixas temperaturas e baixa umidade, vindas da porção sul do continente ou após terem transpostas os Andes, enquanto no verão dominam as massas tropicais marítimas, formando as correntes de norte e nordeste, com sucessivos avanços e recuos acompanhados de instabilidade pré e pós-frontais, originando chuvas pesadas quase que diárias (TROPPMAIR,1990, p. 68).

nos meses de transição, especialmente no outono, predominam as correntes de oeste formando a linha de instabilidade tropical, originando chuvas convectivas, que caem no período da tarde (TROPPMAIR, 1990, p. 68).

Conforme Silva, Nery (2001) o Paraná é um Estado que tem seu clima atingido por diferentes efeitos, tais como maritimidade (Oceano Atlântico), continentalidade (região central e oeste do Estado), orografia (Serra Geral, ao sul e Serra do Mar a leste).

Associado a isso, há a dinâmica da baixa do Chaco e as bandas convectivas e/ou Zonas de Convergências do Atlântico Sul (ZCAS), na primavera e verão e os sistemas polares (principalmente no inverno e outono) (SILVA, NERY, 2001).

\subsection{CARACTERIZAÇÃO DA ÁREA DE ESTUDO - MARINGÁ}

Maringá, situada ao Norte do Estado do Paraná, no Terceiro Planalto ou planalto de Guarapuava, possui 288.653 habitantes, IBGE (2000), estimativa de 331.412 habitantes, IBGE (2008) e 357.077 habitantes IBGE (2011). A área do município é de $473,06 \mathrm{~km}^{2}$, é cortado pela linha imaginária do Trópico de Capricórnio, aproximadamente na altura do Cemitério Público, situado na área central. Apresenta-se a uma distância de 430 km de Curitiba.

A Figura 1 apresenta a localização do município de Maringá, inserida na região Sul, na latitude entre $23^{\circ} 30^{\prime} \mathrm{S}$ e longitude de $52^{\circ} 00^{\prime}$ Oeste, com altitude variando de 542 a 600 metros, em relação ao nível do mar.

Nos aspéctos históricos, Maringá foi fundada em 10 de maio de 1947 como distrito de Mandaguari. Em 1948 passou a categoria de vila, sendo elevada a município através da lei no790 de 14/11/1951, tendo como distritos Iguatemi, Floriano e Ivatuba. 


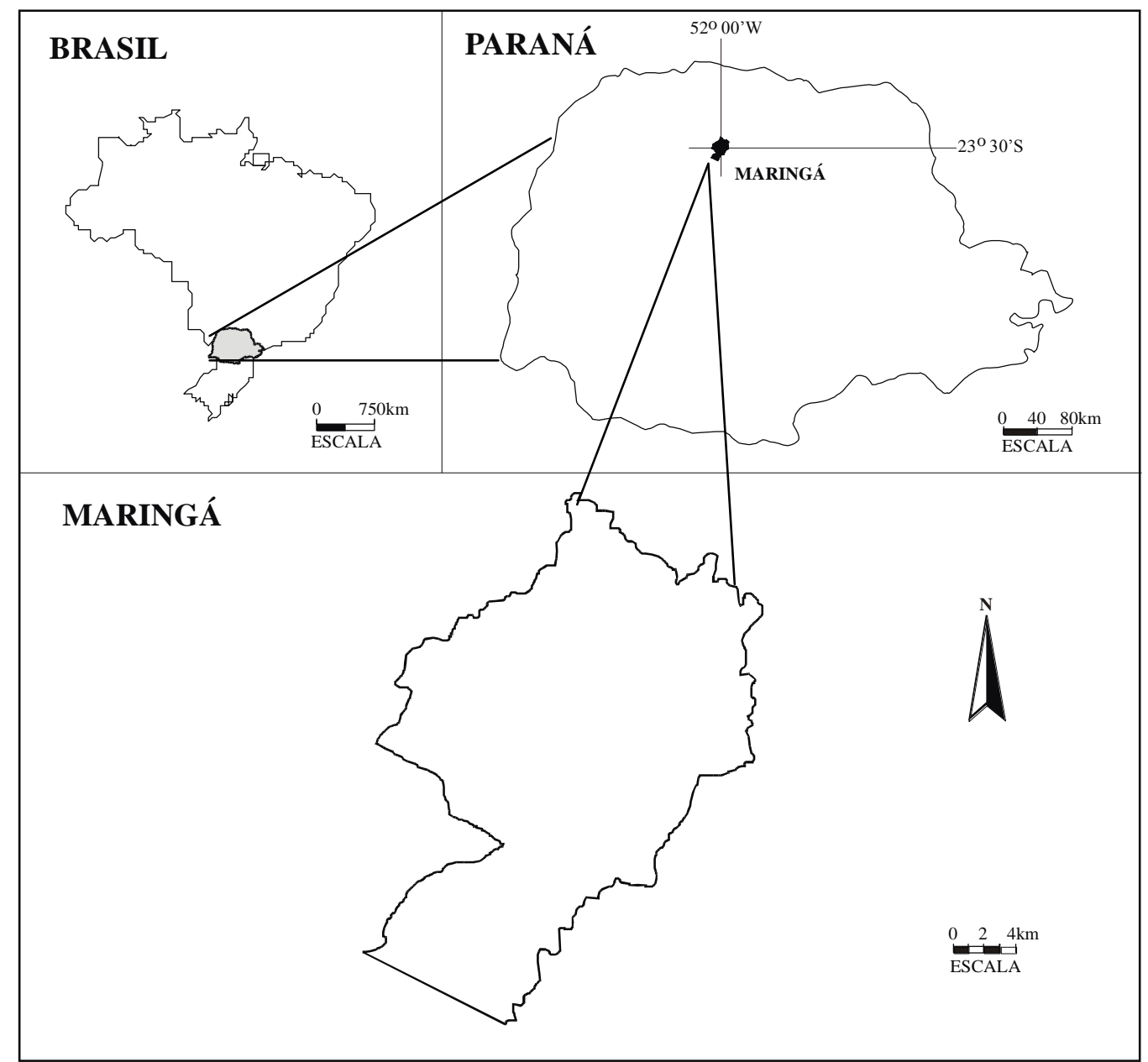

Figura 1: Localização da área de estudo.

A categoria de COMARCA foi elevada em 1954. Em 1998, tornou-se sede da Região Metropolitana, integrada além de Maringá, pelos municípios de Astorga, Ângulo, Doutor Camargo, Floresta, Iguaraçu, Itambé, Ivatuba, Mandaguari, Mandaguaçu, Paiçandu e Sarandi.

Foi desde o início uma cidade planejada e teve como objetivo tornar-se um dos mais importantes centros urbanos do Norte do Paraná, colonizada pela Companhia de Terras Norte do Paraná, o café foi o principal motivo para a ocupação e valorização das terras dessa micro região (ENDLICH, MORO, 2003, p. 16).

O Plano Diretor apresentava as seguintes características: uma avenida principal que ainda hoje atravessa a cidade de um extremo ao outro, chamada de Avenida Brasil e o zoneamento do uso de solo denominado por funções.

Essa Companhia planejou a instalação de uma rede urbana hierarquizada que compreendia a instalação de pequenos núcleos a distância aproximada de 15 
$\mathrm{km}$ uns dos outros, procurando atender as necessidades mais imediatas da população rural (ENDLICH, MORO, 2003, p. 16).

Esse processo de colonização foi realizado em toda a região norte e noroeste, do Paraná, numa distância, aproximadamente a cada $100 \mathrm{~km}$ foi planejada uma cidade de porte maior, cujo objetivo seria fornecer serviços e produtos de demanda para as cidades menores.

Além das relações espaciais internacionais, as relações capitalistas envolvidas na produção do café, contribuíram para o fortalecimento de um mercado interno, a medida que empregava abundantemente mão-de-obra na sua produção, mas a fragilidade provocada pela concorrência internacional, principalmente os países africanos e centro-americanos, geraram uma política de erradicação de cafeeiros (ENDLICH, MORO, 2003, p. 16).

Com a crise cafeeira que ocorreu, as grandes áreas cafeeiras foram sendo substituídas pela plantação de cana-de-açucar, algodão, destacando para o plantio do trigo, soja e milho. Hoje, são encontradas na região apenas pequenas áreas de culturas permanente.

A Tabela 1 apresenta a população urbana e rural desde 1950 até 2000, observa-se que Maringá aumentou rapidamente o seu contingente populacional, passando de 38.588 habitantes em 1950 a 104.131 para 1960, ou seja, três vezes mais. Em 1990 contava com 240.292 habitantes, atingindo 288.653 em 2000.

Tabela 1: Censos realizados no Município de Maringá: 1950-2000.

\begin{tabular}{c|ccccc}
\hline ANO/CENSO & RURAL & $\%$ & URBANA & $\%$ & TOTAL POP. \\
\hline 1950 & 31.318 & 81,16 & 7.270 & 18,84 & 38.588 \\
1960 & 56.539 & 54,30 & 47.592 & 45,70 & 104.131 \\
1970 & 21.274 & 17,53 & 100.100 & 82,47 & 121.374 \\
1980 & 7.550 & 4,49 & 160.689 & 95,51 & 168.239 \\
1990 & 6.213 & 2,59 & 234.079 & 97,41 & 240.292 \\
2000 & 4.675 & 1,62 & 283.978 & 98,38 & 288.653 \\
\hline
\end{tabular}

Fonte: Prefeitura Municipal de Maringá (2000).

A taxa de aumento populacional para essa cidade, foi elevada na década de 1950/1960, sendo de 10,44, diminuindo na década de 1960/1970 para 1,54, na década de 1970/1980 foi de 3,31, década de 1980/1991 foi de 3,29 e na década de $1991 / 2000$ foi de 1,86 .

Conforme IBGE (2000) o município de Maringá apresentava o lixo domiciliar per capita diário (0,87 kg/dia), consumo per capita de água (152 l/dia) fluoretação de água (100\%) índice de qualidade de água distribuída (100\%). 
Domicílios com energia elétrica totalizavam (100\%), quantidade de pessoas por veículo $(2,6)$, veículos por grupos de 10 pessoas (3,9\%). A média de pessoas por domicílio variavam entre 2,97 a 3,80.

A Tabela 2 apresenta informações sobre o Índice de Desenvolvimento Humano Municipal em 2000, para as principais cidades do Paraná. Maringá encontrava-se em 6⿳a posição em relação à taxa bruta de frequência escolar e no Índice de Renda (IDHM-R).

Tabela 2: Comparativo do Índice de Desenvolvimento Humano Municipal (IDH-M), 2000: 1) Esperança de vida ao nascer (em anos); 2) Taxa de alfabetização de adultos (\%); 3) Taxa bruta de frequência escolar (\%); 4) Renda per capita em (R\$); 5) Índice de longevidade (IDHM-L); 6) Índice de Educação (IDHM-E); 7) Índice de Renda (IDHM-R); 8) Índice de Desenvolvimento Humano Municipal (IDH-M); 9) Classificação na UF; 10) Classificação Nacional.

\begin{tabular}{c|cccccccccc}
\hline Municipio & $\mathbf{1}$ & $\mathbf{2}$ & $\mathbf{3}$ & $\mathbf{4}$ & $\mathbf{5}$ & $\mathbf{6}$ & $\mathbf{7}$ & $\mathbf{8}$ & $\mathbf{9}$ & $\mathbf{1 0}$ \\
\hline Curitiba & 71,57 & 96,62 & 90,44 & 619,82 & 0,776 & 0,946 & 0,846 & 0,856 & 1 & 19 \\
C. Mourão & 67,99 & 89,32 & 88,79 & 283,08 & 0,717 & 0,891 & 0,715 & 0,774 & 74 & 1.199 \\
Cascavel & 69,60 & 93,01 & 95,10 & 347,01 & 0,743 & 0,937 & 0,749 & 0,810 & 15 & 375 \\
F. Iguaçu & 68,28 & 92,52 & 86,46 & 326,19 & 0,721 & 0,905 & 0,739 & 0,788 & 41 & 841 \\
Londrina & 71,37 & 92,93 & 87,28 & 439,35 & 0,773 & 0,910 & 0,788 & 0,824 & 10 & 189 \\
Maringá & $\mathbf{7 2 , 2 1}$ & $\mathbf{9 4 , 6 1}$ & $\mathbf{9 2 , 2 6}$ & $\mathbf{4 6 5 , 3 7}$ & $\mathbf{0 , 7 8 7}$ & $\mathbf{0 , 9 3 8}$ & $\mathbf{0 , 7 9 8}$ & $\mathbf{0 , 8 4 1}$ & $\mathbf{6}$ & $\mathbf{6 7}$ \\
Paranaguá & 68,20 & 94,06 & 80,97 & 305,36 & 0,720 & 0,897 & 0,728 & 0,782 & 61 & 1.014 \\
P. Grossa & 70,88 & 94,29 & 84,64 & 318,22 & 0,765 & 0,911 & 0,735 & 0,803 & 19 & 494 \\
Sarandi & 72,93 & 89,75 & 77,84 & 187,13 & 0,799 & 0,858 & 0,646 & 0,768 & 96 & 1.394 \\
\hline
\end{tabular}

Fonte: Prefeitura Municipal de Maringá (2000).

Em anexo 1 e anexo 2 estão apresentadas as Zonas Municipais de Maringá, com os respectivos bairros pertencentes e a população estimada por sexo. Vale ressaltar que todos os apontamentos referente a Maringá são do IBGE (2000), pois as doenças respiratórias foram analisadas entre 2000 a 2007, tornando inviável utilizar o Censo (2010).

Conforme a Prefeitura Municipal de Maringá (2008) na zona 1, concentra o comércio, edificações, Prefeitura Municipal, Fórum, Câmara Municipal, Biblioteca, Catedral, estabelecimentos bancários e hotéis. A zona 2 e 5 destinam-se as residências e a zona 3 destinada a área industrial.

Maringá é organizada em 51 Zonas municipais, sendo 298 bairros agregados a essas zonas. A zona 33 pertence ao Distrito de Iguatemi, 34 ao Distrito de Floriano, a zona 49 pertence ao Jardim São Domingos, sendo este mais afastado da malha urbana, a zona 50 corresponde a área da Praça da Catedral, zona 51 ao Parque Industrial 200, conforme apresentado na Figura $1 \mathrm{~A}$. 
O limite municipal de Maringá, bem como a área urbana, a hipsometria, hidrografia, altimetria e sistema viário estão apresentados nas Bases Cartográficas, conforme Queiroz (2003), nas Figuras 1B, 1C e 1D.

\section{Zonas municipais - Maringá/ PR}

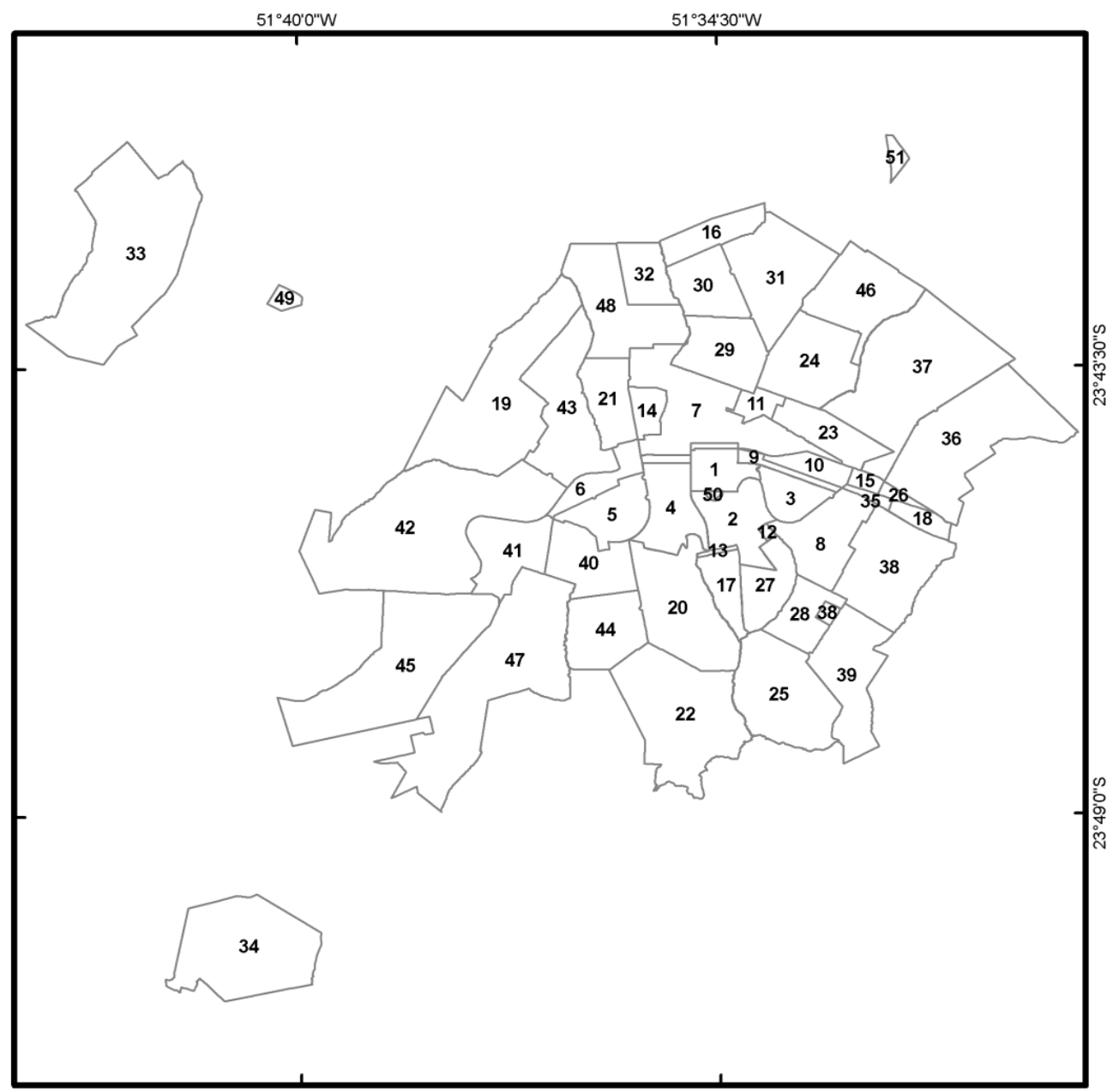

1 Zonas municipais - Maringá/PR

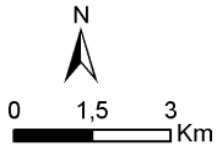

Fonte: Pref. Municipal Maringá Secretaria Municipal de Saúde Maringá, 2008

Org.: ANJOS, I. B., 2010

Figura 1A: Organização do espaço urbano de Maringá-PR. 


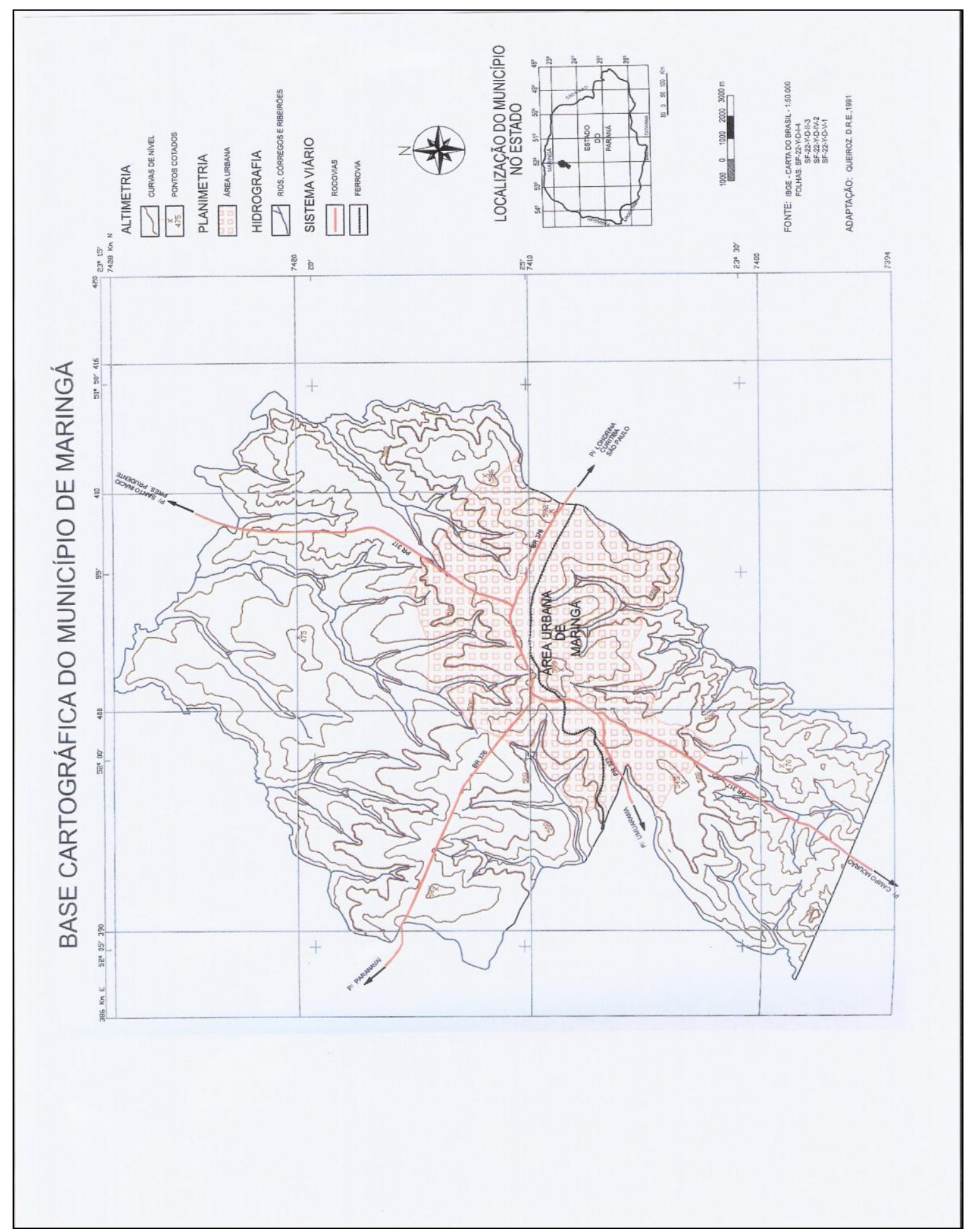

Figura 1B: Base cartográfica do Município de Maringá-PR. 


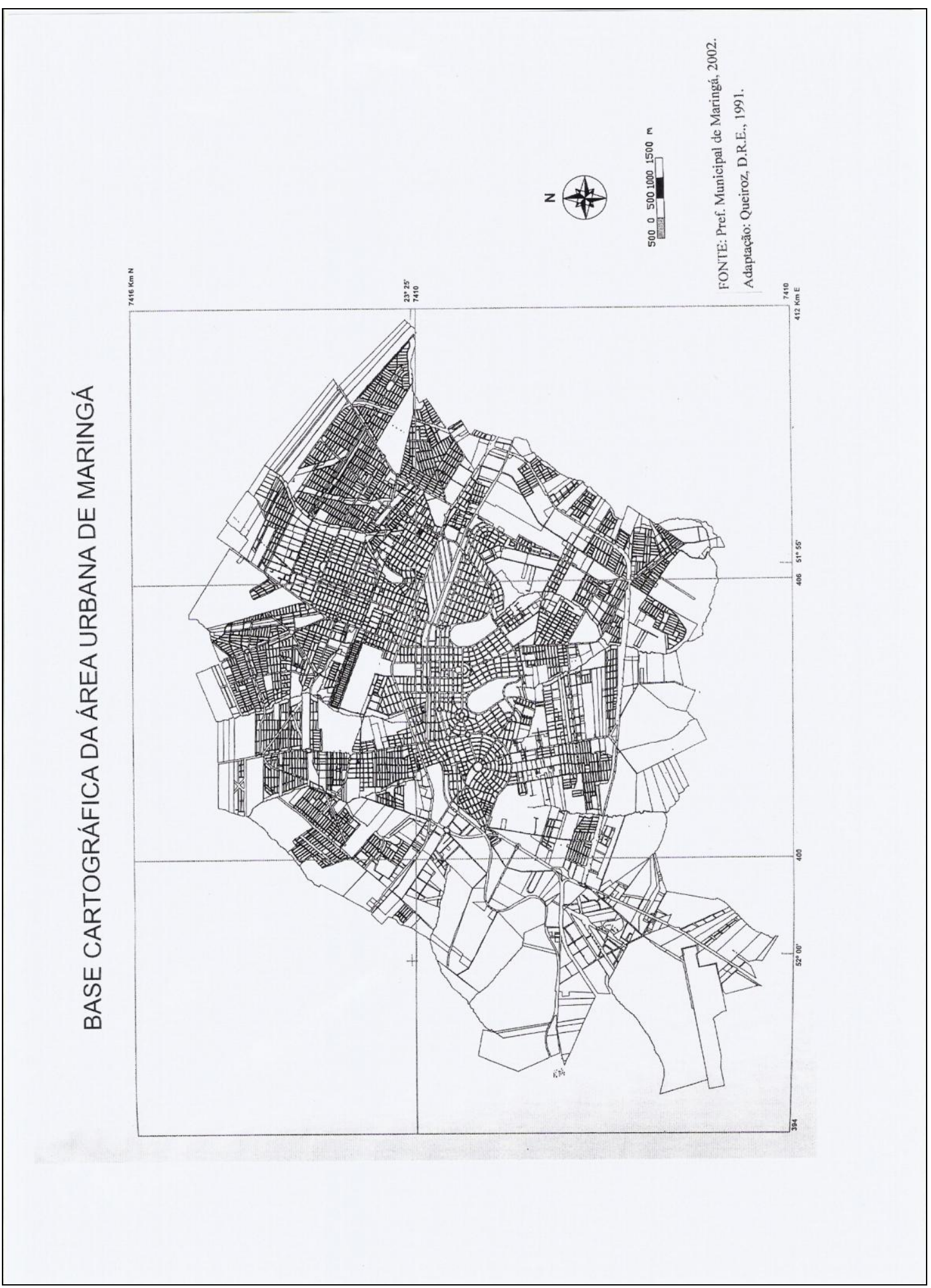

Figura 1C: Base cartográfica da área urbana de Maringá-PR. 


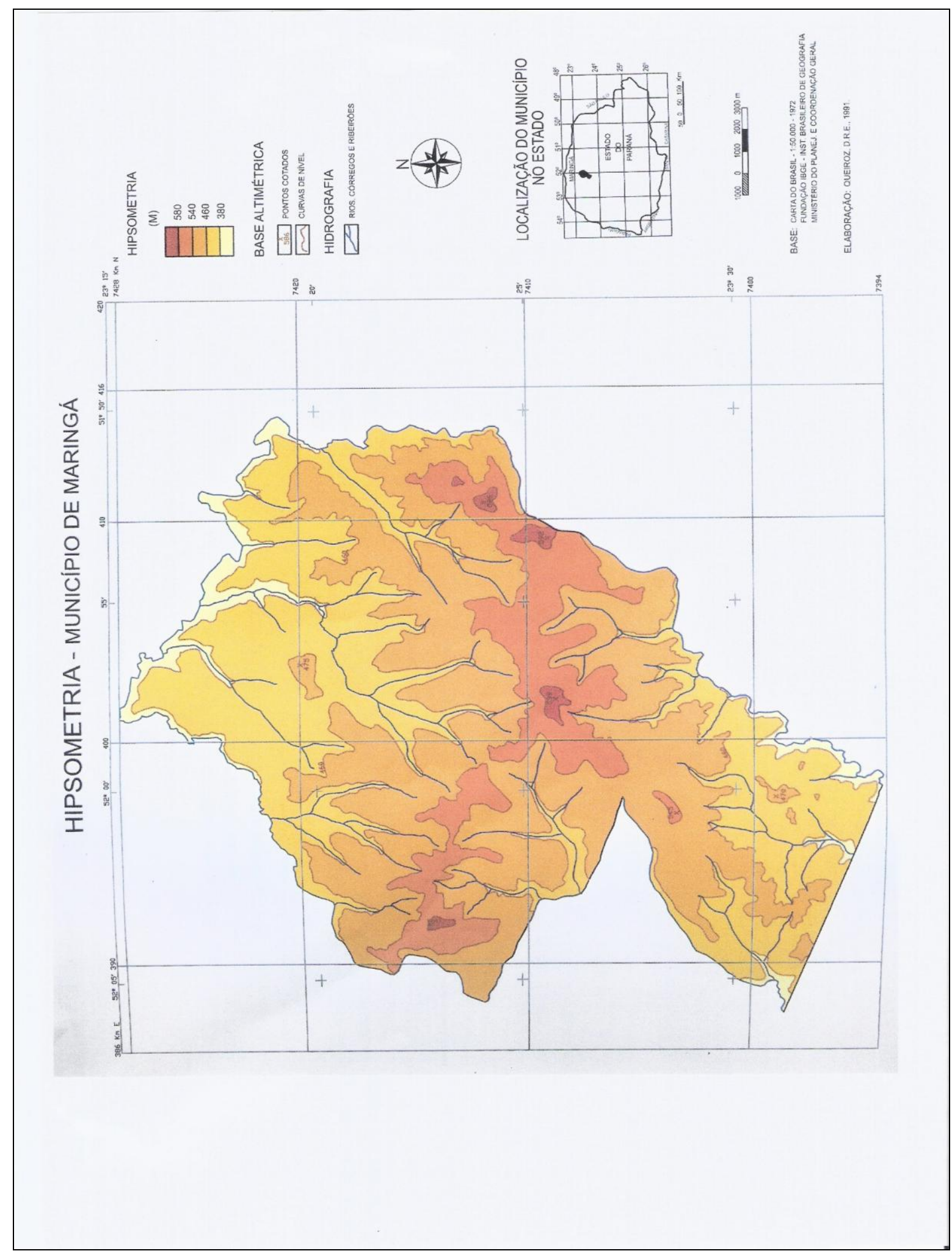

Figura 1D: Hipsometria do Município de Maringá-PR.

\subsubsection{ASPECTOS FÍSICOS DE MARINGÁ}


O sítio urbano de Maringá localiza-se no espigão divisores de água das bacias hidrográficas, os rios Ivaí (afluente do rio Paraná) e Pirapó (afluente do rio Paranapanema), o município é banhado pelos rios: Pirapó, manancial que fornece água para o abastecimento da cidade e também por Camapuã, Mandacaru, Centenário, Morangueira e Maringá.

Os tributários do rio Paranapanema são: córregos de Mandaguaçu, Osório, Isalto, Miosótis, Narazeth, Ibitanga e ribeirão Maringá. Os tributários do rio Ivaí são: córregos Borba Gato, Nhanguaçu, Birigui, Cleópatra, Moscados e Merlos, os ribeirões Pinguim, Bandeirantes do Sul, Paiçandu e Floriano. Em relação a geologia, tem formação nos derrames dos períodos Jurássico-Cretácio, da Era mesozóica.

Maringá pertence a Bacia do Prata, tendo como o rio principal o rio Paraná, que tem sistema dentrítico com a orientação $\mathrm{N}$-S dos rios principais e $\mathrm{F}-\mathrm{W}$ para seus afluentes. A drenagem tem sentido norte em direção do rio Pirapó e ao sul no rio Ivaí (PREFEITURA MUNICIPAL DE MARINGÁ, 1994).

A região de Maringá, apresenta relevo predominantemente suave, com platôs. O solo apresenta-se em linhas gerais profundos, bem desenvolvidos e de alta fertilidade como o latossolo vermelho eutroférrico e os nitossolos (EMBRAPA, 1999).

Em algumas áreas o relevo mostra feições levementente acidentados, em alguns pontos os ribeirões apresentam-se em vales encaixados, tendo um alinhamento de $\mathrm{E}-\mathrm{W}$, forma uma crista topográfica que define um divisor de águas entre os rios Paranapanema ao norte e o Ivaí ao sul (PREFEITURA MUNICIPAL DE MARINGÁ, 1994).

Nas florestas que haviam na região, eram comum árvores de grande porte, como o pau-d'alho (Gallesia integrifolia), cebolão, ceboleiro caviúna, cedro (Cedrela fissilis), ingá, figueira branca (Ficus) e o palmito (Euterpe edulis), estas eram simbolizadas pelos colonos como exemplos de solos férteis.

A primeira cobertura vegetal da parte Norte do Paraná (Terceiro Planalto), era de floresta estacional semidecidual, com uma vegetação diversificada e uma gradativa transição para o subtropical relacionado com a altitude.

Essa cobertura vegetal era rica em palmeiras do tipo Euterpe edulis, conhecida como palmito, os cedros, canelas e massarandubas atingiam até 50 metros de altura, com troncos de 1,5 a $3,0 \mathrm{~m}$ de diâmetro. Essa floresta foi 
substituída pela cultura cafeeira e sua derrubada mais intensiva ocorreu em 1935 (MAACK, 1981, p 233).

Devido a colonização da região, as imensas florestas naturais se transformaram em apenas florestas secundárias, capoeiras e formações rasteiras. Segundo a Prefeitura Municipal de Maringá (1994) as matas naturais que restaram estão localizadas na área urbana, nas reservas florestais de Maringá, local onde apresentam alguns gêneros como a Parapiptadenia, Peltophorum, Tabebuia, Astrinium e Copaifera.

A área urbana possui densa arborização, juntamente com os três bosques (Parque do Ingá, Bosque 2 e Horto Florestal) de florestas nativas preservadas, sendo aproximadamente $25,9 \mathrm{~m}^{2}$ de área verde (PREFEITURA MUNICIPAL DE MARINGÁ, 2008).

Em relação ao clima de Maringá, de acordo com o Atlas do Estado do Paraná (1987, p. 16) é Cfa (subtropical Mesotérmico úmido, de verão quente e geadas pouco frequentes), a média da temperatura dos meses mais quentes é superior a $22,0^{\circ} \mathrm{C}$ e a dos meses mais frio é inferior a $18,0^{\circ} \mathrm{C}$, com verões chuvosos e invernos secos.

Conforme o IAPAR (2000) nas Cartas Climáticas do Paraná, a média anual da precipitação, varia de 1.400 a 1.600mm. A média pluviométrica do período chuvoso (dezembro, janeiro, fevereiro) está entre 500 a $600 \mathrm{~mm}$. A variação do período seco (junho, julho, agosto) está entre 225 a 250mm.

Quanto às temperaturas, a média anual é de $22,0^{\circ} \mathrm{C}$ a $23,0^{\circ} \mathrm{C}$ e o trimestre mais quente (dezembro, janeiro, fevereiro) apresenta temperaturas de 28,0 a $29,0^{\circ} \mathrm{C}$, nos meses mais frios (junho, julho e agosto) de 17,0 a $18,0^{\circ} \mathrm{C}$. A umidade relativa, média anual varia de 75 a $80 \%$.

Maringá, tem influência da massa Tropical continental (mTc) de baixa umidade e temperaturas altas, da massa Equatorial continental (mEc) quente e de umidade específica, da massa Tropical atlântica, com tendência a estabilidade, com atuação o ano todo, pela massa Polar atlântica, fria e seca, atuando com mais intensidade no inverno.

Galvani, Pereira e Klosowski (1998, p. 533) analisaram o regime pluvial entre 1976 a 1996, concluíram os dados médios de chuva para Maringá caracterizam essa região em duas estações: uma chuvosa com início em setembro e término em maio do ano seguinte e outra, seca nos meses de inverno. 
Maringá estabelece dois regimes de precipitação pluvial bem definidos, verão, denominado período úmido (sob o domínio essencialmente de chuvas convectivas) e inverno denominado de período seco (sob influência das massas polares) (ANJOS, MARTINS e NERY, 2001, p. 119).

A direção predominante dos ventos do quadrante nordeste ocorre durante todos os meses do ano, em seguida, observam-se os ventos de leste. Os ventos de sudeste, sudoeste e sul manifestam-se com mais frequência durante os meses de outono e inverno. Os ventos de norte e noroeste e oeste são registrados em menor frequência (ANJOS et al., 1999, p. 26).

Com o intuito de analisar três anos por amostragem, sendo 1997, 1998 e 1999, Silveira (2003) utilizou-se da análise rítmica das variáveis climáticas e da identificação dos tipos de tempo, para quantificar a precipitação pluvial em relação à gênese para Maringá.

Através da análise rítmica das variáveis climáticas, correlacionada a análise dos sistemas atmosféricos atuantes sobre o Norte do Paraná, durante o outono e inverno de 1996, Silveira (2006, p. 84) apontou que as temperaturas muito baixas decorreram das incursões de vigorosos anticiclones frios que penetraram na retaguarda dos sistemas frontais, principalmente quando penetraram pelo sudoeste, com características continentais (deslocamento rápido e baixo teor de umidade).

Borsato, Souza Filho (2008a, p. 123) analisaram a dinâmica atmosférica na série de 1980-2003 na região de Maringá, através da análise rítmica dos elementos climáticos e da dinâmica das massas de ar, assim definiram:

Os resultados mostraram que a massa de ar Polar atlântica e a Equatorial continental ampliaram a sua participação na atuação no quadro geral dos tipos de tempo a partir da década de 1990. No inverno, a massa Polar está se ampliando e no verão a Equatorial. A massa Tropical atlântica e a Tropical continental apresentaram redução no tempo de participação. As chuvas também apresentaram tendência de aumento para as convectivas.

Borsato, Souza Filho (2008b, p. 221) o ritmo dos sistemas atmosféricos e a intensidade variam no tempo e no espaço. Por isso, para caracterizar a dinâmica de uma região é necessário estudar a dinâmica das massas de ar, ao longo de uma série. 
Para Monteiro (1971, p. 9), apenas a partir da escala diária é possível associar à variação dos elementos do clima e os tipos de tempo que se sucedem segundo os mecanismos da circulação regional. Associando-se, nesta escala, a variação de todos os elementos, concomitantemente, a interpretação é sobretudo enriquecida pelo dinamismo de que se reveste acrescentou:

O ritmo climático só poderá ser compreendido através da representação concomitante dos elementos fundamentais do clima em unidades de tempo cronológico pelo menos diárias, compatíveis com a representação da circulação atmosférica regional, geradora dos estados atmosféricos que se sucedem e constituem o fundamento do ritmo (MONTEIRO,1971, p. 9).

Conforme Mendonça, Danni-Oliveira (2007, p. 21) os estados atmosféricos tomados como tipos de tempos revelam-se claramente na escala do dia, sendo que sua sucessão pode ser observada a partir da variação dos elementos do clima em interação com a circulação atmosférica terciária e regional.

$\mathrm{Na}$ Tabela 3 estão apresentados a série histórica mensais para o período de 1976-2007, de temperaturas máxima, máxima absoluta, mínima, mínima absoluta, média compensada $\left({ }^{\circ} \mathrm{C}\right)$, umidade relativa $(\%)$, precipitação pluvial $(\mathrm{mm})$, pressão atmosférica $(\mathrm{hPa})$, ventos a direção e velocidade $(\mathrm{m} / \mathrm{s})$.

A temperatura máxima acima de $30,0^{\circ} \mathrm{C}$ são registradas de janeiro a março, as mínimas inferior a $16,0^{\circ} \mathrm{C}$ são registradas entre maio a agosto. A temperatura máxima absoluta registrada de 40,0C , ocorreu no dia 17 de novembro de 1985.

A temperatura mínima negativa foi registrada por quatro vezes, sendo $-1,0^{\circ} \mathrm{C}$ registrada no dia 21 de julho de 1981 , de $-0,2^{\circ} \mathrm{C}$ no dia 26 de agosto de 1984 e dia 26 de junho de 1994, para o dia 09 de julho foi 0,0 ํ․ A média compensada oscila acima de $24,0^{\circ} \circ \mathrm{C}$ de janeiro a março, novembro e dezembro. Sendo de $18,1^{\circ} \mathrm{C}$ em junho e de $18,5^{\circ} \mathrm{C}$ para julho.

A média da umidade relativa do ar oscila acima de $76 \%$ em janeiro e de $75 \%$ em fevereiro, para $60 \%$ em agosto. As umidades máximas sempre foram acima de $80 \%$ em todos os meses, porém, com umidade mínima baixa de $46 \%$ em agosto e de $50 \%$ em setembro. A precipitação pluvial são intensas em janeiro, fevereiro e dezembro, com diminuição entre junho, julho e agosto.

A pressão atmosférica variando de 949,4 hPa em dezembro a 956,1 hPa em julho. A velocidade média do vento variando entre de 1,1 a 1,3 m/s, com direção 
predominante de norte e nordeste. Para junho e julho, da direção nordeste e sudoeste.

Tabela 3: Média dos principais atributos do clima, em Maringá-PR, período: 1976-2007.

\begin{tabular}{|c|c|c|c|c|c|c|c|c|c|c|c|c|}
\hline \multirow[t]{2}{*}{ Meses } & \multicolumn{4}{|c|}{ Temperaturas ${ }^{\circ} \mathrm{C}$} & \multirow{2}{*}{$\begin{array}{l}\text { média } \\
\text { Comp. }\end{array}$} & \multicolumn{3}{|c|}{ Umidade Relativa } & \multirow{2}{*}{$\begin{array}{l}\text { Precip. } \\
\text { Pluvial }\end{array}$} & \multirow{2}{*}{$\begin{array}{l}\text { Pressão } \\
\text { Atmosférica }\end{array}$} & \multicolumn{2}{|c|}{ Ventos } \\
\hline & máx & Abs. & Min & Abs. & & máx & & Média & & & Dir. & Veloc \\
\hline Jan & 30,1 & 36,0 & 20,9 & 11,2 & 24,7 & 86 & 65 & 76 & 209,5 & 949,4 & $\mathrm{NE} / \mathrm{E}$ & 1,0 \\
\hline Fev & 30,2 & 37,8 & 20,7 & 13,9 & 24,6 & 85 & 62 & 75 & 173,1 & 0 & $\mathrm{NE} / \mathrm{E}$ & 1,0 \\
\hline Mar & 30,2 & 37,6 & 20,4 & 9,3 & 24 & 80 & 64 & $7 \mathfrak{c}$ & 14 & & NE & 1,0 \\
\hline Abr & 28,4 & 35,2 & 18,5 & 4, & 22,6 & 82 & 62 & 71 & 12 & 952,8 & $\mathrm{NE} / \mathrm{E}$ & 1,1 \\
\hline $\mathrm{Ma}$ & 24,9 & 32,6 & 15,6 & 1,2 & 19 & 86 & 63 & 73 & 125,5 & & NE & 1,1 \\
\hline Jun & 3,8 & 30,4 & 14,4 & $-0,2$ & & 84 & 62 & 73 & & & NE/SW & 1,1 \\
\hline Jul & 24,2 & 31,8 & 14,0 & $-1,0$ & & $7 \varepsilon$ & 57 & 6 & & & $\mathrm{NE} / \mathrm{SW}$ & 1,3 \\
\hline Ago & 26,4 & 34,9 & 15,5 & $-0,2$ & & 7 & 46 & 60 & 5 & 9 & $\mathrm{NE}$ & 1,3 \\
\hline $\mathrm{Se}$ & 26,9 & 37,2 & 16,4 & 3,5 & & 80 & 50 & 6 & 13 & & $\mathrm{NE}$ & 1,3 \\
\hline $\mathrm{Ou}$ & 29,2 & 36,9 & 18 & 9 & & 80 & 56 & 6 & & & $\mathrm{NE}$ & 1,2 \\
\hline Nov & 29,8 & 40,0 & 19,3 & 8,9 & 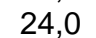 & 84 & 5 & $G$ & 14 & & $\mathrm{NE} / \mathrm{E}$ & 1,1 \\
\hline Dez & 29,9 & 37,2 & 20,3 & 13,1 & 24,5 & 81 & 61 & 72 & 198,2 & 949,5 & $\mathrm{NE} / \mathrm{E}$ & 1,0 \\
\hline
\end{tabular}

Fonte: ECPM/INMET

Tabela 4: Dias de Geadas com as respectivas temperaturas mínimas registradas, MaringáPR, período: 1976-2007.

\begin{tabular}{cc|cc}
\hline DIA/MÊS/ ANO & TEMPERATURA (ํㅜ) & DIA/MÊS/ ANO & TEMPERATURA (우) \\
\hline $31 / 05 / 1979$ & 1,2 & $31 / 07 / 1993$ & 1,5 \\
$01 / 06 / 1979$ & 2,3 & $01 / 08 / 1993$ & 0,9 \\
$02 / 06 / 1979$ & 2,8 & $26 / 06 / 1994$ & $-0,2$ \\
$21 / 07 / 1979$ & 1,1 & $27 / 06 / 1994$ & 0,3 \\
$27 / 06 / 1980$ & 2,8 & $28 / 06 / 1994$ & 1,9 \\
$18 / 06 / 1981$ & 2,7 & $09 / 07 / 1994$ & $-0,0$ \\
$19 / 06 / 1981$ & 1,0 & $13 / 07 / 1996$ & 7,0 \\
$20 / 07 / 1981$ & 0,4 & $13 / 07 / 2000$ & 0,7 \\
$21 / 07 / 1981$ & $-1,0$ & $14 / 07 / 2000$ & 3,1 \\
$25 / 07 / 1981$ & 4,3 & $17 / 07 / 2000$ & 0,5 \\
$26 / 08 / 1984$ & $-0,2$ & $18 / 07 / 2000$ & 4,5 \\
$10 / 06 / 1985$ & 4,5 & $20 / 07 / 2000$ & 3,2 \\
$01 / 06 / 1988$ & 2,0 & $21 / 07 / 2000$ & 6,0 \\
$02 / 06 / 1988$ & 6,0 & $24 / 07 / 2000$ & 3,0 \\
$05 / 06 / 1988$ & 2,4 & $25 / 07 / 2000$ & 8,2 \\
$06 / 06 / 1988$ & 4,0 & $21 / 06 / 2001$ & 3,6 \\
$06 / 07 / 1989$ & 1,8 & $22 / 06 / 2001$ & 6,3 \\
$08 / 07 / 1989$ & 3,2 & $29 / 07 / 2001$ & 5,6 \\
$29 / 07 / 1990$ & 3,2 & $09 / 07 / 2002$ & 5,6 \\
$31 / 07 / 1990$ & 1,8 & $03 / 09 / 2002$ & 6,2 \\
$19 / 07 / 1992$ & 2,4 & $14 / 06 / 2004$ & 5,8 \\
$20 / 07 / 1992$ & 4,4 & $01 / 08 / 2004$ & 6,2 \\
$15 / 07 / 1993$ & 3,6 & $27 / 07 / 2007$ & 6,7 \\
\hline
\end{tabular}

Fonte: ECPM/INMET

Os dias com ocorrências de geadas, estão presente na Tabela 4. Pode-se observar que os dias de geadas são pouco frequentes em Maringá, normalmente ocorrem de um a cinco dias de geadas, entre maio a setembro, ou até mesmo nenhum dia de ocorrência, durante o ano. Para o mês de julho de 2000, foram oito dias de geadas registradas, com a temperatura mínima entre $0,5^{\circ} \mathrm{C}$ ocorrida no dia 17 a $8,2^{\circ} \mathrm{C}$ ocorridas no dia 25 de julho. 
A Figura 2 apresenta o índice pluvial mensal e a temperatura média, para o período de 1976-2007. Observa-se que o ritmo da precipitação pluvial diminuem consideravelmente a partir de abril, ligeiro acréscimo em maio e decresce novamente entre junho, julho e agosto.

Os meses chuvosos, são janeiro, fevereiro, novembro e dezembro. A temperatura média são altas de janeiro a abril, outubro, novembro e dezembro e diminui significativamente a partir de maio, permanecendo até setembro.

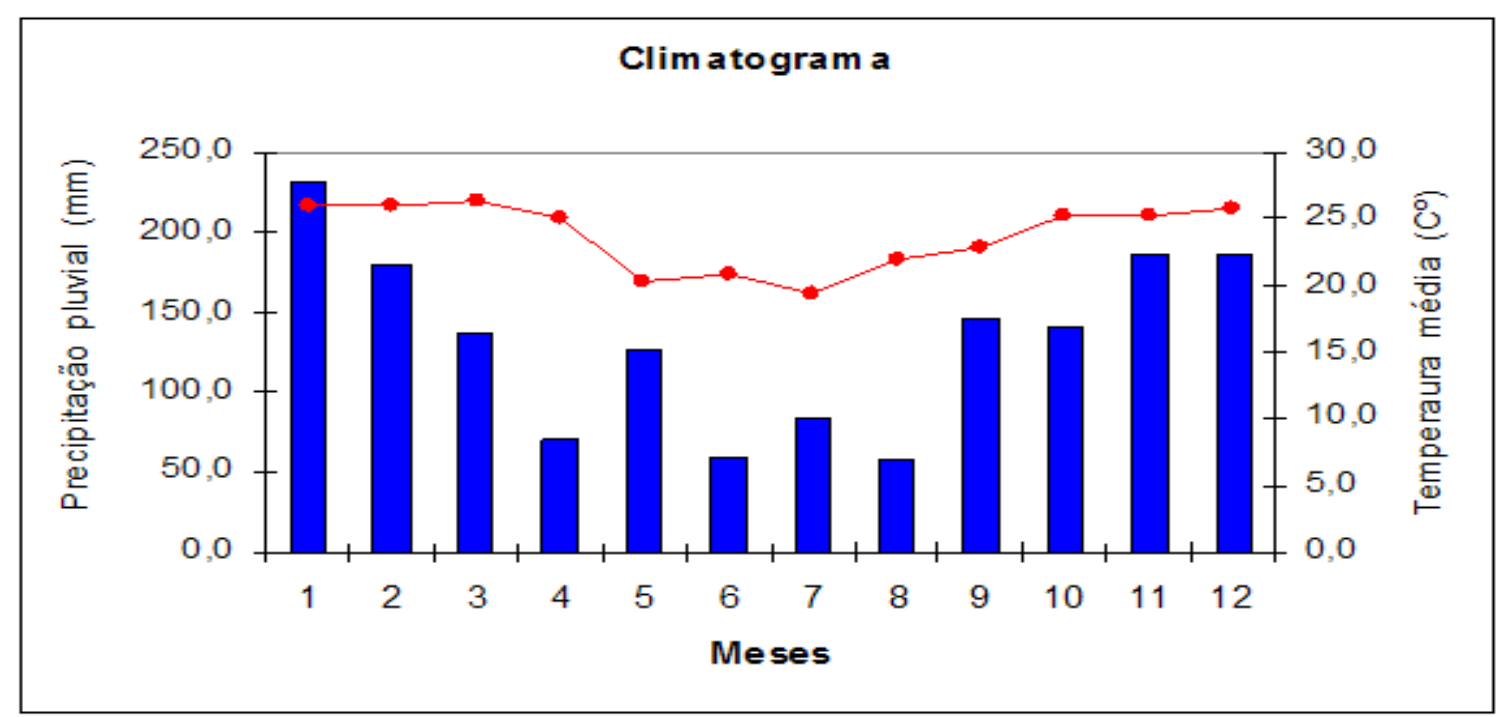

Figura 2: Comportamento da precipitação pluvial e temperatura, período: 1976-2007. Fonte: ECPM/INMET

\subsubsection{ASPECTOS DA SAÚDE EM MARINGÁ}

Maringá é sede da 15 $5^{\mathrm{a}}$ Regional de Saúde, faz parte da mesorregião Norte Central Paranaense e da Associação dos Municípios de Setentrião Paranaense (AMUSEP). Conforme Machado e Mendes (2003, p. 101):

O município dispõe de 25 unidades de saúde, sendo 21 unidades básicas (UBS) distribuídas geográfica e estrategicamente em vários bairros e nos dois distritos Floriano e Iguatemi, uma unidade de pronto-atendimento 24 horas com leitos de observação, uma unidade mista com plantão de 12 horas, um CISAM (Centro Integral de Saúde Mental) um centro de atenção psico-social (álcool, drogas), um CRA (Centro de Referência Ambulatorial), além de vários serviços ambulatoriais contratados para prestar atendimentos. 
Maringá se destaca pela multifuncionalidade das atividades exercidas pelas clinicas, que estão concentradas na zona central da cidade, principalmente no oeste e sudoeste dessa zona:

Essas zonas, além de possuírem as melhores localizações geográficas, concentram as famílias com os níveis de renda mais altos da cidade. Uma das características marcantes foi a grande concentração das clínicas especializadas, atendendo nas mais diversas especialidades, localizadas próximo aos hospitais existentes na cidade. Exceções a isso são o Hospital Universitário, situado na região noroeste da cidade e o Hospital Psiquiátrico, localizado na zona 5, em cujos derredores não se instalou nenhuma clinica ou consultório médico. O primeiro, pelo serviço que presta a comunidade e pela própria localização geográfica, está começando a formar uma pequena centralidade, com o hemocentro e as clinicas de psicologia e odontologia da Universidade Estadual de Maringá (MACHADO, MENDES, 2003, p. 101).

Maringá conta com 01 hospital municipal, 07 hospitais privados, 03 filantrópicos e um hospital universitário. Corrêa (2010, p. 67) fez as seguintes anotações:

- Sanatório Maringá (Hospital Psiquiátrico - privado); Hospital Universitário de Maringá (público); Hospital do Câncer (privado); Associação Beneficente Bom Samaritano (Santa Rita - filantrópico); Hospital Santa Casa (filantrópico); Hospital Municipal de Maringá (público); Hospital e Maternidade de Maringá (privado); Hospital Memorial (filantrópico); Hospital São Marcos (privado); Hospital de Olhos de Maringá (privado); Hospital Paraná (privado).

Segundo Corrêa (2010) destes apenas dois são considerados de alta complexidade: a Santa Casa e o Hospital Universitário. Todos com exceção do Hospital Paraná mantém convênio com o SUS, acrescenta ainda:

Conforme os dados obtidos junto a Secretaria de Saúde, Maringá possui 1.203 leitos para internação hospitalar, destes 57 são de Unidade de Terapia Intensiva - UTI geral, 12 leitos de UTI coronária, 17 leitos de UTI pediátrica, 6 leitos de UTI neonatal e 16 leitos de emergência psiquiátrica. Disponibilizados ao SUS são 700 leitos para internação hospitalar, destes 23 leitos de UTI - geral, 7 leitos de UTI coronária, 13 leitos de UTI pediátrica, 6 leitos de UTI neonatal e 16 de emergência psiquiátrica (CORRÊA, 2010, p. 68). 
Para o município de Maringá, conforme as informações de Sapata, Soares e Souza (2006, p. 63) a população dependente do SUS assemelha-se a 70\%, pois os dados do Sistema de Informações da Atenção Básica (SIAB-SUS) mostraram que em 2003, 25,16\% dos residentes nas áreas cobertas pelas equipes atuantes no Programa Saúde da Família (PSF) utilizavam planos privados alternativos.

Para efeito de informação complementar, na Tabela 5 estão especificados 0 total de internações por todas as causas ocorridas em Maringá, levantamento realizado na página do DATASUS, no período de 2000-2007. Em todos os anos foram às doenças respiratórias que destacaram com valores mais elevados, totalizando com 23.516 casos, sendo esta apontada como a primeira causa de internações.

Tabela 5: Internações por grupo de causas (CID-10) em Maringá-PR, no período de 20002007.

\begin{tabular}{|c|c|c|c|c|c|c|c|c|c|}
\hline Capítulo CID-10 & 2000 & 2001 & 2002 & 2003 & 2004 & 2005 & 2006 & 2007 & Total \\
\hline $\begin{array}{l}\text { I. Algumas doenças infecciosas. } \\
\text { II. Neoplasias (tumores). }\end{array}$ & $\begin{array}{l}686 \\
713\end{array}$ & $\begin{array}{l}685 \\
981\end{array}$ & $\begin{array}{c}697 \\
1.480\end{array}$ & $\begin{array}{c}803 \\
1.538\end{array}$ & $\begin{array}{c}658 \\
1.760\end{array}$ & $\begin{array}{c}686 \\
1.781\end{array}$ & $\begin{array}{c}737 \\
1.659\end{array}$ & $\begin{array}{l}1.364 \\
2.079\end{array}$ & $\begin{array}{c}6.316 \\
11.991\end{array}$ \\
\hline $\begin{array}{l}\text { III. Doenças do sangue órgãos.. } \\
\text { IV. Doenças endócrinas... }\end{array}$ & $\begin{array}{l}111 \\
391\end{array}$ & $\begin{array}{l}117 \\
363\end{array}$ & $\begin{array}{l}166 \\
461\end{array}$ & $\begin{array}{l}115 \\
495\end{array}$ & $\begin{array}{c}88 \\
377\end{array}$ & $\begin{array}{c}67 \\
507\end{array}$ & $\begin{array}{c}82 \\
603\end{array}$ & $\begin{array}{l}133 \\
593\end{array}$ & $\begin{array}{c}879 \\
3.790\end{array}$ \\
\hline V. Transtornos mentais... & 1.128 & 1.437 & 1.237 & 1.115 & 778 & 1.900 & 1.497 & 1.619 & 10.711 \\
\hline VI. Doenças do sistema nervoso & 504 & 426 & 271 & 543 & 509 & 568 & 644 & 839 & 4.304 \\
\hline VII. Doenças do olho e anexos. & 123 & 70 & 52 & 71 & 56 & 56 & 43 & 76 & 547 \\
\hline VIII. Doenças do ouvido e da ... & 21 & 19 & 22 & 37 & 42 & 20 & 28 & 29 & 218 \\
\hline IX. Doenças do aparelho circu... & 2.906 & 2.428 & 2.137 & 2.701 & 2.556 & 2.122 & 1.972 & 2.485 & 19.307 \\
\hline X. Doenças do aparelho respir... & 4.046 & 3.660 & 2.421 & 2.806 & 2.678 & 2.515 & 2.344 & 3.046 & 23.516 \\
\hline XI. Doenças do aparelho diges.. & 1.699 & 1.619 & 1.396 & 1.341 & 982 & 856 & 1.231 & 1.425 & 10.549 \\
\hline XII. Doenças da pele e do ... & 135 & 140 & 104 & 182 & 130 & 124 & 177 & 182 & 1.174 \\
\hline XIII.Doenças sist osteomuscul... & 514 & 518 & 576 & 602 & 572 & 517 & 533 & 739 & 4.571 \\
\hline XIV. Doenças do aparelho ge.... & 1.137 & 1.042 & 987 & 870 & 842 & 834 & 948 & 1.110 & 7.770 \\
\hline XV. Gravidez parto e puerpéri... & 1.921 & 2.034 & 2.095 & 2.771 & 2.598 & 2.627 & 2.649 & 2.643 & 19.338 \\
\hline XVI. Algumas afec originadas... & 366 & 389 & 213 & 285 & 265 & 197 & 220 & 197 & 2.132 \\
\hline XVII. Mal formação congênita... & 367 & 130 & 112 & 145 & 160 & 206 & 194 & 159 & 1.473 \\
\hline XVIII. Sintomas, sinais e ... & 207 & 238 & 148 & 189 & 230 & 307 & 328 & 255 & 1.902 \\
\hline XIX. Lesões envenenamentos... & 1.483 & 1.467 & 1.653 & 1.675 & 1.471 & 1.675 & 1.637 & 1.728 & 12.789 \\
\hline XX. Causas externas de morbi... & 39 & 14 & 7 & 6 & - & - & - & - & 66 \\
\hline XXI. Contatos com serviços... & 381 & 658 & 609 & 997 & 909 & 993 & 869 & 1.192 & 6.608 \\
\hline
\end{tabular}

Morbidade Hospitalar do SUS - Por local de residência - Maringá.

Fonte: Brasil (2007).

Em segundo lugar de internações foi por causas de gravidez, parto e puerpério, com 19.338 registros, a terceira causa de internações foi por doenças do aparelho circulatório com 19.307. Houve o maior predomínio de internações por doenças respiratórias para o ano de 2000, com 4.046, em 2001 com 3.660 e 2007 com 3.046 registros.

A Tabela 6 apresenta o percentual de causas de internações por faixa etária em Maringá, levantamento realizado na página do DATASUS, para o ano de 2007. 
Em comparação às demais causas, as doenças do aparelho respiratório alcançaram o total de $13,9 \%$.

Com maior destaque para as crianças menores de um ano, com 41,8\% e entre um a quatro anos, com 51,5\%, de cinco a nove anos apresentou com $20,0 \%$, de sessenta a sessenta e nove anos foram $20,3 \%$ e mais de setenta anos com 19,2\%. Em segunda posição destacou as doenças do aparelho circulatório com $11,4 \%$, com o maior número de registros para a faixa etária acima de cinqüenta anos.

Tabela 6: Percentual das internações por grupo de causas e faixa etária, CID-10 (por local de residência - Maringá-PR) em 2007.

\begin{tabular}{|c|c|c|c|c|c|c|c|c|c|c|}
\hline Capítulo CID-10 & -1 & $1-4$ & $5-9$ & $10-14$ & $15-19$ & $20-49$ & $50-64$ & $65-70$ & +70 & Total \\
\hline I. Algumas doenças infecciosas. & 5,4 & 11,6 & 11,8 & 12,7 & 6,8 & 5,5 & 5,4 & 6,4 & 6,1 & 6,2 \\
\hline II. Neoplasias (tumores). & 1,5 & 3,9 & 7,4 & 3,6 & 4,3 & 7,6 & 16,3 & 13,4 & 13,7 & 9,5 \\
\hline III. Doenças do sangue órgãos.. & 0,3 & 0,7 & 1,0 & 0,9 & 1,7 & 0,5 & 0,3 & 0,8 & 0,7 & 0,6 \\
\hline IV. Doenças endócrinas... & 1,9 & 2,8 & 1,6 & 2,9 & 0,4 & 1,6 & 4,4 & 5,2 & 5,2 & 2,7 \\
\hline V. Transtornos mentais... & - & - & 0,4 & 5,8 & 9,2 & 12,5 & 2,9 & 0,8 & 1,0 & 7,4 \\
\hline VI. Doenças do sistema nervoso & 4,6 & 3,5 & 2,5 & 2,5 & 0,8 & 4,0 & 4,4 & 4,1 & 4,2 & 3,8 \\
\hline VII. Doenças do olho e anexos. & 0,1 & 0,3 & 1,2 & 0,5 & 0,3 & 0,3 & 0,5 & 0,3 & 0,5 & 0,3 \\
\hline VIII. Doenças do ouvido e da ... & 0,4 & 0,8 & 0,6 & 0,4 & 0,3 & 0,1 & 0,0 & - & 0,0 & 0,1 \\
\hline IX. Doenças do aparelho circu... & 1,2 & 0,8 & 0,8 & 0,4 & 1,0 & 7,2 & 20,3 & 24,5 & 24,0 & 11,4 \\
\hline X. Doenças do aparelho respir... & 41,8 & 51,5 & 20,0 & 10,5 & 6,1 & 8,1 & 14,3 & 20,3 & 19,2 & 13,9 \\
\hline XI. Doenças do aparelho diges.. & 3,1 & 3,8 & 7,4 & 7,1 & 4,0 & 6,8 & 8,2 & 5,8 & 6,3 & 6,5 \\
\hline XII. Doenças da pele e do ... & 0,6 & 1,1 & 1,6 & 1,3 & 1,3 & 0,7 & 0,9 & 0,7 & 0,7 & 0,8 \\
\hline XIII.Doenças sist osteomuscul... & 0,7 & 1,1 & 2,1 & 5,5 & 1,4 & 4,1 & 3,3 & 2,9 & 2,7 & 3,4 \\
\hline XIV. Doenças do aparelho ge.... & 1,8 & 2,9 & 4,5 & 3,3 & 6,0 & 5,7 & 5,4 & 4,0 & 4,3 & 5,1 \\
\hline XV. Gravidez parto e puerpéri... & - & - & - & 4,2 & 40,0 & 19,7 & 0,1 & 0,0 & 0,0 & 12,1 \\
\hline XVI. Algumas afec originadas... & 28,7 & 0,1 & - & - & 0,1 & 0,0 & - & - & - & 0,9 \\
\hline XVII. Mal formação congênita... & 4,2 & 2,9 & 4,3 & 1,3 & 1,0 & 0,3 & 0,6 & 0,2 & 0,4 & 0,7 \\
\hline XVIII. Sintomas, sinais e ... & 0,6 & 0,6 & 0,6 & 0,7 & 1,1 & 1,1 & 1,1 & 1,7 & 1,5 & 1,2 \\
\hline XIX. Lesões envenenamentos... & 1,5 & 7,4 & 22,7 & 24,0 & 10,1 & 8,5 & 6,1 & 4,0 & 4,2 & 7,9 \\
\hline XX. Causas externas de morbi... & - & - & - & - & - & - & - & - & - & - \\
\hline XXI. Contatos com serviços... & 1,5 & 4,2 & 9,7 & 12,4 & 4,0 & 5,6 & 5,5 & 4,8 & 5,1 & 5,4 \\
\hline$\overline{\text { Total }}$ & 100,0 & 100,0 & 100,0 & 100,0 & 100,0 & 100,0 & 100,0 & 100,0 & 100,0 & 100,0 \\
\hline
\end{tabular}

Fonte: Brasil (2007). 


\section{PROCEDIMENTOS METODOLÓGICOS}

Essa pesquisa insere-se no contexto de estudo ecológico ${ }^{2}$ de séries temporais, esse tipo de estudo é caracterizado por analisar grupos de indivíduos, geralmente por regiões geográficas. A área de estudo é Maringá, localizada ao norte do Paraná e o público alvo são os pacientes internados por doenças respiratórias, residentes nesta cidade.

Os dados de internações referente à doenças respiratórias, foram obtidas na Secretaria Regional de Saúde de Maringá (SRS), através de cd/rom, contendo as Informações Hospitalares do Sistema Único de Saúde (SIH/SUS), nas Autorizações de Internações Hospitalares (AIH).

Foi definido o recorte temporal de $1^{\circ}$ de janeiro de 2000, devido aos anos anteriores desta data serem armazenados de forma e programas diferentes, com encerramento em 31 de dezembro de 2007.

As informações contidas nas AlH vão desde o número de cadastro geral do hospital, cidade de localização, idade e sexo do paciente, causa de internação, procedimento realizado, endereçamento postal da residência do paciente, tempo de internação, data de alta (se óbito).

Das Autorizações de Internações Hospitalares, foi selecionado o código referente a doenças respiratórias, identificando o grupo de causa da internação, se houve óbito, o sexo, faixa etária e o CEP de residência.

Identificou alguns itens principais de internações e utilizou-se a Classificação Internacional de Doenças (CID-10 $)$, no qual, apresenta-se no capítulo $X$ as Doenças do Aparelho Respiratório (J00-J99), para verificar os seguintes grupos: infecções agudas das vias aéreas superiores (J00-J06), influenza [gripe] e pneumonia (J10J18), outras infecções agudas das vias aéreas inferiores (J20-J22), outras doenças

\footnotetext{
${ }^{2}$ Segundo a Organização Pan-Americana da Saúde (2002, p. 23), os estudos ecológicos (ou de agregados) têm o objetivo de descrever, em termos quantitativos, a relação entre a frequência e a variação geográfica de um evento relacionado com a saúde, bem como a frequência e a variação concomitante de uma característica ou fator de risco entre diferentes grupos de população. [...] o termo ecológico decorre do uso frequente de áreas geográficas como base para definir aglomerados espaciais ou grupos de pessoas (exemplo: populações), mais do que indivíduos, como unidades de observação e análise. Conforme Rouquayrol, Filho (1999, p. 151) estudos ecológicos abordam áreas geográficas bem delimitadas, analisando comparativamente variáveis globais, quase sempre por meio de correlação entre indicadores de situação de saúde.
} 
das vias aéreas superiores (J30-J39), doenças crônicas das vias aéreas inferiores (J40-J47) e outras doenças do aparelho respiratório (J95-J99).

A faixa etária destes pacientes foram organizados em: 0-4; 05-09; 10-14; 15 19; 20-29; 30-39; 40-49; 50-59; 60-69 e mais de 70, seguindo o critério adotado do IBGE (2000), no qual apresenta-se os dados referente à população organizado por essas faixa etárias. Com exceção da faixa etária de 20-24 e 25-29 que foram agrupadas na mesma faixa de 20-29 anos.

A listagem do CEP foi adquirida junto ao correio desta cidade. A relação dos bairros foi cedida pela Secretaria de Desenvolvimento Urbano e Habitação de Maringá (SEDUH) e a listagem das Zonas Municipais com as respectivas populações foi adquirida junto ao IBGE, a partir do censo de 2000.

Para o mesmo período, de 2000 a 2007, utilizou-se as informações meteorológicas, fornecidas pela Estação Climatológica Principal de Maringá (ECPM), conveniada com o Instituto Nacional de Meteorologia (INMET), localizada dentro do campus da Universidade Estadual de Maringá, vinculada ao Departamento de Geografia, com coordenadas geográficas de $23^{\circ} 25^{\prime} \mathrm{S}$, longitude $51^{\circ} 57^{\prime} \mathrm{W}$ e altitude de 542 metros.

Os dados meteorológicos, foram utilizados em diferentes escalas, conforme as necessidades executadas no momento da análise, sendo portanto, observadas em escala horária, diária, mensal, anual e para o período de estudo, do mesmo modo, para as informações de internações por doenças respiratórias. Assim, foi realizada os seguintes procedimentos:

A) - O número do CEP de residência do paciente, foi agrupado nas respectivas Zonas Municipais, para verificar as internações por grupo de causa, sexo e a faixa etária, bem como o número de óbitos.

Foi observado o número absoluto da população, o número absoluto das internações e o coeficiente de incidência, sendo indexado na base vetorial do Município de Maringá de 2008, que apresenta subdividido pelas zonas. Os dados foram organizados na planilha de Excel versão $2003^{3}$ e depois transferido ao aplicativo "ArcGis 9.2" para gerar os mapas temáticos.

\footnotetext{
3 "Microsoft Corporation, CA.".

4 "ArcGis 9.2" programa de domínio público, pode ser baixado pela internet, em anúncios Google - ArcGis 9.2.
} 
As zonas 16, 22, 32, 49, 50 e 51 foram consideradas como áreas sem informação, vale ressaltar que tais zonas estão provavelmente atreladas a outras, de acordo com a aproximidade. A zona 22 considerando a dimensão, não foi constatado nenhuma informação, deve existir algum problema de ordem relacionada ao CEP. A zona 50 é a área da catedral e localiza-se ao centro e a zona 49 e 51 são consideradas rurais, não contendo informações sobre CEP e consequentemente sobre internamentos.

Na representação quantitativa referente ao número absoluto de população, foi utilizado com base no IBGE (2000) e para o número absoluto de internações utilizou toda a base do período de estudo, ou seja, 2000-2007. Para essas duas representações, usou o método de símbolos de tamanho crescente, implantando-a no centro de gravidade da área considerada, ou seja, de cada Zona Municipal.

Segundo Martinelli (2007, p. 55) esta solução é frequentemente utilizada para mostrar dados referentes a um determinado ponto, faz valer a proporcionalidade do tamanho de uma figura geométrica plana, também de um valor absoluto, centralizado para toda a unidade observacional.

Como o coeficiente de incidência é uma medida relativa, utilizou-se o método coroplético, no qual, os valores relativos foram agrupados em classes crescentes e representados em cores de claro para as áreas sem informação, para o mais escuro, com alta intensidade.

Esse método de representação foi introduzido no inicio do século XIX, tendo sido, desde então amplamente empregado por cartógrafos e geógrafos, por resultar de fácil assimilação para o usuário. Embora exaustivamente explorado para representar valores absolutos, é mais adequadamente recomendado para valores relativos (MARTINELLI, 2007, p. 61).

B) - Fez-se a análise rítmica, para observar a variação dos dados meteorológicos e as internações. Procedeu-se do seguinte modo, inicialmente foram organizadas os dados mensais de internações, para cada ano, através da soma diária de registros. Utilizou-se como critério para a escolha dos meses a serem analisados concomitantemente com condições climáticas, aqueles nos quais sobressaíram com maior número de ocorrência de registros.

Ao findar esse processo, encontrou-se maior quantidade para julho de 2000 , junho de 2003 e junho de 2007, sendo esses meses utilizados como referenciais, 
para os mesmos anos de 2000, 2003 e 2007, tomou-se o mês de janeiro, para efeito de comparação. Tais meses foram simultaneamente analisados junto com as informações meteorológicas, sendo possível visualizar em relação a variabilidade climática.

Apoiou-se no método da análise rítmica em Climatologia, desenvolvida por Monteiro (1971) e o estudo da dinâmica das massas de ar de Pédelaborde (1970). As figuras foram elaboradas no aplicativo Excel versão 2003.

Para essa análise, utilizou-se as médias da pressão atmosférica (hPa), umidade relativa do ar (\%), temperaturas: máxima, mínima e média $\left({ }^{\circ} \mathrm{C}\right)$, nebulosidade e a soma de precipitação pluvial $(\mathrm{mm})$, bem como, a direção dos ventos referente à $09,15,21 \mathrm{~h}(12,18,00$ TMG).

Incluindo, os sistemas atmosféricos atuantes, com base nas cartas sinóticas (12TMG) da Marinha, para identificar as principais massas de ar, como a massa Tropical continental (mTc), massa Equatorial continental (mEc), massa Tropical atlântica $(\mathrm{mTc})$, massa Polar atlântica $(\mathrm{mPa})$ e Sistemas Frontais $(\mathrm{S} / \mathrm{F})$.

C) - Para os meses da análise rítmica, ou seja, janeiro e julho de 2000, janeiro e junho de 2003, janeiro e junho de 2007, calculou-se o índice de conforto térmico, para encontrar a sensação de conforto ou de desconforto, de hora em hora e em relação a média diária. E, para verificar de acordo com o período de estudo, fez-se um balanço referente à $09,15,21 \mathrm{~h}(12,18,00$ TMG) e associou-os com as internações ocorridas.

Utilizou-se da metodologia sugerida por THOM (1959) ${ }^{5}$, Apud AYOADE (1986, p. 65), no qual são obtidas pelas informações de temperatura do termômetro de bulbo seco e a temperatura do termômetro de bulbo úmido, para encontrar o valor da Temperatura Efetiva (TE), que pode ser classificada como zona de conforto ou de desconforto térmico.

Foi utilizada a base de 24 horas do termômetro de bulbo seco e do termômetro de bulbo úmido, com a complementação do aparelho termohigrógrafo para os horários compreendidos entre 00h00min a 06h00min, devido à leitura horária pelos observadores iniciar-se a 07h00min a 23h00min.

A temperatura do ar é obtida através do termômetro de bulbo seco e o termômetro de bulbo úmido. Por meio dos dois termômetros, encontra-se a umidade

\footnotetext{
${ }^{5}$ THOM, E. C. The disconfort index. Weatherwise. v. 12, p. 57-60, 1959.
} 
relativa do ar. Por isso, analisou simultaneamente com a temperatura Efetiva (TE), a temperatura do ar e a umidade relativa do ar, pois ambas estão interligadas com a relação de conforto ou de desconforto humano. A planilha de dados foi organizada no apliativo Excel versão 2003 e depois transferido ao aplicativo "Surfer 8.0", para a confecção das figuras.

D) - Para os meses selecionados para a análise rítmica, aplicou-se a análise de regressão e correlação múltipla, que é um modelo matemático para verificar a relação existente, entre as variáveis climáticas (independentes), nesse momento, utilizou a temperatura máxima, temperatura mínima, temperatura média, temperatura efetiva, umidade relativa e precipitação pluvial e o número absoluto das internações por doenças respiratórias (dependente), para gerar as correlações.

Fez-se essa análise sem defasagem para janeiro de 2000, 2003 e 2007 e com defasagem de um até sete dias para julho de 2000, junho de 2003 e 2007 . A defasagem é importante sob o ponto de vista de que as condições climáticas ocorridas em um determinado dia, poderão desencadearem algum tipo de problema durante os próximos dias. A base de dados foi organizada no Excel versão 2003 e

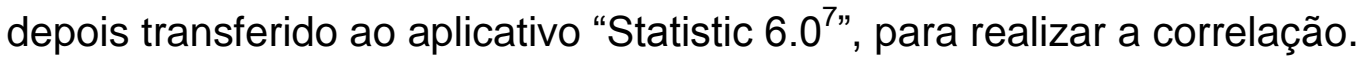

\subsection{PROCEDIMENTOS ESTATÍSTICOS}

Utilizou a média aritmética, o coeficiente de incidência, o índice de conforto térmico e a análise de regressão múltipla, como segue:

\section{Média}

Calculou-se a média dos controles climáticos e das internações por doenças respiratórias, a expressão utilizada para os cálculos foi:

$$
\bar{X}=\frac{\sum_{i=1}^{n} X_{i}}{n}
$$

$\bar{X}=$ é a média aritmética para cada série;

\footnotetext{
6 "Copyrigt ( Golden Sotware, inc 2002".

7 "Copyrigt (C Statsoft, inc 2001".
} 
$\sum_{i}^{n} X_{i}=$ é a soma dos valores da variável estudada, do primeiro ao último $(i=1$ a $n)$; $n=$ é o total do número de informações ou registros.

Através da média de doenças respiratórias, calculou-se a amplitude dos registros, ou seja, tomou-se o número absoluto de internações referente a cada mês e diminuiu pela média do período de estudo. Os resultados podem indicar maior ou menor número de registros, em relação a média encontrada dentro do período em questão.

\section{Coeficiente de incidência}

Quando analisa-se uma doença, faz-se necessário verificar como ocorrem a incidência, por isso aplicou-se esse tipo de investigação. Os números absolutos de internações, transformam-se em coeficientes, denominados de medidas de probabilidade. Segundo Rouquayrol, Filho (1999, p. 33) denominam-se coeficientes as relações entre o número de eventos reais e os que poderiam acontecer.

Conforme Rouquayrol, Filho (1999, p. 48) o coeficiente de incidência é obtido através da divisão do número de internações por doenças respiratórias ocorridas e a população exposta e, a seguir multiplica o resultado por 100.000, base referencial da população, mediante a seguinte expressão:

Coeficiente de incidência $=\underline{n^{\circ}}$. de casos de uma doença $\times 10^{\text {n }}$

$$
\text { População }
$$

O coeficiente de incidência é aplicado para efeito de relativização de estudo comparativo da incidência de doenças numa mesma população em épocas diferentes, ou em populações diversas numa mesma época ${ }^{8}$. Considerando os parâmetros de avaliação epidemiológicas.

\footnotetext{
${ }^{8}$ De acordo com Rouquayrol, Filho (1999, p. 48) incidência em epidemiologia traduz a idéia de intensidade com que acontece a morbidade em uma população. Pode ser descrito como o número de casos de uma determinada doença em uma comunidade em certo período de tempo. [...] a incidência de doenças é medida, grosso modo, pela frequência absoluta de intervalo de tempo, dia, mês ou ano.
} 
Fez-se o cálculo do coeficiente de incidência, para o Município de Maringá, do seguinte modo:

Coeficiente de incidência: $\underline{18.339} \times 10^{\mathrm{n}}$

288.653

Coeficiente de incidência: 0,063533 x 100.000

Coeficiente de incidência: 6,4

Com o valor relativo encontrado de 6,4/100.000 hab., baseado nesse parâmetro, estabeleceu como critério de orientação para os dados encontrados, referente às Zonas Municipais e para a faixa etária, organizados numa margem de probabilidades de riscos:

0,0: sem informação;

0,1-5,0: muito baixa;

5,1-10,0: baixa ;

10,1-20,0: média;

20,0-54,9: alta.

Ou seja, numa probabilidade de riscos em 100.000 hab., para o período de estudo, destes, aconteceram entre 0,1-5,0 (muito baixa), 5,1-10,0 (baixa), 10,1-20,0 (média) e 20,0-54,9 (alta).

\section{Índice de conforto térmico}

O cálculo do índice de conforto térmico, consiste num índice de Temperatura Efetiva (TE), obtida através da equação, proposta por Thom (1959):

$\mathrm{TE}=0,4(\mathrm{Ts}+\mathrm{Tu})+4,8$.

Onde:

$\mathrm{TE}=$ Temperatura Efetiva, medidas em ${ }^{\circ} \mathrm{C}$.

Ts $=$ Temperatura do termômetro de bulbo seco, medidas em ${ }^{\circ} \mathrm{C}$.

$\mathrm{Tu}=$ Temperatura do termômetro de bulbo úmido, medidas em ${ }^{\circ} \mathrm{C}$.

De acordo com esse índice, o valor da TE encontrada será compreendida como segue:

$\mathrm{TE}=$ inferior a $18,9^{\circ} \mathrm{C}$ é considerada como desconforto ao frio;

$\mathrm{TE}=19,0^{\circ} \mathrm{C}$ a $25,5^{\circ} \mathrm{C}$, faixa de conforto térmico; 
$\mathrm{TE}=$ superior a $25,6^{\circ} \mathrm{C}$ significa desconforto ao calor.

$\mathrm{Na}$ apresentação da Temperatura Efetiva (TE), utilizou-se da cor vermelho: representando o desconforto térmico, relacionado ao calor. A cor azul: representando o desconforto térmico, relacionado ao frio e a cor verde: representando a zona de conforto térmico.

Para a temperatura, as cores das figuras foram classificadas na tonalidade de claro: temperaturas mais frias e de escuro: temperaturas mais quentes. Para a umidade relativa do ar, as cores das figuras foram classificadas na tonalidade de claro: maior umidade relativa e de escuro: menor umidade relativa.

\section{Regressão múltipla}

Conforme Spiegel (1972, p. 55) quando estão em jogo somente duas variáveis, fala-se em correlação e regressão simples. Quando se trata de mais de duas variáveis, fala-se de correlação e regressão múltipla.

Assim, a análise de regressão múltipla tem por objetivo descrever por meio de um modelo matemático, a variação conjunta de ( $x$ e y). Somando $x_{1}$ sobre $x_{2}$, e $x_{3}$, tem-se a seguinte expressão:

$y=a_{1}+b_{1} \cdot x_{1}+b_{2} \cdot x_{2}+b_{3} \cdot x_{3}+b_{4} \cdot x_{4}+\ldots+b_{n} \cdot x_{n}$

Em que: y = estimativa da variação dependente;

$\mathrm{x}=$ variação independente;

$\mathrm{a}=$ constante: intercepto múltiplo, que corta o eixo do y;

$\mathrm{b}=$ constante: coeficiente de correlação;

$\mathrm{n}=$ total do número de informações, ou registros.

Onde: multiplicando e somando as equações sucessivamente por $1, x_{2}$ e $x_{3}$, calculase os seguintes dados, que estarão disponíveis por colunas numa tabela.

$\Sigma \mathrm{x}_{1}, \Sigma \mathrm{x}_{2}, \Sigma \mathrm{x}_{3}, \Sigma \mathrm{x}_{1}^{2}, \Sigma \mathrm{x}_{2}^{2}, \Sigma \mathrm{x}_{3}^{2}, \Sigma \mathrm{x}_{1}, \mathrm{x}_{2}, \Sigma \mathrm{x}_{1}, \mathrm{x}_{3}, \Sigma \mathrm{x}_{2}, \mathrm{x}_{3} \ldots$

$\mathrm{Na}$ análise de regressão múltipla, a medida relativa de adequação do ajuste é chamada de coeficiente de determinação, designado pelo símbolo $\left(R^{2}\right)$, que representa o grau de explicação da variabilidade do modelo, é a relação entre a variável explicada pela equação da regressão múltipla e a variação total da variável dependente. Apresenta sempre valores positivos. 
O coeficiente de correlação $(R)$ é um número que mede o grau de relação, sendo que valores próximos de zero significa pouco ou nenhuma relação. Podem ser valores positivos ou negativos.

Assim, os resultados encontrados para o coeficiente de determinação e o coeficiente de correlação, devem ser significativos em $p<0,05$, que indicam, quanto mais próximos de 0,00 encontrar o valor de $p$, melhor será a correlação encontrada.

\section{RESULTADOS E DISCUSSÕES}

O número absoluto das internações foi observada, a priori, por grupo de causas, por categoria, sexo, faixa etária, por Zonas Municipais e por último relacionadas os com as informações climáticas.

\subsection{GRUPO DE CAUSAS, CATEGORIA, SEXO E FAIXA ETÁRIA}

$\mathrm{Na}$ Tabela 7 está apresentada as informações referente ao grupos de causas das internações, para o período de estudo. As infecções agudas das vias aéreas superiores apresentaram 890 internações, ou 4,9\%. A maior quantidade foi para influenza \{gripe\} e pneumonia, abrangendo o maior número de eventos, totalizando com 10.818 internações, ou $59 \%$ dos registros.

Em menor quantidade apontaram as outras infecções agudas das vias aéreas inferiores com 448 internações, ou 2,4\% e as outras doenças das vias aéreas superiores, com 277 ou $1,5 \%$ dos registros. As doenças crônicas das vias aéreas inferiores, foram 4.794 internações, ou $26 \%$. Outras doenças do aparelho respiratório, totalizaram com 1.112 ou $6,1 \%$ das internações.

Quanto ao número de óbitos, foram predominante para a influenza \{gripe\} e pneumonia, 363 registros, ou 35,7\% e para outras doenças do aparelho respiratório, 362 registros, ou 49,2\%, as doenças crônicas das vias aéreas inferiores, foram 111 registros, ou $15,1 \%$. Os demais grupos não apresentaram óbitos. 
Tabela 7: Grupos de causas das internações e óbitos, por doenças respiratórias, em número absoluto e percentual. Maringá-PR, 2000-2007.

\begin{tabular}{|c|c|c|c|c|c|}
\hline (CID-10) & Grupos de causas & \multicolumn{2}{|c|}{ Internações } & \multicolumn{2}{|c|}{ Óbitos } \\
\hline & & №. & $\%$ & $\mathrm{n}$ ㅇ. & $\%$ \\
\hline J00-J06 & $\begin{array}{l}\text { Infecções agudas das vias } \\
\text { aéreas superiores }\end{array}$ & 890 & 4,9 & - & - \\
\hline J10-J18 & $\begin{array}{l}\text { Influenza \{gripe }\} \text { e } \\
\text { pneumonia }\end{array}$ & 10.818 & 59,1 & 263 & 35,7 \\
\hline J20-J22 & $\begin{array}{l}\text { Outras infecções agudas das } \\
\text { vias aéreas inferiores }\end{array}$ & 448 & 2,4 & - & - \\
\hline J30-J39 & $\begin{array}{l}\text { Outras doenças das vias } \\
\text { aéreas superiores }\end{array}$ & 277 & 1,5 & - & - \\
\hline J40-J47 & $\begin{array}{c}\text { Doenças crônicas das vias } \\
\text { aéreas inferiores }\end{array}$ & 4.794 & 26,0 & 111 & 15,1 \\
\hline J95-J99 & $\begin{array}{c}\text { Outras doenças do aparelho } \\
\text { respiratório }\end{array}$ & 1.112 & 6,1 & 362 & 49,2 \\
\hline Total & - & 18.339 & 100,0 & 736 & 100,0 \\
\hline
\end{tabular}

Para o período de estudo, foram 18.339 registros de internações e 736 óbitos, vale ressaltar que este levantamento foi realizado no Sistema único de Saúde, através da $(\mathrm{AlH})$, que abrange cerca de $70 \%$ das internações, não inclui aqui as internações particulares e os Planos de Saúde.

$\mathrm{Na}$ Tabela 8 estão apresentados o grupo de causas, com as respectivas categorias pertencentes. Para o grupo das infecções agudas das vias aéreas superiores a maior quantidade de internações foi para laringotraqueíte aguda com $4,0 \%$ dos registros.

Para a influenza \{gripe\} e pneumonia, as maiores intensidade de internações foram para pneumonia viral, com 11,7\%, pneumonia devida a outros microorganismos infecciosos especificados com $23,1 \%$ e broncopneumonia com $22,4 \%$. Normalmente as pneumonias manifestam-se com tosse intensa, dificuldade respiratória, dor de garganta, corrimento nasal, dores de ouvido e dores pelo corpo.

Para outras infecções agudas das vias aéreas inferiores, a intensidade foi mostrada somente por bronquiolite aguda, com 2,3\%. Nas outras doenças das vias aéreas, destacou a rinite, nasofaringite e faringite crônica com 4,0\%. Para outras doenças do aparelho respiratório, destacou a insuficiência respiratória aguda, 3,3\%.

As doenças crônicas das vias inferiores, a maior quantidade foi para as outras doenças pulmonares obstrutivas crônicas com 13,0\% e por asma com $8,5 \%$ dos registros de internações. 
Em menor quantidade de internações destacaram a laringofaringite aguda, influenza com pneumonia devida a vírus da influenza \{gripe\}, com 0,3\% e enfisema, com $0,2 \%$ dos registros. A laringite e traqueíte agudas, estado de mal asmático e insuficiência respiratória, não especificada, apresentaram com 0,5\% das internações, para o período de estudo.

Tabela 8: Internações por doenças respiratórias, com o grupo de causas e as categorias. Maringá-PR. 2000-2007.

\begin{tabular}{c|l|c}
\hline J00-J06 & Infecções agudas das vias aéreas superiores & $\%$ \\
\hline J04 & Laringite e traqueíte agudas. & 0,5 \\
J04.2 & Laringotraqueíte aguda & 4,0 \\
J06.0 & Laringofaringite aguda & 0,3 \\
J10-J18 & Influenza \{gripe\} e pneumonia & \\
J10.1 & Influenza com pneumonia devida a vírus da influenza \{gripe\} & 0,3 \\
J12 & Pneumonia viral & 11,7 \\
J15.2 & Pneumonia devida a Staphylococcus & 0,9 \\
J15.8 & Outras pneumonias bacterianas & 3,5 \\
J16.8 & Pneumonia devida a outros microorganismos infecciosos & 23,1 \\
J18 & especificados & 22,4 \\
J20-J22 & Broncopneumonia não especificada & \\
J21.8 & Bronquiolite aguda & 2,3 \\
J30-J39 & Outras doenças das vias aéreas superiores & \\
J31 & Rinite, nasofaringite e faringite crônica. & 4,0 \\
J33 & Pólipo nasal & 1,1 \\
J40-J47 & Doenças crônicas das vias aéreas inferiores & 0,5 \\
J43 & Enfisema & 0,2 \\
J44 & Outras doenças pulmonares obstrutivas crônicas & 13,0 \\
J45 & Asma & $\mathbf{2}$ \\
J47 & Estado de mal asmático & $\mathbf{1 0 0 , 0}$ \\
J95-J99 & Outras doenças do aparelho respiratório & \\
J96.0 & Insuficiência respiratória aguda & \\
J96.9 & Insuficiência respiratória, não especificada. & \\
\hline Total & & \\
\hline & & \\
\hline
\end{tabular}

Na Tabela 9 podem ser acompanhados o número absoluto das internações por doenças respiratórias para cada ano de estudo. A menor quantidade ocorreu 
para 2006 com 1.872 internações. Destacou 2003 com 2.649 e 2007 com 2.513 registros.

Predominaram em todos os anos analisados para a faixa etária de 0-4 anos, com o total de 4.199 registros, mais de 70 anos, totalizou com 4.100 registros. Em seguida, a faixa etária de 5-9 anos com 1.807 registros e 60-69 anos somou com 1.883 registros. Em menor quantidade destacou para a faixa etária entre 10-14 anos e de 15-19 anos, sendo de 822 e 485 registros, respectivamente.

Tabela 9: Número absoluto das internações por doenças respiratórias por faixa etária, Maringá-PR, para cada ano: 2000-2007.

\begin{tabular}{c|cccccccc|c}
\hline Etária & $\mathbf{2 0 0 0}$ & $\mathbf{2 0 0 1}$ & $\mathbf{2 0 0 2}$ & $\mathbf{2 0 0 3}$ & $\mathbf{2 0 0 4}$ & $\mathbf{2 0 0 5}$ & $\mathbf{2 0 0 6}$ & $\mathbf{2 0 0 7}$ & Total \\
\hline $\mathbf{0 - 4}$ & 629 & 519 & 391 & 895 & 521 & 422 & 418 & 404 & 4.199 \\
$\mathbf{5 - 9}$ & 315 & 234 & 112 & 310 & 242 & 221 & 177 & 196 & 1.807 \\
$\mathbf{1 0 - 1 4}$ & 99 & 136 & 80 & 146 & 96 & 82 & 100 & 83 & 822 \\
$\mathbf{1 5 - 1 9}$ & 52 & 67 & 71 & 60 & 69 & 42 & 50 & 74 & 485 \\
$\mathbf{2 0 - 2 9}$ & 118 & 163 & 160 & 125 & 147 & 136 & 124 & 224 & 1.197 \\
$\mathbf{3 0 - 3 9}$ & 143 & 166 & 132 & 108 & 125 & 124 & 97 & 164 & 1.059 \\
$\mathbf{4 0 - 4 9}$ & 143 & 166 & 170 & 163 & 173 & 163 & 127 & 208 & 1.313 \\
$\mathbf{5 0 - 5 9}$ & 192 & 193 & 174 & 165 & 200 & 175 & 136 & 239 & 1.474 \\
$\mathbf{6 0 - 6 9}$ & 236 & 240 & 229 & 184 & 258 & 219 & 208 & 309 & 1.883 \\
$\mathbf{+ 7 0}$ & 421 & 492 & 512 & 493 & 634 & 501 & 435 & 612 & 4.100 \\
\hline Total & $\mathbf{2 . 3 4 8}$ & $\mathbf{2 . 3 7 6}$ & $\mathbf{2 . 0 3 1}$ & $\mathbf{2 . 6 4 9}$ & $\mathbf{2 . 4 6 5}$ & $\mathbf{2 . 0 8 5}$ & $\mathbf{1 . 8 7 2}$ & $\mathbf{2 . 5 1 3}$ & $\mathbf{1 8 . 3 3 9}$ \\
\hline
\end{tabular}

Em relação ao coeficiente de incidência por idade, apresentados na Tabela 10 , os maiores valores ocorreram para a faixa etária de 0-4 anos, apresentando 19,7/100.000 hab., para indivíduos de 60-69 anos foi de 12,5/100.000 hab., classificado de média, na margem da probabilidade de riscos.

Tabela 10: Número absoluto das internações por doenças respiratórias, por faixa etária, o coeficiente de incidência (100.000 hab.), a probabilidade e a população estimada. MaringáPR. 2000-2007.

\begin{tabular}{c|c|c|c}
\hline Etária & Coeficiente & probabilidade & Pop. \\
\hline $\mathbf{0 - 4}$ & 19,7 & Média & 21.323 \\
$\mathbf{5 - 9}$ & 7,7 & Baixa & 23.618 \\
$\mathbf{1 0 - 1 4}$ & 3,2 & muito baixa & 25.820 \\
$\mathbf{1 5 - 1 9}$ & 1,8 & muito baixa & 27.632 \\
$\mathbf{2 0 - 2 9}$ & 2,4 & muito baixa & 50.596 \\
$\mathbf{3 0 - 3 9}$ & 2,2 & muito baixa & 49.257 \\
$\mathbf{4 0 - 4 9}$ & 3,4 & muito baixa & 39.100 \\
$\mathbf{5 0 - 5 9}$ & 5,8 & Baixa & 25.431 \\
$\mathbf{6 0 - 6 9}$ & 12,5 & Média & 15.109 \\
$\mathbf{+ 7 0}$ & $\mathbf{3 8 , 1}$ & Alta & 10.767 \\
\hline Total & $\mathbf{9 6 , 8}$ & - & $\mathbf{2 8 8 . 6 5 3}$ \\
\hline
\end{tabular}

A faixa etária de 5-9 anos e 50-59 anos apresentaram baixa probabilidade, sendo de 7,7/100.00 hab. e 5,8/100.000 hab., respectivamente. Para as pessoas acima de 70 a incidência foi de 38,1/100.000 hab., classificada como de alta 
probabilidade de riscos. Em menor expressão, de muito baixa, apontaram para a faixa etária de 10-14 anos, com apenas 1,8/100.000 hab., até a faixa etária de 40-49 anos.

De 0-4 anos conta com 21.323 habitantes e para mais de 70 anos conta com 10.767 habitantes, mostrando esta última faixa etária ainda mais vulnerável a essa enfermidade, de acordo com a população estimada, mostrou-se como necessitando de maior atenção.

Na Figura 3 são mostrados o total de internações, segundo o grupo de causas e o sexo. O maior número de ocorrência foi para o sexo masculino em todos os grupos. Predominou a influenza \{gripe\} e pneumonia (J10-J18), com 5.938 dos registros para o sexo masculino e 4.880 dos registros para o sexo feminino, com a diferença entre os sexos de 1.058 internações.

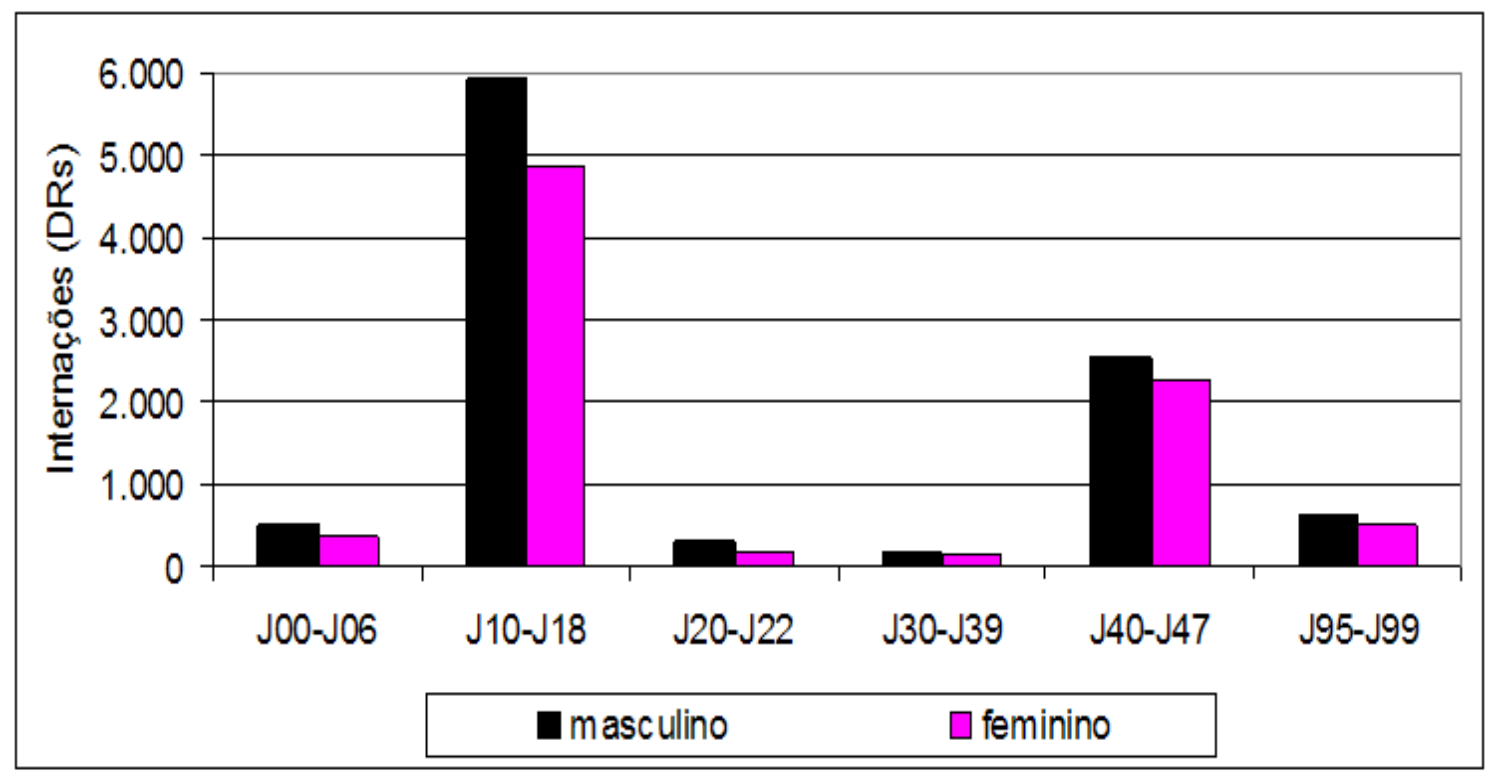

Figura 3: Número absoluto de internações por doenças respiratórias, conforme o grupo de causas e sexo. Maringá-PR, 2000-2007.

As infecções agudas das vias aéreas superiores (J00-J06), apresentaram 515 registros para o sexo masculino e 375 para o feminino, a diferença entre os sexos foi de 140 registros.

Para outras infecções agudas das vias aéreas inferiores (J20-J22), a diferença foi de 120 registros, sendo 284 para o sexo masculino e de 164 para o sexo feminino. 
Outras doenças das vias aéreas superiores (J30-J39), apresentaram 157 registros para o sexo masculino e 120 para o sexo feminino, com diferença de 37 internações entre os sexos.

As doenças crônicas das vias aéreas inferiores (J40-J47), destacaram com 2.520 registros para o sexo masculino e 2.274 para o sexo feminino, com a diferença entre os sexos de 246 registros.

Outras doenças do aparelho respiratório (J95-J99), foram 624 registros para o sexo masculino e 488 para o sexo feminino, com a diferença entre os sexos de 136 internações, totalizando com 1.112 internações.

Conforme o IBGE (2000) a população de Maringá é formada de 150.139 habitantes do sexo feminino e 138.514 habitantes do sexo masculino. Embora seja uma cidade que apresenta maior predominância para o sexo feminino, as maiores quantidades de internações ocorreram para o sexo masculino em todos os grupos de causas.

Essa diferença abrangeu para o período de estudos 10.038 registros de internações, com $54,7 \%$ para o sexo masculino e $45,3 \%$ registro para o sexo feminino.

Ao analisar as admissões hospitalares por doenças respiratórias agudas em crianças de até dois anos, Lima (2000, p. 57) afirmou que a maioria das internações foi crianças de até 11 meses, pacientes do sexo masculino predominaram.

Na Figura 4 está apresentada as internações, por sexo para cada faixa etária, verificou que apenas entre 15-19 anos ocorreu a menor diferença, sendo de 237 internações para o sexo feminino e 248 internações para o masculino, com diferença de 11 registros entre os sexos. Esta foi à única faixa etária que apresentou menor quantidade de internações, com o total de 485 registros.

A maior quantidade encontrada foram para a faixa etária de 0-4 anos, com 2.333 registros para o sexo masculino e 1.866 para o sexo feminino, para mais de 70 anos, apresentaram 2.161 do sexo masculino e 1.939 do sexo feminino.

Em seguida, destacou a faixa etária de 5-9 anos com 1.033 registros para o sexo masculino e 774 para o sexo feminino, a faixa etária de 60-69 anos apresentaram 1.078 registros para o sexo masculino e 805 para o sexo feminino.

A faixa etária de 20-29 anos foi 637 registros para o sexo masculino e 560 para o sexo feminino, 30-39 anos apresentaram 550 para o sexo masculino e 509 para o sexo feminino, 40-49 anos foram 723 registros para o sexo masculino e 590 
para o sexo feminino, 50-59 anos apresentaram 844 registros para o sexo masculino e 630 para o sexo feminino.

Em menor quantidade de internações destacaram para a faixa etária de 10-14 anos, foram 442 para o sexo masculino e 380 para o sexo feminino, 15-19 anos foi 237 para o sexo masculino e 248 para o sexo feminino.

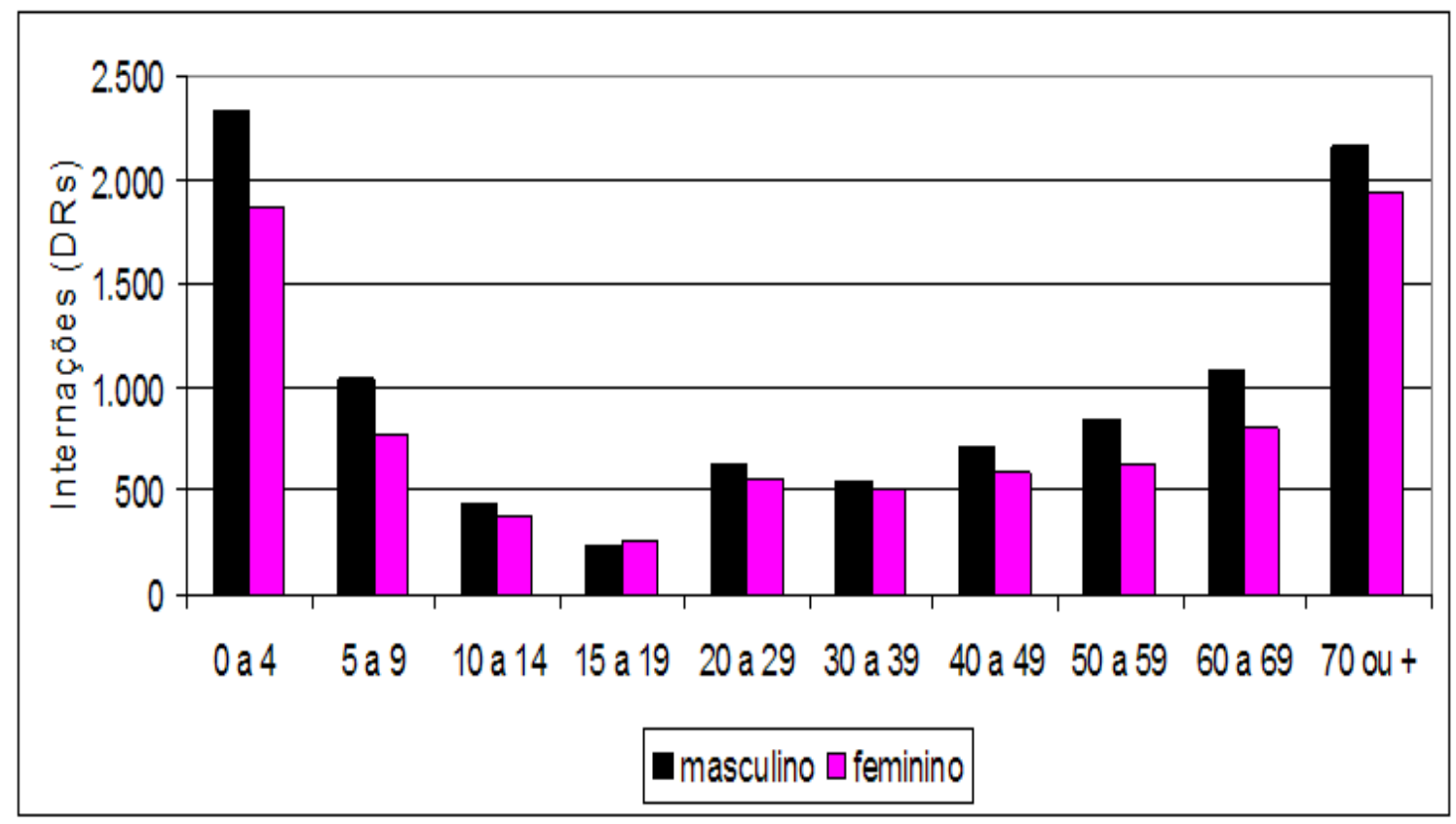

Figura 4: Número absoluto de internações por doenças respiratórias, por sexo, para cada faixa etária. Maringá-PR, 2000-2007.

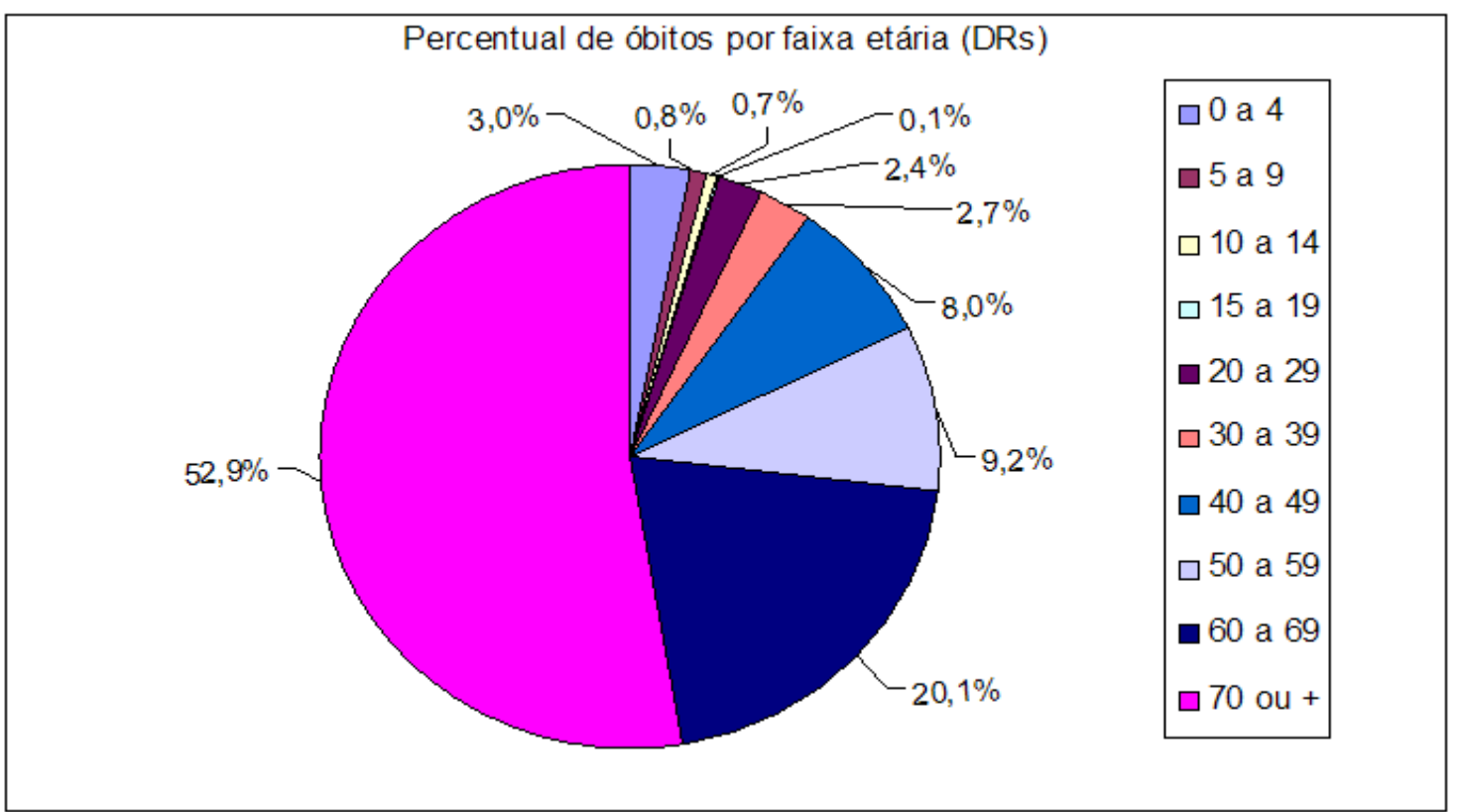

Figura 5: Percentual de óbitos por doenças respiratórias, para cada faixa etária. Maringá-PR, 2000-2007. 
Na Figura 5 está apresentada a relação dos registros de óbitos por doenças respiratórias, para o período de 2000 a 2007. A maior quantidade encontrada foi a partir da faixa etária de 40-49 anos, com 59 óbitos (8,0\%) e para 50-59 anos com 68 óbitos (9,2\%). Esse número eleva-se, atingindo 148 óbitos $(20,1 \%)$ para a faixa etária de 60-69 anos e de 389 óbitos (52,9\%) para a faixa etária com mais de 70 anos.

Para a faixa etária de 0-4 anos ocorreram 22 óbitos (3,0\%), 20-29 anos foram 18 óbitos (2,4\%), 30-39 anos foram 20 óbitos (2,7\%). As menores quantidades de óbitos registrados foram para a faixa etária de 5-9, 10-14 e 15-19, com a ocorrência de óbitos entre 1 a 6 casos $(0,1$ a $0,8 \%)$, respectivamente.

\subsection{INTERNAÇÕES POR DOENÇAS RESPIRATÓRIAS E O ESPAÇO URBANO}

A análise do número absoluto das internações por Zonas Municipais em Maringá, representa uma contribuição importante, pois é através do conhecimento da realidade que possibilitam aos serviços de saúde a melhor organização, para atender a demanda de necessidades no âmbito local de cada área específica.

Seguramente, contem em cada zona, realidades diferenciadas em seu universo, com padrões distintos principalmente nas condições socio econômicas, moradia, laser, cultura, transporte e incluindo o atendimento hospitalar. A Figura 6 serviu de base para serem inseridas as informações de população, o número absoluto de internações e o coeficiente de incidência. Pode ser observados que as zonas localizadas junto ao centro são menores em relação as zonas lozalizadas em áreas períféricas, que são bem maiores.

Ao analisar a espacialização por doenças cardiovasculares, neoplasias e causas externas, Fonzar, Soares e Santil (2003, p. 773) enfatizaram a importância de caracterizar a situação em que ocorrem os eventos nos espaços determinados e o conhecimento da realidade distinta de cada unidade espacial, constituindo assim como ferramentas importantes, que o setor de saúde deve adotar e que poderão subsidiar no planejamento das ações de controle, na alocação de recursos, na execução e avaliação das ações. 


\section{Zonas municipais - Maringá/ PR}

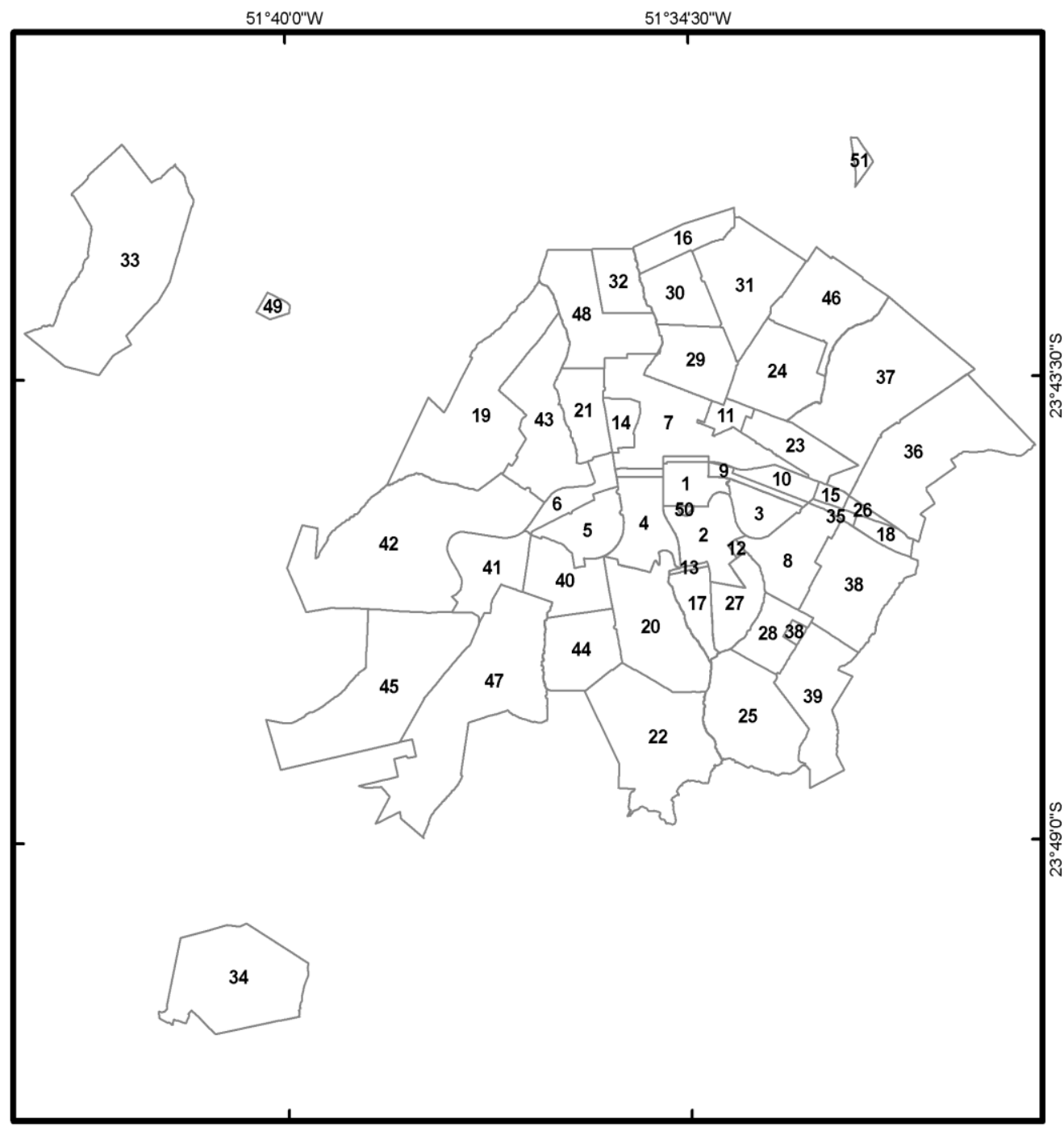

1 Zonas municipais - Maringá/PR

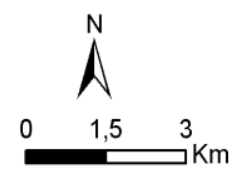

Fonte: Pref. Municipal Maringá Secretaria Municipal de Saúde Maringá, 2008

Org.: ANJOS, I. B., 2010

Figura 6: Respectivas Zonas Municipais de Maringá-PR.

A cidade é um lugar de diferentes classes sociais, diferenças nas condições de moradias, com áreas industriais de diversos níveis e modelos, fluxos de bens e de serviços, tornando-se um espaço heterogêneo, dinâmico e abstrato, favorecendo 
os estudos relacionando a saúde da sua população, nesse caso, as internações por doenças respiratórias.

Nesse aspecto, a distribuição espacial da população nas Zonas Municipais, pode ser evidenciada na Figura 7, a distribuição das doenças respiratórias pode ser visualizada, na Figura 8 e o coeficiente de incidência pode ser encontrada na Figura 9.

\subsubsection{POPULAÇÃO POR ZONAS MUNICIPAIS}

Na Figura 7 está apresentada as Zonas Municipais com as respectivas população, as zonas: 16, 22, 32, 49, 50 e 51 são as áreas sem informação. Sendo que de 1-1.000 habitantes, apresentaram sete zonas inclusas: 10, 12, 13, 26, 41, 42 e 45, no qual a quantidade de habitantes iniciou com 278 pessoas na zona 41, encerrando com 951 habitantes na zona 45. Destas, somente a zona 42 e 45 está localizada em área periférica da cidade.

De 1.001-5.000 habitantes, foram quatorze Zonas Municipais inclusas: 6, 9, $11,14,15,17,18,20,28,34,35,38,40$ e 46 , com a quantidade de população variando entre 1.017 habitantes para a zona 35 até 4.865 habitantes para a zona 20 . Destas, a zona 34 é o Distrito de Floriano e as zonas 18, 35, 38 e 46, estão localizadas mais na área periférica de Maringá.

De 5.001-10.000, foram dezessete zonas: 2, 3, 4, 5, 8, 19, 21, 25, 27, 29, 31, $33,39,43,44,47,48$, em que a quantidade populacional variaram entre 5.234 habitantes na zona 44 atingindo 9.784 habitantes na zona 21. Destas, a zona 33 é o Distrito de Iguatemi e as zonas 19, 25, 29, 31, 39, 43, 44, 47 e 48 localiza-se a periferia.

De 10.001-23.874, foram sete zonas: 1, 7, 23, 24, 30, 36 e 37, com a população variando entre 10.577 habitantes na zona 1 e de 23.874 habitantes na zona 37. Estas zonas estão localizadas no sentido norte/nordeste de Maringá, é um local de forte concentração imobiliária, notadamente, esse fato contribuiu para o maior crecimento populacional. Destas, as zonas 1, 7 são centrais, a 23 numa área intermediária e o restante em área periférica de Maringá. 


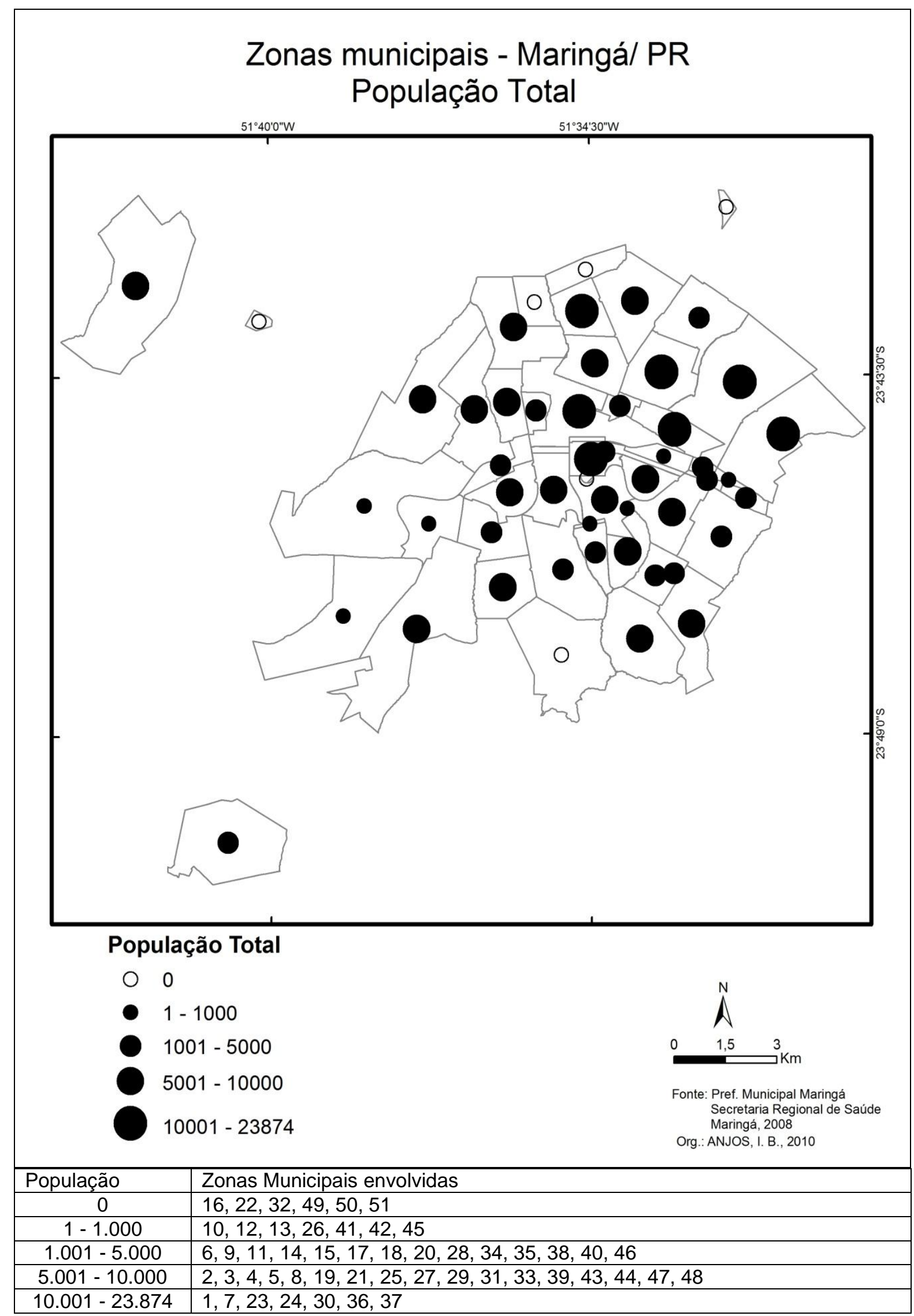

Figura 7: População por Zonas Municipais, Maringá-PR. 


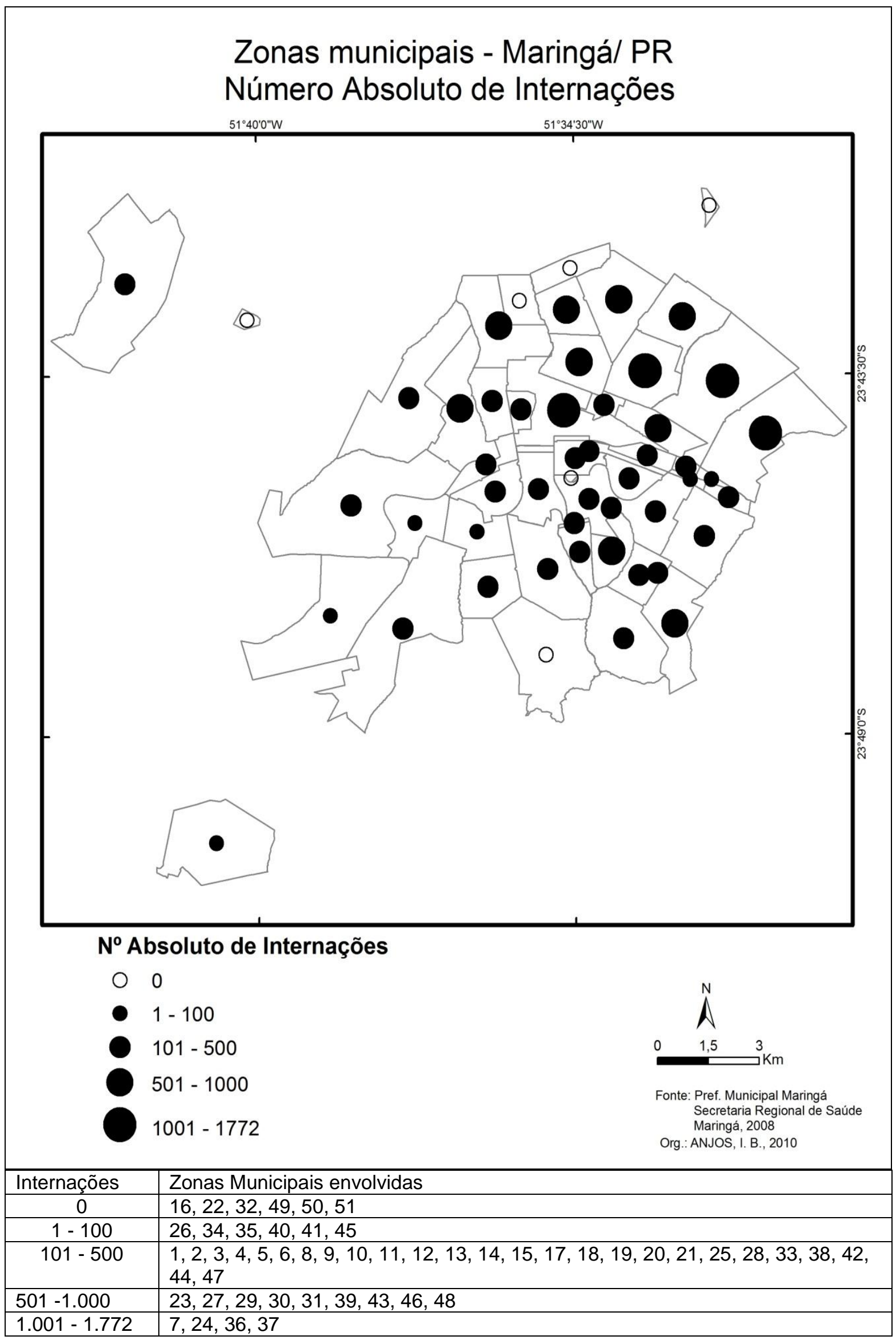

Figura 8: Número absoluto de internações, por Zonas. Maringá-PR, 2000-2007. 


\subsubsection{INTERNAÇÕES POR ZONAS MUNICIPAIS}

A Figura 8, apresentou o número absoluto de registros para o período de estudo. As zonas: 16, 22, 32, 49, 50 e 51 são áreas sem informação. Com variação entre 1-100 registros de internamentos nos hospitais, foram seis zonas inclusas: 26 , $34,35,40,41,45$, em que variaram de 33 internações para a zona 41, de 73 para a zona 40, com 92 para a zona 35, de 97 para a zona 34 e de 98 internações para a zona 26 e 45.

De 101-500 registros, foram destacadas vinte e seis zonas: 1, 2, 3, 4, 5, 6, 8 , $9,10,11,12,13,14,15,17,18,19,20,21,25,28,33,38,42,44$ e 47 . No qual, a quantidade variaram entre 102 para a zona 12 até 479 internações para a zona 28.

De 501-1.000 registros, foram destacadas nove zonas: $23,27,29,30,31,39$, 43, 46, 48. Com variação entre 520 internações para a zona 31 até 933 internações para a zona 23.

De 1.001-1.772 registros, foram quatro zonas: $7,24,36$ e 37 , com quantidade que variaram entre 1.010 na zona 7 , de 1.772 na zona 24 , de 1.231 internações para a zona 36 e de 1.299 internações para a zona 37.

Através das Figuras 7 e 8, pôde-se verificar como ocorrem as internações por problemas respiratóris em Maringá, na verdade, tem um seguimento, levando em consideração o contingente populacional das áreas em questão, pois praticamente todas as Zonas Municipais apresentaram com casos de internações por doenças respiratórias, apenas em maior ou menor quantidade, conforme a população existente.

\subsubsection{COEFICIENTE DE INCIDÊNCIA POR ZONAS MUNICIPAIS}

A incidência é uma medida relativa de intensidade em que acontece a morbidade (doenças) e está intimamente relacionada com a quantidade da população de cada localidade. Primeiramente foi calculado o coeficiente de incidência para o Município de Maringá, sendo encontrado 6,4/100.000 hab., classificado para essa análise de baixa probabilidade em riscos, para o período de estudo. 
Com base nesse cálculo, na Figura 9 está apresentada a distribuição do coeficiente de incidência, para cada Zona Municipal. Assim as zonas: 16, 22, 32, 49, 50 e 51 são áreas sem informação.

O que comumente ocorre, nesse tipo de análise, é que as áreas com menor densidade populacional e menor número de casos, mostraram-se com o coeficiente de incidência mais elevado, isso ocorre porque os casos de internações são divididos pela população e o resultado multiplicado por 100.000, base do referencial.

Os cálculos de coeficiente de incidência são utilizado na epidemiologia, quando refere-se à população, servem para observar se está ocorrendo casos considerados críticos, severos, ou não, em uma determinada área e dentro de uma margem de probabilidade em riscos.

Assim sendo, cassificada de probabilidade muito baixa, com o coeficiente de incidência, variando entre 0,1-5,0/100.000 hab., foram relacionadas 12 zonas: 1, 2, $3,5,6,7,11,17,19,21,30,44$, com variação entre 2,6 para a zona 2 que possui 5.866 habitantes, a 4,9 para a zona 30 que possui 12.479 habitantes e apresentaram-se abaixo do coeficiente do Município.

Classificado de probabilidade baixa, com o coeficiente de incidência, variando entre 5,1-10,0/100.000 hab., foram 21 zonas em destaque: 4, 8, 9, 18, 20, 23, 24, $25,27,29,31,33,34,35,36,37,38,39,40,43,47$, com variação entre 5,2 para a zona 47 até 9,1 para a zona 9 . A zona 47 possui 5.417 habitantes e a zona 9 possui 1. 337 habitantes.

Sendo que, com o coeficiente de incidência classificado como de média probabilidade, variando entre 10,1-20,0/100.000 hab., foram oito zonas: 14, 15, 26, $41,42,45,46,48$, com variação entre 10,5 para a zona 48 que possui uma população de 5.329 habitantes a 14,7 para a zona 26 que possui a população de 667 habitantes. Estas zonas apresentaram-se com o coeficiente de incidência acima do coeficiente do município.

Para o coeficiente de incidência, classificado de probabilidade alta, com variação entre 20,1-54,9/100.000 hab., foram quatro zonas, em destaque: 10, 12, 13 e 28. Estas zonas obtiveram o coeficiente de incidência de 54,9 para a zona 10, que possui 395 habitantes, zona 12 com o coeficiente de 21,6 e a população de 473 habitantes, zona 13 com o coeficiente de 41,7 e população de 343 habitantes. A zona 28 apresentou o coeficiente de 30,0 e a população de 1.576 habitantes. Acima do coeficiente de incidência do múnicipio. 


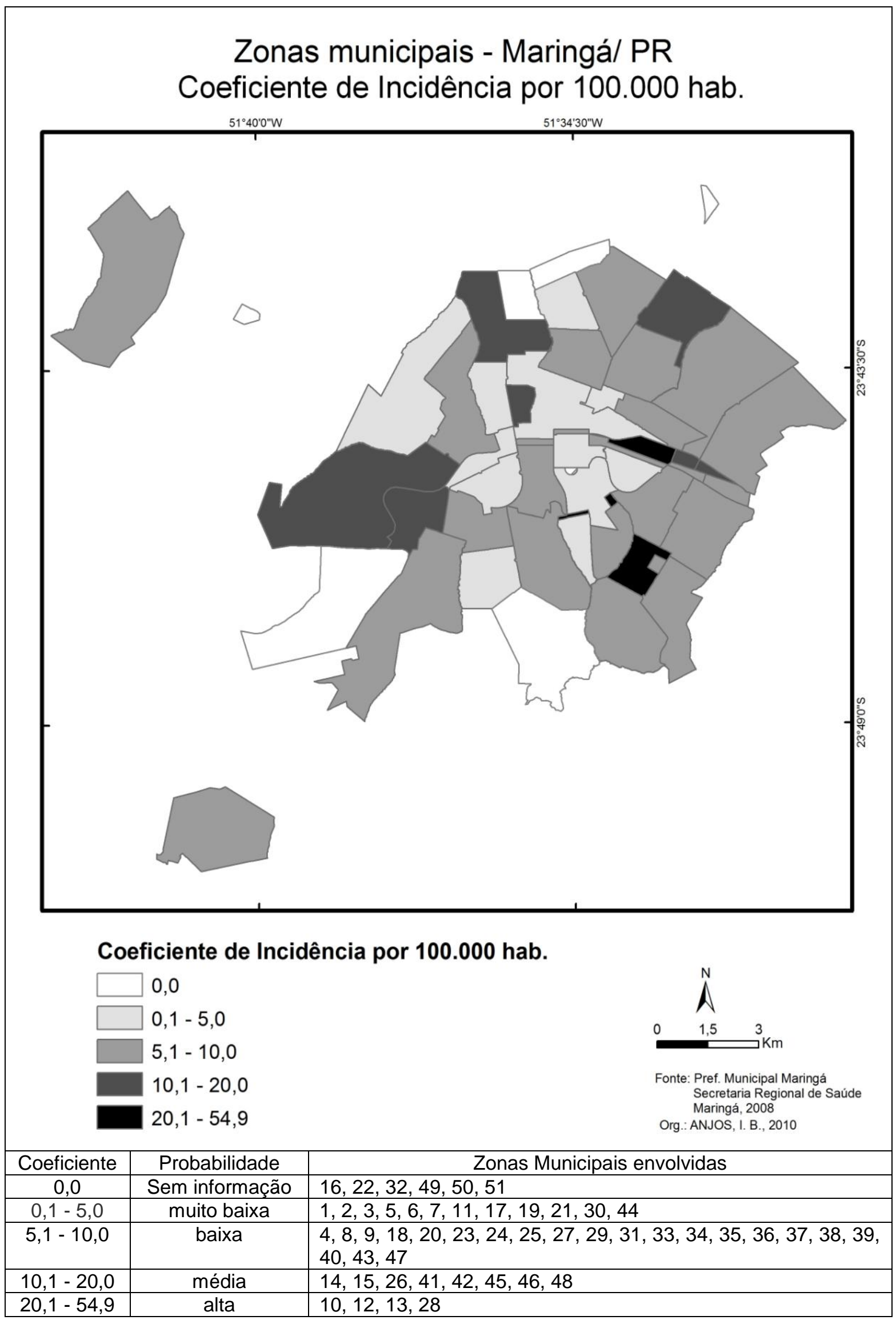

Figura 9: Coeficiente de incidência, para cada Zona de Maringá, 2000-2007. 
Segundo a Organização Pan-Americana de Saúde (2002, p. 19) contudo, é preciso ter cuidado com ao tratar-se de um número muito pequeno de casos, visto que, podem causar uma grande distorção na taxa dos resultados.

Haja visto que, nessa abordagem, as zonas no qual foram obtidas os resultados do coeficiente de incidência como de probabilidade alta, caracterizandose como de maior margem de riscos, entretanto, possuem um número populacional muito baixo, assim sendo, pode-se identificar como sendo apenas uma mancha nos resultados dos casos de internações, sem mais agravantes, não consideradas de riscos altos, nos casos de internações por doenças respiratórias.

Ao analisar a espacialização das três principais causas de morte em Maringá, sendo as doenças cardiovasculares, neoplasias e causas externas, Fonzar et al.; (2002) advertiu sobre essa possibilidade.

Quando a unidade espacial e a população considerada dentro dela forem pequenas, poderá acontecer que o número de vítimas seja muito baixo e, nesse caso, as taxas calculadas com numeradores pequenos poderão apresentar certa instabilidade (FONZAR et al.; 2002, p. 768).

\subsection{4 ÓBITOS POR ZONAS MUNICIPAIS}

Na Tabela 11 está apresentada o número absoluto de óbitos ocorridos por doenças respiratórias, para o período de estudo. Foram registradas 28 óbitos para a zona 3 e 46, a zona 4 destacou em maior quantidade, com 88 óbitos, a zona 21 apresentou 32 óbitos, a zona 23 com 41 óbitos, a zona 24 com 61 óbitos, a zona 27 com 67 óbitos e a zona 37 com 44 óbitos. Em menor quantidade com 1 a 3 registros de óbitos, ocorreram para as zonas 2, 9, 12, 34, 35, 39, 40, 41 e 42.

A quantidade de número de óbitos registrados nem sempre acompanharam as zonas mais populosas, podem ser observadas certa disparidade, na zona $4 \mathrm{com}$ população de 5.655 habitantes apresentou 88 óbitos e a zona 27 com população de 7.738 habitantes apresentou 67 óbitos, estas duas zonas estão localizadas na área central, podem ser compostas por uma população mais envelhecidas, é possível que esse fato possa justificar o excedente em número de óbitos em relação as demais zonas. 
Tabela 11: Número absoluto de óbitos por doenças respiratórias, por Zonas Municipais. Maringá-PR. 2000-2007.

\begin{tabular}{cc|cc|cc}
\hline Zonas & Óbitos & Zonas & Óbitos & Zonas & Óbitos \\
\hline $\mathbf{1}$ & 8 & $\mathbf{1 8}$ & 5 & $\mathbf{3 5}$ & 2 \\
$\mathbf{2}$ & 3 & $\mathbf{1 9}$ & 8 & $\mathbf{3 6}$ & 17 \\
$\mathbf{3}$ & 28 & $\mathbf{2 0}$ & 7 & $\mathbf{3 7}$ & 44 \\
$\mathbf{4}$ & 88 & $\mathbf{2 1}$ & 32 & $\mathbf{3 8}$ & 16 \\
$\mathbf{5}$ & 22 & $\mathbf{2 2}$ & - & $\mathbf{3 9}$ & 2 \\
$\mathbf{6}$ & 6 & $\mathbf{2 3}$ & 41 & $\mathbf{4 0}$ & 3 \\
$\mathbf{7}$ & 22 & $\mathbf{2 4}$ & 61 & $\mathbf{4 1}$ & 1 \\
$\mathbf{8}$ & 13 & $\mathbf{2 5}$ & 10 & $\mathbf{4 2}$ & 3 \\
$\mathbf{9}$ & 2 & $\mathbf{2 6}$ & - & $\mathbf{4 3}$ & 11 \\
$\mathbf{1 0}$ & 16 & $\mathbf{2 7}$ & 67 & $\mathbf{4 4}$ & 11 \\
$\mathbf{1 1}$ & 9 & $\mathbf{2 8}$ & 17 & $\mathbf{4 5}$ & 4 \\
$\mathbf{1 2}$ & 2 & $\mathbf{2 9}$ & 14 & $\mathbf{4 6}$ & 28 \\
$\mathbf{1 3}$ & 11 & $\mathbf{3 0}$ & 20 & $\mathbf{4 7}$ & 8 \\
$\mathbf{1 4}$ & 5 & $\mathbf{3 1}$ & 21 & $\mathbf{4 8}$ & 14 \\
$\mathbf{1 5}$ & 8 & $\mathbf{3 2}$ & - & $\mathbf{4 9}$ & - \\
$\mathbf{1 6}$ & - & $\mathbf{3 3}$ & 13 & $\mathbf{5 0}$ & - \\
$\mathbf{1 7}$ & 10 & $\mathbf{3 4}$ & 3 & $\mathbf{5 1}$ & - \\
\hline
\end{tabular}

Já na zona 7 densamente populosa que possui 23.671 habitantes, registrou 22 óbitos, esta zona também encontra-se numa área residencial próxima ao centro e também localiza-se a Universidade Estadual de Maringá, composta pela população de jovens universitários.

O mesmo ocorreu para a zona 36, com 21.632 habitantes, registrou 17 óbitos e a zona 37 com 23.874 habitantes apresentou 44 óbitos. Essas zonas são formadas por bairros residenciais mais novos, à periferia, composta por uma população mais jovens e crianças, esse fato pode ter justificado na relação do número de óbitos serem menores, de acordo com a população existente.

\subsubsection{MÉDIAS E AMPLITUDES DE INTERNAÇÕES, PARA O PERÍODO DE ESTUDO}

A Tabela 12 apresenta as médias mensais de internações para o período de estudo, com 124,9 para janeiro e de 129,9 em dezembro, com proporções elevadas a partir de março com 220,1 permanecendo até agosto, com média de 221,8, destacando para junho a média de 242,8 e julho de 234,0. 
Tabela 12: Médias mensais de internações e óbitos para Maringá-PR. 2000-2007.

\begin{tabular}{c|c|c}
\hline Meses & Média internações & Média de óbitos \\
\hline Jan & 124,9 & 6,6 \\
Fev & 131,1 & 6,5 \\
Mar & 220,1 & 7,3 \\
Abr & 217,0 & 8,3 \\
Mai & 223,5 & 7,4 \\
Jun & 242,8 & 8,8 \\
Jul & 234,0 & 10,3 \\
Ago & 221,8 & 9,0 \\
Set & 189,1 & 7,4 \\
Out & 191,0 & 7,6 \\
Nov & 166,8 & 6,3 \\
Dez & 129,9 & 6,8 \\
\hline
\end{tabular}

Em relação aos óbitos, apresentados na Tabela 12, destacam-se com média de 6,6 em janeiro, 6,5 em fevereiro e de 6,3 em novembro. Elevam-se a partir de março com média de 7,2 a outubro de 7,6, sendo marcadamente para junho com 8,8, julho de 10,3 e agosto com média de 9,0.

Em relação a amplitude de internações, tendo como referencial as médias mensais do período de estudo, são observadas na Tabela $12 \mathrm{~A}$, percebe-se que mesmo para a primavera e verão também ocorrem amplitudes acima da média, nos registros de internações. Como em outubro com três situações, sendo o mais importante em 2005, com 32 registros de internações, acima da média do período, para esse mês.

Em novembro esse fato ocorreu duas vezes, sendo com maior acréscimo para 2005, com 57 registros, acima da média. Em dezembro foram três momentos, janeiro apenas uma vez e fevereiro duas vezes, com indicação considerável para 2007, sendo de 52 registros acima da média, do período, destes meses.

Contudo, nos meses de outono e inverno, ou entre março a setembro ocorreram variações com mais frequência. Para março foram quatro momentos com registros de internações acima da média do período, como mostra com 56, 41, 40 e 38 casos, para os anos de 2003, 2004, 2005 e 2007.

Para abril foram seis momentos com registros de internações acima da média do período, maio destacou por cinco momentos, junho apresentou-se quatro momentos, com o maior grau de importância para 2003 no qual destacou-se com 98 registros de internações e em 2007 com 111 registros.

No entanto, ainda em junho mostrou-se em alguns momentos com internações abaixo da média do período, como em 2002 com 108 e 2006 com 111 
registros de internações. Julho apresentou para 2006 com 114 internações abaixo da média, destacando acima da média por cinco momentos, sendo de 49 registros em 2000, 18 em 2001, 30 em 2002 e 2007 e de 55 registros em 2003.

Já para setembro mostrou-se por 4 vezes acima da média, sendo de maior quantidade de internações para 2003, apresentando com 31 registros.

Tabela 12A: Amplitudes de internações por doenças respiratórias, em relação com a média do período: 2000-2007. Maringá-PR.

\begin{tabular}{|c|c|c|c|c|c|c|c|c|c|c|c|c|}
\hline Anos & Jan & Fev & Mar & $A b r$ & Mai & Jun & Jul & Ago & Set & Out & Nov & Dez \\
\hline 2000 & 7 & 7 & 8 & 18 & 0 & $20^{*}$ & $49^{\star}$ & $57^{\star}$ & $15^{\star}$ & 10 & 21 & 15 \\
\hline 2001 & 9 & 15 & 21 & $40^{\star}$ & $21^{*}$ & 1 & $18^{*}$ & $16^{*}$ & $4^{*}$ & $12^{*}$ & $8^{*}$ & $10^{\star}$ \\
\hline 2002 & 8 & 10 & 60 & $31^{*}$ & 79 & 108 & $30^{*}$ & $28^{*}$ & 0 & $12^{*}$ & 31 & 21 \\
\hline 2003 & $18^{*}$ & $31^{*}$ & $56^{*}$ & $61^{*}$ & $36^{*}$ & $98^{*}$ & $55^{\star}$ & $17^{\star}$ & $31^{*}$ & 12 & 15 & 16 \\
\hline 2004 & 13 & 28 & $41^{*}$ & $1^{*}$ & $32^{*}$ & $33^{*}$ & 13 & $10^{\star}$ & 6 & 4 & 21 & 8 \\
\hline 2005 & 26 & 36 & $40^{*}$ & $37^{*}$ & $10^{*}$ & 43 & 55 & 29 & 40 & $32^{*}$ & $57^{*}$ & 1 \\
\hline 2006 & 9 & 42 & 2 & $12^{\star}$ & 29 & 111 & 114 & 53 & 19 & 24 & 35 & $11^{*}$ \\
\hline 2007 & 7 & $52^{*}$ & $38^{*}$ & 4 & $5^{\star}$ & $111^{*}$ & $30^{*}$ & 14 & $16^{*}$ & 14 & 16 & $23^{*}$ \\
\hline
\end{tabular}

Negrito* as amplitudes acima da média do período estudado.

\subsubsection{SÍNTESE DOS RESULTADOS DE INTERNAÇÕES POR GRUPO DE CAUSAS, SEXO E FAIXA ETÁRIA.}

Observou que em Maringá, as doenças respiratóras ocorreram em maior número de internações para a influenza \{gripe\} e pneumonia com $59 \%$ dos registros de internações, seguidas por doenças crônicas das vias aéreas inferiores com $26,0 \%$ das internações.

A maior quantidade ocorreram para o sexo masculino, com $54,7 \%$ dos registros e o sexo feminino com 45,3\%. A faixa etária mais acometida, primeiramente destacou de 0-4 anos e para mais de 70 anos. Logo após, apontaram para a faixa etária de 5-9 anos. Quanto aos óbitos, foi mais expressivo para a faixa etária de 60 a 69 anos, com 20,0\% e de 52,8\% para a faixa etária com mais de 70 anos.

Através da Tabela 13, na síntese dos dados, observa-se que a maior concentração de casos respiratórios, ocorreram para as áreas mais populosas, como a zona 7 que possui 23.671 habitantes, a zona 23 com 12.859 habitantes, a zona 24 com 23.312 habitantes, a zona $30 \mathrm{com} 12.479$ habitantes, a zona $36 \mathrm{com}$ 21.632 habitantes e a zona 37 que possui 23.874 habitantes. 
Verificou-se que em todas as camadas sociais os problemas de ordem respiratória são existentes, observando resultados diferenciados em relação à quantidade de habitantes, ou seja, um determinado bairro ou zona sobressaiu a outro em maior contingente populacional, consequentemente ocorreu nesse local a maior quantidade de problemas respiratórios.

Foram as Zonas Municipais mais populosas, que destacaram-se com 0 coeficiente de incidência classificado de muito baixa probabilidade na margem de riscos, contando com 12 zonas e de probabilidade baixa, somaram 21 zonas. Conforme mostrado, apresentou a zona 7, com o incidência de 4,3, a zona 23 com 7,2, a zona 24 com 7,6, a zona 30 com 4,9, a zona 36 com 5,7 e a zona 37 com incidência de 5,4.

As Zonas Municipais com menores densidades populacionais, apresentaramse com o número reduzido de internações. Consequentemente foram estas que destacaram-se com o coeficiente de incidência de média ou alta probabilidade.

Tabela 13: Síntese do número absoluto da população, das internações, do coeficiente de incidência e a probabilidade de riscos, por Zonas Municipais.

\begin{tabular}{|c|c|c|}
\hline $\begin{array}{c}\text { Número de População } \\
0,0\end{array}$ & $\begin{array}{c}\text { Número de Internações } \\
0,0\end{array}$ & $\begin{array}{c}\text { Coeficiente de Incidência } \\
0,0 \text { (nulo) }\end{array}$ \\
\hline $\begin{array}{c}6 \text { Zonas: } \\
16,22,32,49,50,51\end{array}$ & $\begin{array}{c}6 \text { Zonas: } \\
16,22,32,49,50,51\end{array}$ & $\begin{array}{c}\text { 6 Zonas: } \\
16,22,32,49,50,51\end{array}$ \\
\hline $\begin{array}{l}\text { Número de População } \\
1 \text { a } 1.000\end{array}$ & $\begin{array}{l}\text { Número de Internações } \\
1 \text { a } 100\end{array}$ & $\begin{array}{c}\text { Coeficiente de Incidência } \\
20,1 \text { a } 54,9 \text { (probabilidade alta) }\end{array}$ \\
\hline $\begin{array}{c}7 \text { Zonas: } \\
10,12,13,26,41,42,45\end{array}$ & $\begin{array}{c}6 \text { Zonas: } \\
26,34,35,40,41,45\end{array}$ & $\begin{array}{l}\text { 4 Zonas: } \\
10,12,13,28\end{array}$ \\
\hline $\begin{array}{c}\text { Número de População } \\
1.001 \text { a } 5.000\end{array}$ & $\begin{array}{l}\text { Número de Internações } \\
101 \text { a } 500\end{array}$ & $\begin{array}{l}\text { Coeficiente de Incidência } \\
10,1 \text { a } 20,0 \text { (probabilidade média) }\end{array}$ \\
\hline $\begin{array}{l}14 \text { Zonas: } \\
6,9,11,14,15,17,18,20 \\
28,34,35,38,40,46\end{array}$ & $\begin{array}{c}26 \text { Zonas: } \\
1,2,3,4,5,6,8,10,11 \\
12,13,14,15,17,18,19 \\
20,21,25,28,33,38,42 \\
44,47\end{array}$ & $\begin{array}{c}\text { 8 Zonas: } \\
14,15,26,41,42,45,46,48\end{array}$ \\
\hline $\begin{array}{c}\text { Número de População } \\
5.001 \text { a } 10.000\end{array}$ & $\begin{array}{c}\text { Número de Internações } \\
501 \text { a } 1.000\end{array}$ & $\begin{array}{c}\text { Coeficiente de Incidência } \\
5,1 \text { a } 10,0 \text { (probabilidade baixa) }\end{array}$ \\
\hline $\begin{array}{c}17 \text { Zonas: } \\
2,3,4,5,8,19,21,25,27 \\
29,31,33,39,43,44,47 \\
48\end{array}$ & $\begin{array}{c}17 \text { Zonas: } \\
23,27,29,30,31,39,43 \\
46,48\end{array}$ & $\begin{array}{l}\text { 21 Zonas: } \\
\begin{array}{l}4,8,18,20,23,24,25,27,29,31,33 \\
34,35,36,37,38,39,40,43,47\end{array}\end{array}$ \\
\hline $\begin{array}{c}\text { Número de População } \\
10.001 \text { a } 23.874\end{array}$ & $\begin{array}{c}\text { Número de Internações } \\
1.001 \mathrm{a} 1.772\end{array}$ & $\begin{array}{c}\text { Coeficiente de Incidência } \\
0,1 \text { a } 5,0 \text { (probabilidade muito } \\
\text { baixa) }\end{array}$ \\
\hline $\begin{array}{c}07 \text { Zonas: } \\
1,7,23,24,30,36,37\end{array}$ & $\begin{array}{l}\text { 4 Zonas: } \\
7,24,36,37\end{array}$ & $\begin{array}{c}12 \text { Zonas: } \\
1,2,3,5,6,7,11,17,19,21,30,44\end{array}$ \\
\hline
\end{tabular}


Como mostrou principalmente a zona 10 com 395 habitantes somou-se 217 internações e o coeficiente de incidência de 54,9. A zona 12 com 473 habitantes e a incidência de 21,5, a zona 13 com 343 habitantes e incidência de 41,7, a zona 28 com 1.576 habitantes e a incidência de 30,0. Entretanto, para essas zonas, foi considerado apenas como uma mancha de probabilidades, na margem de riscos.

\subsection{INTERNAÇÕES POR DOENÇAS RESPIRATÓRIAS RELACIONADAS COM A VARIABILIDADE CLIMÁTICA}

Para verificar as doenças respiratórias de acordo com o clima de Maringá, a princípio fez-se uma análise dos dados meteorológicos, como a temperatura máxima, mínima e média, umidade relativa do ar, precipitação pluvial, pressão atmosférica, juntamente com o número absoluto dos registros das internações e óbitos por doenças respiratórias para o período de 2000-2007, conforme está apresentada na Figura 10.

No qual, a precipitação pluvial mostrou-se elevada em janeiro de $231,1 \mathrm{~mm}$, fevereiro $179,4 \mathrm{~mm}$, diminuiu em abril para $70,0 \mathrm{~mm}$, em maio elevou-se novamente $126,0 \mathrm{~mm}$ e com queda evidenciada nos meses de junho, com $58,8 \mathrm{~mm}$, em julho $84,3 \mathrm{~mm}$ e em agosto com 58,5mm. Elevando-se a partir de setembro com 146,2mm, até dezembro com 186,2mm.

A umidade relativa do ar apresentou superior a 70\% entre janeiro a março, em maio e dezembro, abaixo de $70 \%$ destaca para abril, junho, julho e de setembro a novembro, em torno de $57 \%$ para o mês de agosto.

A temperatura máxima em torno de $30,0^{\circ} \mathrm{C}$ ocorreu entre janeiro a março e entre outubro a dezembro. A mínima apresentou a partir de maio com $15,1^{\circ} \mathrm{C}$, permanecendo até agosto com $15,8^{\circ} \mathrm{C}$. A temperatura média apresentou em torno de $25,0^{\circ} \mathrm{C}$ entre janeiro a abril e novamente entre outubro a dezembro.

A pressão atmosférica destacou em janeiro com 949,4 hPa, com elevação a partir de maio até setembro, com picos acentuados em junho com 955,9 hPa, julho com $956,1 \mathrm{hPa}$ e agosto com $955,3 \mathrm{hPa}$, novamente com diminuição em novembro e dezembro. 

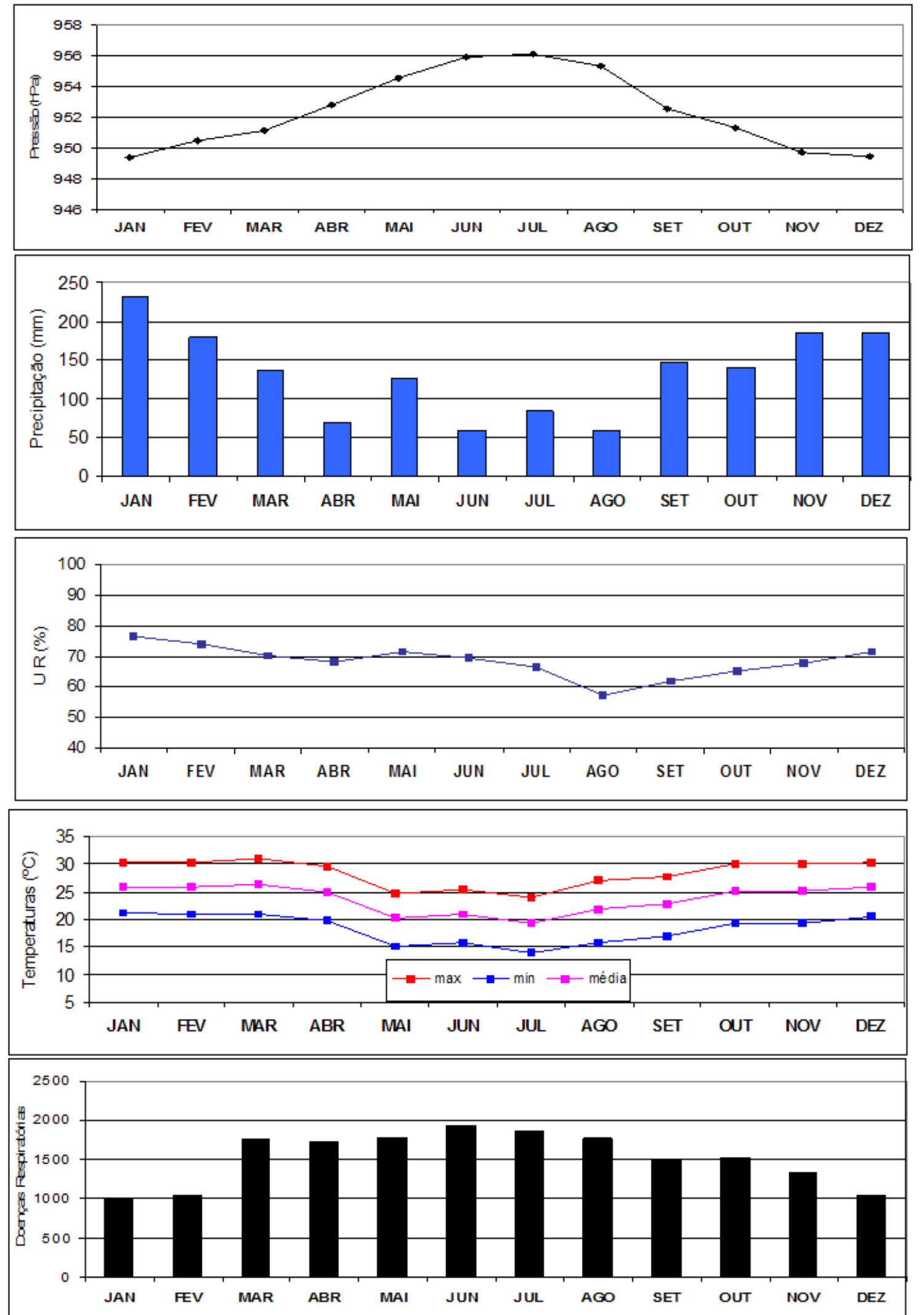

Figura 10: Médias mensais da pressão atmosférica ( $\mathrm{hPa}$ ), precipitação pluvial $(\mathrm{mm})$, umidade relativa do ar (\%), temperatura máxima, mínima e média $\left({ }^{\circ} \mathrm{C}\right)$. Número absoluto de registros de internações por doenças respiratórias. Maringá-PR, 20002007. 
Em relação ao número absoluto de registros de internações, foram 999 internações para janeiro, 1.049 em fevereiro. Essa quantidade apresentou acréscimo a partir de março, com 1.764 internações, nesse mês algumas mudanças nas características do clima passam a ocorrer, é o período de transição entre o fim de verão e inicio do outono.

Para abril foram 1.736 registros de internações, maio com 1.788, essa quantidade destacou-se em maior proporção para junho com 1.943, julho com 1.872 e agosto com 1.774 registros de internações.

Setembro é o mês de transição entre o fim do inverno e início da primavera, a quantidade de internações começaram a diminuir a partir deste mês, apresentando 1.513 registros. Em novembro foram 1.334 e dezembro com 1.039 registros.

Foram registradas 53 para janeiro, 52 para fevereiro, 50 em novembro e 54 para dezembro, aumentando a partir de março com 58 óbitos, abril com 66, maio e setembro com 59 e outubro 61 registros. Observou que a quantidade de óbitos teve acréscimo acentuado em junho com 70, julho com 82 e agosto com 72 registros, para o período de estudo.

Em Apêndices $A$ estão apresentados na Tabela $A .1$ o número absoluto mensais de internações e a Tabela A.2 apresenta o número absoluto mensais de óbitos ocorridos, para o período de estudo.

$\mathrm{Na}$ Tabela 14 está apresentada a variação sazonal das informações de temperatura máxima, mínima, média, precipitação pluvial, umidade relativa e o número absoluto dos registros das internações.

Com temperaturas altas apresentou na primavera e verão, sendo a média da máxima de $30,6^{\circ} \mathrm{C}$ e $30,1^{\circ} \mathrm{C}$. A temperatura mínima destacou-se com média de $16,7^{\circ} \mathrm{C}$ no outono e de $15,6^{\circ} \mathrm{C}$ no inverno. A precipitação pluvial com média de $547,1 \mathrm{~mm}$ no verão e 254,9 no outono. A umidade relativa do ar com média de $73 \%$ no verão e $62 \%$ no inverno.

Tabela 14: Variação sazonal: Primavera; verão; Outono; Inverno, referente à temperatura (máxima mínima e média), precipitação pluvial, umidade relativa do ar e as doenças respiratórias para Maringá-PR. 2000-2007.

\begin{tabular}{|c|c|c|c|c|c|c|}
\hline & \multicolumn{3}{|c|}{ Temperaturas ${ }^{\circ} \mathrm{C}$} & \multirow{2}{*}{$\begin{array}{c}\text { precipitação } \\
(\mathrm{mm})\end{array}$} & \multirow{2}{*}{$\begin{array}{l}\text { UR } \\
(\%)\end{array}$} & \multirow{2}{*}{$\begin{array}{c}\text { Internações } \\
\text { Doenças respiratórias }\end{array}$} \\
\hline & Máx & $\min$ & média & & & \\
\hline Primavera & 30,1 & 19,7 & 25,5 & 513,3 & 68 & 3.901 \\
\hline Verão & 30,6 & 21,0 & 26,0 & 547,1 & 73 & 3.822 \\
\hline Outono & 26,6 & 16,7 & 22,0 & 254,9 & 70 & 5.447 \\
\hline Inverno & 26,3 & 15,6 & 21,4 & 289,0 & 62 & 5.169 \\
\hline
\end{tabular}


Os maiores acréscimos de internações ocorreram no período de outono, atingindo o número de 5.447 registros e no inverno 5.169 registros Sendo para a primavera com 3.901 registros e no verão com 3.822 registros de internações.

\subsubsection{ANÁLISE RÍTMICA}

Castro (2000), Zem (2004) e Barros (2006) utilizaram da análise rítmica entre os atributos climáticos e as internações por doenças respiratórias e afirmaram que é possível atribuir o aumento de problemas respiratórios em condições de tempo provocadas pela sucessivas atuação da massa de ar Polar, no qual ocorrem diminuição da umidade relativa e variação na temperatura do ar, no outono e principalmente no inverno.

Para observar em relação a sazonalidade, a variação dos controles climáticos e as internações, tomou o mês com muitos casos de internações e o mês com menos, para o aquele mesmo ano, dentro do período de estudo.

Foi utilizado para essa análise a temperatura máxima, mínima, média, umidade relativa do ar, precipitação pluvial, pressão atmosférica, direção e velocidade do vento de 9, 15 e $21 \mathrm{~h}(12,18,00$ TMG) e os sistemas atmosféricos de 12 TMG. Conforme apresentados nas Figuras 11 a 16.

Assim, a Figura 11 está mostrando a evolução dos principais elementos do tempo, assim como os sistemas atmosférico que predominaram, ou seja, o ritmo do tempo atmosférico em Maringá, em janeiro de 2000. Durante esse mês a pressão atmosférica foi acima de 948,0 hPa, entre os dias 06 a 12, de 16 a 20, de 22 a 24 e de 27 ao dia 31.

Ocorreram dezesseis dias de precipitação pluvial, com o maior acúmulo pluvial para o dia 01 , com $90,3 \mathrm{~mm}$, entre os dias 01 a 20 choveu praticamente todos os dias. Para o dia 26 foi 2,5mm e 3,6mm no dia 31 .

A umidade relativa apresentou $49 \%$ no dia 23 , de $55 \%$ no dia 28 , de $51 \%$ no dia 29 e de 54\%, para o dia 30. Nos demais dias foi acima de $60 \%$. Com frequência a temperatura máxima foi superior a $30,0^{\circ} \mathrm{C}$, sendo de $34,2^{\circ} \mathrm{C}$ registradas no dia 16 , com temperatura média permanecendo sempre acima de $25,0^{\circ} \mathrm{C}$. 

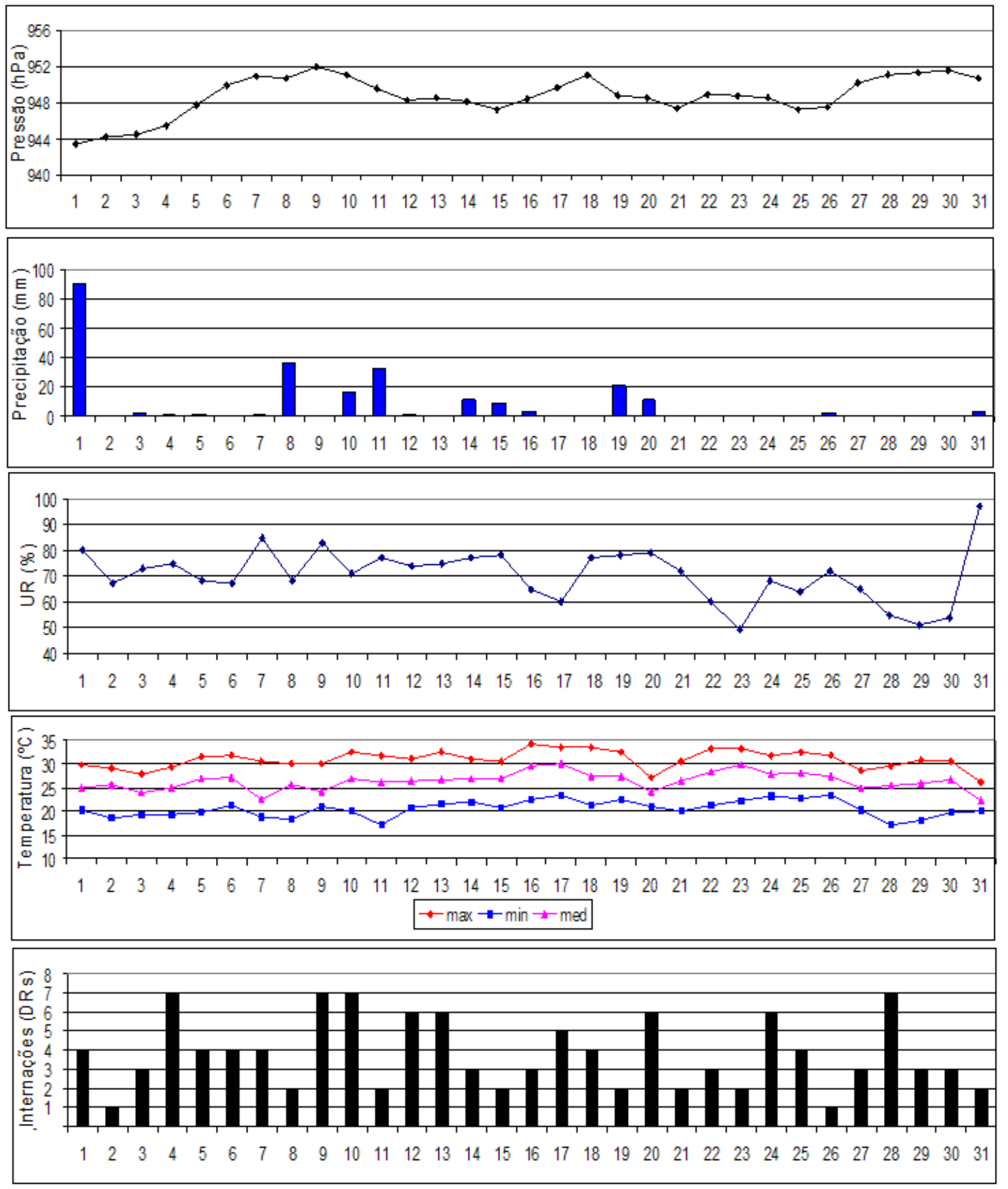

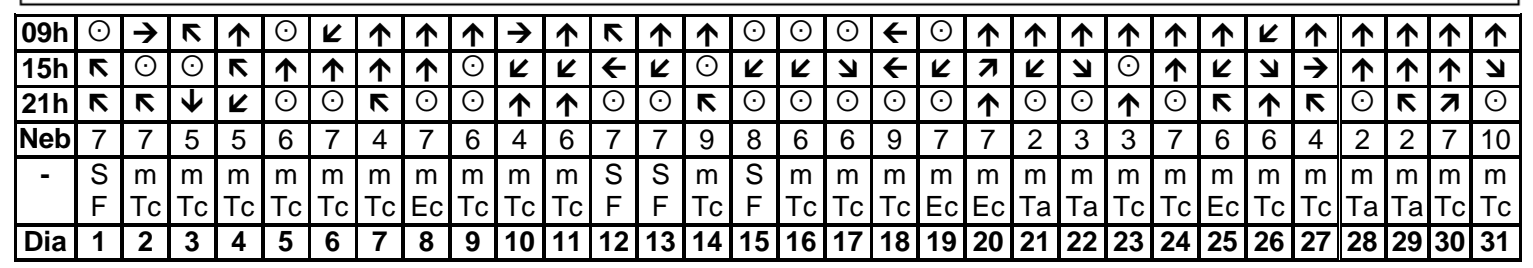

Direção Ventos: $\mathbf{m} / \mathbf{s}-\odot$ Calmo, $\boldsymbol{k} \mathrm{NE}, \leftarrow \mathrm{E}, \boldsymbol{\kappa} \mathrm{SE}, \boldsymbol{\top} \mathrm{S}, \boldsymbol{\lambda} \mathrm{SW}, \boldsymbol{\Downarrow} \mathrm{NW}, \boldsymbol{\downarrow}, \boldsymbol{\rightarrow} \mathrm{W}$.

Nebulosidade: céu claro: (0-3), céu parcialmente nublado: (4-7), céu encoberto: (8-10).

Massa de ar: massa Tropical continental (mTc), massa Tropical atlântica (mTa), massa Polar atlântica $(\mathrm{mPa})$, massa Equatorial continental $(\mathrm{mEc})$, Sistema Frontal $(\mathrm{S} / \mathrm{F})$.

Figura 11: Análise rítmica: das informações meteorológicas e o número absoluto dos registros de internações por doenças respiratórias, em janeiro de 2000. Maringá-PR. 
A temperatura mínima entre os dias 02 a 05, 07, 08, 11, 28 e 29 apresentou inferior a $20,0^{\circ} \mathrm{C}$, a menor mínima registrada foi no dia 11 , sendo de $17,2^{\circ} \mathrm{C}$. A maior amplitude térmica, que é a diferença entre a temperatura máxima e a temperatura mínima ocorreu no dia 11 , de $14,5^{\circ} \mathrm{C}$.

O vento foi predominante da direção Nordeste, com 31\% e Noroeste 11\%, $10 \%$ da direção Sudeste, 2\% Norte, 3\% Leste, 1\% Sul, 4\% Sudoeste e 3\% da direção Oeste, $27 \%$ de calmaria, com média diária de velocidade entre 0,3 a 3,0 m/s. Em relação à nebulosidade, foram cinco dias de céu claro, vinte e dois dias de céu parcialmente nublado e quatro dias de céu encoberto.

Quatro dias houve a atuação de sistemas frontais, durante o mês, sendo os dias 1, 12, 13 e 15. A massa Tropical continental foi mais intensa, predominando em dezenove dias. A massa Equatorial continental foi atuante por quatro dias e a massa Tropical atlântica atuando também por quatro dias.

Em relação às internações, observa-se que foram poucos os registros, sendo uma internação para os dias 02 e 26, duas internações, entre os dias 11, 15, 19, 21 , 23 e 31, três internações dias para os dias 03, 14, 16, 27, 29 e 30, quatro internações nos dias 01, 05, 06, 07, 18 e 25, cinco internações dia 17, seis internações no dia 12, 13, 20, 24 e sete internações nos dias 04, 09, 10 e 28. Totalizando com 118 registros e 05 óbitos.

Na Figura 12 está mostrado a evolução dos principais elementos do tempo, assim como os sistemas atmosférico que predominaram, ou seja, o ritmo do tempo atmosférico em Maringá para julho de 2000. Intensas massas de ar frio ingressaram no País, por várias vezes, causando declínio acentuado de temperatura na região Sul e parte da região Sudeste, principalmente após o dia 15.

O primeiro anticiclone frio atuou no período de 15 a 20 de julho. Este sistema teve um deslocamento pelo interior das regiões Sul e pelo sul da região CentroOeste. Durante a sua trajetória, causou declínio acentuado de temperatura, bem como, geadas para estas regiões (BOLETIM CLIMANÁLISE, 2000).

Nos dias 17, 18 e 20, ocorreram os mais fortes episódios de geadas na região Sul. No período de 24 a 27, uma nova massa de ar frio ingressou no País, provocando geada forte no dia 24 (BOLETIM CLIMANÁLISE, 2000).

Para esse mês em Maringá a pressão atmosférica foi acima de 950,0 hPa, com picos mais elevados no dia 12 , de $962,9 \mathrm{hPa}$, no dia 13 de $963,8 \mathrm{hPa}$, entre os dias 09, 10, 21, 22 variou entre 950,7 hPa a 951,6 hPa. 

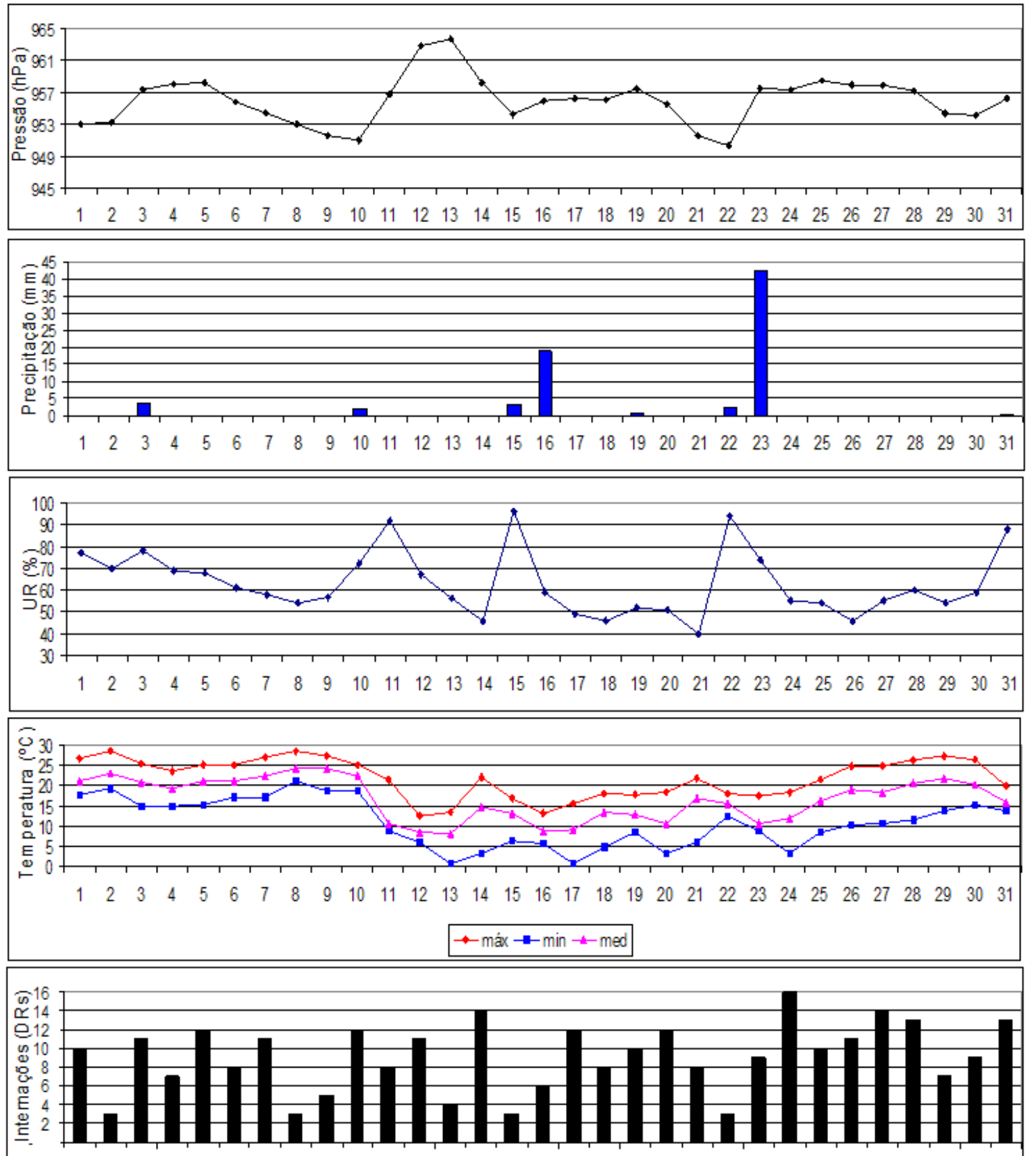

$\begin{array}{lllllllllllllllllllllllllllllll}1 & 2 & 3 & 4 & 5 & 6 & 7 & 8 & 9 & 10 & 11 & 12 & 13 & 14 & 15 & 16 & 17 & 18 & 19 & 20 & 21 & 22 & 23 & 24 & 25 & 26 & 27 & 28 & 29 & 30 & 31\end{array}$

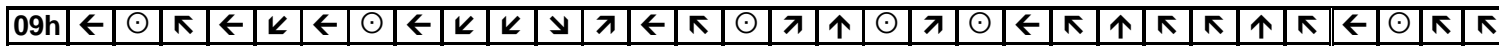

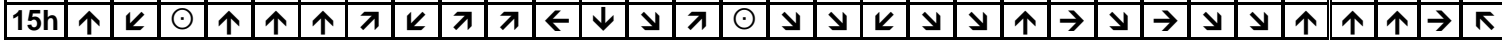

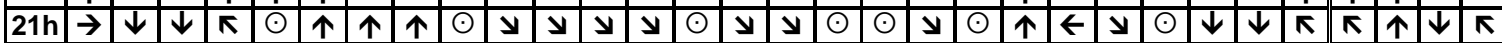

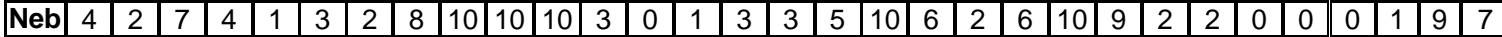

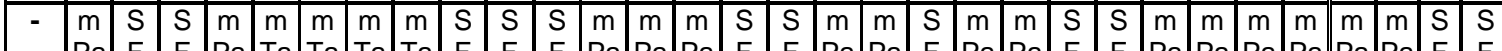

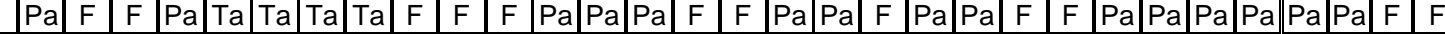

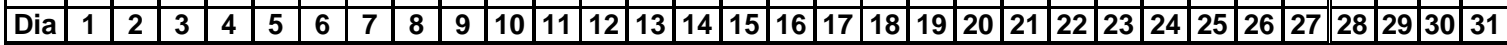

Direção dos ventos: $\mathbf{m} / \mathbf{s}-\odot$ Calmo, $\boldsymbol{k} \mathrm{NE}, \leftarrow \mathrm{E}, \boldsymbol{\kappa} \mathrm{SE}, \uparrow \mathrm{S}, \boldsymbol{\lambda} \mathrm{SW}, \boldsymbol{\nabla} \mathrm{NW}, \downarrow \mathrm{N}, \boldsymbol{\rightarrow} \mathrm{W}$.

Nebulosidade: céu claro (0-3), céu parcialmente nublado (4-7), céu encoberto (8-10).

Massa de ar: massa Tropical continental (mTc), massa Tropical atlântica (mTa), massa Polar atlântica $(\mathrm{mPa})$, massa Equatorial continental $(\mathrm{mEc})$, Sistema Frontal $(\mathrm{S} / \mathrm{F})$.

Figura 12: Análise rítmica: das informações meteorológicas e o número absoluto dos registros de internações por doenças respiratórias, em julho de 2000. Maringá-PR. 
Foram sete dias de precipitação pluvial, com o maior acúmulo pluvial para o dia 16 , com $18,8 \mathrm{~mm}$ e dia 23 com $42,1 \mathrm{~mm}$.

A umidade relativa variou entre $88 \%$ a $96 \%$ nos dias 11, 15, 22 e 31 . Entre $50 \%$ a $60 \%$ predominante para os dias $08,09,13,16,19,24,25$ e entre os dias 27 , 28 e 30. Entre 40 a 50\% foram para os dias 14, 17, 18, 21 e 26.

Foram vários dias de temperaturas baixas, principalmente entre os dias 13 a 25 de julho, totalizando oito dias de geadas, considerado um episódio atípico para Maringá, sendo este mês com mais dias de geadas registradas, desde 1976.

A temperatura média permaneceu abaixo de $15,0^{\circ} \mathrm{C}$. A temperatura máxima mais elevadas nesse mês, ocorreram para o dia 02 de $28,4^{\circ} \mathrm{C}$ e dia 07 de $28,6^{\circ} \mathrm{C}$. A média da temperatura mínima foi de $10,8^{\circ} \mathrm{C}$.

Para os dias que houve geadas, a temperatura mínima registrada foi $0,7^{\circ} \mathrm{C}$ para o dia 13 , de $3,1^{\circ} \mathrm{C}$ no dia 14 , de $0,5^{\circ} \mathrm{C}$ no dia 17 , de $4,5^{\circ} \mathrm{C}$ para o dia 18 , de $3,2^{\circ} \mathrm{C}$ no dia 20 , de $6,0^{\circ} \mathrm{C}$ no dia 21 , de $3,0^{\circ} \mathrm{C}$ no dia 24 e de $8,2^{\circ} \mathrm{C}$ para o dia 25. Maior amplitude térmica de $18,8^{\circ} \mathrm{C}$, foi registrada no dia 14.

O vento predominou da direção Sudoeste, com 19\%, as demais direções foram 16\% Nordeste, 13\% Sudeste, 4\% Norte, 11\% Leste, 9\% Sul, 4\% Noroeste e $2 \%$ Oeste, $27 \%$ de calmaria, com média diária de velocidade entre 0,3 a 2,3 m/s.

Quanto à nebulosidade, foram dezessete dias de céu claro, sete dias de céu parcialmente nublado e sete dias de céu encoberto. Por doze dias houve a atuação de sistemas frontais, sendo os dias 02 e 03, 09 a 11, 15 e 16, 19, 22 e 23, 30 e 31. A massa Polar atlântica foi predominante, com quinze dias de atuação. A massa Tropical atlântica foi atuante por quatro dias, entre os dias 05 a 08.

Em relação às internações, foram intensificadas para 0 mês todo, apresentando entre três internações nos dias $02,08,15,22$, quatro internações para o dia 13.

Para os demais dias apresentaram-se bem mais elevadas, como nos dias 14 e 27 que foram quatorze internações e dezesseis internações no dia 24, totalizando com 283 registros de internações com 10 óbitos.

$\mathrm{Na}$ Figura 13 está apresentada a evolução dos principais elementos do tempo, assim como os sistemas atmosférico que predominaram, ou seja, o ritmo do tempo atmosférico em Maringá, para janeiro de 2003. A pressão atmosférica foi 945,1 hPa no dia 05, 945,4 hPa dia 21 e de 945,8 hPa no dia 27, sendo estas os valores mais baixos, elevando-se no dia 24, para 952,7 hPa. 

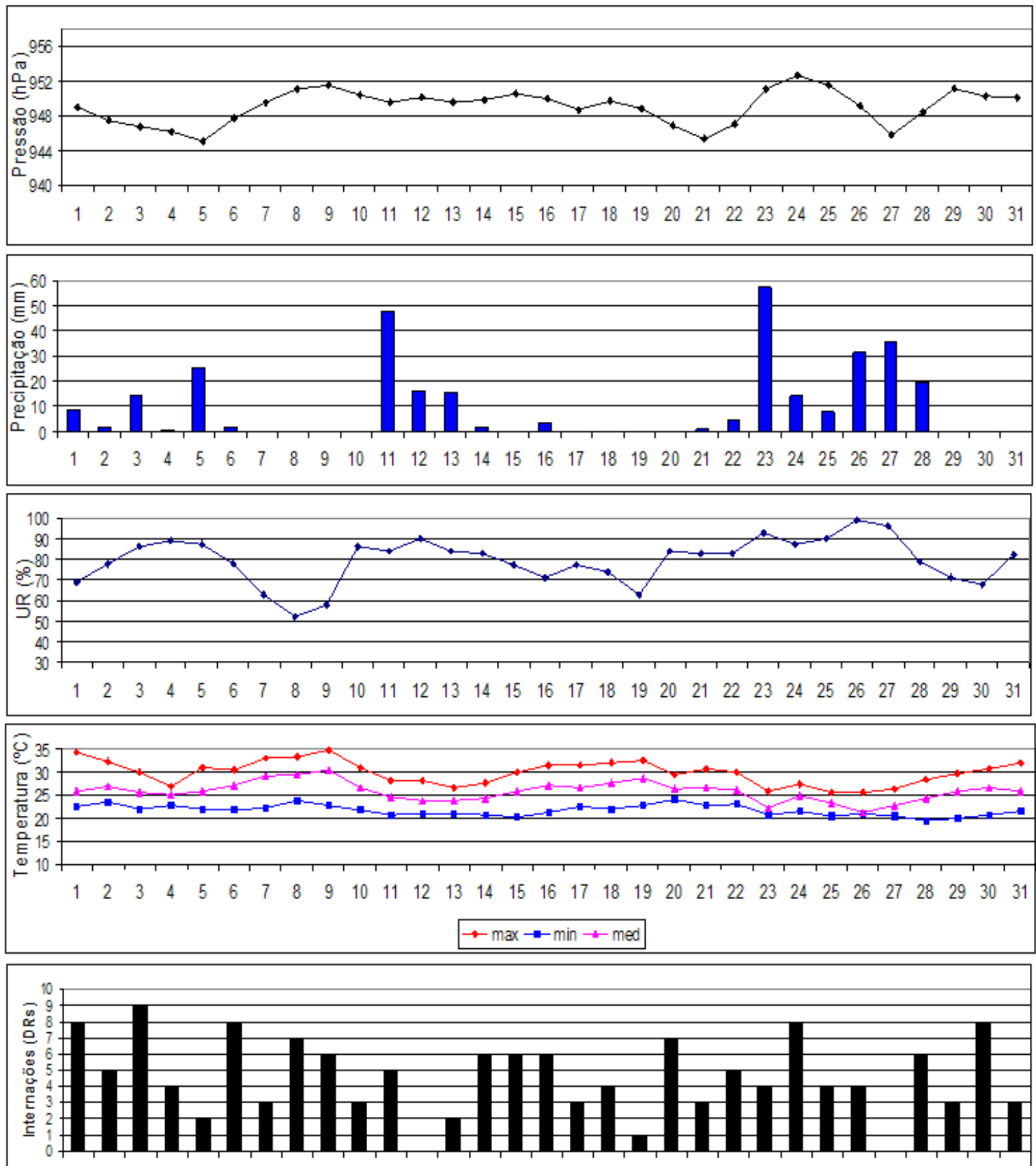

$\begin{array}{lllllllllllllllllllllllllllllll}1 & 2 & 3 & 4 & 5 & 6 & 7 & 8 & 9 & 10 & 11 & 12 & 13 & 14 & 15 & 16 & 17 & 18 & 19 & 20 & 21 & 22 & 23 & 24 & 25 & 26 & 27 & 28 & 29 & 30 & 31\end{array}$

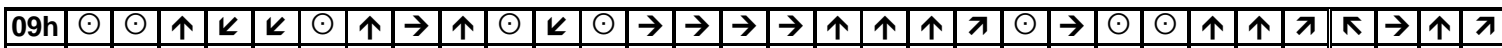

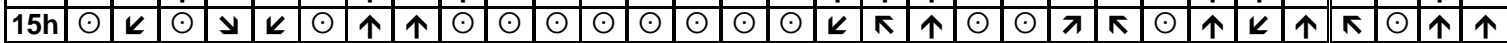

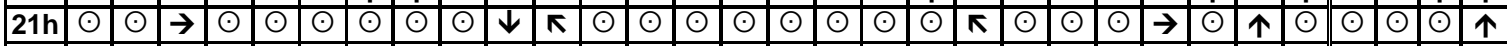
\begin{tabular}{|l|l|l|l|l|l|l|l|l|l|l|l|l|l|l|l|l|l|l|l|l|l|l|l|l|l|l|l|l|l|l|l|}
\hline Neb & 6 & 10 & 9 & 10 & 9 & 9 & 5 & 3 & 3 & 8 & 9 & 10 & 9 & 7 & 7 & 6 & 7 & 8 & 6 & 10 & 7 & 10 & 10 & 9 & 10 & 10 & 10 & 8 & 5 & 3 & 10 \\
\hline
\end{tabular}

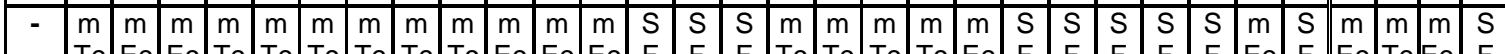

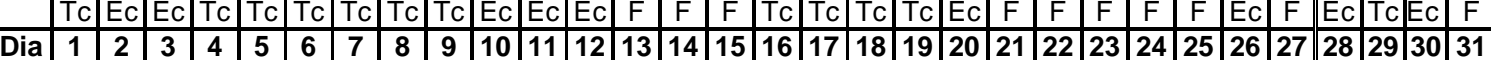

Direção dos ventos: $\mathbf{m} / \mathbf{s}-\odot$ Calmo, $\boldsymbol{k} \mathrm{NE}, \leftarrow \mathrm{E}, \boldsymbol{\kappa} \mathrm{SE}, \uparrow \mathrm{S}, \boldsymbol{\lambda} \mathrm{SW}, \boldsymbol{\Downarrow} \mathrm{NW}, \downarrow \mathrm{N}, \boldsymbol{\rightarrow} \mathrm{W}$.

Nebulosidade: céu claro: (0-3), céu parcialmente nublado: (4-7), céu encoberto: (8-10).

Massa de ar: massa Tropical continental $(\mathrm{mTc})$, massa Tropical atlântica $(\mathrm{mTa})$, massa Polar atlântica $(\mathrm{mPa})$, massa Equatorial continental $(\mathrm{mEc})$, Sistema Frontal $(\mathrm{S} / \mathrm{F})$.

Figura 13: Análise rítmica: das informações meteorológicas e o número absoluto dos registros de internações por doenças respiratórias, em janeiro de 2003. Maringá-PR. 
A precipitação pluvial foi intensa, com dezenove dias, o maior acúmulo ocorreu dia 11 de $48,2 \mathrm{~mm}$ e dia $23 \mathrm{com} 57,4 \mathrm{~mm}$. A umidade relativa com frequência permaneceu acima de $70 \%$, inferior a $60 \%$ ocorrendo no dia 08 , com $52 \%$ e o dia 09 com $58 \%$.

A temperatura média normalmente foi acima de $25,0^{\circ} \mathrm{C}$. A temperatura máxima alta ocorreu no dia $01 \mathrm{com} 34,3^{\circ} \mathrm{C}$ e dia $09 \mathrm{com} 34,8^{\circ} \mathrm{C}$. A temperatura mínima mais baixa foi registrada no dia 28 de $19,5^{\circ} \mathrm{C}$. A maior amplitude térmica foi de $12,0^{\circ} \mathrm{C}$ ocorrida no dia 09.

Em relação à nebulosidade, foram três dias de céu claro, nove dias de céu parcialmente nublado e dezenove dias de céu encoberto. Durante o mês predominou a massa Tropical continental com doze dias de atuação, dez dias de atuação dos sistemas frontais e nove dias com predomínio da massa Equatorial continental.

O vento foi predominante da direção Nordeste com 18\%, demais 9\% Leste, $6 \%$ Sudeste, $7 \%$ Noroeste, $4 \%$ Norte, $1 \%$ Sul e Sudoeste, com $47 \%$ de calmaria, a velocidade média diária entre 0,3 a 1,3 m/s. Em relação às doenças respiratórias, variam entre uma internação para o dia 19 e de nove internações no dia 03. Inclusive apresentou para o dia 12 e 27 sem nenhuma internação. Nesse mês foram registradas 143 internações e apenas 01 óbito.

$\mathrm{Na}$ Figura 14 está apresentada a evolução dos principais elementos do tempo, assim como os sistemas atmosférico que predominaram, ou seja, o ritmo do tempo atmosférico em Maringá, para junho de 2003.

Segundo o Boletim Climanálise (2003) as massas de ar frio que ingressaram no Sul do país, causaram o registro de geadas de intensidade moderada a fraca na região Sul, Sudeste e precipitação de neve fraca em santa Catarina.

Para esse mês em Maringá, a pressão atmosférica mais baixa foi registrada no dia 03 de 951,7 hPa, para os demais dias permaneceu acima de 952,0 hPa, sendo de 957,9 hPa para o dia 24, de 957,5 hPa dia 25 e de 957,1 hPa no dia 30.

Foram apenas três dias de precipitação pluvial, sendo de $27,2 \mathrm{~mm}$ dia 04 , de $29,5 \mathrm{~mm}$ dia 05 e de $2,0 \mathrm{~mm}$ dia 06 . A temperatura média variou entre $18,4^{\circ} \mathrm{C}$ a $25,1^{\circ} \mathrm{C}$. A temperatura máxima foi alta no dia $01,02,07,10,12,14,18$ e 20 , variando entre $28,1^{\circ} \mathrm{C}$ a $28,7^{\circ} \mathrm{C}$, a partir do dia 20 a temperatura mínima permaneceu entre baixa $13,7^{\circ} \mathrm{C}$ a $15,8^{\circ} \mathrm{C}$. A maior amplitude térmica foi de $14,6^{\circ} \mathrm{C}$, registrada no dia 20. 

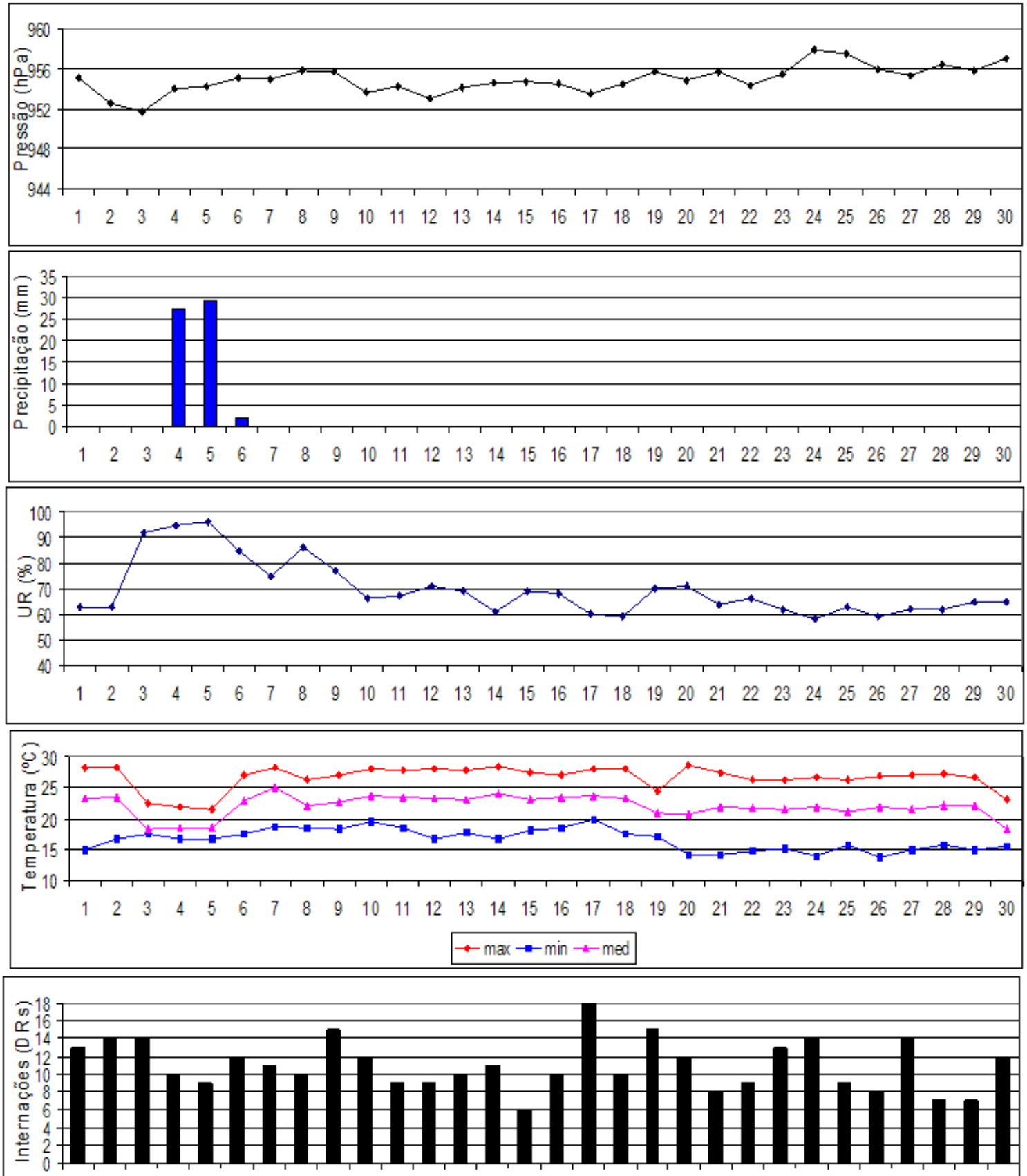

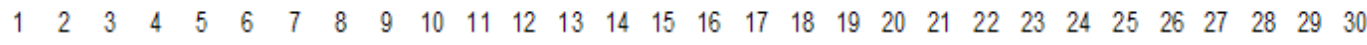

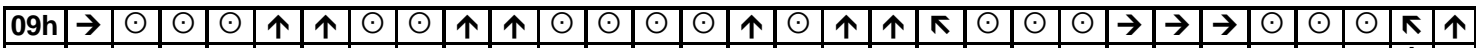

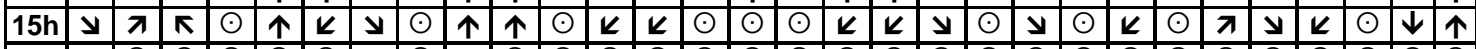

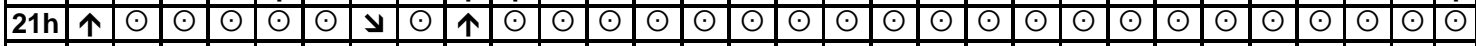
\begin{tabular}{|l|l|l|l|l|l|l|l|l|l|l|l|l|l|l|l|l|l|l|l|l|l|l|l|l|l|l|l|l|l|l|}
\hline Neb & 3 & 0 & 10 & 10 & 9 & 8 & 6 & 8 & 4 & 2 & 5 & 5 & 7 & 1 & 3 & 8 & 5 & 2 & 3 & 0 & 2 & 4 & 0 & 3 & 3 & 4 & 0 & 8 & 4 & 4 \\
\hline
\end{tabular}

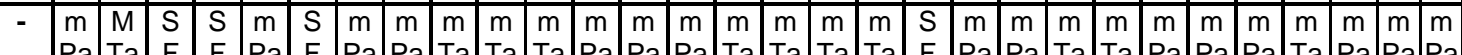

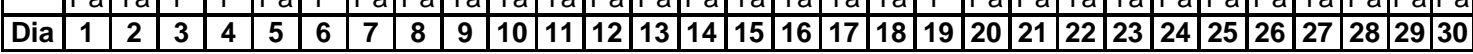

Direção dos ventos: $\mathbf{m} / \mathbf{s}-\odot$ Calmo, $\boldsymbol{k} \mathrm{NE}, \leftarrow \mathrm{E}, \boldsymbol{\kappa} \mathrm{SE}, \uparrow \mathrm{S}, \boldsymbol{\lambda} \mathrm{SW}, \boldsymbol{\Downarrow} \mathrm{NW}, \downarrow \mathrm{N}, \boldsymbol{\rightarrow} \mathrm{W}$.

Nebulosidade: céu claro: (0-3), céu parcialmente nublado: (4-7), céu encoberto: (8-10).

Massa de ar: massa Tropical continental $(\mathrm{mTc})$, massa Tropical atlântica (mTa), massa Polar atlântica $(\mathrm{mPa})$, massa Equatorial continental $(\mathrm{mEc})$, Sistema Frontal $(\mathrm{S} / \mathrm{F})$.

Figura 14: Análise rítmica: das informações meteorológicas e o número absoluto dos registros de internações por doenças respiratórias, em junho de 2003. Maringá-PR. 
A umidade relativa apresentou acima de $70 \%$ entre os dias 03 a 09 , de $60 \%$ no dia 17 , de $59 \%$ dia 18 e 26 , de $58 \%$ para o dia 24 . Em relação a nebulosidade, foram treze dias de céu claro, onze dias de céu parcialmente nublado e seis dias de céu encoberto.

O vento foi predominante da direção Nordeste com 14\%, Noroeste 8\%, 5\% de Sudoeste, $2 \%$ Norte, $4 \%$ Leste, $3 \%$ da direção Sul e Sudeste, 53\% de calmaria. A velocidade média variou de 0,3 a 1,3 $\mathrm{m} / \mathrm{s}$.

Durante esse mês em Maringá, houve a atuação de quatro dias de sistemas frontais, sendo os dias 03, 04, 06 e 19, onze dias com a atuação da massa Tropical atlântica e predominou a massa Polar atlântica, com quinze dias de participação.

Em relação às internações, foram registradas 331 internações com 07 óbitos. Os dados diários apresentaram elevação, apenas em menor quantidade sendo de sete internações para os dias 28 e 29, os demais dias variando de dez internações para os dias $04,13,16,18$, dezesseis internações no dia 15 e de dezoito para o dia 17.

Na Figura 15 está apresentada a evolução dos principais elementos do tempo, assim como os sistemas atmosférico que predominaram, ou seja, o ritmo do tempo atmosférico em Maringá, para janeiro de 2007.

Em relação a pressão atmosférica na maioria dos dias do mês foi acima de 948,0 hPa, apresentando mais baixa dia 05 de 943,6 hPa, dia 06 de 944,4 hPa e dia 13 de 943,5 hPa. A precipitação pluvial foi intensa, apresentando dezoito dias com chuva, inclusive entre os dias 01 a 09 choveu todos os dias, sendo o maior acúmulo de $66,4 \mathrm{~mm}$ para o dia 14 e de $38,8 \mathrm{~mm}$ para o dia 20 .

A umidade relativa nesse mês foi acima de $70 \%$ na maioria dos dias, sendo de $67 \%$ no dia 15 e de $57 \%$, no dia 16 . A temperatura máxima mais alta ocorreu no dia 10 de $31,4^{\circ} \mathrm{C}$, dia 16 de $31,2^{\circ} \mathrm{C}$, dia 19 de $32,5^{\circ} \mathrm{C}$, dia 25 de 31,6 e dia 30 de $32,3^{\circ} \mathrm{C}$. A menor mínima ocorreu no dia 23 de 19,4ํㅡ. A temperatura média com frequência foi acima de $25,0^{\circ} \mathrm{C}$. A maior amplitude térmica foi de $10,9^{\circ} \mathrm{C}$ ocorridas no dia 23 e dia 30.

Quanto a nebulosidade, foi apenas um dia de céu claro, nove dias de céu parcialmente nublado, vinte e um dias com o céu encoberto. A direção predominantemente foi de Nordeste com 29\%, 10\% de Sudoeste e Noroeste, 4\% de Norte, $9 \%$ de Leste, $2 \%$ de Sul e Sudeste, $3 \%$ da direção Oeste, $24 \%$ de calmaria. A velocidade média variou de 0,3 a $1,3 \mathrm{~m} / \mathrm{s}$. 

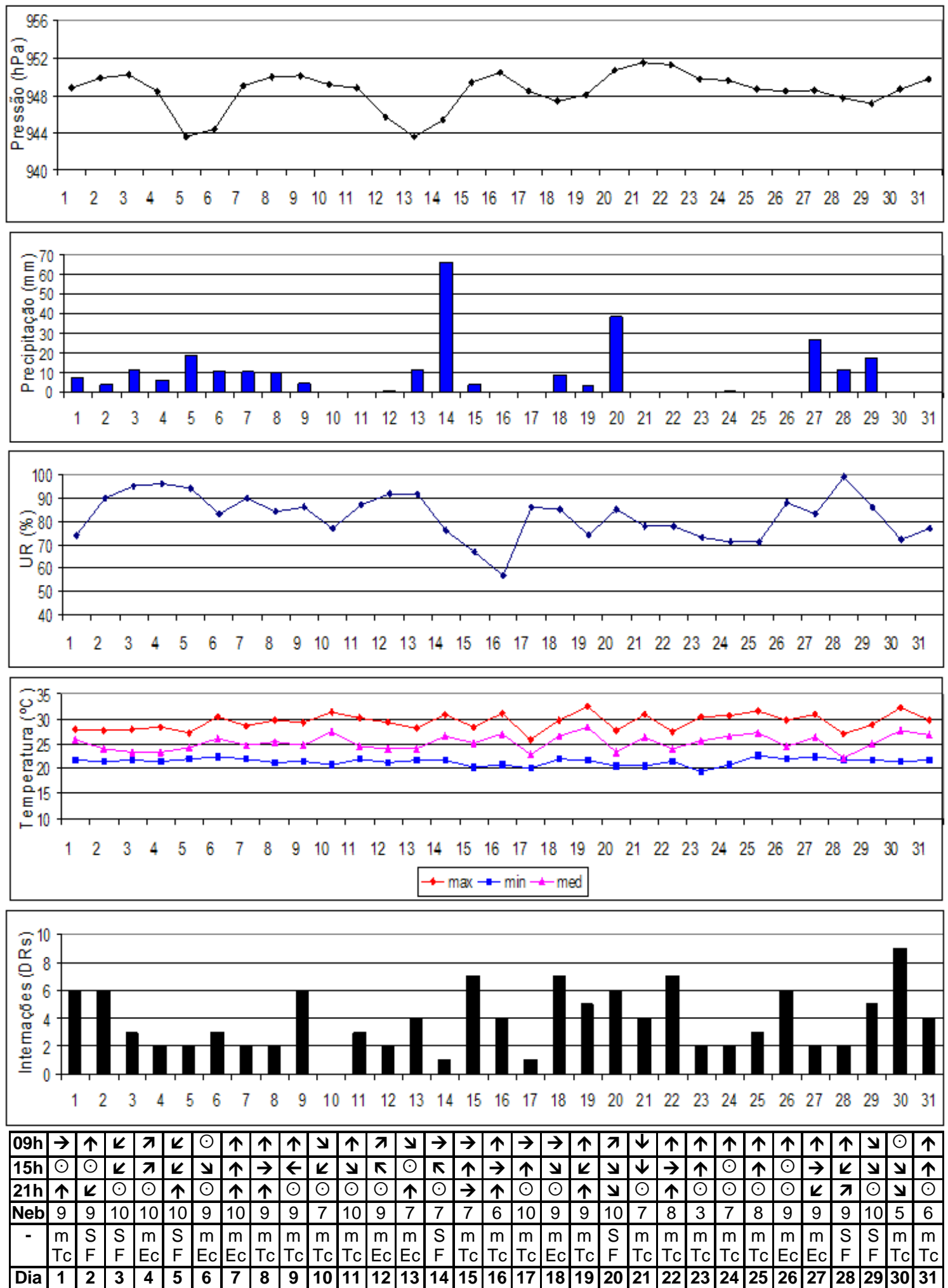

Direção dos ventos: $\mathbf{m} / \mathbf{s}-\odot$ Calmo, $\boldsymbol{k} \mathrm{NE}, \leftarrow \mathrm{E}, \boldsymbol{\kappa} \mathrm{SE}, \uparrow \mathrm{S}, \boldsymbol{\lambda} \mathrm{SW}, \boldsymbol{\nabla} \mathrm{NW}, \downarrow \mathrm{N}, \boldsymbol{\rightarrow} \mathrm{W}$.

Nebulosidade: céu claro: (0-3), céu parcialmente nublado: (4-7), céu encoberto (8-10).

Massa de ar: massa Tropical continental (mTc), massa Tropical atlântica (mTa), massa Polar atlântica $(\mathrm{mPa})$, massa Equatorial continental $(\mathrm{mEc})$, Sistema Frontal $(\mathrm{S} / \mathrm{F})$.

Figura 15: Análise rítmica: das informações meteorológicas e o número absoluto dos registros de internações por doenças respiratórias, em janeiro de 2007. Maringá-PR. 
Durante esse mês em Maringá, o sistema frontal atuou sete dias, oito dias foi por atuação da massa Equatorial continental, predominando a massa Tropical continental, com dezesseis dias.

Em relação às doenças respiratórias, nesse mês foram registradas 118 internações com 08 óbitos. Os dados diários mostraram para o dia 10 sem nenhuma internação, com uma internação para o dia 14 e 17. Predominaram entre duas a três registros de internações na maior parte do mês. Sendo de sete internações nos dias 15, 18 e 22. Com nove internações no dia 30.

$\mathrm{Na}$ Figura 16 está mostrada a evolução dos principais elementos do tempo, assim como os sistemas atmosférico que predominaram tais condições, ou seja, o rítimo do tempo atmosférico em Maringá em junho de 2007.

Conforme o Boletim Climanálise (2007) durante esse mês foram seis massas de ar frio ingressante no País, sendo quatro mais intensas que proporcionaram acentuado declínio de temperatura mínima, na região Sul do Brasil.

Em Maringá a pressão atmosférica apresentou elevada de 957,0 hPa no dia 03 a 958,9 hPa no dia 30, baixa de 951,7 hPa no dia 01 e 14, de 952,1 hPa no dia 15. A precipitação pluvial foi bem escassa, apresentando apenas dois dias de chuva, sendo de 7,5mm para o dia 02 e 0,3mm para o dia 27.

A umidade relativa inferior a $60 \%$ foi predominante por dezenove dias, inclusive no dia 12,13 e 20 foi de $49 \%$. A temperatura média variou de $24,0^{\circ} \mathrm{C}$ no dia 03 a $24,6 \circ \mathrm{C}$ no dia 18.

A temperatura máxima atingiu $30,0^{\circ} \mathrm{C}$ no dia 18 . A temperatura mínima de $9,7^{\circ} \mathrm{C}$ dia 03 , de $6,8^{\circ} \mathrm{C}$ dia 04 , de $7,3^{\circ} \mathrm{C}$ dia 05 e de $9,6^{\circ} \mathrm{C}$ no dia 29 . A maior amplitude térmica foi de $15,7^{\circ} \mathrm{C}$, dia 05 .

Quanto a nebulosidade foram dez dias de céu claro, dezessete dias de céu parcialmente nublado e três dias de céu encoberto. A direção dos ventos foi predominante da direção Nordeste com 34\%, $4 \%$ de Norte e Oeste, $7 \%$ leste e Noroeste, $3 \%$ Sudeste, $2 \%$ Sul e $8 \%$ da direção Sudoeste, $21 \%$ de calmaria. A velocidade média variou de 0,3 a $1,7 \mathrm{~m} / \mathrm{s}$.

Durante esse mês em Maringá, houve a atuação de cinco dias sob o domínio dos sistemas frontais, foram os dias $02,15,23,24$, e 27 , oito dias de atuação da massa Tropical atlântica e a massa Polar atlântica, predominou com dezessete dias. 

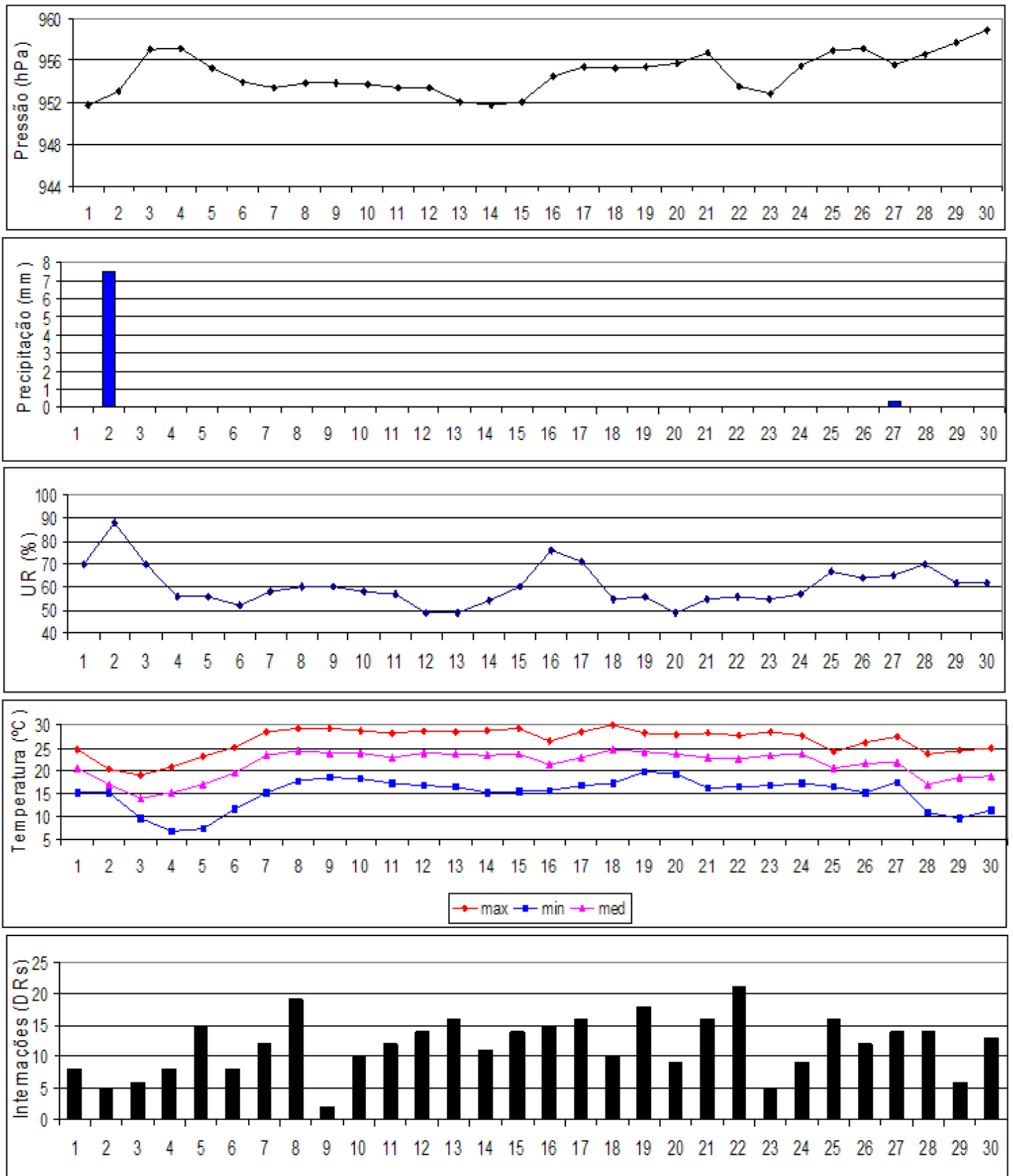

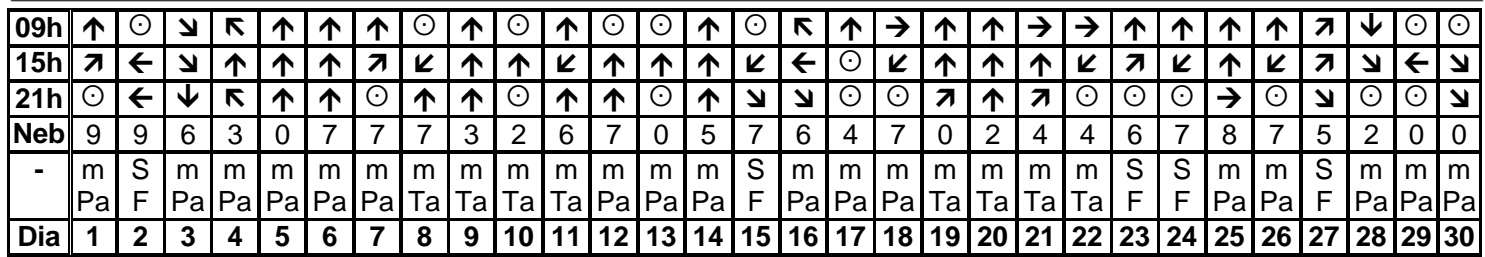

Direção dos ventos: $\mathbf{m} / \mathbf{s}-\odot$ Calmo, $\boldsymbol{k} \mathrm{NE}, \leftarrow \mathrm{E}, \boldsymbol{\kappa} \mathrm{SE}, \uparrow \mathrm{S}, \boldsymbol{\lambda} \mathrm{SW}, \boldsymbol{\nabla} \mathrm{NW}, \boldsymbol{\downarrow} \mathrm{N}, \boldsymbol{\rightarrow} \mathrm{W}$.

Nebulosidade: céu claro: (0-3), céu parcialmente nublado: (4-7), céu encoberto: (8-10).

Massa de ar: massa Tropical continental $(\mathrm{mTc})$, massa Tropical atlântica (mTa), massa Polar atlântica $(\mathrm{mPa})$, massa Equatorial continental $(\mathrm{mEc})$, Sistema Frontal $(\mathrm{S} / \mathrm{F})$.

Figura 16: Análise rítmica: das informações meteorológicas e o número absoluto dos registros de internações por doenças respiratórias, em junho de 2007. Maringá-PR. 
Em relação às internações por doenças respiratórias, foram registradas 354 internações com 08 óbitos. Os registros diários apresentaram muito elevado. A menor quantidade foi registrada no dia 09, com duas internações, para os dias $02 \mathrm{e}$ 23 foram cinco internações.

Nos demais dias houve acréscimo acentuado, com dez internações para o dia 10, doze internações para os dias $07,11,26$, treze internações para o dia 13 , quatorze internações no dia 12, 15, 27 e 28.

Ocorreram quinze internações nos dias 05 e 16, dezesseis internações nos dias $13,17,21$, e 25 , dezoito no dia 19 , dezenove no dia 08 , vinte e uma internações para o dia 22.

\subsubsection{ANÁLISE DE CONFORTO TÉRMICO (DE HORA EM HORA).}

Ao estudar a variação dos tipos de tempo na Região Metropolitana de São Paulo e sua influência na sensação térmica, no ano padrão de 1996, Funari (2006, p. 9), definiu que no verão não houve, na prática desconforto, já para o inverno, apenas na parte da tarde ocorreram alguns poucos dias com conforto, na maioria dos dias de inverno houve desconforto ou resfriamento.

Para os mesmos meses da análise, fez-se a análise de conforto ou desconforto térmico, de hora em hora, foram utilizadas as informações de temperatura do termômetro de bulbo seco e úmido, para calcular o índice de conforto térmico e encontrar o valor da Temperatura Efetiva (TE).

Analisou em conjunto a temperatura e a umidade relativa do ar, haja visto que, esses fatores são contribuintes para a sensação de bem estar. Em seguida procurou associar essas informações com o número absoluto de internações diárias.

O termômetro de bulbo úmido possui a sua base envolvida em uma gaze porosa e mergulhada em um recipiente contendo água destilada. Essa água faz com que a temperatura medida seja mais baixa que a temperatura medida pelo termômetro de bulbo seco, através da leitura obtida por esses dois termômetros e utilizando-se da Tabela psicrométrica, encontra-se a umidade relativa do ar no momento. 
Como consequência, define-se que, quanto mais seco o ar atmosférico estiver, maior a evaporação da água destilada em volta do bulbo. Se o ar estiver saturado a evaporação da água do bulbo será praticamente nula. Esse fato é idêntico ao que ocorre quando as pessoas transpiram, se o ar está muito seco e quente, a transpiração é evaporada rapidamente, mas se o ar estiver com muita umidade o suor ficará a superfície da pele.

Assim, as Figuras 17 a 22 apresentam as informações da temperatura do ar, da umidade relativa do ar e da temperatura efetiva, bem como as internações diárias e o sistema atmosférico atuante.

No qual o eixo vertical (esquerdo) indica as horas e no eixo horizontal os dias do mês, sendo possível acompanhar a situação da temperatura, da umidade, da temperatura efetiva, em diferentes horários do dia. Os valores apresentados não unirão as mesmas informações encontradas e sim os horários de igual informação.

Na Figura 17 está apresentada os dados diários referente ao mês de janeiro de 2000, em relação à temperatura do ar, observa que de 01h00min até 09h00min e após $22 \mathrm{~h} 00 \mathrm{~min}$, encontra-se entre $17,0^{\circ} \mathrm{C}$ a $23,0^{\circ} \mathrm{C}$. Entre $12 \mathrm{~h} 00 \mathrm{~min}$ até $18 \mathrm{~h} 00 \mathrm{~min}$, variando de $29,0^{\circ} \mathrm{C}$ a $34,2^{\circ} \mathrm{C}$.

A umidade relativa do ar, com frequência foi superior a $60 \%$, já entre $15 \mathrm{~h} 00 \mathrm{~min}$ até $18 \mathrm{~h} 00 \mathrm{~min}$ apresentou inferior a 55\%, inclusive para os dias 28 e 29 a umidade do ar foi abaixo de $50 \%$ em todos os horários do dia deste mês.

Para a temperatura efetiva, de maneira geral, foi predominantemente para faixa de conforto térmico, entre $19,0^{\circ} \mathrm{C}$ a $25,5^{\circ} \mathrm{C}$, Apresentando entre $10 \mathrm{~h} 00 \mathrm{~min}$ a 20h00min, como condição de desconforto ao calor, com a TE superior a $25,6^{\circ} \mathrm{C}$.

Houve uma pequena faixa considerada de desconforto ao frio, com a temperatura efetiva abaixo de $18,9^{\circ} \mathrm{C}$, por volta de $06 \mathrm{~h} 00 \mathrm{~min}$ no dia 03, para 07h00min do dia 26 e entre 03h00min e 07h00min nos dias 28, 29 e 30.

Essa faixa de conforto aconteceu devido o período mais frio do dia ocorrer pouco antes do nascer do sol, a superfície do planeta ainda está irradiando o calor recebido no dia anterior, favorecendo ao surgimento de uma pequena faixa de temperatura efetiva de desconforto, mesmo durante o verão.

A Terra recebe maior radiação solar ao meio do dia, porém até a superfície absorver essa luz e transformar em calor, até a 1,5m do solo demora um certo tempo, esse motivo favorece a ocorrência de temperatura máxima seguidas por menor umidade relativa do ar, principalmente entre $14 \mathrm{~h} 00 \mathrm{~min}$ a $16 \mathrm{~h} 00 \mathrm{~min}$. 

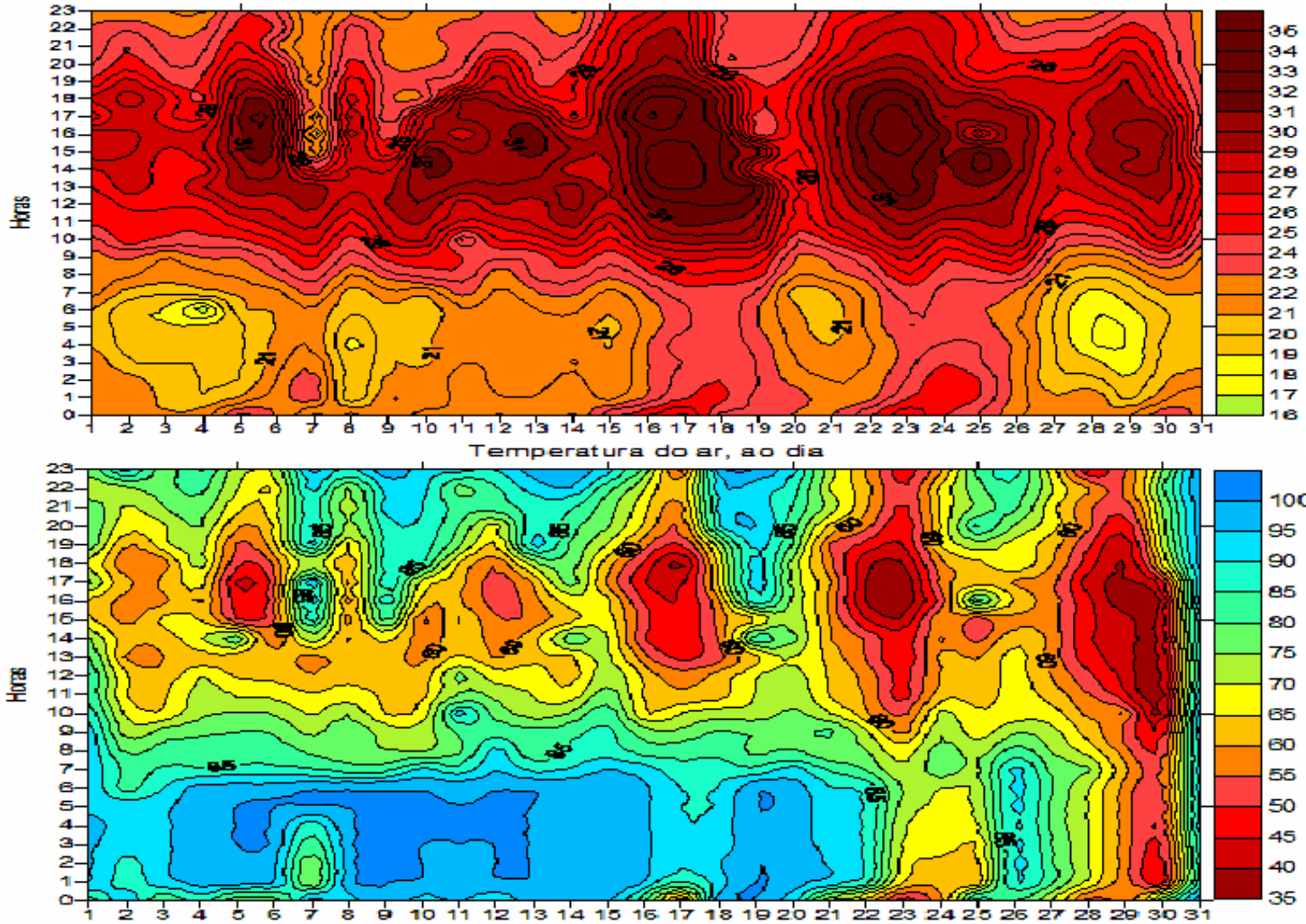
umidede reletive do er, eo die
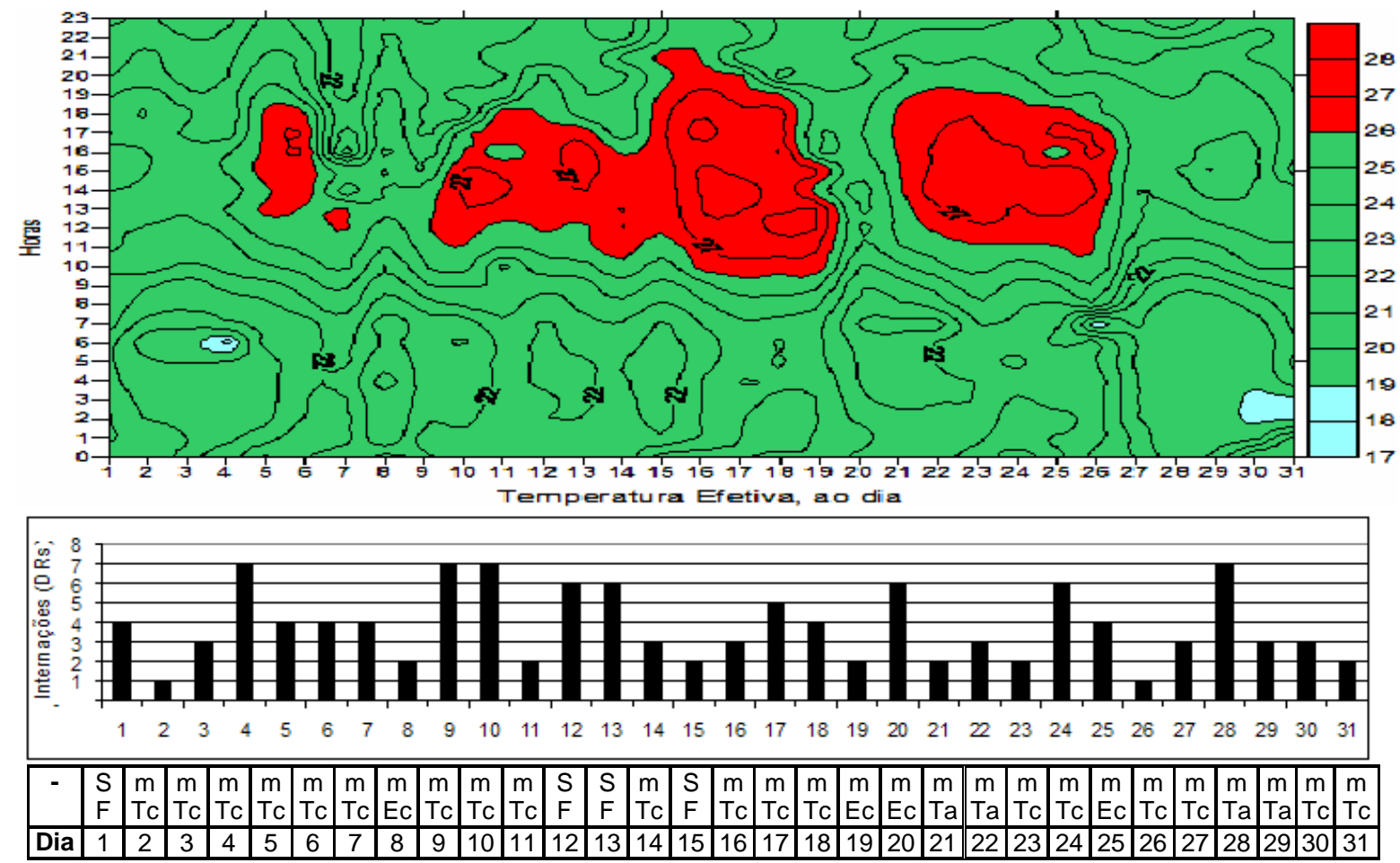

Temperatura Efetiva $(\mathrm{TE})=$ inferior a $18,9^{\circ} \mathrm{C}$ é considerada como condição de desconforto ao frio, (azul). $\mathrm{TE}=19,0^{\circ} \mathrm{C}$ a $25,5^{\circ} \mathrm{C}$, faixa de conforto térmico, (verde), $\mathrm{TE}=$ superior a $25,6^{\circ} \mathrm{C}$ significa condição de desconforto ao calor, (vermelho).

Figura 17: Variação diária da temperatura do ar, da umidade relativa do ar e da Temperatura Efetiva (TE), das massas de ar atuantes e as internações (DRs), em janeiro de 2000. Maringá-PR. 
A temperatura mais elevada continua durante o inicio da noite, pois a superfície terrestre ainda está irradiando o calor recebido pela insolação durante o dia.

Na Figura 18, está apresentada os dados diários referente ao mês de julho de 2000, a temperatura do ar, para os dias 01 a 09 houve variação entre $17,0^{\circ} \mathrm{C}$ a $23,0^{\circ} \mathrm{C}$, nos horários de 01h00min até por volta de 11h00min e novamente após $19 \mathrm{~h} 00 \mathrm{~min}$. Acima de $26,0^{\circ} \mathrm{C}$ entre $12 \mathrm{~h} 00 \mathrm{~min}$ a $18 \mathrm{~h} 00 \mathrm{~min}$.

Após dia 10 deste mês, a massa de ar polar foi predominante, as temperaturas permaneceram extremamente baixas, de $1,0^{\circ} \mathrm{C}$ a $9,0^{\circ} \mathrm{C}$ entre 01 h00min até $11 \mathrm{~h} 00 \mathrm{~min}$ e logo após $18 \mathrm{~h} 00 \mathrm{~min}$, sendo de $11,0^{\circ} \mathrm{C}$ a $17,0^{\circ} \mathrm{C}$ entre $12 \mathrm{~h} 00 \mathrm{~min}$ a $17 \mathrm{~h} 00 \mathrm{~min}$. Para os dias 26 a 31 , as temperaturas foram acima de 26,0ํ nos horários de 12 h00min a 17h00min.

A umidade relativa do ar permaneceu baixa praticamente o mês inteiro, com frequência esteve entre $20 \%$ a $45 \%$, principalmente entre $12 \mathrm{~h} 00 \mathrm{~min}$ a $19 \mathrm{~h} 00 \mathrm{~min}$. Com 90\% de umidade ocorreu para alguns horários nos dias 03, 11 e 23.

A temperatura efetiva, predominou para a condição de desconforto ao frio, inferior a $18,9^{\circ} \mathrm{C}$ em todos os horários, entre os dias 11 a 25 . Apenas entre os dias 01 a 09, houve faixa de conforto térmico, principalmente após 09h00min no dia 26 entre 13h00min a 18h00min e no dia 27 a 30 nos horários de 11 h00min a 20h00min.

Na Figura 19 está apresentada os dados diários referente ao mês de janeiro de 2003. Em relação a temperatura do ar, apresentou de $19,0^{\circ} \mathrm{C}$ a $23,0^{\circ} \mathrm{C}$, nos horários de 01h00min a 08h00min. Já de 09h00min até 18h00min foram elevadas, principalmente entre $11 \mathrm{~h} 00 \mathrm{~min}$ permanecendo até $17 \mathrm{~h} 00 \mathrm{~min}$, com variação em torno de $28,0^{\circ} \mathrm{C}$ a $34,8^{\circ} \mathrm{C}$.

A umidade relativa do ar predominou acima de $60 \%$ em todos os horários deste mês. Com 55\% de umidade foram encontrados nos dias 01, 18, 19, 30 e 31, para os horários entre $12 \mathrm{~h} 00 \mathrm{~min}$ a $18 \mathrm{~h} 00 \mathrm{~min}$. Destacou de $30 \%$ a $50 \%$ apenas nos dias 08 e 09, nos horários de 09h00min até 18h00min.

Em relação a temperatura efetiva, foi predominante para a situação considerada de faixa de conforto térmico, entre $19,0^{\circ} \mathrm{C}$ a $25,5^{\circ} \mathrm{C}$. Para a condição de desconforto ao calor, com a TE acima de $25,6^{\circ} \mathrm{C}$ ocorreu nos dias 01 nos horários entre 09h00min a 16h00min e dia 03 de 13h00min a 16h00min. 

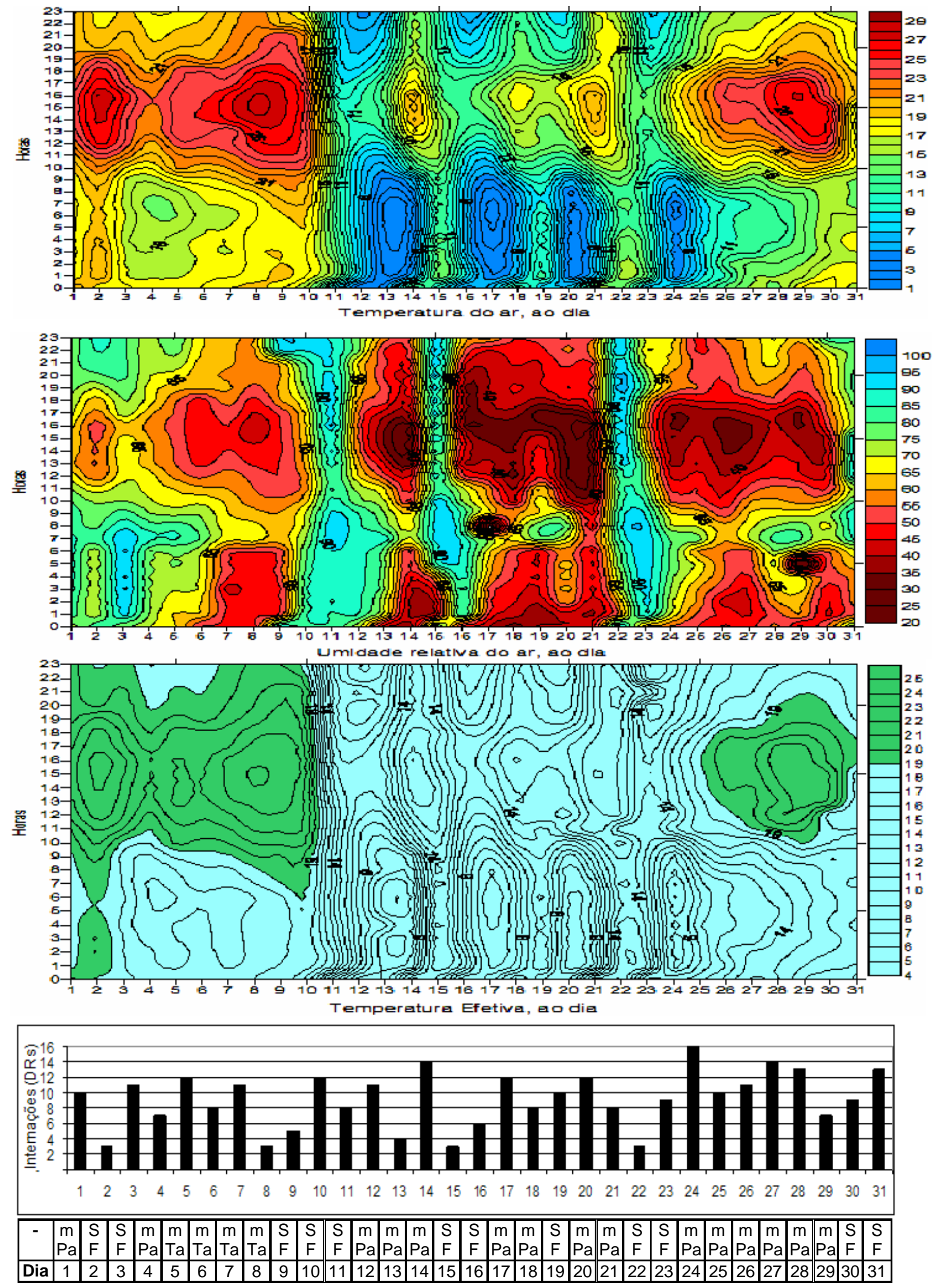

Temperatura Efetiva $(\mathrm{TE})=$ inferior a $18,9^{\circ} \mathrm{C}$ é considerada como condição de desconforto ao frio, (azul). $\mathrm{TE}=19,0^{\circ} \mathrm{C}$ a $25,5^{\circ} \mathrm{C}$, faixa de conforto térmico, (verde), $\mathrm{TE}=$ superior a $25,6^{\circ} \mathrm{C}$ significa condição de desconforto ao calor, (vermelho).

Figura 18: Variação diária da temperatura do ar, da umidade relativa do ar e da Temperatura Efetiva (TE), das massas de ar atuantes e as internações (DRs), em julho de 2000. Maringá-PR. 

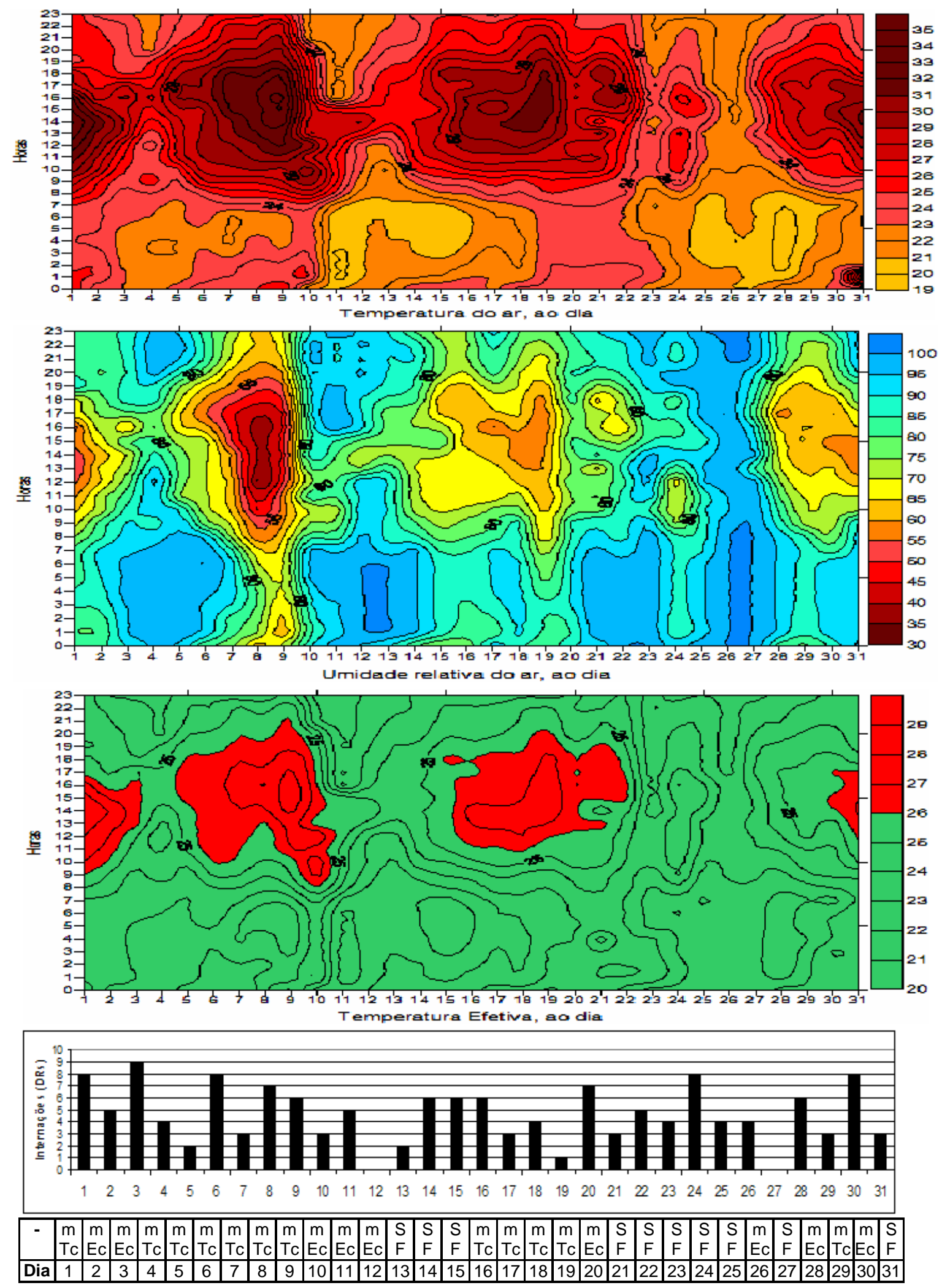

Temperatura Efetiva TE $=$ inferior a $18,9^{\circ} \mathrm{C}$ é considerada como condição de desconforto ao frio, (azul), (TE) = 19,0ㅇ a $25,5^{\circ} \mathrm{C}$, faixa de conforto térmico, (verde), $\mathrm{TE}=$ superior a $25,6^{\circ} \mathrm{C}$ significa condição de desconforto ao calor, (vermelho).

Figura 19: Variação diária da temperatura do ar, da umidade relativa do ar e da temperatura efetiva (TE), das massas de ar atuantes e as internações (DRs), em janeiro de 2003. Maringá-PR. 
Novamente, entre os dias 05 a 10, nos horários entre 10h00min a 20h00min. A partir do dia 16 a 21, nos horários entre 11h00min a 19h00min e no dia 31 entre 11 h00min a 19h00min, principalmente. FIGURA 19.

Na Figura 20 está apresentada os dados diários referente ao mês de junho de 2003 , a temperatura do ar esteve entre $13,0^{\circ} \mathrm{C}$ a $23,0^{\circ} \mathrm{C}$ durante todo o mês, nos horários entre $01 \mathrm{~h} 00 \mathrm{~min}$ a $09 \mathrm{~h} 00 \mathrm{~min}$ e após $19 \mathrm{~h} 00 \mathrm{~min}$. De $24,0^{\circ} \mathrm{C}$ a $28,7^{\circ} \mathrm{C}$, nos horários entre 10h00min a 18h00min.

A umidade relativa do ar apresentou-se acima de 65\% nos horários de 01 h00min a 10 h00min e após $19 \mathrm{~h} 00 \mathrm{~min}$, para o mês todo. Foi inferior a $55 \%$ de umidade entre os horários de 12h00min a 17h00min, para o dia 01 e 02, após o dia 09 permanecendo até o final do mês.

Em relação a temperatura efetiva, predominou para a faixa de conforto térmico, praticamente todo esse mês, entre $19,0^{\circ} \mathrm{C}$ a $25,5^{\circ} \mathrm{C}$, principalmente nos horários de 09h00min a 20h00min. Para os dias 07 a 08, 10, 16 e 17, a faixa de conforto estendeu-se para todas as horas do dia.

Para condição considerada de desconforto ao frio, com a TE inferior a $18,9^{\circ} \mathrm{C}$, ocorreu para os horários, de 01h00min a 08h00min e novamente após 22h00min, entre os dias 01, 02 e 05, de 12 a 15 e após o dia 18 permanecendo até o dia 30.

Na Figura 21 está apresentada os dados diários referente ao mês de janeiro de 2007 , a temperatura do ar foi predominante de $18,0^{\circ} \mathrm{C}$ a $23,0^{\circ} \mathrm{C}$, para os horários de $01 \mathrm{~h} 00 \mathrm{~min}$ a $08 \mathrm{~h} 00 \mathrm{~min}$ e após $21 \mathrm{~h} 00 \mathrm{~min}$, destacando de $28,0^{\circ} \mathrm{C}$ a $32,5^{\circ} \mathrm{C}$ entre $12 \mathrm{~h} 00 \mathrm{~min}$ a $18 \mathrm{~h} 00 \mathrm{~min}$.

A umidade relativa do ar foi superior a $70 \%$, para todos os dias do mês, entre 01 h00min a 10 h00min e novamente após 17 h00 min, de $35 \%$ a $55 \%$ nos dias 15 e 16 para os horários entre $09 \mathrm{~h} 00 \mathrm{~min}$ a $18 \mathrm{~h} 00 \mathrm{~min}$, de $50 \%$ a $65 \%$ nos dias $23,24,25,30$ e 31, nos horários entre 09h00min a 17h00min.

Quanto a temperatura efetiva, esta foi predominante para a faixa de conforto térmico, entre $19,0^{\circ} \mathrm{C}$ a $25,5^{\circ} \mathrm{C}$. Ocorreu a condição considerada de desconforto ao calor com a TE superior a $25,6^{\circ} \mathrm{C}$ entre $11 \mathrm{~h} 00 \mathrm{~min}$ até $18 \mathrm{~h} 00 \mathrm{~min}$, estendendo até 19h00min nos dias 06, 10, 30 e 31, inclusive no dia 19 até 21 h00min.

Na Figura 22 está apresentada os dados diários referente ao mês de junho de 2007, a temperatura do ar para os dias 01 a 06 , variando entre $6,0^{\circ} \mathrm{C}$ a $18,0^{\circ} \mathrm{C}$ em todos os horários. Já entre os dias 07 a 27 , entre $15,0^{\circ} \mathrm{C}$ a $22,0^{\circ} \mathrm{C}$ para os horários de $01 \mathrm{~h} 00 \mathrm{~min}$ a $09 \mathrm{~h} 00 \mathrm{~min}$. Após $10 \mathrm{~h} 00 \mathrm{~min}$ até $18 \mathrm{~h} 00 \mathrm{~min}$ entre $24,0^{\circ} \mathrm{C}$ a $30,0^{\circ} \mathrm{C}$. 

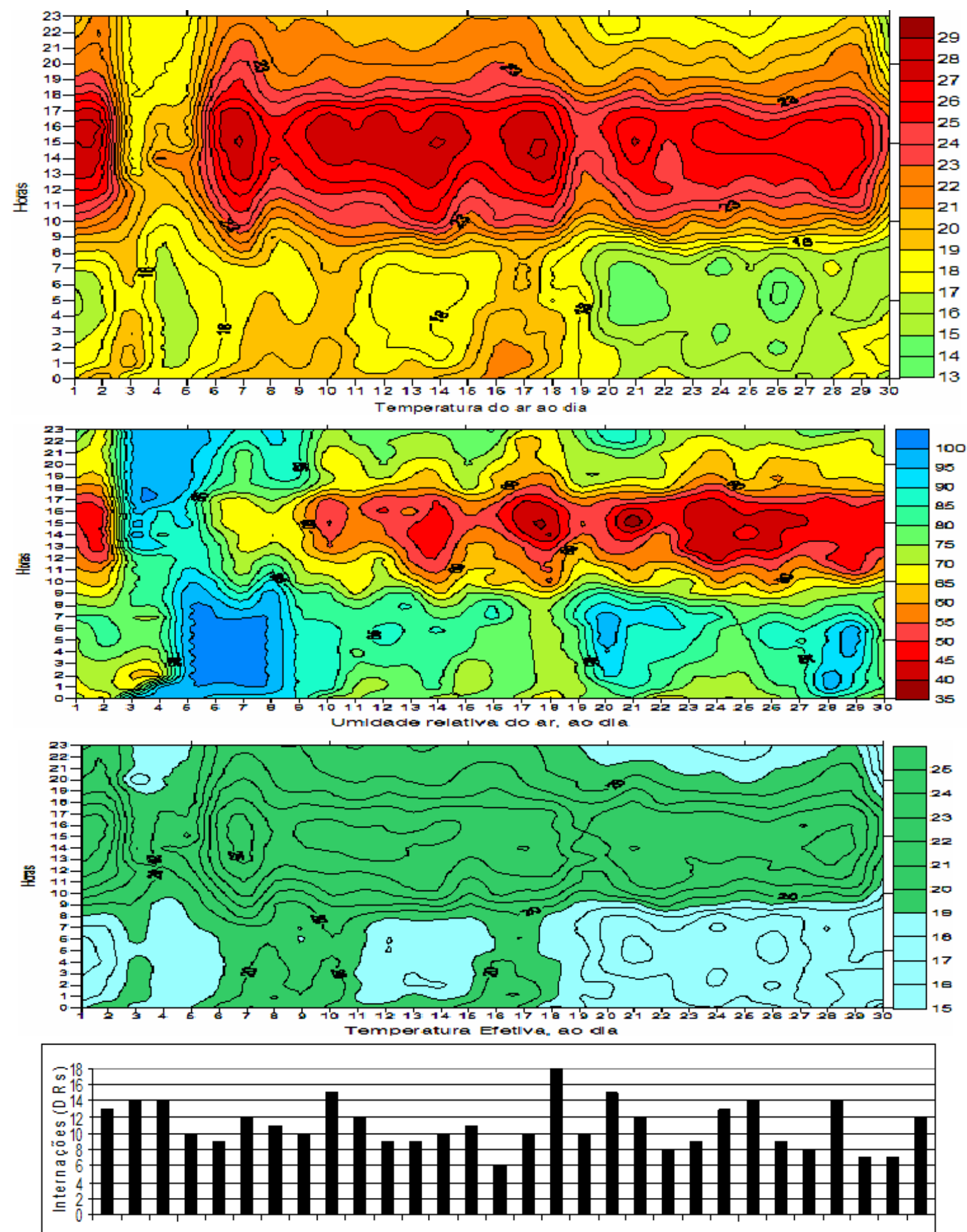

$\begin{array}{llllllllllllllllllllllllllllll}1 & 2 & 3 & 4 & 5 & 6 & 7 & 8 & 9 & 10 & 11 & 12 & 13 & 14 & 15 & 16 & 17 & 18 & 19 & 20 & 21 & 22 & 23 & 24 & 25 & 26 & 27 & 28 & 29 & 30\end{array}$

\begin{tabular}{|l|c|c|c|c|c|c|c|c|c|c|c|c|c|c|c|c|c|c|c|c|c|c|c|c|c|c|c|c|c|c|}
\hline \hline- & $\mathrm{m}$ & $\mathrm{m}$ & $\mathrm{S}$ & $\mathrm{S}$ & $\mathrm{m}$ & $\mathrm{S}$ & $\mathrm{m}$ & $\mathrm{m}$ & $\mathrm{m}$ & $\mathrm{m}$ & $\mathrm{m}$ & $\mathrm{m}$ & $\mathrm{m}$ & $\mathrm{m}$ & $\mathrm{m}$ & $\mathrm{m}$ & $\mathrm{m}$ & $\mathrm{m}$ & $\mathrm{S}$ & $\mathrm{m}$ & $\mathrm{m}$ & $\mathrm{m}$ & $\mathrm{m}$ & $\mathrm{m}$ & $\mathrm{m}$ & $\mathrm{m}$ & $\mathrm{m}$ & $\mathrm{m}$ & $\mathrm{m}$ & $\mathrm{m}$ \\
\hline & $\mathrm{Pa}$ & $\mathrm{Ta}$ & $\mathrm{F}$ & $\mathrm{F}$ & $\mathrm{Pa}$ & $\mathrm{F}$ & $\mathrm{Pa}$ & $\mathrm{Pa}$ & $\mathrm{Ta}$ & $\mathrm{Ta}$ & $\mathrm{Ta}$ & $\mathrm{Pa}$ & $\mathrm{Pa}$ & $\mathrm{Pa}$ & $\mathrm{Ta}$ & $\mathrm{Ta}$ & $\mathrm{Ta}$ & $\mathrm{Ta}$ & $\mathrm{F}$ & $\mathrm{Pa}$ & $\mathrm{Pa}$ & $\mathrm{Ta}$ & $\mathrm{Ta}$ & $\mathrm{Pa}$ & $\mathrm{Pa}$ & $\mathrm{Pa}$ & $\mathrm{Ta}$ & $\mathrm{Pa}$ & $\mathrm{Pa}$ & $\mathrm{Pa}$ \\
\hline Dia & 1 & 2 & 3 & 4 & 5 & 6 & 7 & 8 & 9 & 10 & 11 & 12 & 13 & 14 & 15 & 16 & 17 & 18 & 19 & 20 & 21 & 22 & 23 & 24 & 25 & 26 & 27 & 28 & 29 & 30 \\
\hline
\end{tabular}

Temperatura Efetiva TE = inferior a $18,9^{\circ} \mathrm{C}$ é considerada como condição de desconforto ao frio, (azul), $(T E)=19,0^{\circ} \mathrm{C}$ a $25,5^{\circ} \mathrm{C}$, faixa de conforto térmico, (verde), $\mathrm{TE}=$ superior a $25,6^{\circ} \mathrm{C}$ significa condição de desconforto ao calor, (vermelho).

Figura 20: Variação diária da temperatura do ar, da umidade relativa do ar e da temperatura efetiva (TE), das massas de ar atuantes e as internações (DRs), em junho de 2003. Maringá-PR. 

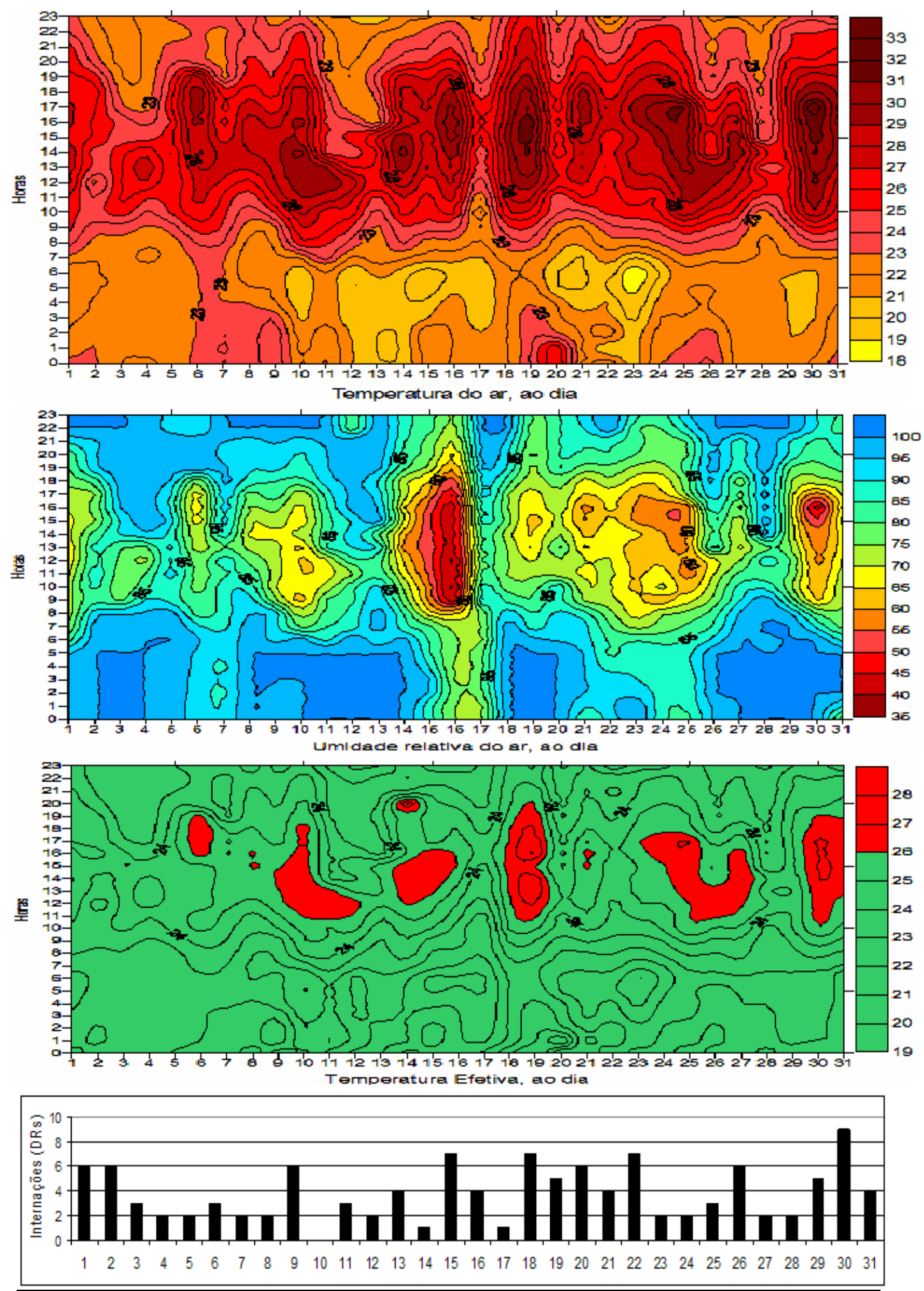

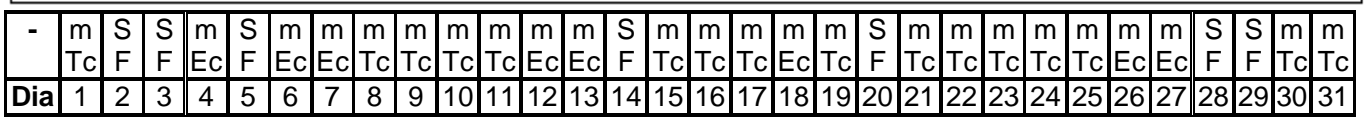

Temperatura Efetiva TE $=$ inferior a $18,9^{\circ} \mathrm{C}$ é considerada como condição de desconforto ao frio, (azul), (TE) $=19,0^{\circ} \mathrm{C}$ a $25,5^{\circ} \mathrm{C}$, faixa de conforto térmico, (verde), $\mathrm{TE}=$ superior a 25,6ํㅡ significa condição de desconforto ao calor, (vermelho).

Figura 21: Variação diária da temperatura do ar, da umidade relativa do ar e da temperatura efetiva (TE), das massas de ar atuantes e as internações (DRs), em janeiro de 2007. Maringá-PR. 

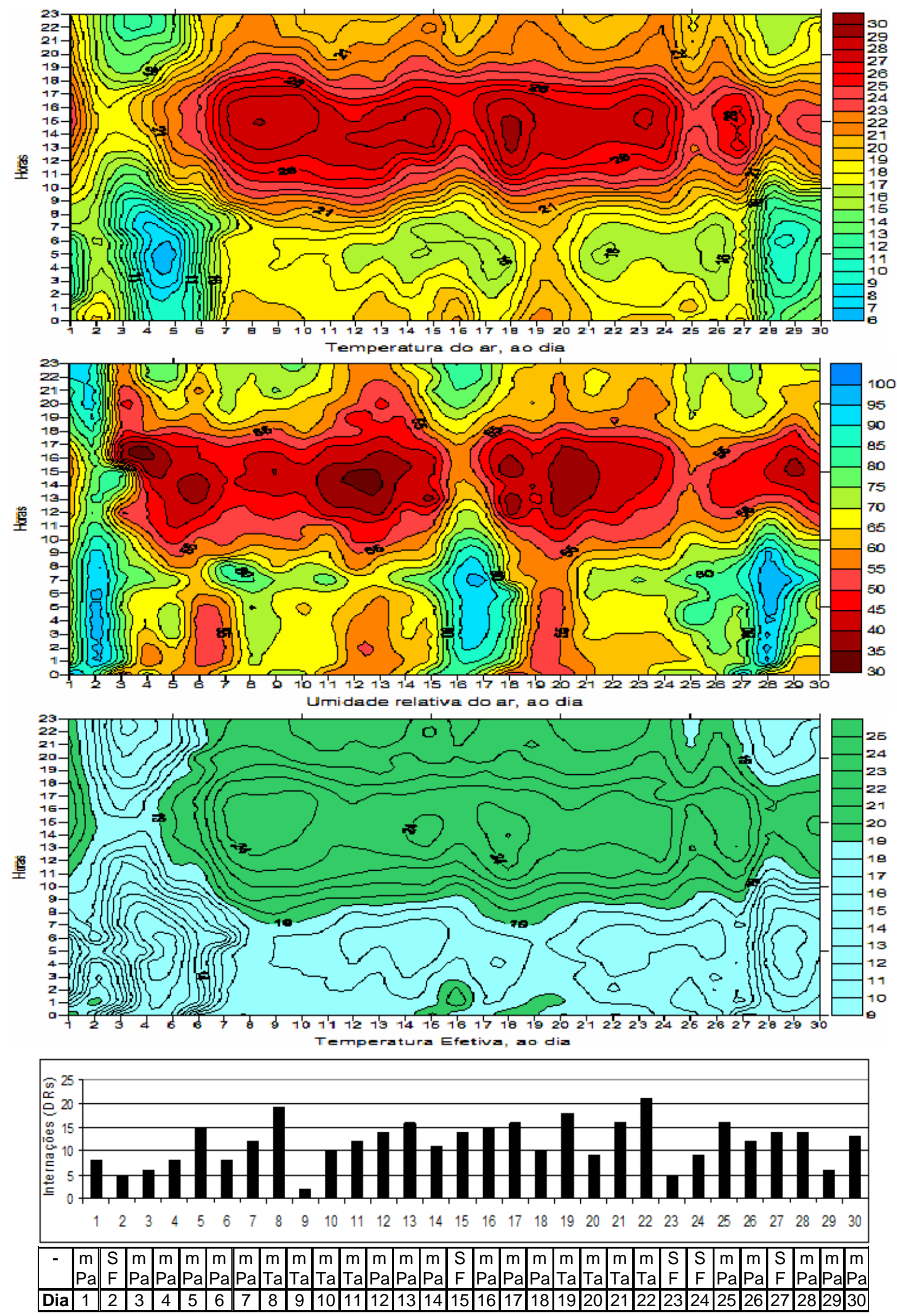

Temperatura Efetiva TE $=$ inferior a $18,9^{\circ} \mathrm{C}$ é considerada como condição de desconforto ao frio, (azul), $(\mathrm{TE})=19,0^{\circ} \mathrm{C}$ a $25,5^{\circ} \mathrm{C}$, faixa de conforto térmico, (verde), $\mathrm{TE}=$ superior a 25,6ํㅡ significa condição de desconforto ao calor, (vermelho).

Figura 22: Variação da diária da temperatura do ar, da umidade relativa do ar e da temperatura efetiva (TE), das massas de ar atuantes e as internações (DRs), em junho de 2007. Maringá-PR. 
Ainda na Figura 22, a umidade relativa do ar nos dias 01, 15, 16 e 17 foi entre $65 \%$ a $75 \%$ e superior a $80 \%$ entre os dias 02 e 03 em todos os horários. Já entre os dias 19, 20 e 21, foi inferior a 60\% em todos os horários. Para os dias 04 a 14 e de 18 a 30 , entre $30 \%$ a $55 \%$, para os horários de $10 \mathrm{~h} 00 \mathrm{~min}$ a $18 \mathrm{~h} 00 \mathrm{~min}$. Sendo de $60 \%$ a $75 \%$ após o dia 03 permanecendo até o dia 30, para os horários de 01h00min a 10h00min e após 18h00min.

Em relação a temperatura efetiva, foi predominante para a faixa de conforto térmico, de $19,0^{\circ} \mathrm{C}$ a $25,5^{\circ} \mathrm{C}$, a partir de $11 \mathrm{~h} 00 \mathrm{~min}$, para o dia 01 e a partir de 09h00min para o restante dos dias deste mês.

A condição de desconforto a frio, com a TE abaixo de 18,9 , destacou praticamente em todos os horários dos dias 02 a 04 . A partir do dia 06 permanecendo até o dia 27, com destaque para os horários entre 01h00min a 08h00min, dias 25 e 27 após 21 h00min, para os dias 28, 29 e 30 apresentou logo após 18h00min.

Em Apêndices B estão apresentados nas Tabelas B.01 a B.06, todos os cálculos diários do índice de conforto térmico, com os resultados obtidos para a temperatura efetiva, de hora em hora, para janeiro e julho de 2000 , janeiro e junho de 2003 e janeiro e junho de 2007.

\subsubsection{ANÁLISE DE CONFORTO TÉRMICO (MÉDIA DIÁRIA)}

Conforme evidenciado na Tabela 15, em relação a média diária dos dados meteorológicos, da temperatura efetiva e a sensação térmica, pode ser observado que para janeiro de 2000, ocorreu maior estabilidade entre as temperaturas do termômetro seco, permanecendo na maior parte dos dias deste mês entre $24,0^{\circ} \mathrm{C}$ a $28,8^{\circ} \mathrm{C}$ e a temperatura do termômetro úmido, entre $17,9^{\circ} \mathrm{C}$ a $24,3^{\circ} \mathrm{C}$, assim como a umidade relativa do ar que esteve sempre alta, praticamente durante o mês todo.

Por conseguinte, as condições meteorológicas favoreceram para a faixa de conforto térmico o mês todo, TE entre $19,0^{\circ} \mathrm{C}$ a $25,5^{\circ} \mathrm{C}$, apenas dois dias, surgiram como condição de desconforto ao calor, sendo nos dias 16 e 17, em que a TE foi de $25,6^{\circ} \mathrm{C}$. Os tipos de tempo predominante para esse mês foram originados das 
massas Tropical continental (mTc) instáveis e dos sistemas frontais (S/F). A quantidade de registros de internações mantiveram consideravelmente baixa.

Tabela 15: Média de temperatura do Termômetro de bulbo seco (Ts), temperatura do Termômetro de bulbo úmido (Tu), umidade relativa do ar (UR), temperatura efetiva (TE), sistema atmosférico, sensação térmica e o número absoluto de internações por doenças respiratórias. Janeiro de 2000.

\begin{tabular}{|c|c|c|c|c|c|c|c|}
\hline $\begin{array}{l}\text { Janeiro } \\
\text { Dias }\end{array}$ & $\begin{array}{l}\text { Ts } \\
\left({ }^{\circ} \mathrm{C}\right)\end{array}$ & $\begin{array}{c}\mathrm{Tu} \\
\left({ }^{\circ} \mathrm{C}\right)\end{array}$ & $\begin{array}{l}\text { UR } \\
\text { (\%) }\end{array}$ & $\begin{array}{l}\text { TE } \\
\left({ }^{\circ} \mathrm{C}\right)\end{array}$ & $\begin{array}{c}\text { Sistema } \\
\text { atmosférico }\end{array}$ & $\begin{array}{c}\text { sensação } \\
\text { térmica }\end{array}$ & $\begin{array}{c}\text { doenças } \\
\text { respiratórias }\end{array}$ \\
\hline 01 & 23,8 & 21,9 & 84 & 23,1 & S/F & conforto & 4 \\
\hline 02 & 24,1 & 20,8 & 74 & 22,7 & $\mathrm{mTc}$ & conforto & 1 \\
\hline 03 & 23,3 & 20,1 & 75 & 22,2 & $\mathrm{mTc}$ & conforto & 3 \\
\hline 04 & 23,1 & 20,7 & 81 & 22,4 & $\mathrm{mTc}$ & conforto & 7 \\
\hline 05 & 25,4 & 21,8 & 74 & 23,7 & $\mathrm{mTc}$ & conforto & 4 \\
\hline 06 & 25,6 & 22,1 & 74 & 23,9 & $\mathrm{mTc}$ & conforto & 4 \\
\hline 07 & 23,2 & 21,2 & 83 & 22,8 & $\mathrm{mTc}$ & conforto & 4 \\
\hline 08 & 24,0 & 20,9 & 77 & 22,8 & $\mathrm{mEc}$ & conforto & 2 \\
\hline 09 & 23,6 & 21,9 & 86 & 23,0 & $\mathrm{mTc}$ & conforto & 7 \\
\hline 10 & 24,8 & 22,3 & 81 & 23,6 & $\mathrm{mTc}$ & conforto & 7 \\
\hline 11 & 25,1 & 22,7 & 82 & 24,0 & $\mathrm{mTc}$ & conforto & 2 \\
\hline 12 & 25,6 & 22,7 & 79 & 24,1 & $S / F$ & conforto & 6 \\
\hline 13 & 25,2 & 22,9 & 83 & 24,1 & $S / F$ & conforto & 6 \\
\hline 14 & 25,2 & 23,0 & 84 & 24,2 & $\mathrm{mTc}$ & conforto & 3 \\
\hline 15 & 25,5 & 23,3 & 83 & 24,4 & $S / F$ & conforto & 2 \\
\hline 16 & 28,0 & 24,0 & 73 & $25,6^{\star \star}$ & $\mathrm{mTc}$ & desconforto & 3 \\
\hline 17 & 28,8 & 23,5 & 65 & $25,6^{\star \star}$ & $\mathrm{mTc}$ & desconforto & 5 \\
\hline 18 & 27,3 & 24,3 & 79 & 25,4 & $\mathrm{mTc}$ & conforto & 4 \\
\hline 19 & 25,6 & 24,0 & 88 & 24,6 & $\mathrm{mEc}$ & conforto & 2 \\
\hline 20 & 23,8 & 21,8 & 84 & 23,1 & $\mathrm{mEc}$ & conforto & 6 \\
\hline 21 & 25,4 & 21,9 & 73 & 23,8 & $\mathrm{mTa}$ & conforto & 2 \\
\hline 22 & 27,1 & 22,1 & 66 & 24,4 & $\mathrm{mTa}$ & conforto & 3 \\
\hline 23 & 28,5 & 21,5 & 53 & 24,8 & $\mathrm{mTc}$ & conforto & 2 \\
\hline 24 & 27,2 & 22,5 & 65 & 24,7 & $\mathrm{mTc}$ & conforto & 6 \\
\hline 25 & 26,7 & 22,4 & 69 & 24,5 & $\mathrm{mEc}$ & conforto & 4 \\
\hline 26 & 25,9 & 22,9 & 78 & 24,1 & $\mathrm{mTc}$ & conforto & 1 \\
\hline 27 & 23,7 & 19,8 & 69 & 22,2 & $\mathrm{mTc}$ & conforto & 3 \\
\hline 28 & 23,8 & 18,2 & 58 & 21,7 & $\mathrm{mTa}$ & conforto & 7 \\
\hline 29 & 24,5 & 17,9 & 51 & 21,7 & $\mathrm{mTa}$ & conforto & 3 \\
\hline 30 & 25,1 & 18,7 & 53 & 22,3 & $\mathrm{mTc}$ & conforto & 3 \\
\hline 31 & 22,5 & 22,0 & 95 & 22,6 & $\mathrm{mTc}$ & conforto & 2 \\
\hline
\end{tabular}

Temperatura Efetiva TE $=$ inferior a 18,9ํㅡ é considerada como condição de desconforto ao frio, (TE) $=19,0^{\circ} \mathrm{C}$ a $25,5^{\circ} \mathrm{C}$, faixa de conforto térmico, $\mathrm{TE}=$ superior a $25,6^{\circ} \mathrm{C}$ significa condição de desconforto ao calor**.

Esse fato muda completamente para julho de 2000 Tabela 15A, no qual observa-se maior variabilidade nas temperaturas do termômetro seco, que oscilaram entre $6,7^{\circ} \mathrm{C}$ a $22,5^{\circ} \mathrm{C}$ e a temperatura do termômetro úmido, entre $3,8^{\circ} \mathrm{C}$ a $18,6^{\circ} \mathrm{C}$, a umidade relativa do ar, na maioria dos dias foi inferior a $60 \%$.

Os sistemas frontais $(\mathrm{S} / \mathrm{F})$ e a massa de ar Polar atlântica $(\mathrm{mPa})$, foram predominantes, trazendo mudanças no tempo atmosférico, com queda rápida na temperatura e formação de geadas. 
Tabela 15A: Média de temperatura do termômetro de bulbo seco (Ts), temperatura do Termômetro de bulbo úmido (Tu), umidade relativa do ar (UR), temperatura efetiva (TE), sistema atmosférico, sensação térmica e o número absoluto de internações por doenças respiratórias. Julho de 2000.

\begin{tabular}{|c|c|c|c|c|c|c|c|}
\hline $\begin{array}{l}\text { Julho } \\
\text { Dias }\end{array}$ & $\begin{array}{l}\text { Ts } \\
(\text { (oC) }\end{array}$ & $\begin{array}{l}\mathrm{Tu} \\
\left({ }^{\circ} \mathrm{C}\right)\end{array}$ & $\begin{array}{l}\text { UR } \\
(\%)\end{array}$ & 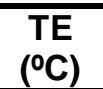 & $\begin{array}{c}\text { sistema } \\
\text { atmosférico }\end{array}$ & $\begin{array}{l}\text { sensação } \\
\text { térmica }\end{array}$ & $\begin{array}{c}\text { doenças } \\
\text { respiratórias }\end{array}$ \\
\hline 01 & 20,4 & 17,8 & 78 & 20,1 & $\mathrm{mPa}$ & conforto & 10 \\
\hline 02 & 22,4 & 18,6 & 69 & 21,2 & $\mathrm{~S} / \mathrm{F}$ & conforto & 3 \\
\hline 03 & 19,9 & 17,9 & 82 & 19,9 & $\mathrm{~S} / \mathrm{F}$ & conforto & 11 \\
\hline 04 & 18,4 & 15,2 & 70 & $18,2^{*}$ & $\mathrm{mPa}$ & desconforto & 7 \\
\hline 05 & 19.9 & 16,2 & 67 & 19.2 & $\mathrm{mTa}$ & conforto & 12 \\
\hline 06 & 20,2 & 15,7 & 61 & 19,2 & $\mathrm{mTa}$ & conforto & 8 \\
\hline 07 & 20,8 & 15,8 & 56 & 19,5 & $\mathrm{mTa}$ & conforto & 11 \\
\hline 08 & 22,5 & 16,6 & 53 & 20,4 & $\mathrm{mTa}$ & conforto & 3 \\
\hline 09 & 22,4 & 17,2 & 58 & 20,6 & $\mathrm{~S} / \mathrm{F}$ & conforto & 5 \\
\hline 10 & 20,9 & 17,9 & 74 & 20,3 & $S / F$ & conforto & 12 \\
\hline 11 & 11,3 & 10,5 & 91 & $13,5^{*}$ & S/F & desconforto & 8 \\
\hline 12 & 7,7 & 5,6 & 72 & $10,2^{*}$ & $\mathrm{mPa}$ & desconforto & 11 \\
\hline 13 & 6,7 & 3,8 & 61 & $9,2^{*}$ & $\mathrm{mPa}$ & desconforto & 4 \\
\hline 14 & 12,1 & 6,9 & 43 & $12,4^{*}$ & $\mathrm{mPa}$ & desconforto & 14 \\
\hline 15 & 13,1 & 11,8 & 86 & $14,8^{*}$ & $S / F$ & desconforto & 3 \\
\hline 16 & 8,3 & 5,3 & 62 & $10,3^{*}$ & S/F & desconforto & 6 \\
\hline 17 & 7,3 & 3,7 & 48 & $9,2^{*}$ & $\mathrm{mPa}$ & desconforto & 12 \\
\hline 18 & 11,5 & 6,6 & 45 & $12,1^{*}$ & $\mathrm{mPa}$ & desconforto & 8 \\
\hline 19 & 12,1 & 7,6 & 49 & $12,7^{*}$ & $\mathrm{~S} / \mathrm{F}$ & desconforto & 10 \\
\hline 20 & 9,2 & 5,0 & 47 & $10,6^{*}$ & $\mathrm{mPa}$ & desconforto & 12 \\
\hline 21 & 14,2 & 8,3 & 40 & $13,9^{*}$ & $\mathrm{mPa}$ & desconforto & 8 \\
\hline 22 & 15,3 & 14,1 & 88 & $16,9^{*}$ & $\mathrm{~S} / \mathrm{F}$ & desconforto & 3 \\
\hline 23 & 10,7 & 9.0 & 79 & $12.9^{*}$ & S/F & desconforto & 9 \\
\hline 24 & 10,1 & 6,4 & 58 & $11,5^{*}$ & $\mathrm{mPa}$ & desconforto & 16 \\
\hline 25 & 14,1 & 9,6 & 54 & $14,4^{*}$ & $\mathrm{mPa}$ & desconforto & 10 \\
\hline 26 & 16,8 & 11,2 & 45 & $16,0^{*}$ & $\mathrm{mPa}$ & desconforto & 11 \\
\hline 27 & 16,9 & 11,8 & 51 & $16,4^{*}$ & $\mathrm{mPa}$ & desconforto & 14 \\
\hline 28 & 18,2 & 13,8 & 60 & $17,7^{*}$ & $\mathrm{mPa}$ & desconforto & 13 \\
\hline 29 & 19,8 & 14,5 & 53 & $18,5^{\star}$ & $\mathrm{mPa}$ & desconforto & 7 \\
\hline 30 & 19,6 & 14,5 & 56 & $18,2^{*}$ & $\mathrm{~S} / \mathrm{F}$ & desconforto & 9 \\
\hline 31 & 16,7 & 14,5 & 77 & $17,3^{*}$ & $\mathrm{~S} / \mathrm{F}$ & desconforto & 13 \\
\hline
\end{tabular}

Temperatura Efetiva TE = inferior a $18,9^{\circ} \mathrm{C}$ é considerada como condição de desconforto ao frio*, $(\mathrm{TE})=19,0^{\circ} \mathrm{C}$ a $25,5^{\circ} \mathrm{C}$, faixa de conforto térmico, TE = superior a $25,6^{\circ} \mathrm{C}$ significa condição de desconforto ao calor.

Quanto ao conforto térmico, mostrou-se para a condição de desconforto ao frio, TE inferior a $18,9^{\circ} \mathrm{C}$, predominante o mês todo. Como faixa de conforto térmico apresentou-se no inicio do mês, até o dia 10, observa-se que a quantidade de internações por doenças respiratórias foram elevadas e constantes, para o mês todo.

A Tabela 16, apresenta os dados meteorológicos para janeiro 2003, a temperatura do termômetro seco apresentou-se estabilizada, a maior parte dos dias deste mês acima de 25,0ํำ e a temperatura do termômetro úmido, oscilando entre $21,1^{\circ} \mathrm{C}$ a $24,5^{\circ} \mathrm{C}$, a umidade relativa do ar apresentou sem alterações ou variações importantes, sempre elevada, acima de $70 \%$. 
Tabela 16: Média de temperatura do Termômetro de bulbo seco (Ts), temperatura do Termômetro de bulbo úmido (Tu), umidade relativa do ar (UR), temperatura efetiva (TE), sistema atmosférico, sensação térmica e o número absoluto de internações por doenças respiratórias. Janeiro de 2003.

\begin{tabular}{c|ccccccc}
\hline $\begin{array}{c}\text { Janeiro } \\
\text { Dias }\end{array}$ & $\begin{array}{c}\text { Ts } \\
\text { (-C) }\end{array}$ & $\begin{array}{c}\text { Tu } \\
(\mathbf{(} \text { C) }\end{array}$ & $\begin{array}{c}\text { UR } \\
(\text { \%) }\end{array}$ & $\begin{array}{c}\text { TE } \\
\text { (o-C) }\end{array}$ & $\begin{array}{c}\text { sistema } \\
\text { atmosférico }\end{array}$ & $\begin{array}{c}\text { sensação } \\
\text { térmica }\end{array}$ & $\begin{array}{c}\text { doenças } \\
\text { respiratórias }\end{array}$ \\
\hline $\mathbf{0 1}$ & 27,6 & 24,0 & 73 & 25,4 & $\mathrm{mTc}$ & conforto & 8 \\
$\mathbf{0 2}$ & 26,2 & 23,7 & 79 & 24,7 & $\mathrm{mEc}$ & conforto & 5 \\
$\mathbf{0 3}$ & 24,9 & 23,2 & 86 & 24,0 & $\mathrm{mEc}$ & conforto & 9 \\
$\mathbf{0 4}$ & 23,8 & 23,0 & 93 & 23,5 & $\mathrm{mTc}$ & conforto & 4 \\
$\mathbf{0 5}$ & 25,3 & 23,6 & 87 & 24,3 & $\mathrm{mTc}$ & conforto & 2 \\
$\mathbf{0 6}$ & 26,4 & 26,4 & 80 & 24,8 & $\mathrm{mTc}$ & conforto & 8 \\
$\mathbf{0 7}$ & 27,3 & 23,2 & 70 & 24,9 & $\mathrm{mTc}$ & conforto & 3 \\
$\mathbf{0 8}$ & 27,7 & 21,7 & 56 & 24,5 & $\mathrm{mTc}$ & conforto & 7 \\
$\mathbf{0 9}$ & 28,4 & 22,8 & 59 & 25,2 & $\mathrm{mTc}$ & conforto & 6 \\
$\mathbf{1 0}$ & 25,8 & 24,5 & 89 & 24,8 & $\mathrm{mEc}$ & conforto & 3 \\
$\mathbf{1 1}$ & 22,7 & 21,6 & 89 & 22,4 & $\mathrm{mEc}$ & conforto & 5 \\
$\mathbf{1 2}$ & 22,8 & 22,0 & 93 & 22,7 & $\mathrm{mEc}$ & conforto & 0 \\
$\mathbf{1 3}$ & 23,0 & 21,8 & 89 & 22,8 & $\mathrm{~S} / \mathrm{F}$ & conforto & 2 \\
$\mathbf{1 4}$ & 24,0 & 22,1 & 84 & 23,2 & $\mathrm{~S} / \mathrm{F}$ & conforto & 6 \\
$\mathbf{1 5}$ & 24,9 & 22,0 & 76 & 23,5 & $\mathrm{~S} / \mathrm{F}$ & conforto & 6 \\
$\mathbf{1 6}$ & 25,8 & 22,5 & 74 & 24,0 & $\mathrm{mTc}$ & conforto & 6 \\
$\mathbf{1 7}$ & 26,0 & 23,2 & 79 & 24,5 & $\mathrm{mTc}$ & conforto & 3 \\
$\mathbf{1 8}$ & 26,2 & 23,3 & 77 & 24,5 & $\mathrm{mTc}$ & conforto & 4 \\
$\mathbf{1 9}$ & 27,3 & 23,2 & 68 & 25,0 & $\mathrm{mEc}$ & conforto & 1 \\
$\mathbf{2 0}$ & 25,8 & 23,8 & 84 & 24,6 & $\mathrm{~S} / \mathrm{F}$ & conforto & 7 \\
$\mathbf{2 1}$ & 26,0 & 24,2 & 86 & 24,9 & $\mathrm{~S} / \mathrm{F}$ & conforto & 3 \\
$\mathbf{2 2}$ & 25,2 & 23,6 & 87 & 24,3 & $\mathrm{~S} / \mathrm{F}$ & conforto & 5 \\
$\mathbf{2 3}$ & 22,3 & 22,0 & 96 & 22,4 & $\mathrm{~S} / \mathrm{F}$ & conforto & 4 \\
$\mathbf{2 4}$ & 23,7 & 22,6 & 85 & 23,3 & $\mathrm{~S} / \mathrm{F}$ & conforto & 8 \\
$\mathbf{2 5}$ & 22,1 & 21,4 & 93 & 22,2 & $\mathrm{~S} / \mathrm{F}$ & conforto & 4 \\
$\mathbf{2 6}$ & 21,3 & 21,3 & 99 & 21,8 & $\mathrm{mEc}$ & conforto & 4 \\
$\mathbf{2 7}$ & 22,4 & 22,1 & 96 & 22,5 & $\mathrm{~S} / \mathrm{F}$ & conforto & 0 \\
$\mathbf{2 8}$ & 23,4 & 21,1 & 81 & 22,6 & $\mathrm{mEc}$ & conforto & 6 \\
$\mathbf{2 9}$ & 24,7 & 21,6 & 75 & 23,3 & $\mathrm{mTc}$ & conforto & 3 \\
$\mathbf{3 0}$ & 25,1 & 22,2 & 77 & 23,7 & $\mathrm{mEc}$ & conforto & 8 \\
$\mathbf{3 1}$ & 25,8 & 23,2 & 83 & 24,2 & $\mathrm{~S} / \mathrm{F}$ & conforto & 3 \\
\hline
\end{tabular}

Temperatura Efetiva TE $=$ inferior a $18,9^{\circ} \mathrm{C}$ é considerada como condição de desconforto ao frio, (TE) $=19,0^{\circ} \mathrm{C}$ a $25,5^{\circ} \mathrm{C}$, faixa de conforto térmico, $\mathrm{TE}=$ superior a $25,6^{\circ} \mathrm{C}$ significa condição de desconforto ao calor.

Com a participação ativa da massa Tropical continental (mTc), massa Equatorial continental (mEc) e de sistemas frontais $(\mathrm{S} / \mathrm{F})$, que facilitaram para as condições de faixa de conforto térmico, apresentando para a média do dia a TE entre $19,0^{\circ} \mathrm{C}$ a $25,5^{\circ} \mathrm{C}$, durante todo o mês. A quantidade de registros de internações mostrou-se baixa, inclusive alguns dias nem houve internações por doenças respiratórias.

Para junho 2003 Tabela 16A, inverno sem variação bruscas nas temperaturas, em que, ocorreu pequena variação na temperatura do termômetro seco, oscilando entre $18,2^{\circ} \mathrm{C}$ a $23,2^{\circ} \mathrm{C}$ e a temperatura do termômetro úmido, entre 
$14,6^{\circ} \mathrm{C}$ a $21,1^{\circ} \mathrm{C}$. Na maioria dos dias deste mês a umidade relativa permaneceu acima de $65 \%$.

Tabela 16A: Média de temperatura do termômetro de bulbo seco (Ts), temperatura do termômetro de bulbo úmido (Tu), umidade relativa do ar (UR), temperatura efetiva (TE), sistema atmosférico, sensação térmica e o número absoluto de internações por doenças respiratórias. Junho de 2003.

\begin{tabular}{|c|c|c|c|c|c|c|c|}
\hline $\begin{array}{l}\text { Junho } \\
\text { Dias }\end{array}$ & $\begin{array}{c}\text { Ts } \\
\left({ }^{\circ} \mathrm{C}\right)\end{array}$ & $\begin{array}{c}\mathrm{Tu} \\
\left({ }^{\circ} \mathrm{C}\right)\end{array}$ & $\begin{array}{l}\text { UR } \\
(\%)\end{array}$ & $\begin{array}{c}\text { TE } \\
\left(\stackrel{\circ}{ }-{ }_{0}\right)\end{array}$ & $\begin{array}{c}\text { sistema } \\
\text { atmosférico }\end{array}$ & $\begin{array}{c}\text { sensação } \\
\text { térmica }\end{array}$ & $\begin{array}{c}\text { doenças } \\
\text { respiratórias }\end{array}$ \\
\hline 01 & 21,5 & 17,5 & 67 & 20,5 & $\mathrm{mPa}$ & conforto & 13 \\
\hline 02 & 22,0 & 17,7 & 65 & 20,7 & $\mathrm{mTa}$ & conforto & 14 \\
\hline 03 & 19,0 & 17,5 & 87 & 19,3 & $S / F$ & conforto & 14 \\
\hline 04 & 18,2 & 17,7 & 86 & 19,2 & $S / F$ & conforto & 10 \\
\hline 05 & 18,4 & 18,0 & 96 & 19,4 & $\mathrm{mPa}$ & conforto & 9 \\
\hline 06 & 21,5 & 20,3 & 90 & 21,5 & $S / F$ & conforto & 12 \\
\hline 07 & 23,2 & 21,1 & 83 & 22,5 & $\mathrm{mPa}$ & conforto & 11 \\
\hline 08 & 21,5 & 20,2 & 89 & 21,5 & $\mathrm{mPa}$ & conforto & 10 \\
\hline 09 & 21,7 & 19,4 & 80 & 21,2 & $\mathrm{mPa}$ & conforto & 15 \\
\hline 10 & 22,8 & 19,3 & 72 & 21,6 & $\mathrm{mTa}$ & conforto & 12 \\
\hline 11 & 22,1 & 18,5 & 70 & 21,0 & $\mathrm{mTa}$ & conforto & 9 \\
\hline 12 & 21,9 & 18,5 & 73 & 21,0 & $\mathrm{mPa}$ & conforto & 9 \\
\hline 13 & 22,0 & 18,2 & 70 & 20,9 & $\mathrm{mPa}$ & conforto & 10 \\
\hline 14 & 22,4 & 18,1 & 66 & 21,0 & $\mathrm{mPa}$ & conforto & 11 \\
\hline 15 & 21,8 & 18,3 & 71 & 20,9 & $\mathrm{mTa}$ & conforto & 16 \\
\hline 16 & 22,7 & 19,0 & 70 & 21,5 & $\mathrm{mTa}$ & conforto & 10 \\
\hline 17 & 23,0 & 18,5 & 62 & 21,4 & $\mathrm{mTa}$ & conforto & 18 \\
\hline 18 & 22,2 & 17,4 & 62 & 20,6 & $\mathrm{mTa}$ & conforto & 10 \\
\hline 19 & 20,1 & 16,9 & 72 & 19,7 & $S / F$ & conforto & 15 \\
\hline 20 & 19,5 & 16,7 & 76 & 19,3 & $\mathrm{mPa}$ & conforto & 12 \\
\hline 21 & 20,1 & 16,7 & 71 & 19,5 & $\mathrm{mPa}$ & conforto & 8 \\
\hline 22 & 20,1 & 16,8 & 72 & 19,6 & $\mathrm{mTa}$ & conforto & 9 \\
\hline 23 & 20,0 & 16,1 & 67 & 19,2 & $\mathrm{mTa}$ & conforto & 13 \\
\hline 24 & 20,0 & 15,1 & 63 & 19,0 & $\mathrm{mPa}$ & conforto & 14 \\
\hline 25 & 19,7 & 15,7 & 66 & 19,0 & $\mathrm{mPa}$ & conforto & 9 \\
\hline 26 & 19,6 & 15,5 & 66 & $18,9^{*}$ & $\mathrm{mPa}$ & desconforto & 8 \\
\hline 27 & 20,1 & 16,4 & 68 & 19,4 & $\mathrm{mTa}$ & conforto & 14 \\
\hline 28 & 20,6 & 17,1 & 71 & 19,9 & $\mathrm{mPa}$ & conforto & 7 \\
\hline 29 & 20,7 & 17,1 & 71 & 19,9 & $\mathrm{mPa}$ & conforto & 7 \\
\hline 30 & 18,3 & 14,6 & 66 & $17,9^{*}$ & $\mathrm{mPa}$ & desconforto & 12 \\
\hline
\end{tabular}

Temperatura Efetiva $\mathrm{TE}=$ inferior a $18,9^{\circ} \mathrm{C}$ é considerada como condição de desconforto ao frio*, $(T E)=19,0^{\circ} \mathrm{C}$ a $25,5^{\circ} \mathrm{C}$, faixa de conforto térmico, $\mathrm{TE}=$ superior a $25,6^{\circ} \mathrm{C}$ significa condição de desconforto ao calor.

A massa Polar atlântica, $(\mathrm{mPa})$ juntamente com a massa Tropical atlântica (mTa) foi predominante. Como não ocorreu temperaturas muito baixas, esse mês foi favorecido para faixa de conforto térmico, apresentando na média do dia a TE entre $19,0^{\circ} \mathrm{C}$ a $25,5^{\circ} \mathrm{C}$. Apenas em dois dias, sendo 26 e 30, apresentou-se com média para desconforto ao frio sendo de $18,9^{\circ} \mathrm{C}$ e $17,9^{\circ} \mathrm{C}$, respectivamente. A quantidade de registros de internações mostraram-se alta, todos os dias. 
A Tabela 17 apresenta a média dos dados meteorológicos para janeiro 2007, verifica-se que as temperaturas do termômetro seco, oscilaram entre $22,5^{\circ} \mathrm{C}$ a $27,1^{\circ} \mathrm{C}$ e úmido entre $19,7^{\circ} \mathrm{C}$ a $24,4^{\circ} \mathrm{C}$, com a umidade relativa do ar elevada, sempre acima de $70 \%$, nesse mês.

Tabela 17: Média de temperatura do termômetro de bulbo seco (Ts), temperatura do termômetro de bulbo úmido (Tu), umidade relativa do ar (UR), temperatura efetiva (TE), sistema atmosférico, sensação térmica e o número absoluto de internações por doenças respiratórias. Janeiro de 2007.

\begin{tabular}{|c|c|c|c|c|c|c|c|}
\hline Dias & $\begin{array}{c}\text { Ts } \\
\left({ }^{\circ} \mathrm{C}\right)\end{array}$ & $\begin{array}{c}\mathrm{Tu} \\
\left({ }^{\circ} \mathrm{C}\right)\end{array}$ & $\begin{array}{l}\text { UR } \\
(\%)\end{array}$ & $\begin{array}{l}\text { TE } \\
(\stackrel{\circ}{-C})\end{array}$ & $\begin{array}{c}\text { sistema } \\
\text { atmosférico }\end{array}$ & $\begin{array}{c}\text { sensação } \\
\text { térmica }\end{array}$ & $\begin{array}{c}\text { doenças } \\
\text { respiratórias }\end{array}$ \\
\hline 01 & 24,7 & 22,4 & 82 & 23,6 & $\mathrm{mTc}$ & conforto & 6 \\
\hline 02 & 23,5 & 22,5 & 92 & 23,3 & $S / F$ & conforto & 6 \\
\hline 03 & 23,2 & 22,4 & 94 & 23,0 & $S / F$ & conforto & 3 \\
\hline 04 & 23,4 & 22,7 & 95 & 23,3 & $\mathrm{mEc}$ & conforto & 2 \\
\hline 05 & 23,8 & 23,1 & 95 & 23,6 & $\mathrm{~S} / \mathrm{F}$ & conforto & 2 \\
\hline 06 & 25,7 & 23,6 & 84 & 24,2 & $\mathrm{mEc}$ & conforto & 3 \\
\hline 07 & 24,4 & 23,3 & 91 & 23,8 & $\mathrm{mEc}$ & conforto & 2 \\
\hline 08 & 24,7 & 23,4 & 90 & 24,0 & $\mathrm{mTc}$ & conforto & 2 \\
\hline 09 & 24,5 & 23,0 & 88 & 23,8 & $\mathrm{mTc}$ & conforto & 6 \\
\hline 10 & 25,7 & 23,3 & 83 & 24,4 & $\mathrm{mTc}$ & conforto & 0 \\
\hline 11 & 24,1 & 22,8 & 90 & 23,6 & $\mathrm{mTc}$ & conforto & 3 \\
\hline 12 & 22,9 & 21,9 & 92 & 22,7 & $\mathrm{mEc}$ & conforto & 2 \\
\hline 13 & 22,7 & 22,1 & 95 & 22,7 & $\mathrm{mEc}$ & conforto & 4 \\
\hline 14 & 24,8 & 22,4 & 82 & 23,9 & $S / F$ & conforto & 1 \\
\hline 15 & 23,9 & 20,4 & 72 & 23,3 & $\mathrm{mTc}$ & conforto & 7 \\
\hline 16 & 25,5 & 19,7 & 59 & 22,9 & $\mathrm{mTc}$ & conforto & 4 \\
\hline 17 & 22,1 & 20,5 & 85 & 21,8 & $\mathrm{mTc}$ & conforto & 1 \\
\hline 18 & 25,3 & 23,8 & 89 & 24,4 & $\mathrm{mEc}$ & conforto & 7 \\
\hline 19 & 27,1 & 24,4 & 81 & 25,3 & $\mathrm{mTc}$ & conforto & 5 \\
\hline 20 & 23,3 & 21,8 & 87 & 22,9 & $S / F$ & conforto & 6 \\
\hline 21 & 24,9 & 22,1 & 80 & 23,6 & $\mathrm{mTc}$ & conforto & 4 \\
\hline 22 & 23,7 & 21,3 & 81 & 22,8 & $\mathrm{mTc}$ & conforto & 7 \\
\hline 23 & 24,4 & 21,2 & 76 & 23,0 & mTc & conforto & 2 \\
\hline 24 & 25,3 & 22,0 & 74 & 23,7 & $\mathrm{mTc}$ & conforto & 2 \\
\hline 25 & 26,1 & 22,8 & 75 & 24,4 & $\mathrm{mTc}$ & conforto & 3 \\
\hline 26 & 24,1 & 22,9 & 91 & 23,6 & $\mathrm{mEc}$ & conforto & 6 \\
\hline 27 & 24,8 & 23,2 & 88 & 24,0 & $\mathrm{mEc}$ & conforto & 2 \\
\hline 28 & 22,5 & 22,1 & 97 & 22,7 & $S / F$ & conforto & 2 \\
\hline 29 & 24,0 & 22,5 & 88 & 23,4 & $S / F$ & conforto & 5 \\
\hline 30 & 26,2 & 22,9 & 78 & 24,4 & $\mathrm{mTc}$ & conforto & 9 \\
\hline 31 & 25,4 & 23,0 & 81 & 24,2 & $\mathrm{mTc}$ & conforto & 4 \\
\hline
\end{tabular}

Temperatura Efetiva TE $=$ inferior a $18,9^{\circ} \mathrm{C}$ é considerada como condição de desconforto ao frio, (TE) $=19,0^{\circ} \mathrm{C}$ a $25,5^{\circ} \mathrm{C}$, faixa de conforto térmico, $\mathrm{TE}=$ superior a $25,6^{\circ} \mathrm{C}$ significa condição de desconforto ao calor.

A participação da massa Tropical continental (mTc), massa Equatorial continental $(\mathrm{mEc})$ e de sistemas frontais $(\mathrm{S} / \mathrm{F})$, favoreceram para a predominância da faixa de conforto térmico durante o mês todo, a quantidade de internações mostraram-se baixo, houve inclusive alguns dias sem registros de internações, por doenças respiratórias. 
Para junho 2007 Tabela 17A, a temperatura do termômetro seco apresentouse, entre $13,1^{\circ} \mathrm{C}$ a $23,0^{\circ} \mathrm{C}$, a temperatura do termômetro úmido entre $9,2^{\circ} \mathrm{C}$ a $18,2^{\circ} \mathrm{C}$, a umidade relativa do ar apresentou-se abaixo de $70 \%$, praticamente o mês todo.

A faixa de conforto térmico foi predominante, com TE entre $19,0^{\circ} \mathrm{C}$ a $25,5^{\circ} \mathrm{C}$, sendo que entre os dias 01 a 06 e de 28 a 30, apresentaram-se para a condição de desconforto ao frio, TE abaixo de 18,9ํㅡ. A massa Polar atlântica (mPa) foi predominante. A quantidade de registros de internações foi elevada, todos os dias.

Tabela 17A: Média de temperatura do termômetro de bulbo seco (Ts), temperatura do termômetro de bulbo úmido (Tu), umidade relativa do ar (UR), temperatura efetiva (TE), sistema atmosférico, sensação térmica e o número absoluto de internações por doenças respiratórias. Junho de 2007.

\begin{tabular}{|c|c|c|c|c|c|c|c|}
\hline Dias & $\begin{array}{c}\text { Ts } \\
\left({ }^{\circ} \mathrm{C}\right)\end{array}$ & $\begin{array}{c}\text { Tu } \\
\left({ }^{\circ} \mathrm{C}\right)\end{array}$ & $\begin{array}{l}\text { UR } \\
(\%)\end{array}$ & $\begin{array}{c}\text { TE } \\
(\stackrel{\circ}{ })\end{array}$ & $\begin{array}{c}\text { sistema } \\
\text { atmosférico }\end{array}$ & $\begin{array}{c}\text { sensação } \\
\text { térmica }\end{array}$ & $\begin{array}{c}\text { doenças } \\
\text { respiratórias }\end{array}$ \\
\hline 01 & 18,4 & 15,4 & 72 & $18,2^{*}$ & $\mathrm{mPa}$ & desconforto & 8 \\
\hline 02 & 16,8 & 15,9 & 90 & $17,8^{*}$ & $S / F$ & desconforto & 5 \\
\hline 03 & 14,1 & 10,8 & 64 & $14,7^{*}$ & $\mathrm{mPa}$ & desconforto & 6 \\
\hline 04 & 13,1 & 9,2 & 59 & $13,8^{*}$ & $\mathrm{mPa}$ & desconforto & 8 \\
\hline 05 & 15,3 & 11,0 & 59 & $15,3^{*}$ & $\mathrm{mPa}$ & desconforto & 15 \\
\hline 06 & 18,1 & 13,0 & 53 & $17,3^{*}$ & $\mathrm{mPa}$ & desconforto & 8 \\
\hline 07 & 21,5 & 16,6 & 60 & 20,1 & $\mathrm{mPa}$ & conforto & 12 \\
\hline 08 & 22,9 & 18,2 & 63 & 21,2 & $\mathrm{mTa}$ & conforto & 19 \\
\hline 09 & 22,8 & 17,9 & 61 & 21,1 & $\mathrm{mTa}$ & conforto & 2 \\
\hline 10 & 22,5 & 17,7 & 62 & 20,8 & $\mathrm{mTa}$ & conforto & 10 \\
\hline 11 & 22,0 & 16,8 & 59 & 20,3 & $\mathrm{mTa}$ & conforto & 12 \\
\hline 12 & 22,0 & 16,1 & 52 & 20,0 & $\mathrm{mPa}$ & conforto & 14 \\
\hline 13 & 22,3 & 16,1 & 51 & 20,2 & $\mathrm{mPa}$ & conforto & 16 \\
\hline 14 & 21,6 & 16,4 & 57 & 20,0 & $\mathrm{mPa}$ & conforto & 11 \\
\hline 15 & 22,1 & 17,3 & 62 & 20,5 & S/F & conforto & 14 \\
\hline 16 & 20,6 & 18,1 & 79 & 20,3 & $\mathrm{mPa}$ & conforto & 15 \\
\hline 17 & 21,3 & 18,2 & 75 & 20,6 & $\mathrm{mPa}$ & conforto & 16 \\
\hline 18 & 22,8 & 17,6 & 60 & 21,0 & $\mathrm{mPa}$ & conforto & 10 \\
\hline 19 & 23,0 & 17,4 & 55 & 20,9 & $\mathrm{mTa}$ & conforto & 18 \\
\hline 20 & 22,5 & 16,2 & 50 & 20,3 & $\mathrm{mTa}$ & conforto & 9 \\
\hline 21 & 21,5 & 16,3 & 58 & 20,0 & $\mathrm{mTa}$ & conforto & 16 \\
\hline 22 & 21,4 & 16,2 & 57 & 20,0 & $\mathrm{mTa}$ & conforto & 21 \\
\hline 23 & 21,8 & 16,7 & 58 & 20,1 & $S / F$ & conforto & 5 \\
\hline 24 & 21,8 & 16,9 & 60 & 20,3 & $S / F$ & conforto & 9 \\
\hline 25 & 19,7 & 16,3 & 69 & 19,2 & $\mathrm{mPa}$ & conforto & 16 \\
\hline 26 & 20,3 & 16,4 & 67 & 19,5 & $\mathrm{mPa}$ & conforto & 12 \\
\hline 27 & 20,5 & 16,8 & 69 & 19,7 & $\mathrm{~S} / \mathrm{F}$ & conforto & 14 \\
\hline 28 & 15,8 & 13,2 & 76 & $16,4^{*}$ & $\mathrm{mPa}$ & desconforto & 14 \\
\hline 29 & 16,7 & 13,0 & 65 & $16,7^{*}$ & $\mathrm{mPa}$ & desconforto & 6 \\
\hline 30 & 17,7 & 13,7 & 64 & $17,4^{*}$ & $\mathrm{mPa}$ & desconforto & 13 \\
\hline
\end{tabular}

Temperatura Efetiva TE $=$ inferior a $18,9^{\circ} \mathrm{C}$ é considerada como condição de desconforto ao frio*, $(T E)=19,0^{\circ} \mathrm{C}$ a $25,5^{\circ} \mathrm{C}$, faixa de conforto térmico, $\mathrm{TE}=$ superior a $25,6^{\circ} \mathrm{C}$ significa condição de desconforto ao calor.

As Tabelas 15, 15A, 16, 16A, 17 e 17A, referem-se a média diária, mas quando analisados as informações de hora em hora, conforme apresentados nas 
Figuras 17 a 22, os resultados são diferenciados, sendo estes com melhor representação, pois as respostas para a sensação de conforto ou de desconforto foram encontradas de acordo com a variação das temperaturas do termômetro seco e úmido, daquele momento.

Já na representação da média do termômetro seco e úmido do dia, na maior parcela das informações, mudaram-se completamente, consequentemente as faixas de conforto ou de desconforto, também mudaram.

De maneira geral, observou que baixas temperaturas, juntamente com baixa umidade relativa do ar, favorecem ao surgimento da temperatura efetiva para a condição de desconforto ao frio, que podem contribuir para os aumentos de problemas respiratórios nos meses de junho e de julho.

\subsubsection{ANÁLISE DE CONFORTO TÉRMICO, PARA O PERÍODO DE ESTUDO.}

Tabela 18: Médias mensais de temperatura do termômetro de bulbo seco (Ts), temperatura do termômetro de bulbo úmido (Tu), umidade relativa do ar (UR), temperatura efetiva (TE) e a sensação térmica, para 09h00min, 2000-2007.

\begin{tabular}{c|ccccc}
\hline $\begin{array}{c}\text { 09 horas } \\
\text { 12 TMG }\end{array}$ & $\begin{array}{c}\text { Ts } \\
\left({ }^{\circ} \mathbf{C}\right)\end{array}$ & $\begin{array}{c}\text { Tu } \\
\left({ }^{\circ} \mathbf{C}\right)\end{array}$ & $\begin{array}{c}\text { UR } \\
(\%)\end{array}$ & $\begin{array}{c}\text { TE } \\
\left({ }^{\circ} \mathbf{C}\right)\end{array}$ & $\begin{array}{c}\text { sensação } \\
\text { térmica }\end{array}$ \\
\hline $\begin{array}{c}\text { Janeiro } \\
\text { fevereiro }\end{array}$ & 24,5 & 21,8 & 79 & 23,3 & conforto \\
março & 24,1 & 21,3 & 78 & 23,0 & conforto \\
abril & 24,3 & 21,1 & 75 & 23,0 & conforto \\
maio & 22,9 & 19,6 & 74 & 21,8 & conforto \\
junho & 18,2 & 15,6 & 76 & $18,3^{*}$ & desconforto \\
julho & 18,6 & 15,8 & 75 & $18,6^{*}$ & desconforto \\
agosto & 16,9 & 14,0 & 73 & $17,2^{*}$ & desconforto \\
setembro & 19,2 & 15,0 & 64 & $18,5^{*}$ & desconforto \\
outubro & 20,5 & 16,5 & 67 & 19,6 & conforto \\
novembro & 23,3 & 19,3 & 69 & 21,8 & conforto \\
dezembro & 24,4 & 19,8 & 70 & 22,2 & Conforto \\
\hline
\end{tabular}

Temperatura Efetiva TE = inferior a 18,9ำ é considerada como condição de desconforto ao frio*, $(T E)=19,0^{\circ} \mathrm{C}$ a $25,5^{\circ} \mathrm{C}$, faixa de conforto térmico, $\mathrm{TE}=$ superior a $25,6^{\circ} \mathrm{C}$ significa condição de desconforto ao calor.

A Tabela 18 apresenta o comportamento das temperaturas do termômetro seco e úmido, da umidade relativa, da temperatura efetiva e a sensação térmica, de 09h00min, para o período de estudo. Nesse horário, as temperaturas normalmente são amenas, apresentando de janeiro a março, outubro e dezembro, entre $23,3^{\circ} \mathrm{C}$ a $24,5^{\circ} \mathrm{C}$, registradas no termômetro seco, o termômetro úmido apresentou $21,8^{\circ} \mathrm{C}$ em 
janeiro a $14,0^{\circ} \mathrm{C}$ em julho, as umidades relativa apresentam-se elevadas, oscilando entre $64 \%$ em agosto, $79 \%$ em janeiro e $74 \%$ em dezembro.

Destacou como faixa de conforto térmico, de janeiro a abril e de setembro a dezembro, com a TE variando entre $19,6^{\circ} \mathrm{C}$ em setembro e $23,3^{\circ} \mathrm{C}$ em janeiro. Maio a agosto, apresentaram-se com a TE para a condição de desconforto ao frio, de $18,3^{\circ} \mathrm{C}$ para maio, $18,6^{\circ} \mathrm{C}$ em junho, $17,2^{\circ} \mathrm{C}$ em julho, $18,5^{\circ} \mathrm{C}$ em agosto.

A Tabela 19 apresenta o comportamento das temperaturas do termômetro seco e úmido, da umidade relativa, da temperatura efetiva e a sensação térmica de $15 \mathrm{~h} 00 \mathrm{~min}$, para o período de estudo. Verificou-se que a temperatura do termômetro seco apresenta-se elevada, de janeiro a abril e de outubro a dezembro, permanecendo sempre acima de $28,0^{\circ} \mathrm{C}$ e a temperatura do termômetro úmido, oscilando entre $16,9^{\circ} \mathrm{C}$ em julho a $19,0^{\circ} \mathrm{C}$ em setembro.

Tabela 19: Médias mensais de temperatura do termômetro de bulbo seco (Ts), temperatura do termômetro de bulbo úmido (Tu), umidade relativa do ar (UR), temperatura efetiva (TE) e a sensação térmica, para 15h00min, 2000-2007.

\begin{tabular}{|c|c|c|c|c|c|}
\hline $\begin{array}{l}15 \text { horas } \\
18 \text { TMG }\end{array}$ & $\begin{array}{l}\text { Ts } \\
\left({ }^{\circ} \mathrm{C}\right)\end{array}$ & $\begin{array}{l}\mathrm{Tu} \\
(\stackrel{\circ}{\mathrm{C}})\end{array}$ & $\begin{array}{l}\text { UR } \\
\text { (\%) }\end{array}$ & $\begin{array}{l}\text { TE } \\
(\stackrel{\circ}{-C})\end{array}$ & $\begin{array}{c}\text { sensação } \\
\text { térmica }\end{array}$ \\
\hline Janeiro & 28,7 & 23,7 & 66 & $25,8^{* *}$ & desconforto \\
\hline fevereiro & 29,1 & 23,3 & 61 & $25,8^{* *}$ & desconforto \\
\hline março & 29,7 & 23,0 & 57 & $25,9^{* *}$ & desconforto \\
\hline abril & 28,5 & 21,7 & 55 & 24,9 & conforto \\
\hline maio & 23,8 & 18,2 & 58 & 21,6 & conforto \\
\hline junho & 24,6 & 18,5 & 55 & 22,0 & conforto \\
\hline julho & 23,2 & 16,9 & 53 & 20,8 & conforto \\
\hline agosto & 26,3 & 18,0 & 44 & 22,5 & conforto \\
\hline setembro & 26,6 & 19,0 & 50 & 23,0 & conforto \\
\hline outubro & 28,6 & 21,1 & 53 & 24,7 & conforto \\
\hline novembro & 28,3 & 21,7 & 57 & 24,8 & conforto \\
\hline dezembro & 29,0 & 22,9 & 60 & $25,6^{\star *}$ & desconforto \\
\hline
\end{tabular}

Temperatura Efetiva TE = inferior a 18,9 ${ }^{\circ} \mathrm{C}$ é considerada como condição de desconforto ao frio, (TE) $=19,0^{\circ} \mathrm{C}$ a $25,5^{\circ} \mathrm{C}$, faixa de conforto térmico, $\mathrm{TE}=$ superior a $25,6^{\circ} \mathrm{C}$ significa condição de desconforto ao calor**.

A umidade relativa apresentou com $66 \%$ em janeiro, baixa, principalmente em julho e outubro com $53 \%$, agosto com $44 \%$ e setembro com $50 \%$. Em relação a Temperatura efetiva, destacou para a condição de desconforto ao calor, sendo a TE de $25,8^{\circ} \mathrm{C}$ para janeiro e fevereiro, março $25,9^{\circ} \mathrm{C}$ e dezembro $25,6^{\circ} \mathrm{C}$. Os meses de abril a novembro, apresentaram-se na faixa de conforto térmico, com a TE oscilando entre $20,8^{\circ} \mathrm{C}$ em julho a $24,9^{\circ} \mathrm{C}$ em abril.

A Tabela 20 apresenta o comportamento das temperaturas do termômetro seco e úmido, da umidade relativa, da temperatura efetiva e a sensação térmica, 
para 21 h00min. Nesse horário as temperaturas do termômetro seco, $\operatorname{com} 28,2^{\circ} \mathrm{C}$ registradas em dezembro. Demais meses registraram baixas de $18,8^{\circ} \mathrm{C}$ em maio, $19,4^{\circ} \mathrm{C}$ em junho, $18,1^{\circ} \mathrm{C}$ em julho, $20,5^{\circ} \mathrm{C}$ em agosto.

A temperatura do termômetro úmido apresentou-se entre $14,9^{\circ} \mathrm{C}$ para julho, até $24,4^{\circ} \mathrm{C}$ em dezembro. A umidade relativa permaneceu elevada para todos os meses, apenas agosto apresentou $61 \%$ e setembro $65 \%$.

A faixa de conforto térmico apresentou de janeiro a abril e de setembro a novembro, com a TE oscilando entre $20,2^{\circ} \mathrm{C}$ em setembro, $23,6^{\circ} \mathrm{C}$ em janeiro. Para a condição de desconforto ao frio, TE de $18,8^{\circ} \mathrm{C}$ destacou maio e junho, de $18,0^{\circ} \mathrm{C}$ para julho e agosto de $18,9^{\circ} \mathrm{C}$. Na condição de desconforto ao calor apresentou para o mês de dezembro, de $25,8^{\circ} \mathrm{C}$.

Tabela 20: Médias mensais de temperatura do termômetro de bulbo seco (Ts), temperatura do termômetro de bulbo úmido (Tu), umidade relativa do ar (UR), temperatura efetiva (TE) e a sensação térmica, para $21 \mathrm{~h} 00 \mathrm{~min}, 2000-2007$.

\begin{tabular}{c|ccccc}
\hline $\begin{array}{c}\text { 21horas } \\
\text { 00 TMG }\end{array}$ & $\begin{array}{c}\text { Ts } \\
\text { (o- })\end{array}$ & $\begin{array}{c}\text { Tu } \\
\text { (o- })\end{array}$ & $\begin{array}{c}\text { UR } \\
(\%)\end{array}$ & $\begin{array}{c}\text { TE } \\
(\mathbf{(} \mathbf{C})\end{array}$ & $\begin{array}{c}\text { sensação } \\
\text { térmica }\end{array}$ \\
\hline $\begin{array}{c}\text { Janeiro } \\
\text { fevereiro }\end{array}$ & 24,7 & 22,2 & 81 & 23,6 & conforto \\
março & 24,5 & 21,8 & 79 & 23,3 & conforto \\
abril & 24,9 & 21,5 & 73 & 23,4 & conforto \\
maio & 23,7 & 20,1 & 72 & 22,3 & conforto \\
junho & 18,8 & 16,6 & 76 & $18,8^{*}$ & desconforto \\
julho & 19,4 & 16,5 & 75 & $18,8^{*}$ & desconforto \\
agosto & 18,1 & 14,9 & 71 & $18,0^{*}$ & desconforto \\
setembro & 20,5 & 16,3 & 61 & $18,9^{*}$ & desconforto \\
outubro & 21,2 & 17,2 & 65 & 20,2 & conforto \\
novembro & 23,8 & 19,8 & 70 & 22,2 & conforto \\
dezembro & 23,8 & 20,0 & 72 & 22,3 & conforto \\
\hline
\end{tabular}

Temperatura Efetiva TE = inferior a 18,9ㄷ é considerada como condição de desconforto ao frio*, $(T E)=19,0^{\circ} \mathrm{C}$ a $25,5^{\circ} \mathrm{C}$, faixa de conforto térmico, $\mathrm{TE}=$ superior a $25,6^{\circ} \mathrm{C}$ significa condição de desconforto ao calor ${ }^{\star *}$.

Através dos horários 09h00min, 15h00min e 21h00min, do período de estudo, observou que em linhas gerais, a condição de desconforto ao frio ocorrem de manhã e noite, para maio, junho, julho e agosto, sendo à tarde para esses meses, na faixa de conforto térmico.

Para a condição de desconforto ao calor, ocorreu à tarde, para janeiro até março. Sendo que a faixa de conforto térmico ocorreu para esses meses de manhã e noite. Em dezembro ocorreu a condição de desconforto ao calor, no período da tarde e da noite. Para o período de estudo, o número absoluto de registros de internações e de óbitos são proporcionalmente baixos para os meses de janeiro com 
999 internações e 53 óbitos, fevereiro 1.049 internações e 52 óbitos, novembro com 1.334 internações e 50 óbitos, dezembro com 1.039 internações e 54 óbitos, meses em que predominam para a faixa de conforto térmico, TE entre $19,0^{\circ} \mathrm{C}$ a $25,5^{\circ} \mathrm{C}$, ou para o desconforto ao calor, TE acima de $25,6^{\circ} \mathrm{C}$.

Predominaram para a condição de desconforto ao frio, com a TE abaixo de $18,9^{\circ} \mathrm{C}$ de maio a agosto, notadamente, para esses meses ocorreram mais variação no tempo atmosférico, destacando-se para o maior número de registros de internações, sendo maio 1.788 internações e 59 óbitos, junho 1.943 internações e 70 óbitos, julho 1.872 internações e 82 óbitos, agosto 1.774 internações e 72 óbitos.

\subsubsection{ANÁLISE DE REGRESSÃO MÚLTIPLA}

A análise de regressão múltipla é um método matemático, apropriado para indicar estatisticamente se os dados meteorológicos têm relação com os problemas respiratórios, foram observados o valores de $R$, que é o coeficiente de correlação e $R^{2}$, que é o coeficiente de determinação e o valor de $p<0,05$.

Os resultados obtidos referente aos valores de $\mathrm{R}$ e $\mathrm{R}^{2}$ deverão apresentar-se mais elevados possíveis, ou seja, se mostrar um valor de 0,75 isso indica que $75 \%$ de resposta têm relação com a quantidade de registros de internações, devendo ser significativos em $p<0,05$. Se apresentar um resultado de $p<0,06$ ou mais, indica a inexistência de correlação, entre as variáveis utilizadas e as internações.

Utilizou nessa análise a temperatura máxima, temperatura média, temperatura mínima, temperatura efetiva, umidade relativa do ar e a precipitação pluvial, como variáveis independentes e o número absoluto dos registros de doenças respiratórias como variável dependente.

Fez-se a análise sem defasagem para janeiro de 2000, 2003 e 2007. Já para os meses de julho de 2000, junho de 2003 e junho de 2007, fez-se primeiro sem defasagem e na sequência aplicou o teste de defasagem, de um a sete dias consecutivos, com a finalidade de verificar estatisticamente se as condições do tempo atmosférico em um determinado dia poderão contribuir com os problemas respiratórios, durante os próximos dias.

A Tabela 21 apresenta a análise de regressão múltipla, para o mês de janeiro de 2000. O coeficiente de correlação foi $R=0,48$, o coeficiente de determinação foi 
de $R^{2}=28$, não significativos em $p<0,06$, apresentando relação com a temperatura mínima e a umidade relativa, ao nível-p.

Embora os dados meteorológicos mostraram-se com correlação os valores de $R, R^{2}$ em $p$, não foram significativos, provavelmente isso ocorreu, devido a alguns dias apresentarem com registros de internações muito baixo, nesse caso, a temperatura mínima e a umidade relativa que mostraram relação, podem ser desconsideradas.

Tabela 21: Resumo da análise de regressão múltipla, como variáveis independentes: as temperaturas máxima $\left({ }^{\circ} \mathrm{C}\right)$, mínima $\left({ }^{\circ} \mathrm{C}\right)$, média $\left({ }^{\circ} \mathrm{C}\right)$ e a temperatura efetiva $\left({ }^{\circ} \mathrm{C}\right)$, umidade relativa do ar (\%), precipitação pluvial $(\mathrm{mm})$. Variável dependente: o número absoluto das internações por doenças respiratórias. Janeiro de 2000.

Sem defasagem

$\mathbf{R}=\mathbf{0 , 4 8 7 6} \mathbf{R}^{\mathbf{2}}=\mathbf{0 , 2 8 8 0}$ Ajuste $R^{2}=0,6456 \mathrm{~F}(5,25)=18,585 \mathbf{p}<\mathbf{0 , 0 6}$. Erro estimado: 41,781

\begin{tabular}{ccccccc}
\hline & Beta & De Beta & B & De Beta & $t(23)$ & Nível-p \\
\hline Intercept & & & 369,0496 & 194,2454 & 1,8999 & 0,0690 \\
T. máxima & 0,0571 & 0,1920 & 2,4514 & 8,2345 & 0,2977 & 0,7683 \\
T. mínima* & 0,3928 & 0,1514 & 18,5600 & 7,1551 & 2,5939 & $\mathbf{0 , 0 1 5 6}$ \\
T. média & $-0,5021$ & 0,2847 & $-21,9992$ & 12,4742 & $-1,7635$ & 0,0991 \\
T. efetiva & 0,0156 & 0,1806 & 0,15 & 1,7043 & 0,0866 & 0,9318 \\
Umidade* & $-0,3669$ & 0,1589 & $-2,9176$ & 1,2642 & $-2,3079$ & $\mathbf{0 , 0 2 9 5}$ \\
Precipitação & 0,9421 & 0,0995 & 4,3446 & 0,4592 & 9,4618 & 0,6813 \\
\hline
\end{tabular}

Negrito: $R$ - coeficiente de correlação, $R^{2}$ - coeficiente de determinação e $p<0,05$. (Negrito* as variáveis meteorológicas que mostraram correlação ao nível-p).

A Tabela 22 apresenta a análise de regressão múltipla, para o mês de julho de 2000, sem defasagem. Os valores obtidos foram $R=0,91, R^{2}=0,83$, significativos em $p<0,004$, mostrou-se relacionada a temperatura mínima, temperatura média, temperatura efetiva, umidade relativa e a precipitação pluvial.

$\mathrm{Na}$ sequência, em relação às defasagens, de um a sete dias, observou que o coeficiente de correlação e o coeficiente de determinação, mostraram-se com menores valores para a defasagem de dois dias, sendo $R=0,65, R^{2}=0,43 \mathrm{e}$ $p<0,034$, para a defasagem de três dias $R=0,64, R^{2}=0,41$ e $p<0,046$.

Os maiores valores foram obtidos na defasagem de cinco dias, sendo de $\mathrm{R}=$ $0,79, R^{2}=0,62$ e $p<0,002$, na defasagem de seis dias, $R=0,70, R^{2}=0,49$ e $p<0,035$ e na defasagem de sete dias $R=0,69, R^{2}=0,48$ e $p<0,0002$.

Observou que de todas as variáveis meteorológicas relacionadas a temperatura mínima, temperatura média e a precipitação pluvial, apresentaram várias vezes correlacionadas com o número de registros de internações, ao nível-p. 
Tabela 22: Resumo da análise de regressão múltipla, como variáveis independentes: as temperaturas máxima $\left({ }^{\circ} \mathrm{C}\right)$, mínima $\left({ }^{\circ} \mathrm{C}\right)$, média $\left({ }^{\circ} \mathrm{C}\right)$ e a temperatura efetiva $\left({ }^{\circ} \mathrm{C}\right)$, umidade relativa do ar (\%), precipitação pluvial $(\mathrm{mm})$. Variável dependente: o número absoluto das internações por doenças respiratórias. Julho de 2000.

Sem defasagem

$\mathbf{R}=\mathbf{0 , 9 1 6 3} \mathbf{R}^{\mathbf{2}}=\mathbf{0 , 8 3 9 6}$ Ajuste $\mathrm{R}^{2}=0,7908 \mathrm{~F}(7,23)=17,209 \mathbf{p}<\mathbf{0 , 0 0 4}$ Erro estimado: 37,879

\begin{tabular}{ccccccc}
\hline & Beta & De Beta & B & De Beta & t(22) & Nível-p \\
\hline Intercept & & & 7919,097 & 3567,555 & 2,2197 & 0,0365 \\
T. máxima & 0,2799 & 0,1925 & 12,006 & 8,259 & 1,4535 & 0,1595 \\
T. mínima* $^{\text {T. média* }}$ & 0,4132 & 0,1384 & 19,525 & 6,543 & 2,9842 & $\mathbf{0 , 0 0 6 6}$ \\
T. efetiva* & $-0,7672$ & 0,2758 & $-33,614$ & 12,087 & $-2,7809$ & $\mathbf{0 , 0 1 0 6}$ \\
Umidade* $^{\text {Precipitação* }}$ & $-0,2029$ & 0,1016 & $-7,597$ & 3,804 & $-1,9968$ & $\mathbf{0 , 0 0 7 8}$ \\
\hline
\end{tabular}

Defasagem de um dia

$\mathbf{R}=\mathbf{0 , 6 6 5 3} \mathbf{R}^{\mathbf{2}}=\mathbf{0 , 4 4 2 7} \mathrm{F}(6,23)=3,0452 \mathbf{p}<\mathbf{0 , 0 2 4}$ Erro estimado: 9,7989

\begin{tabular}{ccccccc}
\hline & Beta & De Beta & B & De Beta & $\mathrm{t}(23)$ & Nível-p \\
\hline Intercept & & & 111,5780 & 38,0412 & 2,9330 & 0,0074 \\
T. máxima & $-0,3434$ & 0,3636 & $-0,8129$ & 0,8608 & $-0,9443$ & 0,3547 \\
T. mínima* $^{*}$. média* & 0,9452 & 0,4025 & 3,2505 & 1,3842 & 2,3481 & $\mathbf{0 , 0 2 7 8}$ \\
T. efetiva & $-1,4749$ & 0,4508 & $-5,7804$ & 1,7666 & $-3,2719$ & $\mathbf{0 , 0 0 3 3}$ \\
Umidade & 0,2905 & 0,3731 & 0,8734 & 1,1215 & 0,7787 & 0,4440 \\
Precipitação & $-0,2553$ & 0,2336 & $-0,3444$ & 0,3152 & $-1,0926$ & 0,2858 \\
\hline
\end{tabular}

Defasagem de dois dias

$\mathbf{R}=\mathbf{0 , 6 5 9 0} \mathbf{R}^{\mathbf{2}}=\mathbf{0 , 4 3 4 3} F(6,22)=2,8151 \mathbf{p}<\mathbf{0 , 0 3 4}$ Erro estimado: 17,708

\begin{tabular}{ccccccc}
\hline & Beta & De Beta & B & De Beta & $t(22)$ & Nível-p \\
\hline Intercept & & & 142,0621 & 67,7948 & 2,0954 & 0,0478 \\
T. máxima* & $-0,3982$ & 0,3725 & $-1,6793$ & 1,5708 & $-1,0690$ & 0,2966 \\
T. mínima & 0,9087 & 0,4310 & 5,6034 & 2,6580 & 2,1080 & $\mathbf{0 , 0 4 6 6}$ \\
T. média* & $-1,3836$ & 0,4777 & $-9,6398$ & 3,3286 & $-2,8959$ & $\mathbf{0 , 0 0 8 3}$ \\
T. efetiva & 0,4359 & 0,3807 & 2,3162 & 2,0228 & 1,1450 & 0,2645 \\
Umidade & $-0,0315$ & 0,2475 & $-0,0746$ & 0,5861 & $-0,1273$ & 0,8998 \\
Precipitação* $^{*}$ & $-0,4677$ & 0,2138 & $-7,0137$ & 3,2061 & $-2,1875$ & $\mathbf{0 , 0 3 9 6}$ \\
\hline
\end{tabular}

Defasagem de três dias

$\mathbf{R}=\mathbf{0 , 6 4 4 4} \mathbf{R}^{\mathbf{2}}=\mathbf{0 , 4 1 5 3} \mathrm{F}(6,21)=2,4863 \mathbf{p}<\mathbf{0 , 0 4 6}$ Erro estimado: 11,995

\begin{tabular}{ccccccc}
\hline & Beta & De Beta & B & De Beta & $\mathrm{t}(21)$ & Nível-p \\
\hline Intercept & & & 97,9417 & 46,2244 & 2,1188 & 0,0461 \\
T. máxima & $-0,0032$ & 0,3875 & $-0,0091$ & 1,0891 & $-0,0083$ & 0,9934 \\
T. mínima & 0,8815 & 0,4473 & 3,7361 & 1,8959 & 1,9706 & 0,0620 \\
T. média* & $-1,4015$ & 0,4987 & $-6,4904$ & 2,3095 & $-2,8102$ & $\mathbf{0 , 0 1 0 4}$ \\
T. efetiva & 0,0128 & 0,3980 & 0,0448 & 1,3912 & 0,0322 & 0,9745 \\
Umidade & $-0,0282$ & 0,2590 & $-0,0435$ & 0,3995 & $-0,1089$ & 0,9142 \\
Precipitação & $-0,4127$ & 0,2224 & $-4,0314$ & 2,1725 & $-1,8556$ & 0,0775 \\
\hline
\end{tabular}

Defasagem de quatro dias

$\mathbf{R}=\mathbf{0 , 6 7 9 0} \mathbf{R}^{\mathbf{2}}=\mathbf{0 , 4 6 1 0} \mathrm{F}(6,20)=2,8516 \mathbf{p}<\mathbf{0 , 0 3 5}$ Erro estimado: 16,507

\begin{tabular}{ccccccc}
\hline & Beta & De Beta & B & De Beta & t(20) & Nível-p \\
\hline Intercept & & & 148,8942 & 63,6127 & 2,3406 & 0,0297 \\
T. máxima & $-0,1736$ & 0,3843 & $-0,6959$ & 1,5404 & $-0,4517$ & 0,6562 \\
T. mínima* $^{0,9832}$ & 0,4240 & 6,0594 & 2,6135 & 2,3184 & $\mathbf{0 , 0 3 1 1}$ \\
\cline { 3 - 7 }
\end{tabular}




\begin{tabular}{ccccccc}
\cline { 2 - 7 } T. média* & $-1,4927$ & 0,4688 & $-10,1335$ & 3,1829 & $-3,1837$ & $\mathbf{0 , 0 0 4 6}$ \\
T. efetiva & 0,2186 & 0,3985 & 1,0752 & 1,9604 & 0,5484 & 0,5894 \\
Umidade & $-0,0681$ & 0,2533 & $-0,1504$ & 0,5588 & $-0,2690$ & 0,7906 \\
Precipitação* & $-0,5056$ & 0,2230 & $-6,9140$ & 3,0502 & $-2,2666$ & $\mathbf{0 , 0 3 4 6}$ \\
\hline
\end{tabular}

Defasagem de cinco dias

$\mathbf{R}=\mathbf{0 , 7 9 0 9} \mathbf{R}^{\mathbf{2}}=\mathbf{0 , 6 2 5 5} \mathrm{F}(6,19)=5,2909 \mathbf{p}<\mathbf{0 , 0 0 2}$ Erro estimado: 17,626

\begin{tabular}{ccccccc}
\hline & Beta & De Beta & B & De Beta & $\mathrm{t}(19)$ & Nível-p \\
\hline Intercept & & & 43,8328 & 67,9236 & 0,6453 & 0,5264 \\
T. máxima & 0,0909 & 0,3320 & 0,4593 & 1,6777 & 0,2738 & 0,7871 \\
T. mínima & 0,4442 & 0,3672 & 3,4400 & 2,8436 & 1,2097 & 0,2412 \\
T. média & $-0,4627$ & 0,4057 & $-3,9221$ & 3,4395 & $-1,1403$ & 0,2683 \\
T. efetiva & $-0,1199$ & 0,3436 & $-0,7373$ & 2,1130 & $-0,3489$ & 0,7309 \\
Umidade & 0,0181 & 0,2154 & 0,0503 & 0,5970 & 0,0842 & 0,9337 \\
Precipitação* & 0,6116 & 0,1930 & 10,4429 & 3,2953 & 3,1690 & $\mathbf{0 , 0 0 5 0}$ \\
\hline
\end{tabular}

Defasagem de seis dias

$\mathbf{R}=\mathbf{0 , 7 0 3 5} \mathbf{R}^{\mathbf{2}}=\mathbf{0 , 4 9 5 0} F(6,18)=2,9410 \mathbf{p}<\mathbf{0 , 0 3 5}$ Erro estimado: 7,2890

\begin{tabular}{|c|c|c|c|c|c|c|}
\hline & Beta & De Beta & $B$ & De Beta & $t(18)$ & Nível-p \\
\hline Intercept & & & 82,6441 & 28,2903 & 2,9212 & 0,0091 \\
\hline T. máxima & 0,2376 & 0,4082 & 0,4205 & 0,7224 & 0,5820 & 0,5677 \\
\hline T. mínima* & 0,9729 & 0,4386 & 2,6117 & 1,1775 & 2,2178 & 0,0396 \\
\hline T. média* & $-1,5779$ & 0,4845 & $-4,6370$ & 1,4238 & $-3,2566$ & 0,0043 \\
\hline T. efetiva & $-0,1977$ & 0,4219 & $-0,4215$ & 0,8996 & $-0,4685$ & 0,6449 \\
\hline Umidade & $-0,2133$ & 0,2590 & $-0,2057$ & 0,2497 & $-0,8235$ & 0,4209 \\
\hline Precipitação* & $-0,5826$ & 0,2319 & $-3,4507$ & 1,3738 & $-2,5116$ & 0,0217 \\
\hline
\end{tabular}

Defasagem de sete dias

$\mathbf{R}=\mathbf{0 , 6 9 7 7} \mathbf{R}^{\mathbf{2}}=\mathbf{0 , 4 8 2 9} \quad \mathrm{F}(6,17)=8,6371 \quad \mathbf{p}<\mathbf{0 , 0 0 0 2}$ Erro estimado: 5,5970

\begin{tabular}{ccccccc}
\hline & Beta & De Beta & B & De Beta & $\mathrm{t}(17)$ & Nível-p \\
\hline Intercept & & & 8,9494 & 21,8438 & 0,4097 & 0,6871 \\
T. máxima & 0,3156 & 0,2969 & 0,5961 & 0,5606 & 1,0632 & 0,3025 \\
T. mínima & 0,2932 & 0,3282 & 0,8412 & 0,9416 & 0,8933 & 0,3841 \\
T. média & $-0,3304$ & 0,3624 & $-1,0398$ & 1,1407 & $-0,9115$ & 0,3747 \\
T. efetiva & $-0,3365$ & 0,3069 & $-0,7664$ & 0,6992 & $-1,0962$ & 0,2882 \\
Umidade & 0,1773 & 0,1846 & 0,1849 & 0,1925 & 0,9608 & 0,3501 \\
Precipitação* & 0,6088 & 0,1736 & 3,8503 & 1,0984 & 3,5053 & $\mathbf{0 , 0 0 2 7}$ \\
\hline
\end{tabular}

Negrito: $R$ - coeficiente de correlação, $R^{2}$ - coeficiente de determinação e $p<0,05$. (Negrito* as variáveis meteorológicas que mostraram correlação ao nível-p).

A Tabela 23, apresenta a análise de regressão múltipla para janeiro de 2003, embora os valores de $R=0,61, R^{2}=0,45$, significativo em $p<0,04$, nenhuma variável climática mostrou-se correlacionada, ao nível-p.

Tabela 23: Resumo da análise de regressão múltipla, como variáveis independentes: as temperaturas máxima $\left({ }^{\circ} \mathrm{C}\right)$, mínima $\left({ }^{\circ} \mathrm{C}\right)$, média $\left({ }^{\circ} \mathrm{C}\right)$ e a temperatura efetiva $\left({ }^{\circ} \mathrm{C}\right)$, a umidade relativa do ar (\%), precipitação pluvial $(\mathrm{mm})$. Variável dependente: o número absoluto das internações por doenças respiratórias. Janeiro de 2003.

Sem defasagem

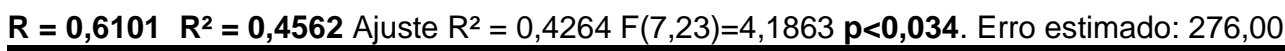

Beta $\quad$ De Beta $\quad$ De Beta t(23)

Nível-p




\begin{tabular}{crrrrrr}
\hline Intercept & & & 1358,092 & 648,0323 & 2,0957 & 0,0463 \\
T. máxima & 1,4192 & 0,2641 & 72,554 & 13,5038 & 5,3728 & 0,4532 \\
T. mínima & 0,3627 & 0,1613 & 41,024 & 18,2446 & 2,2485 & 0,1336 \\
T. média & $-2,2060$ & 0,3721 & $-139,608$ & 23,5506 & $-5,9280$ & 0,3688 \\
T. efetiva & 0,7369 & 1,7941 & 2,67 & 6,50 & 0,4107 & 0,6852 \\
Umidade & $-0,7485$ & 0,2668 & $-8,931$ & 3,1834 & $-2,8056$ & 0,2215 \\
Precipitação & $-0,1357$ & 0,1594 & $-1,177$ & 1,3826 & $-0,8510$ & 0,4028 \\
\hline
\end{tabular}

Negrito: $R$ - coeficiente de correlação, $R^{2}$ - coeficiente de determinação e $p<0,05$. (Negrito* as variáveis meteorológicas que mostraram correlação ao nível-p.).

A Tabela 24 apresenta a análise de regressão múltipla, para o mês de junho de 2003. Os valores obtidos foram $R=0,83, R^{2}=0,70$, significativos em $p<0,001$, mostrou-se relacionada a temperatura efetiva, a umidade relativa e a precipitação pluvial.

$\mathrm{Na}$ sequência apresentam-se as defasagens, observou o coeficiente de correlação e o coeficiente de determinação mostrando $R=0,76$ e $R^{2}=0,58$, significativos em $p<0,001$ e $p<0,003$ nas defasagens de um e três dias, aumentando gradualmente até apresentar-se com $R=0,81, R^{2}=0,65$ e $p<0,002$ na defasagem de sete dias.

Das variáveis meteorológicas relacionadas, foram a temperatura mínima, temperatura média, temperatura efetiva, umidade relativa que apresentaram-se correlacionadas com o número de registros de internações. Sendo a precipitação pluvial mostrando-se correlacionada apenas na análise sem defasagem, ao nível-p.

Tabela 24: Resumo da análise de regressão múltipla, como variáveis independentes: as temperaturas máxima $\left({ }^{\circ} \mathrm{C}\right)$, mínima $\left({ }^{\circ} \mathrm{C}\right)$, média $\left({ }^{\circ} \mathrm{C}\right)$ e a temperatura efetiva, $\left({ }^{\circ} \mathrm{C}\right)$, a umidade relativa do ar (\%), precipitação pluvial $(\mathrm{mm})$. Variável dependente: o número absoluto das internações por doenças respiratórias. Junho de 2003.

Sem defasagem

$\underline{\mathbf{R}=\mathbf{0 , 8 3 8 1} \mathbf{R}^{\mathbf{2}}=\mathbf{0 , 7 0 2 5} \text { Ajuste } R^{2}=0,6078 \mathrm{~F}(7,22)=7,4216 \mathbf{p}<\mathbf{0 , 0 0 1} \text { Erro de estimação: } 134,10}$

\begin{tabular}{ccccccc}
\hline & Beta & De Beta & B & De Beta & t(22) & Nível-p \\
\hline Intercept & & & 35559,21 & 20722,87 & 1,71594 & 0,1002 \\
T. máxima & 0,1930 & 0,5240 & 1,5240 & 4,1379 & 0,3683 & 0,7162 \\
T. mínima & $-0,0638$ & 0,2914 & $-0,3851$ & 1,7588 & $-0,2189$ & 0,8287 \\
T. média & $-0,7991$ & 1,9588 & $-4,1609$ & 10,1994 & $-0,4080$ & 0,6873 \\
T. efetiva* & 0,7481 & 0,1314 & 23,7255 & 4,1672 & 5,6934 & $\mathbf{0 , 0 0 9 9}$ \\
Umidade* $^{\text {Umecipitação* }}$ & $-0,2997$ & 0,1222 & $-3,2561$ & 1,3270 & $-2,4537$ & $\mathbf{0 , 0 2 2 5}$ \\
Pren $^{*}$ & $-0,2482$ & 0,1384 & $-38,7269$ & 21,6005 & $-1,7929$ & $\mathbf{0 , 0 1 6 8}$ \\
\hline
\end{tabular}

Defasagem de um dia

$\mathbf{R}=\mathbf{0 , 7 6 4 2} \mathbf{R}^{\mathbf{2}}=\mathbf{0 , 5 8 4 0} \mathrm{F}(6,22)=5,1480 \quad \mathbf{p}<\mathbf{0 , 0 0 1}$ Erro estimado: 17,565

\begin{tabular}{ccccccc}
\hline & Beta & De Beta & B & De Beta & $\mathrm{t}(23$ & Nível-p \\
\hline Intercept & & & 47,0105 & 68,4151 & 0,6871 & 0,4991 \\
T. máxima & $-1,2108$ & 0,8816 & $-9,9720$ & 7,2606 & $-1,3734$ & 0,1834 \\
T. mínima & 0,6554 & 0,5695 & 4,6750 & 4,0620 & 1,1508 & 0,2621 \\
\cline { 2 - 7 }
\end{tabular}




\begin{tabular}{ccccccc} 
T. média* & 6,0435 & 1,3059 & 48,7048 & 10,5247 & 4,6276 & $\mathbf{0 , 0 0 0 1}$ \\
T. efetiva* $^{*}$ & $-5,0486$ & 1,2492 & $-59,9888$ & 14,8438 & $-4,0413$ & $\mathbf{0 , 0 0 0 5}$ \\
Umidade* $^{*}$ & 1,5971 & 0,3342 & 4,3745 & 0,9154 & 4,7787 & $\mathbf{0 , 0 0 0 9}$ \\
Precipitação & $-0,3192$ & 0,1910 & $-5,5375$ & 3,3133 & $-1,6713$ & 0,1088 \\
\hline
\end{tabular}

Defasagem de dois dias

$\mathbf{R}=\mathbf{0 , 7 8 6 5} \mathbf{R}^{\mathbf{2}}=\mathbf{0 , 6 1 8 6} F(6,21)=5,6789 \mathbf{p}<\mathbf{0 , 0 0 1}$ Erro estimado: 15,898

\begin{tabular}{ccccccc}
\hline & Beta & De Beta & B & De Beta & t(21) & Nível-p \\
\hline Intercept & & & 40,1315 & 62,2558 & 0,6446 & 0,5261 \\
T. máxima & $-1,0247$ & 0,8556 & $-7,8748$ & 6,5751 & $-1,1976$ & 0,2443 \\
T. mínima* $^{\text {T. média* }}$ & 6,0670 & 1,2542 & 46,1105 & 9,5323 & 4,8372 & $\mathbf{0 , 0 0 0 8}$ \\
T. efetiva* $_{\text {Umidade }}^{-5,2333}$ & 1,1899 & $-59,0872$ & 13,4351 & $-4,3979$ & $\mathbf{0 , 0 0 0 2}$ \\
Precipitação & 1,6800 & 0,3282 & 4,2522 & 0,8308 & 5,1179 & $\mathbf{0 , 0 0 0 4}$ \\
\hline
\end{tabular}

Defasagem de três dias

$\mathbf{R}=\mathbf{0 , 7 6 8 0 0} \mathbf{R}^{\mathbf{2}}=\mathbf{0 , 5 8 9 8} F(6,20)=4,7934 \mathbf{p}<\mathbf{0 , 0 0 3}$ Erro estimado: 12,706

\begin{tabular}{ccccccc}
\hline & Beta & De Beta & B & De Beta & $t(21)$ & Nível-p \\
\hline Intercept & & & 38,8224 & 50,0729 & 0,7753 & 0,4472 \\
T. máxima & $-0,4983$ & 1,0346 & $-2,9406$ & 6,1056 & $-0,4816$ & 0,6353 \\
T. mínima & 0,8634 & 0,5865 & 4,6951 & 3,1890 & 1,4722 & 0,1565 \\
T. média & 5,1889 & 1,3233 & 31,0801 & 7,9265 & 3,9210 & $\mathbf{0 , 0 0 0 8}$ \\
T. efetiva* & $-5,1813$ & 1,2592 & $-45,8228$ & 11,1364 & $-4,1146$ & $\mathbf{0 , 0 0 0 5}$ \\
Umidade* $_{\text {Precipitação }}^{1,6354}$ & 0,3534 & 3,1825 & 0,6878 & 4,6270 & $\mathbf{0 , 0 0 0 1}$ \\
Pren $^{*}$ & $-0,3462$ & 0,1989 & $-4,1772$ & 2,4002 & $-1,7403$ & 0,0971 \\
\hline
\end{tabular}

Defasagem de quatro dias

$\mathbf{R}=\mathbf{0 , 7 6 8 8} \mathbf{R}^{\mathbf{2}}=\mathbf{0 , 5 9 1 1} \quad \mathrm{F}(6,19)=4,5779 \mathbf{p}<\mathbf{0 , 0 0 4}$ Erro estimado: 11,576

\begin{tabular}{ccccccc}
\hline & Beta & De Beta & B & De Beta & $t(20)$ & Nível-p \\
\hline Intercept & & & 44,6285 & 45,7397 & 0,9757 & 0,3414 \\
T. máxima & 0,1129 & 1,2788 & 0,5932 & 6,7181 & 0,0883 & 0,9305 \\
T. mínima* $^{*}$ T. média & 4,8733 & 1,4190 & 25,9611 & 7,5594 & 3,4342 & $\mathbf{0 , 0 0 2 7}$ \\
T. efetiva* & 1,2621 & 0,7236 & 6,1415 & 3,5211 & 1,7441 & 0,0972 \\
Umidade* $_{\text {Precipitação }}^{-5,7930}$ & 1,4237 & $-45,5899$ & 11,2044 & $-4,0689$ & $\mathbf{0 , 0 0 0 6}$ \\
Pren $^{*}$ & $-0,2767$ & 0,3803 & 2,9198 & 0,6622 & 4,4090 & $\mathbf{0 , 0 0 0 3}$ \\
\hline
\end{tabular}

Defasagem de cinco dias

$\mathbf{R}=\mathbf{0 , 8 0 7 2} \mathbf{R}^{\mathbf{2}}=\mathbf{0 , 6 5 1 5} \mathrm{F}(6,19)=5,9219 \mathrm{p}<\mathbf{0 , 0 0 1 2}$ Erro estimado: 14,622

\begin{tabular}{|c|c|c|c|c|c|c|}
\hline & Beta & De Beta & $\bar{B}$ & De Beta & $t(19)$ & Nível-p \\
\hline Intercept & & & 59,5380 & 57,77618 & 1,03049 & 0,315719 \\
\hline T. máxima & 0,09432 & 1,180543 & 0,6780 & 8,48599 & 0,07990 & 0,937154 \\
\hline T. mínima* & 1,32808 & 0,667981 & 8,8431 & 4,44780 & 1,98821 & 0,021390 \\
\hline T. média* & 5,11530 & 1,309926 & 37,2882 & 9,54877 & 3,90503 & 0,000952 \\
\hline T. efetiva* & $-6,05845$ & 1,314261 & $-65,2416$ & 14,15287 & $-4,60978$ & 0,000191 \\
\hline Umidade $^{\star}$ & 1,75598 & 0,351092 & 4,1838 & 0,83650 & 5,00148 & 0,000079 \\
\hline Precipitação & $-0,30718$ & 0,188139 & $-4,5101$ & 2,76226 & $-1,63275$ & 0,118985 \\
\hline
\end{tabular}

Defasagem de seis dias

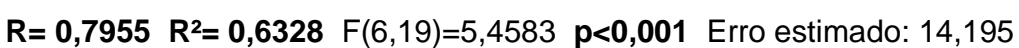

\begin{tabular}{ccccccc}
\hline & Beta & De Beta & B & De Beta & t(18) & Nível-p \\
\hline Intercept & & & 50,0249 & 56,08869 & 0,89189 & 0,383608 \\
T. máxima & 0,13777 & 1,211855 & 0,9366 & 8,23813 & 0,11369 & 0,910679 \\
T. mínima & $-0,35930$ & 0,193129 & $-4,9889$ & 2,68158 & $-1,86043$ & 0,078375 \\
\hline
\end{tabular}




\begin{tabular}{ccccccc}
\cline { 2 - 7 } T. média* & 4,80014 & 1,344669 & 33,0912 & 9,26987 & 3,56975 & $\mathbf{0 , 0 0 2 0 4 4}$ \\
T. efetiva* & $-5,82587$ & 1,349119 & $-59,3310$ & 13,73950 & $-4,31828$ & $\mathbf{0 , 0 0 0 3 7 1}$ \\
Umidade* $^{*}$ & 1,74217 & 0,360404 & 3,9255 & 0,81207 & 4,83394 & $\mathbf{0 , 0 0 0 1 1 5}$ \\
Precipitação & 1,35499 & 0,685698 & 8,5324 & 4,31789 & 1,97607 & 0,062850 \\
\hline
\end{tabular}

Defasagem de sete dias

$\mathbf{R}=\mathbf{0 , 8 1 2 1} \mathbf{R}^{\mathbf{2}}=\mathbf{0 , 6 5 9 5} \mathrm{F}(6,17)=5,4897 \mathbf{p}<\mathbf{0 , 0 0 2}$ Erro de estimação: 22,146

\begin{tabular}{ccccccc}
\hline & Beta & De Beta & B & De Beta & $\mathrm{t}(18)$ & Nível-p \\
\hline Intercept & & & 70,0656 & 90,8246 & 0,7714 & 0,4510 \\
T. máxima* & 5,0308 & 1,4200 & 53,3604 & 15,0618 & 3,5427 & $\mathbf{0 , 0 0 2 5}$ \\
T. mínima & 1,2684 & 0,7801 & 12,2659 & 7,5434 & 1,6260 & 0,1223 \\
T. média & $-0,2697$ & 1,5539 & $-2,8546$ & 16,4464 & $-0,1735$ & 0,8642 \\
T. efetiva* & $-5,5878$ & 1,5896 & $-87,2332$ & 24,8161 & $-3,5151$ & $\mathbf{0 , 0 0 2 6}$ \\
Umidade* $_{\text {Precipitação }}^{1,7105}$ & 0,3775 & 6,0129 & 1,3271 & 4,5308 & $\mathbf{0 , 0 0 0 2}$ \\
\hline
\end{tabular}

Negrito: $R$ - coeficiente de correlação, $R^{2}$ - coeficiente de determinação e $p<0,05$. (Negrito* as variáveis meteorológicas que mostraram correlação ao nível-p).

A Tabela 25 apresenta a análise de regressão múltipla, para o mês de janeiro de 2007. Os valores obtidos foram $R=0,49, R^{2}=0,24$, não significativos, pois mostrou-se com $p<0,083$, mesmo assim, foram a temperatura máxima e a temperatura efetiva, que destacaram na correlação, ao nível-p.

Tabela 25: Resumo da análise de regressão múltipla, como variáveis independentes: as temperaturas máxima $\left({ }^{\circ} \mathrm{C}\right)$, mínima $\left({ }^{\circ} \mathrm{C}\right)$, média $\left({ }^{\circ} \mathrm{C}\right)$ e a temperatura efetiva, $\left({ }^{\circ} \mathrm{C}\right)$, a umidade relativa do ar (\%), precipitação pluvial $(\mathrm{mm})$. Variável dependente: o número absoluto das internações por doenças respiratórias. Janeiro de 2007.

Sem defasagem

$\mathbf{R}=\mathbf{0 , 4 9 8 3} \mathbf{R}^{\mathbf{2}}=\mathbf{0 , 2 4 8 3}$ Ajuste $R^{2}=0,0980 F(5,25)=1,6525 \mathbf{p}<\mathbf{0 , 0 8 3}$ Erro de estimação: 158,76

\begin{tabular}{ccccccc}
\hline & Beta & De Beta & B & De Beta & $t(23)$ & Nível-p \\
\hline Intercept & & & 306,4571 & 1096,979 & 0,2793 & 0,7822 \\
T. máxima* $^{*}$ & $-0,9923$ & 0,3718 & $-99,0976$ & 37,136 & $-2,6685$ & $\mathbf{0 , 0 3 3 1}$ \\
T. mínima & 0,1518 & 0,2200 & 36,5905 & 53,023 & 0,6900 & 0,4964 \\
T. média & 0,7553 & 0,4984 & 80,8252 & 53,334 & 1,5154 & 0,1422 \\
T. Efetiva* & 0,4072 & 0,2086 & 37,8 & 19,36 & 1,9520 & $\mathbf{0 , 0 4 5 0}$ \\
Umidade $_{\text {Precipitação }}^{-0,0681}$ & 0,3377 & $-1,1837$ & 5,868 & $-0,2017$ & 0,8417 \\
\hline
\end{tabular}

Negrito: $R$ - coeficiente de correlação, $R^{2}$ - coeficiente de determinação e $p<0,05$. (Negrito* as variáveis meteorológicas que mostraram correlação ao nível-p).

Na Tabela 26 está apresentada a análise de regressão múltipla, para o mês de junho de 2007. Os valores obtidos foram $R=0,75, R^{2}=0,57$, significativos em $\mathrm{p}<0,003$, mostrou-se relacionada a temperatura máxima e a temperatura efetiva. 
$\mathrm{Na}$ sequência apresenta a defasagem de um a sete dias, no qual o menor valor foram obtidos na defasagem de cinco dias, $R=0,68, R^{2}=0,46$ e $p<0,052$ e na defasagem de seis dias, $R=0,61, R^{2}=0,37$, significativos em $p<0,015$.

Resultados mais elevados foram encontrados na defasagem de dois dias, com $R=0,70, R^{2}=0,49$ e $p<0,015$, na defasagem de três dias, $R=0,78, R^{2}=0,61$ e $p<0,002$, para a defasagem de quatro dias, $R=0,80, R^{2}=0,65$ e $p<0,001$, já na defasagem de sete dias foi $R=0,75, R^{2}=0,56$ e $p<0,011$.

Das variáveis meteorológicas relacionadas, foram a temperatura mínima, temperatura média, temperatura efetiva, umidade relativa, que apresentaram mais vezes correlacionadas com o número de registros de internações. A precipitação pluvial mostrou-se com destaque apenas na defasagem de um dia, ao nível-p.

Tabela 26: Resumo da análise de regressão múltipla, como variáveis independentes: as temperaturas máxima $\left({ }^{\circ} \mathrm{C}\right)$, mínima $\left({ }^{\circ} \mathrm{C}\right)$, média $\left({ }^{\circ} \mathrm{C}\right)$ e a temperatura efetiva, $\left({ }^{\circ} \mathrm{C}\right)$, a umidade relativa do ar (\%), precipitação pluvial $(\mathrm{mm})$. Variável dependente: o número absoluto das internações por doenças respiratórias. Junho de 2007.

Sem defasagem

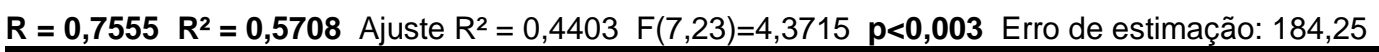

\begin{tabular}{ccccccc}
\hline & Beta & De Beta & B & De Beta & $t(22)$ & Nível-p \\
\hline Intercept & & & $-18083,7$ & 19519,25 & $-0,9264$ & 0,3638 \\
T. máxima* & $-0,6701$ & 0,2968 & $-98,6$ & 43,66 & $-2,2576$ & $\mathbf{0 , 0 3 3 7}$ \\
T. mínima & $-0,0245$ & 0,1791 & $-8,7$ & 63,58 & $-0,1368$ & 0,8923 \\
T. média & 0,6351 & 0,4050 & 100,1 & 63,85 & 1,5678 & 0,1305 \\
T. Efetiva* & $-0,6413$ & 0,1569 & $-78,5$ & 19,20 & $-4,0870$ & $\mathbf{0 , 0 0 0 4}$ \\
Umidade & 0,2070 & 0,2832 & 5,3 & 7,25 & 0,7309 & 0,4721 \\
Precipitação & 0,0291 & 0,1465 & 0,5 & 2,59 & 0,1987 & 0,8442 \\
\hline
\end{tabular}

Defasagem de um dia

$R=0,68350905 R^{2}=0,46718462 F(6,22)=3,2150 \quad p<0,020$ Erro estimado: 6,8284

\begin{tabular}{ccccccc}
\hline & Beta & De Beta & B & De Beta & $\mathrm{t}(23)$ & Nível-p \\
\hline Intercept & & & 24,2016 & 26,5959 & 0,9099 & 0,3726 \\
T. máxima & $-1,2358$ & 0,9977 & $-3,4959$ & 2,8225 & $-1,2385$ & 0,2285 \\
T. mínima & 0,4164 & 0,6445 & 1,0201 & 1,5791 & 0,6460 & 0,5249 \\
T. média* & 5,7346 & 1,4780 & 15,8742 & 4,0914 & 3,8799 & $\mathbf{0 , 0 0 0 8}$ \\
T. Efetiva & $-0,3400$ & 0,2161 & $-2,0261$ & 1,2880 & $-1,5730$ & 0,1299 \\
Umidade* $_{\text {Precipitação* }}^{1,3215}$ & 0,3782 & 1,2433 & 0,3558 & 3,4938 & $\mathbf{0 , 0 0 2 0}$ \\
Pren $^{*}$ & $-4,4723$ & 1,4138 & $-18,2528$ & 5,7704 & $-3,1631$ & $\mathbf{0 , 0 0 4 5}$ \\
\hline
\end{tabular}

Defasagem de dois dias

$\mathbf{R}=\mathbf{0 , 7 0 4 9} \mathbf{R}^{\mathbf{2}}=\mathbf{0 , 4 9 7 0} \mathrm{F}(6,21)=3,4584 \mathbf{p}<\mathbf{0 , 0 1 5}$ Erro estimado: 8,0249

\begin{tabular}{ccccccc}
\hline & Beta & De Beta & B & De Beta & $\mathrm{t}(22)$ & Nível-p \\
\hline Intercept & & & 51,2543 & 31,4246 & 1,6310 & 0,1177 \\
T. máxima & $-0,9349$ & 0,9826 & $-3,1578$ & 3,3189 & $-0,9514$ & 0,3521 \\
T. mínima* & 4,8701 & 1,4405 & 16,2673 & 4,8115 & 3,3808 & $\mathbf{0 , 0 0 2 8}$ \\
T. média & 1,0251 & 0,6189 & 3,1338 & 1,8919 & 1,6564 & 0,1125 \\
T. Efetiva* & $-4,6024$ & 1,3666 & $-22,8378$ & 6,7816 & $-3,3676$ & $\mathbf{0 , 0 0 2 9}$ \\
Umidade* $^{1,2961}$ & 0,3770 & 1,4418 & 0,4193 & 3,4378 & $\mathbf{0 , 0 0 2 4}$ \\
\hline
\end{tabular}




$$
-0,4209
$$

0,2149

$-2,9659$

1,5145

$-1,9582$

0,0636

Defasagem de três dias

$\mathbf{R}=\mathbf{0 , 7 8 1 0} \mathbf{R}^{\mathbf{2}}=\mathbf{0 , 6 1 0 0} \mathrm{F}(6,20)=5,2146 \mathbf{p}<\mathbf{0 , 0 0 2}$ Erro estimado: 9,7363

\begin{tabular}{ccccccc}
\hline & Beta & De Beta & B & De Beta & t(21) & Nível-p \\
\hline Intercept & & & 27,9939 & 38,3700 & 0,7295 & 0,4741 \\
T. máxima & $-0,9665$ & 1,0088 & $-4,4822$ & 4,6786 & $-0,9580$ & 0,3494 \\
T. mínima* $^{\text {T. média* }}$ & 1,6378 & 0,3446 & 2,5048 & 0,5270 & 4,7524 & $\mathbf{0 , 0 0 0 1}$ \\
T. Efetiva* $_{\text {Umidade }}^{5,7266}$ & 1,2903 & 26,9565 & 6,0739 & 4,4380 & $\mathbf{0 , 0 0 0 2}$ \\
Precipitação & $-5,0259$ & 1,2278 & $-34,9314$ & 8,5336 & $-4,0933$ & $\mathbf{0 , 0 0 0 5}$ \\
\hline
\end{tabular}

Defasagem de quatro dias

$\mathbf{R}=\mathbf{0 , 8 0 7 5} \mathbf{R}^{\mathbf{2}}=\mathbf{0 , 6 5 2 1} F(6,19)=5,9369 \mathbf{p}<\mathbf{0 , 0 0 1}$ Erro estimado: 18,484

\begin{tabular}{|c|c|c|c|c|c|c|}
\hline & Beta & De Beta & $B$ & De Beta & $\mathrm{t}(20)$ & Nível-p \\
\hline Intercept & & & 36,2646 & 73,0374 & 0,4965 & 0,6252 \\
\hline T. máxima & 0,74733 & 1,1795 & 6,7965 & 10,7275 & 0,6335 & 0,5339 \\
\hline T. mínima* & 1,54689 & 0,6674 & 13,0316 & 5,6226 & 2,3176 & 0,0317 \\
\hline T. média* & 4,69007 & 1,3088 & 43,2550 & 12,0710 & 3,5833 & 0,0019 \\
\hline T. Efetiva* & $-6,37284$ & 1,3131 & $-86,8265$ & 17,8912 & $-4,8530$ & 0,0001 \\
\hline Umidade* & 1,86089 & 0,3508 & 5,6095 & 1,0574 & 5,3046 & 0,0004 \\
\hline Precipitação & $-0,31673$ & 0,1879 & $-5,8834$ & 3,4919 & $-1,6848$ & 0,1083 \\
\hline
\end{tabular}

Defasagem de cinco dias

$\mathbf{R}=\mathbf{0 , 6 8 2 8} \mathbf{R}^{\mathbf{2}}=\mathbf{0 , 4 6 6 2} F(6,18)=2,6203 \mathbf{p}<\mathbf{0 , 0 5 2}$ Erro estimado: 5,9018

\begin{tabular}{|c|c|c|c|c|c|c|}
\hline & Beta & De Beta & B & De Beta & $t(19)$ & Nível-p \\
\hline Intercept & & & 1,6821 & 23,3843 & 0,0719 & 0,9434 \\
\hline T. máxima & 1,0386 & 1,5350 & 2,3707 & 3,5039 & 0,6765 & 0,5072 \\
\hline T. mínima & 1,5626 & 0,8732 & 3,3033 & 1,8459 & 1,7895 & 0,0903 \\
\hline T. média & 2,2016 & 1,6673 & 5,0952 & 3,8586 & 1,3204 & 0,2032 \\
\hline T. Efetiva* & $-4,2523$ & 1,7170 & $-14,5358$ & 5,8694 & $-2,4764$ & 0,0234 \\
\hline Umidade $^{*}$ & 1,4982 & 0,4462 & 1,1379 & 0,3389 & 3,3574 & 0,0035 \\
\hline Precipitação & $-0,4505$ & 0,2417 & $-2,1011$ & 1,1274 & $-1,8635$ & 0,0787 \\
\hline
\end{tabular}

Defasagem de seis dias

$\mathbf{R}=\mathbf{0 , 6 1 2 3} \mathbf{R}^{\mathbf{2}}=\mathbf{0 , 3 7 4 9} F(6,18)=1,7996 \mathbf{p}<\mathbf{0 , 0 1 5}$ Erro estimado: 3,9856

\begin{tabular}{ccccccc}
\hline & Beta & De Beta & B & De Beta & $t(18)$ & Nível-p \\
\hline Intercept & & & $-2,9466$ & 15,7918 & $-0,1865$ & 0,8540 \\
T. máxima & $-3,0218$ & 1,6611 & $-4,3044$ & 2,3662 & $-1,8191$ & 0,0855 \\
T. mínima* $_{\text {T. média }}^{-1,9783}$ & 0,9449 & $-2,6099$ & 1,2466 & $-2,0936$ & $\mathbf{0 , 0 0 0 7}$ \\
T. Efetiva* & 0,9139 & 1,8042 & 1,3199 & 2,6058 & 0,5065 & 0,6186 \\
Umidade & 3,9224 & 1,8580 & 8,3675 & 3,9637 & 2,1110 & $\mathbf{0 , 0 4 9 0}$ \\
Precipitação & $-0,6953$ & 0,4829 & $-0,3295$ & 0,2288 & $-1,4398$ & 0,1670 \\
\hline
\end{tabular}

Defasagem de sete dias

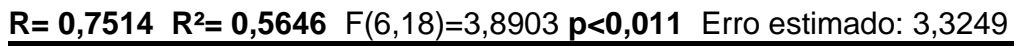

\begin{tabular}{ccccccc}
\hline & Beta & De Beta & B & De Beta & $t(17)$ & Nível-p \\
\hline Intercept & & & 19,9147 & 13,1743 & 1,5116 & 0,1479 \\
T. máxima & 0,3228 & 1,3864 & 0,4596 & 1,9740 & 0,2328 & 0,8185 \\
T. mínima & 0,4644 & 0,7886 & 0,6125 & 1,0399 & 0,5889 & 0,5632 \\
T. média* $^{*}$ T. Efetiva* $^{*}$ & 3,5211 & 1,5058 & 5,0832 & 2,1739 & 2,3382 & $\mathbf{0 , 0 3 1 1}$ \\
Umidade & $-3,8699$ & 1,5507 & $-8,2520$ & 3,3067 & $-2,4955$ & $\mathbf{0 , 0 2 2 5}$ \\
& 0,7033 & 0,4030 & 0,3332 & 0,1909 & 1,7451 & 0,0980 \\
\hline
\end{tabular}


Precipitação

$$
-0,2266 \quad 0,2183
$$

$-0,6593$

0,6352

$-1,0380$

0,3129

Negrito: $R$ - coeficiente de correlação, $\mathbf{R}^{2}$ - coeficiente de determinação e $p<0,05$. (Negrito* as variáveis meteorológicas que mostraram correlação ao nível-p).

Observou que para os meses de janeiro o método estatístico não mostrou-se com correlação significativa, mesmo com os valores de $R$ e $R^{2}$ as vezes elevados, isso denota que existem outros fatores que possam estar relacionados com os problemas respiratórios, que não foram o objeto de estudo, nessa análise, ou na definição do programa estatístico utilizado, não aceitando os dias sem registros informados de internações.

Para julho de 2000, junho de 2003 e 2007, mostraram os resultados elevados e significativos. Em relação à defasagem, de um a sete dias, observou que independente de quais os dias relacionados, os resultados do coeficiente de correlação obtidos mostraram-se entre $61 \%$ a $81 \%$ de relação com as internações e o coeficiente de determinação, mostrou-se entre 37\% a 65\% de relação.

\subsubsection{SÍNTESE DOS RESULTADOS DE INTERNAÇÕES RELACIONADA COM A VARIABILIDADE CLIMÁTICA}

\section{Verão - Janeiro de 2000}

A Média da pressão atmosférica foi 948,7 hPa, máxima 953,1 hPa e mínima 942,2 hPa. Foram dezesseis dias com precipitação pluvial, a altura mensal foi de $242,8 \mathrm{~mm}$. Temperatura média $26,4^{\circ} \mathrm{C}$, máxima $31,0^{\circ} \mathrm{C}$, máxima absoluta $34,2^{\circ} \mathrm{C}$, temperatura mínima $20,6^{\circ} \mathrm{C}$, mínima absoluta $17,2^{\circ} \mathrm{C}$.

Média da umidade relativa do ar de 72\%, com a máxima 97\% e mínima 49\%, foram vinte e sete dias com a umidade relativa acima de $60 \%$, contra quatro dias abaixo desse valor. Predominância de céu nublado, ventos da direção Nordeste, a atuação da massa Tropical continental foi de $61,3 \%$ e a massa Equatorial continental com $12,9 \%$.

A temperatura mostrou-se muito elevada principalmente entre $12 \mathrm{~h} 00 \mathrm{~min}$ a $18 \mathrm{~h} 00 \mathrm{~min}$, com variação entre $29,0^{\circ} \mathrm{C}$ a $35,0^{\circ} \mathrm{C}$ e a umidade relativa entre $35 \%$ a $60 \%$. Após $21 \mathrm{~h} 00 \mathrm{~min}$, as temperaturas variaram entre $16,0^{\circ} \mathrm{C}$ a $23,0^{\circ} \mathrm{C}$. 
A temperatura efetiva, de forma geral mostrou-se para a condição de desconforto ao calor, entre $11 \mathrm{~h} 00 \mathrm{~min}$ a $20 \mathrm{~h} 00 \mathrm{~min}$. Demais horários destacaram como faixa de conforto térmico. $\mathrm{Na}$ análise de regressão múltipla, os valores de $\mathrm{Re}$ $R^{2}$ não mostraram correlação significativas, sendo de $p<0,06$, não considerando as variáveis que apresentaram relação ao nível-p. Nesse mês foram registradas cento e dezoito (118) internações e cinco (05) óbitos.

\section{Inverno - Julho de 2000}

A média da pressão atmosférica foi 956,0 hPa, máxima 965,8 hPa e mínima $949,1 \mathrm{hPa}$. Foram oito dias com precipitação pluvial, a altura mensal de $73,5 \mathrm{~mm}$. Temperatura média $16,5^{\circ} \mathrm{C}$, máxima $21,8^{\circ} \mathrm{C}$, máxima absoluta $28,6^{\circ} \mathrm{C}$, temperatura mínima $10,8^{\circ} \mathrm{C}$, mínima absoluta $0,5^{\circ} \mathrm{C}$.

Média da umidade relativa do ar $63 \%$, com a máxima $96 \%$ e mínima $40 \%$, foram quatorze dias com a umidade relativa acima de $60 \%$, contra dezessete dias abaixo desse valor. Predominância de céu claro, ventos da direção Sudoeste, predominou a atuação da massa Polar atlântica com $48,4 \%$.

A temperatura mostrou-se baixa, principalmente entre $01 \mathrm{~h} 00 \mathrm{~min}$ a $09 \mathrm{~h} 00 \mathrm{~min}$ e novamente após $20 \mathrm{~h} 00 \mathrm{~min}$, com variação entre $1,0^{\circ} \mathrm{C}$ a $18,0^{\circ} \mathrm{C}$. De $23,0^{\circ} \mathrm{C}$ a $29,0^{\circ} \mathrm{C}$ entre $13 \mathrm{~h} 00 \mathrm{~min}$ a $18 \mathrm{~h} 00 \mathrm{~min}$, com umidade relativa entre $20 \%$ a $50 \%$. Quanto a temperatura efetiva, esta mostrou-se para a condição de desconforto ao frio, predominando o mês todo.

Para a análise de regressão múltipla, os valores de $R$ e $R^{2}$ foram significativos em $p<0,05$, tanto na análise sem defasagem como na defasagem de um a sete dias. Os dados meteorológicos e a temperatura efetiva mostraram relação com as internações. Nesse mês foram duzentos oitenta e três (283) registros de internações e dez (10) registros de óbitos.

\section{Verão - Janeiro de 2003}

A média da pressão atmosférica $949,1 \mathrm{hPa}$, máxima 953,8 hPa e mínima $943,9 \mathrm{hPa}$. Foram vinte dias com precipitação pluvial, a altura mensal de $309,9 \mathrm{~mm}$. Temperatura média $25,8^{\circ} \mathrm{C}$, máxima $29,8^{\circ} \mathrm{C}$, máxima absoluta $34,8^{\circ} \mathrm{C}$, temperatura mínima $21,7^{\circ} \mathrm{C}$, mínima absoluta $19,5^{\circ} \mathrm{C}$. 
Média da umidade relativa do ar de 79\%, com a máxima 97\% e mínima 52\%, foram vinte e nove dias com a umidade relativa acima de $60 \%$, contra dois dias abaixo desse valor. Predominância de céu parcialmente nublado a nublado, ventos de Nordeste. Predominou a atuação da massa Tropical continental com 38,7\% e a massa Equatorial continental com 32,3\%.

A temperatura mostrou-se muito elevada após 10h00min permanecendo até 20 h00min, com picos entre $30,0^{\circ} \mathrm{C}$ a $35,0^{\circ} \mathrm{C}$ e umidade relativa entre $35 \%$ a $65 \%$. Após 21 h00min, com variação de temperaturas entre $19,0^{\circ} \mathrm{C}$ a $24,0^{\circ} \mathrm{C}$.

A temperatura efetiva, mostrou-se na condição de desconforto ao calor, entre 10 h00min a 20 h00min. Demais horários como faixa de conforto térmico.

$\mathrm{Na}$ análise de regressão múltipla, embora os valores de $\mathrm{R}$ e $\mathrm{R}^{2}$ foram significativos, nenhuma variável meteorológica mostrou-se relacionada. Nesse mês foram registradas cento quarenta e três (143) registros de internações e um (01) registros de óbitos.

\section{Outono/inverno - Junho de 2003}

A média da pressão atmosférica 959,9 hPa, máxima 959,4 hPa e mínima $951,1 \mathrm{hPa}$. Foram dois dias com precipitação pluvial, com a altura mensal de $58,7 \mathrm{~mm}$. Temperatura média $22,0^{\circ} \mathrm{C}$, máxima $26,6^{\circ} \mathrm{C}$, máxima absoluta $28,7^{\circ} \mathrm{C}$, temperatura mínima $16,7^{\circ} \mathrm{C}$, mínima absoluta $13,7^{\circ} \mathrm{C}$.

Média da umidade relativa do ar de 70\%, com a máxima 96\% e mínima 58\%, foram vinte e seis dias com a umidade relativa acima de $60 \%$, contra quatro dias abaixo desse valor. Predominância de céu claro, ventos da direção Nordeste e sudoeste, predominou a atuação da massa Polar atlântica com 50\%.

A temperatura mostrou-se baixa, entre $01 \mathrm{~h} 00 \mathrm{~min}$ a $09 \mathrm{~h} 00 \mathrm{~min}$, variando de $13,0^{\circ} \mathrm{C}$ a $18,0^{\circ} \mathrm{C}$. Sendo de $23,0^{\circ} \mathrm{C}$ a $29,0^{\circ} \mathrm{C}$ entre $10 \mathrm{~h} 00 \mathrm{~min}$ a $18 \mathrm{~h} 00 \mathrm{~min}$. Quanto a temperatura efetiva, mostrou-se para a condição de desconforto ao frio, principalmente entre $01 \mathrm{~h} 00 \mathrm{~min}$ a $08 \mathrm{~h} 00 \mathrm{~min}$. Para a condição de conforto térmico, apresentando após 09h00min.

Para a análise de regressão múltipla, os valores de $R$ e $R^{2}$ foram significativos em $p<0,05$, tanto na análise sem defasagem como na defasagem de um a sete dias, Os dados meteorológicos e a temperatura efetiva mostraram relação com as 
internações. Nesse mês foram trezentas quarenta e um (341) registros de internações e sete $(07)$ registros de óbitos.

\section{Verão - Janeiro de 2007}

A média da pressão atmosférica 948,4 hPa, máxima 952,7 hPa e mínima 942,3 hPa. Foram vinte e um dias com precipitação pluvial, com a altura mensal de $271,5 \mathrm{~mm}$. Temperatura média $25,3^{\circ} \mathrm{C}$, máxima $29,4^{\circ} \mathrm{C}$, máxima absoluta $32,5^{\circ} \mathrm{C}$, temperatura mínima $21,4^{\circ} \mathrm{C}$, mínima absoluta $19,4^{\circ} \mathrm{C}$.

Média da umidade relativa do ar de 84\%, com a máxima 99\% e mínima 57\%, foram trinta dias com a umidade relativa acima de 60\%, apenas um dia abaixo desse valor. Predominância de céu encoberto, ventos da direção Nordeste, predominou a atuação da massa Tropical continental com 51,5\% e a massa Equatorial continental com $25,8 \%$.

Houve variação de temperatura entre $23,0^{\circ} \mathrm{C}$ a $33,0^{\circ} \mathrm{C}$ após $09 \mathrm{~h} 00 \mathrm{~min}$ até $19 \mathrm{~h} 00 \mathrm{~min}$. Sendo de $18,0^{\circ} \mathrm{C}$ a $23,0^{\circ} \mathrm{C}$ entre $01 \mathrm{~h} 00 \mathrm{~min}$ a $08 \mathrm{~h} 00 \mathrm{~min}$. A temperatura efetiva, mostrou-se para a condição de desconforto ao calor, entre 12h00min a 20h00min. Demais horários como faixa de conforto térmico.

Para a análise de regressão múltipla, os valores de correlação obtidos em $\mathrm{R} e$ $R^{2}$, não foram significativos com $p<0,083$, desconsiderando a relação que a temperatura máxima e a temperatura efetiva apresentaram. Nesse mês foram registradas cento e dezoito (118) registros de internações e oito (08) registros de óbitos.

\section{Outono/inverno - Junho de 2007}

A média da pressão atmosférica 954,8 hPa, máxima 959,6 hPa e mínima 950,3 hPa. Foram dois dias com precipitação pluvial, com a altura mensal de 7,8mm. Temperatura média $21,5^{\circ} \mathrm{C}$, máxima $26,5^{\circ} \mathrm{C}$, máxima absoluta $30,0^{\circ} \mathrm{C}$, temperatura mínima $15,1^{\circ} \mathrm{C}$, mínima absoluta $6,8^{\circ} \mathrm{C}$.

Média da umidade relativa do ar de $62 \%$, com a máxima $88 \%$ e mínima $49 \%$, foram onze dias com a umidade relativa acima de 60\%, contra dezenove dias abaixo desse valor. Predominância de céu claro, ventos da direção Nordeste, predominou a atuação da massa Polar atlântica com 56,7\%. 
Com temperatura baixa, entre $6,0^{\circ} \mathrm{C}$ a $21,0^{\circ} \mathrm{C}$, de $01 \mathrm{~h} 00 \mathrm{~min}$ a $09 \mathrm{~h} 00 \mathrm{~min}$, de $22,0^{\circ} \mathrm{C}$ a $26,0^{\circ} \mathrm{C}$ entre $10 \mathrm{~h} 00 \mathrm{~min}$ a $18 \mathrm{~h} 00 \mathrm{~min}$, com picos de $30,0^{\circ} \mathrm{C}$ entre $13 \mathrm{~h} 00 \mathrm{~min}$ a $16 \mathrm{~h} 00 \mathrm{~min}$ e umidade relativa entre $30 \%$ a $55 \%$. A temperatura efetiva, mostrou-se para a condição de desconforto ao frio entre 01h00min a 08h00min. Para a condição de conforto térmico apresentou após 09h00min.

Para a análise de regressão múltipla, os valores de $R$ e $R^{2}$ foram significativos em $\mathrm{p}<0,05$, tanto na defasagem ou sem defasagem, as variáveis meteorológicas mostraram relação com as internações. Nesse mês foram trezentas cinquenta e quatro (354) registros de internações e oito (08) registros de óbitos.

\section{CONSIDERAÇÕES FINAIS}

O desenvolvimento da presente pesquisa permitiu verificar que em Maringá o número de registros de internações por doenças respiratórias, ocorrem em grande proporção para a faixa etária de 0-4 anos e para mais de 70 anos, seguida pela faixa etária de 5-9 anos.

Os números de óbitos são expressivos para a faixa etária de 60-69 anos com $20,1 \%$ e para a faixa etária com mais de 70 anos, somando $52,9 \%$. A grande predominância de problemas respiratórios foram para o sexo masculino, com 54,7\% dos registros de internações e o sexo feminino apresentou-se 45,3\%.

Ocorreram internações em maior número de registros por influenza \{gripe\} e pneumonias, sendo $59,0 \%$ dos casos, no qual destes, $11,7 \%$ foi por pneumonia viral, $23,1 \%$ por pneumonia devida a outros microorganismos infecciosos especificados e $22,4 \%$ por broncopneumonia não especificada. Em segunda posição destacou para as doenças crônicas das vias aéreas inferiores, em que, com 13,0\% das internações foram por outras doenças obstrutivas crônicas e 8,0\% por asma.

Em relação ao coeficiente de incidência por faixa etária, verificou que 70 anos ou mais, apresentou alta probabilidade de riscos, de média probabilidade destacou a faixa etária de 0-4 e 60-69 anos, para baixa probabilidade a faixa etária de 5-9 e 5059 anos, as demais faixa etárias, destacaram para muito baixa em probabilidade.

Para as Zonas Municipais, verificou o maior número de ocorrências para as zonas com o maior contingente populacional, algumas zonas analisadas não 
apareceram com internações, esse fato mostra que de alguma forma há ligação de proximidade com outra zona. O coeficiente de incidência por Zonas Municipais, apresentou-se como muito baixa na probabilidade de riscos para doze zonas, baixa probabilidade foi para vinte e uma zonas, média para oito zonas e com alta probabilidade de riscos para quatro zonas. Sendo desconsiderado como de alto risco para essas quatro zonas, devido a quantidade de população ser pequena, ocorreu uma distorção nos resultados.

Através da análise rítmica de janeiro e julho de 2000, janeiro e junho de 2003, janeiro e junho de 2007, verificou a questão da sazonalidade, evidenciando as diferentes oscilações que ocorreram em relação aos atributos climáticos, para o verão, outono e inverno. Em relação às internações, observou que para o mês de janeiro ocorrem menos registros, no qual, praticamente triplicam de quantidade para os meses de junho e julho.

Para os meses de janeiro, houve mais dias de instabilidade, que propiciaram pancadas ocasionais de precipitações, limpando a atmosfera, com mais dias de céu encoberto ou parcialmente nublado e poucos dias de céu claro. A umidade relativa do ar normalmente torna-se mais elevada, reduzindo assim o ressecamento das vias respiratórias. Nesses meses a quantidade de internações por doenças respiratórias foram reduzidas.

Para junho e julho, ocorreu acréscimos na quantidade de internações, todos os dias, pode ser justificado pela inconstância de temperatura, de umidade relativa do ar e diminuição das chuvas. Predominância da massa Polar atlântica (mPa), que provoca quedas repentinas nas temperaturas, às vezes com geadas.

Acrescenta-se que durante os meses mais quentes as poluições são dispersadas pelos sistemas de baixa pressão, assim como os microorganismos patológicos. Mas no inverno, com sistemas de alta pressão, maior concentração de poluentes, baixa umidade relativa e baixa temperatura, favorecendo à condição de mais microorganismos e mais partículas alérgicas e consequentemente contribuindo para as instalações de microorganismos infecciosos nas vias respiratórias.

Assim, os resultados apontaram para a possibilidade dos aumentos de internações por problemas respiratórios, estarem relacionados com a variabilidade climática, principalmente quando comparados com a temperatura e a umidade relativa do ar. 
A inclusão dos cálculos do índice de conforto térmico, para a obtenção da Temperatura Efetiva (TE), mostrou como um recurso a mais e eficaz de análise, possível de ser verificadas junto com os problemas respiratórios.

Nas análises mensais verificou a formação da faixa de desconforto ao frio para o mês de julho de 2000 e junho de 2003 e 2007. Para a condição de desconforto ao calor, nos meses de janeiro de 2000, 2003 e 2007, surgindo a faixa de conforto térmico, para todos esses meses, conforme as horas do dia.

Para o período de estudo, verificou que normalmente entre maio, junho, julho e agosto com a participação mais frequente da massa de ar Polar atlântica $(\mathrm{mPa})$, as temperaturas registradas no termômetro seco e úmido, favorecem a TE de desconforto ao frio, abaixo de $18,9^{\circ} \mathrm{C}$, principalmente de madrugada e nas primeiras horas do dia.

Em relação às internações por doenças respiratórias, a partir de março ocorreram aumentos no número de registros, permanecendo até setembro. Entre junho a agosto, diminuem o ritmo das chuvas estendendo-se até meados de setembro, nesse período a umidade relativa do ar, pode ser encontrada com frequência entre $20 \%$ a $50 \%$, dependendo do horário do dia. As baixas umidades são consequências da massa de ar Polar atlântica $(\mathrm{mPa})$ com frequente atuação nessa época do ano. Durante esse período de estiagem, ocorrem também muitas queimadas na região, com muita concentração de fumaça no ar.

Desta forma, observou que o clima tem uma parcela de contribuição significativa na incidência das doenças respiratórias, conclui-se que estudar a base meteorológica de uma determinada região é de suma importância, pois pode assim, traçar metas e diretrizes capazes de prevenir e até mesmo evitar consequências mais graves para a saúde humana.

Vale lembrar, que as doenças respiratórias são transmitidas por vírus, presente na tosse e espirros, ocorrendo à rápida propagação principalmente em aglomerações de pessoas em ônibus, em ambientes fechados e sem ventilação. Por isso, a importância para que os ambientes permaneçam sempre abertos, favorecendo a circulação do ar.

Em condições de baixa umidade relativa do ar, este vírus torna-se mais resistentes e favoráveis à sua sobrevivência, atacando as mucosas das vias respiratórias, por esse motivo recomenda-se ingerir muito líquido para mantê-las sempre umedecidas. 
Com base no que foi exposto, acredita-se que esta tese possa contribuir para os planejadores da área da saúde, bem como, servir de base para futuras investigações, em outros casos de internações por vários outros tipos de causas, pois existe uma infinidade de doenças que constantemente colocam em risco a saúde humana e o conhecimento prévio destas enfermidades, enfocadas com a variabilidade climática de uma determinada região, pode agir como forma de prevenção, sempre. 


\section{REFERÊNCIAS BIBLIOGRÁFICAS}

ABREU, M. L.; FERREIRA, C. C. D. Climatologia médica: um estudo das doenças respiratórias em Belo Horizonte-MG. In: SIMPÓSIO BRASILEIRO DE GEOGRAFIA FíSICA APLICADA. 8., 1999, Belo Horizonte. Anais... Belo Horizonte: UFMG, 1999. p. 10-11.

ANJOS, I. B.; MARTINS, M. L. O. F.; NERY, J. T. Estudo da precipitação pluviométrica e balanço hídrico em Maringá. Boletim de Geografia, Maringá, ano 19, n. 1, p. 115-128, 2001.

ANJOS, I. B. et al. Direção predominante dos ventos na estação climatológica principal de Maringá-PR. In: SIMPÓSIO BRASILEIRO DE GEOGRAFIA FÍSICA APLICADA. 8., 1999, Belo Horizonte. Anais... Belo Horizonte: UFMG, 1999. p. 207208.

AYOADE, J. O. Introdução à climatologia para os trópicos. São Paulo: Difel, 1986.

AZEVEDO, J. M. F. A influência das variáveis ambientais (meteorológicas e de qualidade do ar) na morbidade respiratória e cardiovascular na área

Metropolitana do Porto. 2010. 145 f. Tese (Doutorado)-Instituto de Astronomia Geofísica e Ciências Atmosféricas, Universidade de São Paulo, São Paulo, 2010.

BARROS, J. R. Tipos de tempo e incidência das doenças respiratórias: um estudo geográfico aplicado ao Distrito Federal. 2006. 121 f. Tese (Doutorado)Instituto de Geociências e Ciências Exatas, Universidade Estadual Paulista, Rio Claro, 2006.

BEJARÁN, R. A. Clima e salud humana: temperatura, mortalidade y morbidez. In: CONGRESSO BRASILEIRO DE BIOMETEOROLOGIA. 3., 2001, Maringá. Anais... Maringá: [s.n.], 2001. 1 CD-ROM.

BEREZUK, A. G.; SANT'ANNA NETO, J. L. Eventos climáticos extremos no oeste paulista e norte do Paraná, anos de 1997, 1998 e 2001. Revista Brasileira de Climatologia, Presidente Prudente, v. 2, ano 2, p. 9-22, 2006.

BORSATO, V. A.; SOUZA FILHO, E. E. A dinâmica atmosférica e as mudanças climáticas. In: SIMPÓSIO PARANAENSE DE ESTUDOS CLIMÁTICOS "PASSADO, PRESENTE E FUTURO". 1., 2008a, Campo Mourão. Anais... Campo Mourão: Gráfica Mourão, 2008. p. 237-127.

BORSATO, V. A; SOUZA FILHO, E. E. A dinâmica atmosférica na vertente oriental da bacia do Paraná e a gênese das chuvas. Revista Acta Scientiarum Technology, Maringá, v. 30, n. 2, p. 221-229, 2008b.

BRAGA, A. L. F.; ZANOBETTI, A.; SCHWARTZ, J. The effect of weather on respiratory and cardiovascular deaths in $12 \mathrm{U}$. S. cities. Environmental Health Perspectives, Carolina do Norte, v. 110, n. 9, p. 859-863, 2002. 
BRAGA, A. L. F. et al. Associação entre poluição atmosférica e doenças respiratórias e cardiovasculares na cidade de Itabira, Minas Gerais - Brasil. Caderno de Saúde Pública, Rio de Janeiro, n. 4, p. 570-578, 2007.

BRASIL. Ministério da Marinha. Serviço Meteorológico da Marinha. Cartas sinóticas. Rio de Janeiro. Janeiro e julho de 2000, Janeiro e junho de 2003. 1 CDROM.

BRASIL. Ministério da Marinha. Serviço Meteorológico da Marinha. Cartas sinóticas. Rio de Janeiro. Janeiro e junho de 2007. Disponível em: $<$ http://www.mar.mil.br/dhn/chm/meteo/prev>. Acesso em: 16 abr. 2010.

BRASIL. Ministério da Ciência e Tecnologia. Centro de Previsão e Estudos Climáticos. Instituto Nacional de Pesquisas Espaciais. Climanálise: Boletim de Monitoramento e Análise Climática, Cachoeira Paulista, v. 15, n. 7, jul. 2000. Disponível em: <http://www6.inpe.br/revclima/boletim/>. Acesso em: 8 ago. 2009.

BRASIL. Ministério da Ciência e Tecnologia. Centro de Previsão e Estudos Climáticos. Instituto Nacional de Pesquisas Espaciais. Climanálise: Boletim de Monitoramento e Análise Climática, Cachoeira Paulista, v. 18, n. 6, jun. 2003. Disponível em: <http://www6.inpe.br/revclima/boletim/>. Acesso em: 8 ago. 2009.

BRASIL. Ministério da Ciência e Tecnologia. Centro de Previsão e Estudos Climáticos. Instituto Nacional de Pesquisas Espaciais. Climanálise: Boletim de Monitoramento e Análise Climática, Cachoeira Paulista, v. 22, n. 6, jun. 2007. Disponível em: <http://www6.inpe.br/revclima/boletim/>. Acesso em: 8 ago. 2009.

BRASIL. Ministério da Saúde. Departamento de Informática do SUS. Departamento de Tabulação e Informação do Sistema Unico de Saúde. DATASUS. Informações de saúde: epidemiológicas e morbidade. Disponível em:

$<$ http://www.datasus.gov.br/DATASUS/index.perp?area=0203>. Acesso em: 11 out. 2007.

BRASIL. Ministério da Saúde. Descentralização do Sistema de Informação Hospitalar. SIH. Manual de orientações técnicas. Brasília, DF. v. 1, nov. 2006. Disponível em: <http//www.saúde.gov.br/sas/download/MANUALTÉCNICODOSIH. pdf>. Acesso em: 13 jul. de 2006.

BRAUM, S. Influências meteorotrópicas nas doenças cardiovasculares na cidade de São Paulo. 2003. 148 f. Dissertação (mestrado)-Instituto de Astronomia Geofísica e Ciências Atmosféricas, Universidade de São Paulo, São Paulo, 2003.

BRITTO, F. P.; BARLETTA, R.; MENDONÇA, M. Regionalização sazonal e mensal da precipitação pluvial máxima no Estado do Rio Grande do Sul. Revista Brasileira de Climatologia, Presidente Prudente, v. 2, ano 2, p. 35-51, dez. 2006.

BRODY, $\mathrm{H}$. et al. Map-making and myth-making in Broad Street: the London cholera epidemic, 1854. Departament of medical history. The Lancet, New York, v. 356, no. 1, p. 64-68, 2000. 
CARVALHO, S. M.; PINA, M. F.; SANTOS, S. M. Conceitos básicos de sistemas de informação geográfica e cartografia aplicados a saúde. Brasília, DF: Ministério da Saúde: Fundação Nacional de Saúde, 2000.

CASTRO, A. W. S. Clima urbano e saúde: as patologias do aparelho respiratório associadas aos tipos de tempo no inverno, em Rio Claro-SP. 2000. 202 f. Tese (Doutorado)- Instituto de Geociências e Ciências Exatas, Universidade Estadual Paulista, Rio Claro, 2000.

COELHO-ZANOTTI, M. S. S. Uma análise estatística com vistas a previsibilidade de doenças respiratórias em função de condições meteorotrópicas na cidade de São Paulo. 2007. 196 f. Tese (Doutorado)- Instituto de Astronomia Geofísica e Ciências Atmosféricas, Universidade de São Paulo, São Paulo, 2007.

CORRÊA, K. O. H. R. A Geografia da Saúde no Parque Tarumã e no Residencial Tarumã em Maringá (PR) Brasil: as enfermidades decorrentes dos problemas ambientais. 2010. 142 f. Dissertação (Mestrado)-Departamento de Geografia, Centro de Ciências Humanas, Letras e Artes, Universidade Estadual de Maringá, Maringá, 2010.

COSTA, E. C. Física aplicada a construção; conforto térmico. 3. ed. revisada e ampliada São Paulo: Edgard Blucher Ltda, 1974.

DAVIS, R. E. et al. Decadal changes in summer mortality in U. S. cities.

International Journal of Biometeorology, Germany, v. 47, p. 166-175, 2003.

DESSAI, S. Heat stress and mortality in Lisbon Part 1. Model construction and validation. International Journal of Biometeorology, Heidelberg, v. 47, p. 6-12, 2002.

DOENÇAS DO APARELHO RESPIRATÓRIO (J00-J99). In: CID - 10: Classificação Estatística Internacional de Doenças e Problemas Relacionados à Saúde. 5. ed. São Paulo: Ed. da USP, 1997. p. 499-529, v. 1.

DUSHOFF, J. et al. Mortality due to Influenza in the United States. An annualized regression approach using multiple-cause mortality date. American Journal of Epidemiology, USA, v. 163, no. 2, p. 181-187, 2006.

EMBRAPA. Centro Nacional de Pesquisas de Solos. Sistema Brasileiro de Classificação de Solos. Brasília, DF, 1999.

ENDLICH, A. M.; MORO, D. A. Maringá e a produção do Espaço Regional. In: MORO, D. A. (Org.). Maringá Espaço e tempo-ensaio de geografia urbana. Maringá: Programa de Pós-Graduação em Geografia, Universidade Estadual de Maringá, 2003, p. 9-48.

FERREIRA, M. E. M. C. Tópicos de Geografia Médica. In: SEMANA DE GEOGRAFIA: GLOBALIZAÇÃO E REGIONALIZAÇÃO: INTEGRAÇÃO OU DESINTEGRAÇÃO?, 11, 2001, Maringá. Minicurso... Maringá: Universidade Estadual de Maringá. Departamento de Geografia, 2001. Apostila. 
FONZAR, U. J. V Análise espacial da mortalidade por causas externas no Município de Maringá, 1999 - 2001. 2003. 177 f. Dissertação (Mestrado)Departamento de Geografia, Centro de Ciências Humanas, Letras e Artes, Universidade Estadual de Maringá, Maringá, 2003.

FONZAR, U. J. V.; SOARES, D. F. P. P.; SANTIL, F. P. Espacialização de três principais causas de morte no município de Maringá, Estado do Paraná, em 1996. Revista Acta Scientiarum, Maringá, v. 24, n. 3, p. 765-774, 2002.

FROTA, A. B.; SCHIFFER, S. R. Manual de conforto térmico: arquitetura, urbanismo. 6. ed. São Paulo: Studio Nobel, 2003.

FUNARI, F. L. O índice de Sensação Térmica Humana em função dos tipos de tempo na Região Metropolitana de São Paulo. 2006. 108 f. Tese (Doutorado)Departamento de Geografia Física, Centro de Filosofia, Letras e Ciências Humanas. Universidade de São Paulo, São Paulo, 2006.

GALVANI, E.; PEREIRA, A. R.; KOLOSOWSKI, E. S. Relações entre o índice de Oscilação Sul (IOS) e o total mensal de chuva em Maringá-PR. Revista Acta Scientiarum, Maringá, n. 4, ano 20, p. 531-535, 1998.

GARCÍA, F. F. Clima y confortabilidade humana. Manual de Climatología Aplicada. Clima, médio ambiente y planificación. Espacios y Sociedades. Sintesis, España: Sintesis, 1996.

GERARDI, L. H. O; SILVA, B. C. N. Quantificação em geografia. São Paulo: Difel, 1981.

HANN, J. Handbook of Climatology, New York, Mac Millan. 1903.

IAPAR. Cartas climáticas do Paraná. Londrina, 2000. Disponível em: <http://www.iapar.com.br>. Acesso em: 12 ago. 2007.

IBGE. Censo demográfico 2000. Disponível em: <http://www.ibge.gov.br>. Acesso em: 27 ago. 2008.

IBGE. Censo demográfico 2008. Disponível em: <http://www.ibge.gov.br>. Acesso em: 27 ago. 2008.

IBGE. Censo demográfico 2010. Disponível em: <http://www.ibge.gov.br>. Acesso em: 10 julho. 2011.

LACAZ, C. S.; BARUZZI, G. R.; SIQUEIRA, J. W. Introdução à geografia médica do Brasil. São Paulo: Ed. da USP, 1972.

LIMA, A. S. Admissões hospitalares por doenças respiratórias agudas, de crianças até dois anos, residentes no município de Maringá, Paraná e as variações do tempo atmosférico. 2000. 63 f. Dissertação (Mestrado)Departamento de Medicina, Universidade Estadual de Londrina, Londrina, 2000.

MAACK, R. Geografia física do estado do Paraná. Curitiba: Ed. da UFPR, 1981. 
MACHADO, J. R.; MENDES, C. M. Contribuição à análise espacial do setor médico/hospitalar da cidade de Maringá. In: SEMANA DE GEOGRAFIA - CLIMA E ORGANIZAÇÃO DO ESPAÇO GEOGRÁFICO. 13., 2003, Maringá. Resumos... Maringá: UEM, 2003. p. 99-102.

MAIA, J. A.; GONÇALVES, F. L. Uma análise do conforto térmico e suas relações meteorotrópicas na cidade de São Paulo - Parte 1. In: CONGRESSO BRASILEIRO DE METEOROLOGIA. 12., 2002, Foz do Iguaçu. Anais...Foz do Iguaçu-PR, 2002. 1 CD-ROM, p. 305-314.

MARTINELLI, M. Mapas da geografia e cartografia temática. 4. ed. São Paulo: Contexto, 2007.

MASTRANGELO, G. et al. Pattern and determinants of hospitalization during heat waves: an ecologic study. BMC Public Health, London, v. 7, no. 200, p. 1-8, 2007.

MCPHEE, J. S.; GANONG, W. F. Fisiopatologia da doença: uma introdução a medicina clínica. São Paulo: Mc Graw - Hill Interamericana do Brasil, 2007.

MELLO JORGE, M. H. P.; GOTLIEB, S. L. D. As condições de saúde no Brasil retrospecto de 1979 a 1995. Rio de Janeiro: Fiocruz, 2000.

MELLO JORGE, M. H. P.; GOTLIEB, S. L. D.; LAURENTI, R. A saúde no Brasil: análise do Período de 1996 a 1999. 1. ed. Brasília, DF: Fiocruz: Organização PanAmericana da Saúde OPAS/OMS, 2001.

MENDONÇA, F. Clima e criminalidade: ensaio Analítico da Correlação entre a Temperatura do ar e a Incidência de Criminalidade Urbana. Curitiba: Ed. da UFPR, 2001.

MENDONÇA, F.; BORAX, S. C.; PAULA, E. V. Repercussões das condições climáticas de inverno na incidência de IVAS e Pneumonias na população infantil de Curitiba-PR. In: SIMPÓSIO BRASILEIRO DE CLIMATOLOGIA. 11., 2000, Rio de Janeiro. Anais... Rio de Janeiro: [s.n.], 2000. 1 CD-ROM.

MENDONÇA, F. O Estudo do clima urbano no Brasil - evolução, tendências e alguns desafios. In: MENDONÇA, F.; MONTEIRO, C. A. F. (Org.). Clima urbano. São Paulo: Contexto, 2003. p. 156-175.

MENDONÇA, F.; DANNI-OLIVEIRA, I. M. Climatologia: noções básicas e climas do Brasil. São Paulo: Oficina de Textos, 2007.

MONTESQUIEU, C. L. S. Do Espírito das Leis. Terceira Parte - Livro décimo quarto. Das leis, na relação que elas têm com a natureza. 2. ed. São Paulo: Abril Cultural, 1979. Coleção Os Pensadores.

MONTEIRO, C. A. F. Análise rítmica em climatologia: problemas da atualidade climática em São Paulo e achegas para um programa de trabalho. Climatologia, São Paulo, n. 1, p. 1-21,1971.

MONTEIRO, C. A. F. Clima. In: GEOGRAFIA do Brasil - A grande Região Sul. 2. ed. Rio de Janeiro: IBGE, 1968, t. 1, v. 4, n. 18, série A, p. 114-169. 
MONTEIRO, C. A. F. A frente Polar na fachada sul - oriental do Brasil: Contribuição metodológica à análise rítmica dos tipos de tempo no Brasil. São Paulo. Instituto de Geografia, Universidade de São Paulo, 1969 (séries teses e monografias, 1).

MONTEIRO, C. A. F. Teoria e Clima Urbano - Um projeto e seus caminhos. In: MENDONÇA, F; MONTEIRO, C. A. F. (Org.). Clima urbano. São Paulo: Contexto, 2003. p. 9-67.

NADAL, J. M. R.; VIDE, J. M. La Climatología española em los albores del siglo XXI. Publicaciones de la Associación Española de Climatologia, Série A, n. 1, p. 459469, 1999.

NERY, J. T. Dinâmica Climática da região Sul do Brasil. Revista Brasileira de Climatologia, Presidente Prudente, v. 1, n. 1, p. 62-75, 2006.

NIMER, E. Climatologia da Região Sul. In: CLIMATOLOGIA do Brasil. Rio de Janeiro: IBGE, 1979, n. 4, p. 195-264.

NORONHA, J. C.; LIMA, L. D.; MACHADO, C. V. A Gestão do Sistema de Saúde: características e tendências. In: BRASIL. Ministério da Saúde. Saúde no Brasil: contribuições para a agenda de prioridades de pesquisa. Brasília, DF: Ministério da Saúde. 2. ed. 2006. p. 15-44. Série B. Textos Básicos da Saúde.

ORGANIZAÇÃO PAN-AMERICANA DA SAÚDE. Sistema de Informação Geográfica em Saúde - Conceitos Básicos. Brasília, DF: Ministério da Saúde, 2002.

ORGANIZAÇÃO PAN-AMERICANA DE SAÚDE. Representação da (OPS/OMS) no Brasil. A saúde no Brasil. Brasilia, DF, 1998.

PAIM, J. S. Atenção a Saúde no Brasil. In: BRASIL. Ministério da Saúde. Saúde no Brasil: contribuições para a agenda de prioridades de pesquisa. 2. ed. Brasília, DF: Ministério da Saúde, 2006. p. 45-89. Série B. Textos Básicos da Saúde.

PARANÁ. Secretaria do Estado da Agricultura e do Abastecimento. Instituto de Terras, Cartografias e Florestas. Atlas do Estado do Paraná. Curitiba: Universidade do Paraná, 1987.

PEDELABORDE, P. Introducion a I' étude scientifique du climat. 2. ed. Paris: SEDES, 1970.

PEIXOTO, A. Clima e saúde: introdução bibliográfica à civilização brasileira. 2 . ed. São Paulo: Companhia Editora Nacional, 1975.

PEREHOUSKEI, N. A. Abrangência das Unidades Básicas de Saúde - A percepção da comunidade nos bairros Universo e Pinheiros no Município de Maringá-PR - 2001 a 2005. 2005. 200 f. Dissertação (Mestrado)- Departamento de Geografia, Centro de Ciências Humanas, Letras e Artes Universidade Estadual de Maringá, Maringá, 2005. 
PITTON, S. E. C. Os tipos de Tempo e a ocorrência de Doenças Respiratórias em cidades de pequeno porte In: SIMPÓSIO BRASILEIRO DE CLIMATOLOGIA. 11., 2000, Rio de Janeiro. Anais... Rio de Janeiro: [s.n.], 2000. 1 CD-ROM.

PITTON, S. E. C. Poluição e doenças respiratórias em Piracicaba- SP. In: ENCONTRO DE GEÓGRAFOS DA AMÉRICA LATINA. 9., 2003, Mérida, México. Anais... Mérida, México: [s.n.], 2003. p. 232-236.

PITTON, S. E. C.; DOMINGOS, A. E. Tempos e Doenças: efeitos dos parâmetros climáticos nas crises hipertensivas nos moradores de santa Gertrudes - SP. Revista Estudos Geográficos, Rio Claro, v. 2, n. 1, p. 74-86, 2004.

POLIGNANO, M. V. História das políticas de saúde no Brasil: uma pequena revisão. 2005. Disponível

em:<http://www.medicina.ufmg.br/dmps/internato/saúdenoBrasil.rtf $>$. Acesso em: 2 abr. 2009.

PREFEITURA MUNICIPAL DE MARINGÁ. Nossa cidade: histórico do município. Disponível em: <http:www. Maringá.pr.gov.br> Acesso em: 20 nov. 2008.

PREFEITURA MUNICPAL DE MARINGÁ. Parque do Ingá: plano de manejo. Maringá: Secretaria do Meio Ambiente, 1994.

QUEIROZ, D. R. E. Atlas geoambiental de Maringá - da análise à síntese: a cartografia como subsídio ao planejamento de uso e ocupação do espaço. Maringá: Clichetec, 2003.

ROJAS, L. I. Geografia e saúde: temas y perspectivas em América Latina. Caderno de Saúde Pública, Rio de Janeiro, v. 14, n. 4, p. 701-711, out./dez. 1998.

ROUQUAYROL, M. Z.; FILHO, N. A. 1999. Epidemiologia \& saúde. 5. ed. Rio de Janeiro: Medsi, 1999.

RUSTICUCCI, M.; BETTOLLI, L. M.; ANGELES, H. M. Association between Weater conditions and the number of patients at the emergency room in an Argentine Hospital. International Journal of Biometeorology, Netherlands, no. 46, p. 42-51, 2002.

SAPATA, M. P. M.; SOARES, D. A.; SOUZA, R. K. T. Utilização dos leitos hospitalares sob gestão pública em município de médio porte da Região Sul do Brasil, 1998-2002. Revista Epidemiologia e Serviços de Saúde, Brasília, DF, v. 15, n. 2, p. 57-67, 2006.

SERRA, A. Climatologia do Brasil - 3, Climatologia da América do Sul, Geografia e História - massas de ar. Boletim de Geografia, Rio de Janeiro, 33(245):43-95, abr./jun., 1975.

SILVA, E. N. Ambientes Atmosféricos Intraurbanos na cidade de São Paulo e possíveis correlações com doenças do aparelho respiratório e circulatório. 2010. 215 f. Tese (Doutorado)-Faculdade de Saúde Pública, Universidade de São Paulo, São Paulo, 2010. 
SILVA, E. S.; NERY. J. T. Distribuição Espacial e Temporal da Precipitação na Região Centro-Sul do Estado do Paraná. In: CONGRESSO BRASILEIRO DE BIOMETEOROLOGIA. 3., 2001, Maringá. Anais... Maringá: [s.n.], 2001. 1 CD- ROM.

SILVEIRA, L. M. Os sistemas atmosféricos e a variação do tempo em Maringá, Estado do Paraná, Brasil. Revista Acta Scientiarum Technology, Maringá, v. 28, n. 1, p. 79-84, jan./jun. 2006.

SILVEIRA, L. M. Análise rítmica dos tipos de tempo no Norte do Paraná, aplicada ao clima local de Maringá - Estado do Paraná. 2003. 505 f. Tese (Doutorado)-Departamento de Geografia Física, Centro de Filosofia, Letras e Ciências humanas, Universidade de São Paulo, 2003.

SIMPLE, P.; PASSEL, S. Measurements of dry atmospheric cooling in subfreezing temperatures. Proceedings of the American Philosophical Society, vol. 89, n. 1, p. 177-199, 1945.

SOBRAL, H. R. Poluição do ar e doenças respiratórias em crianças da grande São Paulo: um estudo de Geografia Médica. 1998. 268 f. Tese (Doutorado) Departamento de Geografia Física, Centro de Filosofia, Letras e Ciências humanas, Universidade de São Paulo, 1988.

SODRÉ, N. W. Introdução à geografia (Geografia e Ideologia). Petrópolis, RJ.: Vozes Ltda, 1979.

SORRE, M. A adaptação ao meio climático e biossocial - Geografia Psicológica. In: MEGALE, J. F. (Org.). Max Sorre. Geografia. São Paulo: Ática, n. 46, 1984. p. 2986. (Coleção Grandes Cientistas Sociais).

SOUZA, C. G. A influência do ritmo climático na morbidade respiratória em ambientes urbanos. 2007. 200 f. Dissertação (Mestrado) - Departamento de Geografia, Faculdade de Ciências e Tecnologia, Universidade Estadual Paulista, Presidente Pudente, 2007.

SPIEGEL, R. M. Estatística. Makron Books. 3. ed. São Paulo: Mc Graw-Hill do Brasil Ltda, 1972. (Coleção Schaun).

THOM, E, C., The disconfort index. Weatherwise, v.12, p.57-60, 1959.

TROPPMAIR, H. Perfil fitoecológico do Estado do Paraná. Boletim de Geografia, Maringá, n. 1, p. 67-79, 1990.

YAN, Y. Y. The influence of weather on human mortality in Hong Kong. Social Science \& Medicine, Oxford, v. 50, p. 419-427, 2000.

VAREJÃO-SILVA, M. A. Meteorologia e Climatologia. 2. ed. Brasília, DF: Pax, 2001.

ZEM, J. M. Interações entre a temperatura do ar e a incidência de doenças respiratórias na população infantil da cidade de São José dos Pinhais/PR. 2004. 172 f. Dissertação (Mestrado)-Setor de Ciências da Terra, Departamento de Geografia, Universidade Federal do Paraná, 2004. 
ANEXOS

Anexo 1: Zonas Municipais de Maringá-PR, com os bairros e a população correspondente. Zonas: $33^{*}$ Distrito Iguatemi; $34^{*}$ Distrito Floriano.

\begin{tabular}{|c|c|c|c|c|}
\hline ZONAS & BAIRRO & Mas. & Fem. & Pop. Total \\
\hline 01 & Zona 01. & 5.813 & 4.764 & 10.577 \\
\hline 02 & Parque Res. Anchieta e Zona 02. & 3.187 & 2.679 & 5.866 \\
\hline 03 & Vila Operária. & 3.877 & 3.342 & 7.219 \\
\hline 04 & Zona 04. & 3.065 & 2.590 & 5.655 \\
\hline 05 & Zona 05, Conjunto Hab. Itamaraty. & 3.490 & 3.157 & 6.647 \\
\hline 06 & Zona 06, Conjunto Hab. Planalto. & 2.211 & 1.991 & 4.202 \\
\hline 07 & $\begin{array}{l}\text { Zona 07, Jardim Castor, Jardim Universitário, Jardim Ipiranga, } \\
\text { Jardim Acema, Jardim Carolina. }\end{array}$ & 12.802 & 10.869 & 23.671 \\
\hline 08 & $\begin{array}{l}\text { Zona 08, Jardim Sta Mônica, Vila Cristino, Jardim Vila Rica, } \\
\text { Conjunto Res. Paços D' Arcos. }\end{array}$ & 3.781 & 3.476 & 7.257 \\
\hline 09 & Zona Armazém. & 732 & 605 & 1.337 \\
\hline 10 & Zona 10, Área Industrial. & 148 & 127 & 395 \\
\hline 11 & Vila Esperança, Vila Santo Antonio. & 1.875 & 1.553 & 3.447 \\
\hline 12 & Vila Bosque. & 240 & 199 & 473 \\
\hline 13 & Vila Cleópatra. & 176 & 167 & 343 \\
\hline 14 & Vila Progresso, Jardim Canadá. & 699 & 787 & 1.486 \\
\hline 15 & Vila Nova. & 640 & 570 & 1.436 \\
\hline 17 & $\begin{array}{l}\text { Jardim Social, Jardim Novo Horizonte parte III, Vila Emília, } \\
\text { Jardim Itapuã, Jardim Cerro Azul, Jardim Novo Horizonte parte I. }\end{array}$ & 2.432 & 2.124 & 4.556 \\
\hline 18 & Vila Ipiranga, Vila Cafelândia, Jardim Guararapes. & 817 & 749 & 1.629 \\
\hline 19 & $\begin{array}{l}\text { Conj. Res. Kosmos, Parque Hortência Parte II, Jardim Ouro } \\
\text { Cola, Conj. Res. João De Barro Thaís, Jardim Olímpico, Conj. } \\
\text { Res. Andréia. }\end{array}$ & 3.105 & 3.019 & 6.124 \\
\hline 20 & $\begin{array}{l}\text { Conj. Res. Agatha, Cond. Horizontal Portal de Sevilha, Jardim } \\
\text { Alzira, Cidade Monções - Setor 8, Jardim Universo, Jardim } \\
\text { Higienópolis, Jardim Laodicéia, Jardim Beth, Jardim Alamar, } \\
\text { Conj. Res. Ângelo Planas, Recanto dos Magnatas, Jardim das } \\
\text { Nações, Jardim Botânico. }\end{array}$ & 2.429 & 2.436 & 4.865 \\
\hline 21 & $\begin{array}{l}\text { Jardim Maravilha, Vila Vardelina, Jardim Los Angeles, Jardim } \\
\text { Mandacaru, Vila Santa Isabel, Jardim Monte Carlo, Jardim } \\
\text { Seminário, Núcleo Hab. João XXIII, Jardim Lucianópolis, Jardim } \\
\text { São Jorge, Conj. Res. Cidade Universitária I. }\end{array}$ & 5.019 & 4.765 & 9.784 \\
\hline 22 & Chácaras/sítios - atrás do Contorno Sul. & - & - & - \\
\hline 23 & Vila Morangueira e Ampliação da Vila Morangueira. & 6.373 & 5.823 & 12.859 \\
\hline 24 & $\begin{array}{l}\text { (UBS da Zona Norte), Jardim Alvorada I, Jardim Alvorada II, } \\
\text { Jardim Alvorada III. }\end{array}$ & 12.043 & 11.102 & 23.312 \\
\hline 25 & $\begin{array}{l}\text { Conj. Res. João de Barro I, Núcleo Hab. Santa Felicidade, Conj. } \\
\text { Res. Cidade Alta, Jardim Ipanema, Parque Res. Tarumã, } \\
\text { Loteamento Parque Tarumã. }\end{array}$ & 3.467 & 3.400 & 6.867 \\
\hline 26 & Jardim Internorte. & 356 & 305 & 667 \\
\hline 27 & $\begin{array}{l}\text { (UBS da Zona Sul), Vila Marumbi, Jardim Tabaetê, Jardim Novo } \\
\text { Horizonte - Parte II, Chácara Assai, Jardim Novo Horizonte, } \\
\text { Chácaras Paulista. }\end{array}$ & 3.915 & 3.494 & 7.738 \\
\hline 28 & Parque da Gávea, Parque Lagoa Dourada, Jardim Aclimação. & 817 & 759 & 1.576 \\
\hline 29 & $\begin{array}{l}\text { Parque Res. Cidade Nova, Jardim Imperial, Jardim Imperial II, } \\
\text { Vila Esperança - Parte II, Vila Esperança - Parte III. }\end{array}$ & 4.791 & 4.331 & 9.122 \\
\hline 30 & $\begin{array}{l}\text { Parque Res. Quebec, Jardim das Palmeiras, Conj. Hab. } \\
\text { Hermann Moraes de Barros, Jardim Vitória, Parque das } \\
\text { Palmeiras, Parque Res. Copacabana. }\end{array}$ & 6.459 & 6.020 & 12.479 \\
\hline 31 & $\begin{array}{l}\text { Parque Grevíleas I, Parque Grevíleas III, Parque Res. Eldorado, } \\
\text { Parque Avenida. }\end{array}$ & 3.996 & 3.897 & 7.893 \\
\hline $33^{*}$ & $\begin{array}{l}\text { Jardim Belo Horizonte, Conj. Res. Dona Angelina, Conj. Res. } \\
\text { João Paulo, Conj. Hab. Iguatemi, Jardim Marajoara, Conj. Res. } \\
\text { Santa Terezinha. }\end{array}$ & 2.879 & 2.888 & 5.955 \\
\hline $34^{*}$ & $\begin{array}{l}\text { Conj. Res. João de Barro I, Conj. Res. João de Barro II - } 2^{\underline{a}} \\
\text { Parte, Conj. Res. Natalin Feltrin. }\end{array}$ & 880 & 852 & 1.732 \\
\hline 35 & Vila Ruth, Vila Regina. & 553 & 464 & 1.017 \\
\hline
\end{tabular}

Continua... 
Continua, Anexo 2: Zonas Municipais de Maringá-PR, com os bairros e a população correspondente.

\begin{tabular}{|c|c|c|c|c|}
\hline ZONAS & BAIRRO & Mas. & Fem. & Pop. Total \\
\hline 36 & $\begin{array}{l}\text { Jardim Liberdade I, Jardim Liberdade II, Conj. Hab. Itatiaia, } \\
\text { Parque Industrial I, Parque Industrial II, Conj. Hab. Requião I, } \\
\text { Jardim Fator Imóveis, Jardim América, Conj. Res. Parigot de } \\
\text { Souza, Jardim da Glória, Liberdade IV, Liberdade III, Jardim } \\
\text { Karina, Jardim Atlanta, Conj. Res. Guaiapó. }\end{array}$ & 11.163 & 10.469 & 21.632 \\
\hline 37 & $\begin{array}{l}\text { Conj. Res. João de Barro Champagnat, Jardim Dourados, Conj. } \\
\text { Res. Branca de Jesus Camargo Vieira, Conj. Lea Leal, Jardim } \\
\text { Oásis, Parque Res. Patrícia, Jardim Campos Elíseos, Jardim } \\
\text { Novo Oásis, Jardim Pinheiros II, Parque Res. Tuiuti, Jardim } \\
\text { Virgínia, Conj. Res. Paulino Carlos Filho, Jardim Tupinambá, } \\
\text { Conj. Res. João de Barro Itaparica, Jardim Pinheiros, Jardim } \\
\text { Piatã, Loteamento Batel. }\end{array}$ & 12.233 & 11.641 & 23.874 \\
\hline 38 & $\begin{array}{l}\text { Conj. Res. Céu Azul, Parque Res. Aeroporto - Parte I, Conj. } \\
\text { Res. Aeroporto - Parte II, Jardim Bertioga, Parque Res. } \\
\text { Aeroporto - Parte III, Conj. Res. João De Barro Porto Seguro I, } \\
\text { Conj. Res. João De Barro Porto Seguro II, Conj. Hab. Sanenge } \\
\text { III, Conj. Hab. Del Plata. }\end{array}$ & 2.089 & 2.006 & 4.095 \\
\hline 39 & $\begin{array}{l}\text { Conj. Res. João de Barro Cidade Alta I, Conj. Res. João de } \\
\text { Barro Cidade Alta II, Conj. Res. João de Barro Cidade Canção, } \\
\text { Chácara Aeroporto, Conj. Hab. Sol Nascente, Jardim São } \\
\text { Silvestre, Loteamento Madrid. }\end{array}$ & 3.735 & 3.496 & 7.231 \\
\hline 40 & $\begin{array}{l}\text { Jardim Guaporé, Jardim Parque do Horto, Parque Res. Rio } \\
\text { Branco, Condomínio Res. Batel, Condomínio Res. Horto } \\
\text { Florestal. }\end{array}$ & 549 & 541 & 1.090 \\
\hline 41 & Jardim Ivemar. & 112 & 113 & 278 \\
\hline 42 & $\begin{array}{l}\text { Parque Industrial Bandeirantes - Parte I, Parque Industrial } \\
\text { Bandeirantes - Parte III. }\end{array}$ & 297 & 640 & 937 \\
\hline 43 & $\begin{array}{l}\text { Jardim Indaiá, Jardim dos Pássaros, Jardim Montreal, Conj. } \\
\text { Res. Ney Braga, Parque Hortência I, Parque Industrial } \\
\text { Bandeirantes - Parte II, Conj. Hab. Sanenge, Chácara Estilos. }\end{array}$ & 4.015 & 3.839 & 7.854 \\
\hline 44 & $\begin{array}{l}\text { Jardim Iguaçu, Conj. Res. Inocente Villanova Jr., Jardim } \\
\text { Verônica, Jardim Veredas, Jardim Veredas II. }\end{array}$ & 2.730 & 2.504 & 5.234 \\
\hline 45 & Jardim Nilza, Distrito Industrial II. & 267 & 297 & 564 \\
\hline 46 & $\begin{array}{l}\text { Jardim Andrade, Chácara Alvorada, Conj. Res. Rodolpho } \\
\text { Bernardi, Jardim Ebenezer - Parte I, Jardim Ebenezer - Parte II. }\end{array}$ & 2.542 & 2.416 & 4.958 \\
\hline 47 & $\begin{array}{l}\text { Parque Itaipu - Parte I, Parque Itaipu - Parte II, Jardim } \\
\text { Industrial. }\end{array}$ & 2.805 & 2.612 & 5.417 \\
\hline 48 & $\begin{array}{l}\text { Jardim Tropical, Parque das Laranjeiras, Conj. Hab. Planville, } \\
\text { Jardim Real, Jardim Rebouças. }\end{array}$ & 2.721 & 2.608 & 5.329 \\
\hline 49 & Jardim São Domingos. & - & 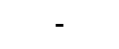 & - \\
\hline 50 & Zona Central. & - & 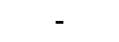 & - \\
\hline 51 & Parque Industrial 200. & - & - & - \\
\hline
\end{tabular}

Fonte: IBGE (2000). 


\section{APÊNDICES A: Registros mensais de internações e óbitos}

Tabela A.1: Registros mensais de internações por doenças respiratórias, (AIH-SUS). Maringá, 2000-2007.

\begin{tabular}{c|cccccccc|c}
\hline & $\mathbf{2 0 0 0}$ & $\mathbf{2 0 0 1}$ & $\mathbf{2 0 0 2}$ & $\mathbf{2 0 0 3}$ & $\mathbf{2 0 0 4}$ & $\mathbf{2 0 0 5}$ & $\mathbf{2 0 0 6}$ & $\mathbf{2 0 0 7}$ & Total/mês \\
\hline Jan & 118 & 116 & 133 & 143 & 138 & 99 & 134 & 118 & $\mathbf{9 9 9}$ \\
Fev & 124 & 116 & 121 & 162 & 159 & 95 & 89 & 183 & $\mathbf{1 . 0 4 9}$ \\
Mar & 212 & 199 & 160 & 276 & 261 & 180 & 218 & 258 & $\mathbf{1 . 7 6 4}$ \\
Abr & 199 & 257 & 186 & 278 & 218 & 180 & 205 & 213 & $\mathbf{1 . 7 3 6}$ \\
Mai & 224 & 245 & 145 & 260 & 256 & 234 & 195 & 229 & $\mathbf{1 . 7 8 8}$ \\
Jun & 263 & 242 & 135 & 341 & 276 & 200 & 132 & 354 & $\mathbf{1 . 9 4 3}$ \\
Jul & 283 & 252 & 264 & 289 & 221 & 179 & 120 & 264 & $\mathbf{1 . 8 7 2}$ \\
Ago & 279 & 238 & 250 & 205 & 232 & 193 & 169 & 208 & $\mathbf{1 . 7 7 4}$ \\
Set & 204 & 193 & 189 & 220 & 183 & 149 & 170 & 205 & $\mathbf{1 . 5 1 3}$ \\
Out & 181 & 203 & 203 & 179 & 195 & 223 & 167 & 177 & $\mathbf{1 . 5 2 8}$ \\
Nov & 146 & 175 & 136 & 182 & 188 & 224 & 132 & 151 & $\mathbf{1 . 3 3 4}$ \\
Dez & 115 & 140 & 109 & 114 & 138 & 129 & 141 & 153 & $\mathbf{1 . 0 3 9}$ \\
\hline Anual & $\mathbf{2 . 3 4 8}$ & $\mathbf{2 . 3 7 6}$ & $\mathbf{2 . 0 3 1}$ & $\mathbf{2 . 6 4 9}$ & $\mathbf{2 . 4 6 5}$ & $\mathbf{2 . 0 8 5}$ & $\mathbf{1 . 8 7 2}$ & $\mathbf{2 . 5 1 3}$ & $\mathbf{1 8 . 3 3 9}$ \\
\hline
\end{tabular}

Tabela A.2: Registros mensais de óbitos por doenças respiratórias, (AIH-SUS). Maringá, 2000-2007.

\begin{tabular}{c|cccccccc|c}
\hline & $\mathbf{2 0 0 0}$ & $\mathbf{2 0 0 1}$ & $\mathbf{2 0 0 2}$ & $\mathbf{2 0 0 3}$ & $\mathbf{2 0 0 4}$ & $\mathbf{2 0 0 5}$ & $\mathbf{2 0 0 6}$ & $\mathbf{2 0 0 7}$ & Total/mês \\
\hline Jan & 5 & 6 & 6 & 1 & 10 & 8 & 9 & 8 & $\mathbf{5 3}$ \\
Fev & 4 & 2 & 7 & 7 & 11 & 7 & 8 & 6 & $\mathbf{5 2}$ \\
Mar & 6 & 8 & 6 & 6 & 8 & 5 & 8 & 11 & $\mathbf{5 8}$ \\
Abr & 6 & 9 & 9 & 8 & 11 & 6 & 8 & 9 & $\mathbf{6 6}$ \\
Mai & 6 & 12 & 3 & 8 & 11 & 7 & 5 & 7 & $\mathbf{5 9}$ \\
Jun & 3 & 10 & 6 & 7 & 16 & 9 & 11 & 8 & $\mathbf{7 0}$ \\
Jul & 10 & 11 & 9 & 9 & 13 & 11 & 11 & 8 & $\mathbf{8 2}$ \\
Ago & 8 & 9 & 10 & 7 & 15 & 5 & 13 & 5 & $\mathbf{7 2}$ \\
Set & 2 & 6 & 7 & 12 & 10 & 8 & 9 & 5 & $\mathbf{5 9}$ \\
Out & 9 & 11 & 4 & 10 & 8 & 6 & 5 & 8 & $\mathbf{6 1}$ \\
Nov & 3 & 8 & 7 & 7 & 7 & 8 & 5 & 5 & $\mathbf{5 0}$ \\
Dez & 7 & 4 & 2 & 8 & 7 & 8 & 10 & 8 & $\mathbf{5 4}$ \\
\hline Anual & $\mathbf{6 9}$ & $\mathbf{9 6}$ & $\mathbf{7 6}$ & $\mathbf{9 0}$ & $\mathbf{1 2 7}$ & $\mathbf{8 8}$ & $\mathbf{1 0 2}$ & $\mathbf{8 8}$ & $\mathbf{7 3 6}$ \\
\hline
\end{tabular}




\section{APÊNDICES B: Cálculos do índice de conforto térmico}

Tabela B.1: Resultados da Temperatura Efetiva (TE), para o dia e hora: janeiro de 2000.

\begin{tabular}{|c|c|c|c|c|c|c|c|c|c|c|c|c|c|c|c|c|c|c|c|c|c|c|c|c|}
\hline$D I A$ & $\overline{O h}$ & $1 \mathrm{~h}$ & $2 h$ & $3 h$ & $4 h$ & $5 h$ & $6 h$ & $7 h$ & $8 h$ & $9 h$ & $10 h$ & $11 h$ & $12 h$ & $13 h$ & $14 h$ & $15 h$ & $16 h$ & $17 h$ & 18h & $19 h$ & $20 h$ & $2 I n$ & $22 h$ & $23 h$ \\
\hline 1 & 1,6 & 22,1 & 2,1 & 22,1 & 21,4 & 1,2 & 21,4 & 22,6 & 22,5 & 22,6 & 23,2 & 24,2 & 8 & & 25,0 & & 057 & 800 & & 23,8 & 2,9 & & 2,3 & 1,7 \\
\hline 2 & 4 & & ,9 & 20,4 & ,2 & 0,2 & 19,2 & 0,4 & 21,6 & 22,1 &, 6 & & 9 & & & & & & & & & & 2,7 & 2,2 \\
\hline 3 & & 0 & & 6 & & 0 & 19,6 & & 12 & ,2 & 9 & 2 & 7 & & & & & & 3 & 1 & 5 & 2 & 2,0 & 1,3 \\
\hline 4 & & 20,7 & & & & & & & 21,4 & 22,4 & 3,4 & & & & & , & & ד & & & & & 2,2 & 1,6 \\
\hline 5 & & & & & & 0,6 & 21 & 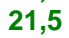 & 21 & 22,6 & & & & & & 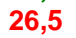 & 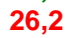 & & & & & & 3,7 & 3,4 \\
\hline 6 & & 22,7 & 1 & 2,0 & & 1,6 & 21,5 & ,4 & 22,7 & 23,4 & , 4 & 25,2 & 5,3 & & 26,6 & 67 & 27,1 & 7,0 & & 1,4 & 3,7 &, 8 & 3,0 & 22,5 \\
\hline 7 & & & & & & & & & & & & & & & & & & & & & & & 1,4 & 21,1 \\
\hline 8 & & & & & & & & & & & & & & & & & & & & & & & & 23,1 \\
\hline 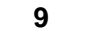 & & & & & & & & & & & & & & & & 2 & & & & & & & & 1,8 \\
\hline 10 & & & & & & & & & & & & & & & & & & & & & & & 6 & 2,4 \\
\hline 11 & & & & & & ,4 & & 0 & 7 & & & &, 4 & & & 5,8 & & & & & & & & 22,0 \\
\hline 12 & & & n & & & & & & 22,2 & & & & & & & & & & & & & & 5 & 3,2 \\
\hline 13 & & 22 & & & & & & & & & & & & & & & & & & & & & & 23,1 \\
\hline 14 & & & & & & & & & & & & & & & & & & & & & & & & 22,2 \\
\hline 15 & & & & & & & & & & & & & & & & & & & & & & & & 25,0 \\
\hline 1 & & & & & & & & & & & & & & & & & & & & & & & & \\
\hline 17 & & & & & & & & & & & & & & & & & & & & & & & & 4,8 \\
\hline 18 & & & & & & & & & 24 & & & & & & & & & & & & & & & 23,8 \\
\hline 19 & & & & & & & & & & & & & & & & & & & & & & & & \\
\hline 20 & & & & & & & & & & & & & & & & & & & & & & & & 2,7 \\
\hline 21 & & & & & & & & & & & & & & & & & & & & & & & & \\
\hline 22 & & & & & & & & & & & & & & & & & & & & & & & & 34 \\
\hline 25 & & & & & 22 & & & & & & & & & & & & & & & & & & & 3,9 \\
\hline 26 & & & & & & & & & & & & & & & & & & & & & & & & \\
\hline 27 & & & & & & & & & & & & & & & & & & & & & & & & 1,2 \\
\hline 28 & & & & & 18 & & & & & & & & & & & & & & & & & & &, 9 \\
\hline 29 & & & & & & & & & & & & & & & & & & & & & & & & \\
\hline 3 & & & & & & & & & & & & & & & & & & & & & & & 2 & 22,8 \\
\hline 31 & & & & & & & & & & & & & & & & & & & & & & & 8 & \\
\hline 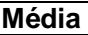 & 22,4 & 22,2 & 21,9 & 21,6 & 21,4 & 21,4 & 21,3 & 21,5 & 22,5 & 23,2 & 24,3 & 25,0 & 25,6 & 26,0 & 25,9 & 26,0 & 25,6 & 25,5 & 25,2 & 24,6 & 23,9 & 23,6 & 23,3 & 22,7 \\
\hline
\end{tabular}

- Abaixo de $18,9^{\circ} \mathrm{C}$, considerada como condição de desconforto ao frio;

- Entre 19,0C a 25,5C, faixa de conforto térmico;

- Acima de 25,6드, significa desconforto ao calor. 
Tabela B.2: Resultados da Temperatura Efetiva (TE), para o dia e hora: julho de 2000.

\begin{tabular}{|c|c|c|c|c|c|c|c|c|c|c|c|c|c|c|c|c|c|c|c|c|c|c|c|c|}
\hline$\overline{D I A}$ & Oh & $1 \mathrm{~h}$ & $2 h$ & $3 h$ & $4 h$ & $5 h$ & $6 h$ & $7 h$ & $8 h$ & $9 h$ & $10 h$ & $11 h$ & $12 h$ & $13 h$ & $14 h$ & $15 h$ & $16 \mathrm{~h}$ & 7/h & 78 & $19 h$ & $20 h$ & $21 h$ & $22 h$ & $23 h$ \\
\hline 1 & 20,4 & 18,6 & 18,4 & 18,3 & 18,6 & 18,6 & 18,6 & 18,3 & 18,5 & 18,7 & 19,3 & 20,0 & 21,2 & & 22,4 & 22,4 & 22,4 & 21,7 & 11 & 20,7 & 20,5 & 20,4 & 20,5 & 20,6 \\
\hline 2 & & & 20,2 & 20,2 & 19,8 & & & & & & & & & & & & & & & & & & 9,0 & 8,7 \\
\hline 3 & & & & & & & & & & & & & & & & & & & & & & & 0 & 9,6 \\
\hline 4 & 4 & 17,2 & 2 & 6,6 & 16,2 & 0 & 15,8 & 15,7 & 6,2 & 16,8 & 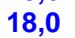 & &, 5 & & 0,6 & & & ,6 & 9,8 & 1 & 8,7 & 4 & 3,2 & 7,9 \\
\hline 5 & & & $3-$ & & 17,2 & & & & 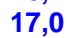 & & & & & & & & 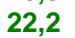 & & & 07 & & & & 18,5 \\
\hline 6 & & 17 & 4 & 6 & 17,4 & 2 & & & 7,9 & &, 6 & 20 & 1,0 & 1,6 & 21,9 & 8 & 0 & 1,4 & & 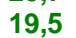 & 9,2 & 9 & 6 & 18,3 \\
\hline 7 & & 16 & $a$ & & 16,3 & & & & & & & & & & & & & & & & & & 6 & 19,4 \\
\hline 8 & & & & & & & & & & & & & & & & & & & & & & & & 0,2 \\
\hline 9 & & 18 , & 17 & 17,6 & 17 & 17,0 & & & 19.6 & & & & & & & & & & & & & & 2 & 0,0 \\
\hline 10 & & & & & & & & & & & & & & & & & & & & & & & & 8,4 \\
\hline 11 & 10,4 & 16 & 16 & 1 & 14,8 & 14,1 & 14,1 & 14 & 14,4 & 14,4 & 1,8 & 15 & 4 & & & 3,3 & 2,6 & & & 11,6 & & & 0 & 10,9 \\
\hline 12 & & & 10 , & 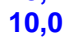 & 10 & & & & & & & & & & & & & & & & & & & 9 \\
\hline 13 & & & & & 8, & & & & & & & & & & & & & & & & & & & 7 \\
\hline 14 & & & & & & & & & & & & & & & & & & & & & & & & 15,5 \\
\hline 15 & & $\therefore$ & , & 4, & 14 & 14,5 & 14,4 & 15 & 1 & & & & & & & & & & & & & & & 13,3 \\
\hline 16 & & 1 & 10,9 & & & 9,5 & & & 3 & & & 10 & & & & & & & & & & & & 8 \\
\hline 17 & & & & & & & & & & & & & & & & & & & & & & & & 2 \\
\hline 18 & & & 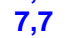 & 8 & & 8, & & & & & & & & & & & & & & & & & & 13,7 \\
\hline 19 & & & 12 & 12 & 11 & 1 & 12 & 12 & 12,0 & & & & & & & & & & & & & & & 10,4 \\
\hline 20 & & & $a$ & & & & & & & & & & & & & & & & & & & & & 10,4 \\
\hline 01 & & & & & & & & & & & & & & & & & & & & & & & & \\
\hline 22 & & & & & & & & & & & & & & & & & & & & & & & & $\begin{array}{l}16,7 \\
\end{array}$ \\
\hline 25 & & & & & & & & & & & & & & & & & & & & & & & & 14,2 \\
\hline 0 & & & & & & & & & & & & & & & & & & & & & & & & 15,8 \\
\hline 27 & & & & & & & & & & & & & & & & & & & & & & & & 16,6 \\
\hline 28 & & & & & & & & & & & & & & & & & & & & & & & & 17,0 \\
\hline 29 & & & & & & & & & & & & & & & & & & & & & & & & 18,0 \\
\hline 30 & & & & & & & & & & & & & & & & & & & & & & & & 17,2 \\
\hline 31 & & & & & & & & & & & & & & & & & & & & & & & & 17,0 \\
\hline 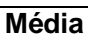 & 4,0 & 13,8 & 13,6 & 13,3 & 12 & 13,1 & 13,0 & 13,3 & 13,8 & 14,5 & 15 & 17,0 & 17,7 & 18,3 & 18,6 & 8 & 18,8 & 18,4 & 17,7 & 16,7 & 6,2 & 16,3 & 15,5 & 152 \\
\hline
\end{tabular}

- Abaixo de $18,9^{\circ} \mathrm{C}$, considerada como condição de desconforto ao frio;

- Entre 19,0ㅇ a $25,5^{\circ} \mathrm{C}$, faixa de conforto térmico:

- Acima de 25,6드, significa desconforto ao calor. 
Tabela B.3: Resultados da Temperatura Efetiva (TE), para o dia e hora: janeiro de 2003.

\begin{tabular}{|c|c|c|c|c|c|c|c|c|c|c|c|c|c|c|c|c|c|c|c|c|c|c|c|c|}
\hline$D I A$ & $O h$ & $1 \mathrm{~h}$ & $2 h$ & $3 h$ & $4 h$ & $5 h$ & $6 h$ & $7 h$ & $8 h$ & $9 h$ & $10 \mathrm{~h}$ & $11 h$ & $12 h$ & $13 \mathrm{~h}$ & $14 h$ & $15 h$ & $16 h$ & $17 \mathrm{~h}$ & $18 \mathrm{~h}$ & $19 h$ & $20 h$ & $21 h$ & $22 h$ & $23 h$ \\
\hline 1 & 24,7 & 23,8 & 23, & & 23, & 8 & 80 & 23,8 & & 26 & 27,0 & 875 & 28,0 & 80 & 29,0 & 28,4 & 27,7 & 25,6 & 25,5 & 80 & 24,3 & 24,2 & 24,2 & 24,7 \\
\hline 2 & & & & & & & & & & & & & & & & & & & & & & & 3,9 & 22,8 \\
\hline 3 & & 3,0 & & , & , & & & & & & & & & 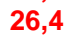 & 26,4 & & & , & 0 & & 8 &, 6 & & 22,8 \\
\hline 4 & 6 & & 22,6 & 2 & 22,2 & & & & & & 1,4 & & & 27 & & & & & 4,5 & & 2,7 & & 22,8 & 2,6 \\
\hline- & & & & & & & & & & & & & & & & & & & 0,2 & & & & & 3,6 \\
\hline 6 & 23,4 & 23,4 & 23,4 & 23,2 & 23,0 & 3,1 & 23,7 & 23,5 & 4,0 & 25,2 & 26,1 & 26,6 & 26,6 & 6,5 & 26,4 & 26,2 & 6,8 & 26,1 & 6,2 & 5,4 & 5,1 & 4,5 & 24,0 & 23,8 \\
\hline 7 & & & & 22 & & & & & & & & & & & 70 & & & 5 & 70 & . & 60 & & 5,3 & 3,5 \\
\hline 8 & 2,8 & & & 2,9 & & ,7 & 21,4 & 22,2 &, 2 & &, 8 & & 25,2 & 8 & 26,8 & $\therefore$ & & & & & & & & 23,1 \\
\hline 9 & & & 0 & 1 & & & & & & & & & & & & & & & & & & & 0,0 & 4,4 \\
\hline 10 & & & & & & & & & & & & & & & & & & & & & & & & 21,3 \\
\hline 11 & & & ),2 & & & & & & & & & & & & & & & & & & & & 1,6 & 1,5 \\
\hline 12 & & & & & & & & & & & & & & & & & & & & & & & & 2,2 \\
\hline 13 & & & 2 & 0 & & & & & & & & & & & 1,3 & & & & & & & & 2,8 & \\
\hline 14 & & & & & & & & & & & & & & & & & & & & & & & & 3,4 \\
\hline 15 & & & & & & & & & & & & & & & & & & & & & & & & 23,3 \\
\hline 16 & & & & & & & & & & & & & & & & & & & & & & & & 4 \\
\hline 17 & & & & & & & & & & & & & & & & & & & & & & & & 23,4 \\
\hline 18 & & & & & & & & & & & & & & & & & & & & & & & & \\
\hline 19 & & & & & & & & & & & & & & & & & & & & & & & & 23,6 \\
\hline 20 & & & & & & & & & & & & & & & & & & & & & & & & , 2 \\
\hline 01 & & & & & & & & & & & & & & & & & & & & & & & & \\
\hline 2 & & & & & & & & & & & & & & & & & & & & & & & & 4,1 \\
\hline 25 & & & & & & & & & & & & & & & & & & & & & & & & \\
\hline 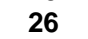 & & & & & & & & & & & & & & & & & & & & & & & & \\
\hline 27 & & & & & & & & & & & & & & & & & & & & & & & & \\
\hline 28 & & & & & & & & & & & & & & & & & & & & & & & & \\
\hline 2 & & & & & & & & & & & & & & & & & & & & & & & & \\
\hline 30 & & & & & & & & & & & & & & & & & & & & & & & & 3,6 \\
\hline ? & & & & 22,9 & & & & & & & & & & & & & & & & & & &, 0 & \\
\hline léd & 22,8 & 22,6 & 22,5 & 22,2 & 22,1 & 22,0 & 22,1 & 22,2 & 23,0 & 23,6 & 24,4 & 24,8 & 25,2 & 25,5 & 25,8 & 25,8 & 25,6 & 25,4 & 25,1 & 24,6 & 24,2 & 23,7 & 23,5 & 23,0 \\
\hline
\end{tabular}

- Abaixo de $18,9^{\circ} \mathrm{C}$, considerada como condição de desconforto ao frio;

- Entre 19,0ㅇ a 25,5으, faixa de conforto térmico:

- Acima de 25,6으, significa desconforto ao calor. 
Tabela B.4: Resultados da Temperatura Efetiva (TE), para o dia e hora: junho de 2003.

\begin{tabular}{|c|c|c|c|c|c|c|c|c|c|c|c|c|c|c|c|c|c|c|c|c|c|c|c|c|}
\hline$\overline{D I A}$ & Oh & $1 h$ & $2 h$ & $3 h$ & $4 h$ & $5 h$ & $6 h$ & $7 h$ & $8 h$ & $9 h$ & $10 h$ & $11 h$ & $12 h$ & $13 h$ & $14 h$ & $15 h$ & $16 h$ & $17 h$ & $18 \mathrm{~h}$ & $19 h$ & $20 h$ & $21 h$ & $22 h$ & $23 h$ \\
\hline 1 & 18,8 & 17,4 & 17,3 & 16,9 & 16,6 & 16,4 & 16,7 & 17,8 & 19,0 & 20,0 & 21,7 & 22,8 & 23,3 & 24,2 & 24,2 & 24,1 & 24,3 & 23,8 & 22,7 & 21,6 & 21,0 & 20,6 & 20,8 & 19,3 \\
\hline 2 & 20,2 & 18,3 & 18,1 & 17,8 & 17,2 & 17,7 & 17,7 & 17,9 & 18,6 & 19,8 & 20,7 & 21,8 & 22,7 & 23,0 & 23,6 & 23,9 & 24,2 & 23,8 & 22,8 & 21,9 & 21,4 & 21,1 & 21,0 & 20,9 \\
\hline 3 & 18,2 & 20,0 & 19,5 & 19,6 & 19,6 & 18,9 & 19,4 & 19,7 & 19,9 & 20,0 & 20,4 & 20,6 & 21,0 & 19,4 & 18,9 & 19,0 & 19,2 & 19,2 & 19,1 & 19,0 & 16,8 & 18,7 & 18,6 & 18,6 \\
\hline 4 & 18,6 & 18,3 & 18,3 & 18,4 & 18,4 & 18,0 & 18,0 & 17,9 & 18,1 & 18,2 & 19,2 & 19,7 & 19,8 & 20,4 & 21,3 & 21,0 & 20,7 & 20,4 & 19,8 & 19,2 & 19,2 & 19,0 & 19,0 & 18,8 \\
\hline 5 & 0 & 8,4 & 18,4 & 18,2 & 18,2 & 18,4 & 18,5 & 18,9 & 19,2 & 19,6 & 19,6 & 20,1 & 20,8 & 21,2 & 21,2 & 19,6 & 20,1 & 19,9 & 19,5 & 19,4 & 19,4 & $\begin{array}{l}19,2 \\
\end{array}$ & 19,0 & 18,8 \\
\hline 6 & 20,4 & 9,2 & 19,0 & 18,8 & 18,8 & 19,0 & 19,0 & 19,3 & 19,9 & 20,6 & 21,5 & 22,5 & 23,6 & 24,0 & 24,1 & 24,6 & 24,6 & 24,5 & 23,5 & 23,0 & 22,1 & 21,7 & 21,4 & 21,3 \\
\hline 7 & &, 2 & 20,2 & 0 & 19,8 & $\begin{array}{l}19,7\end{array}$ & $\begin{array}{l}19,7\end{array}$ & 19,7 & 21,4 & 22,5 & 23,5 & 24,1 & 24,6 & 5,4 & 25,3 & 25,4 & 25,2 & 25,0 & 4,2 & 3,8 & 23,1 & 22,8 & 2,3 & 21,6 \\
\hline 8 & 20,5 & 21,2 & 20,1 & 20,8 & 20,4 & 20,2 & 20,0 & 19,8 & 19,9 & 19,9 & 20,9 & 21,8 & 22,8 & 23,1 & 23,2 & 23,7 & 23,6 & 23,2 & 22,4 & 22,1 & 21,8 & 21,6 & 21,2 & 21,0 \\
\hline 9 & 21,0 & 9,9 & 19,5 & 9,5 & 19,1 & 18,9 & 18,8 & 18,9 & 19,2 & 19,8 & 20,7 & 21,8 & 23,0 & 23,3 & 24,0 & 24,2 & 24,2 & 23,6 & 23,0 & 1,9 & 21,6 & 1,3 & 21,2 & 21,0 \\
\hline 10 & 19,6 & 1,0 & 21,0 & 20,4 & 20,4 & 20,0 & 20,0 & 20,4 & 20,6 & 21,1 & 22,2 & 22,7 & 23,2 & 23,6 & 24,1 & 24,0 & 24,2 & 23,8 & 22,5 & 2,0 & 21,2 & 20,7 & 20,4 & 20,2 \\
\hline 11 & 19,2 & 8,7 & 19,2 & 8,6 & 19,1 & 19,2 & 19,6 & 19,3 & 19,9 & 21,0 & 21,9 & 22,0 & 23,0 & 24,0 & 24,2 & 24,3 & 23,9 & 23,5 & 22,2 & 21,0 & 20,9 & 20,3 & 20,1 & 19,9 \\
\hline 12 & 19,6 & 8,1 & 18,2 & 8,6 & 18,2 & 17,9 & 17 & 18,3 & 19,1 & 21,1 & 21,9 & 22,6 & 23,5 & 24,1 & 24,3 & 24,0 & 24,0 & 23,9 & 22,7 & 22,0 & 3 & 20,8 & 20,5 & 20,3 \\
\hline 13 & 1 & 9,5 & 17,9 & 7,9 & 18,3 & 1 & 18,4 & 18 , & 19,3 & 20,6 & 22,7 & 23,4 & 23,5 & 23,9 & 23,9 & 24,1 & 23,7 & 23,0 & 2 & & 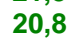 & 20,2 &, 1 & 19,9 \\
\hline 14 & 19,8 & 8,5 & 17,8 & 8,9 & 18,5 & 18,4 & 18,0 & 18,6 & 19,2 & 1,3 & 22,9 & 23,2 & 23,5 & 23,8 & 23,9 & 24,2 & 24,2 & 23,7 & 22,6 & 1,2 & 0,8 & 0,5 & 20,2 & 20,0 \\
\hline 15 & 20,6 & 19,1 & 18,7 & 18,4 & 18,8 & 18,6 & 18,5 & 18,7 & 19,0 & 19,8 & 20,8 & 21,5 & 22,2 & 22,8 & 23,4 & 23,8 & 23,9 & 3,8 & 2 & & & 1 & & 20,6 \\
\hline 16 & 20,7 &, 9 & 20,7 &, 5 & 20,2 & 19,0 & 19,0 & 19,2 & 19,3 & 20,8 & 22,3 & 22,5 & 23,1 & 23,4 & 23,6 & 23,6 & 23,5 & 23,4 & 22,6 & 2,2 & 21,8 & 1,2 & 20,8 & 20,6 \\
\hline 17 & 19,6 & 1,0 & 20,5 & 19,6 & 19,8 & 19,8 & 20,2 & 20,0 & 20,0 & 20,4 & 21,7 & 22,3 & 23,4 & 23,7 & 24,1 & 23,7 & 23,7 & 23,4 & 22,4 & 1,4 & 20,9 & 20,8 & 20,7 & 20,3 \\
\hline 18 & & & 19,3 & & & & & 1 & & 20,2 & 21,7 & 22 . & 23,6 & 0 & & & & & & & & & & 19,5 \\
\hline 19 & I & 17,9 & 18,0 & 8,0 & 18,3 & 18,9 & 18,3 & 18,0 & 18,2 & 18,6 & 19,5 & 21,0 & 21,0 & 22,8 & 21,3 & 22, & ,7 & 21 & 21,0 & $2 C$ & 0 & 9,6 & 19,4 & 19,0 \\
\hline 20 & 17,4 & 18,2 & 18,4 & 17,0 & 16,5 & 16,8 & 16 , & 16 & 16,9 & 18,4 & 20,2 & $20, \varepsilon$ & 21,0 & 21 & 21 & 22, & 2 & & 2 & & &, 1 & & 18,3 \\
\hline 21 & 17,6 & 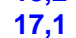 & 17,1 & 7 & 15,9 & 15 & 15 & 16,2 & 17 & 18,3 & 010 & 20. & 22,6 & 22 & 23 & 22,9 & ?2 & & $2 ?$ & & & & & 18,3 \\
\hline 22 & 17,5 & 17,7 & 17,4 & 17,0 & 16,2 & 16,4 & 16,6 & 17,3 & 17,8 & 20,5 & 21,6 & 22,5 & 22,9 & 22,3 & 22,1 & 21,9 & 22,6 & 22,3 & 20,6 & 20,3 & $\begin{array}{l}19,7\end{array}$ & 9,1 & 18,8 & 18,6 \\
\hline 23 & & $6=$ & 16,3 & 68 & 17,0 & 16,4 & 16,8 & 16,8 & & & & & 22,0 & & 20 & & 205 & & 010 & & 19,2 & & & 18,0 \\
\hline 24 & 1 & 16,7 & 15,9 & 15,6 & 16,1 & 16,4 & 16,8 & 15,6 & 16,2 & 19,0 & 20,5 & 21,4 & 21,7 & 22,2 & 22,2 & 22,6 & 22,4 & 2 & 21,1 & 19,7 & 19,4 & 19,0 & 18,1 & 17,8 \\
\hline 25 & & 17,1 & 16,6 & & & & & 16 & & 18 & & 20 & & 21 & 22 & 2 & 2 & & & & & ,2 & 17,8 & 17,6 \\
\hline 26 & & 16,1 & 15,6 & 16,4 & 15,8 & 15 & 15 & 16 & & 19 & & 21 & 22,1 & 22 & 22,5 & 22,6 & 22 & & 20,4 & & 19,4 & 0 & 18,2 & 18,0 \\
\hline 27 & 16,4 & 17,4 & 17,2 & 16,9 & 16,8 & 16,6 & 17 & 16 , & 17 & 18,3 & 20,7 & 21 & 21,8 & 22 & 23,0 & 2 & 23,1 & 2 & 21,2 & 4 & & 1 & 18,7 & 18,4 \\
\hline 28 & & 17, & 17,5 & 18, & 17,3 & 17 & & 18 & & 18 & & & 22,9 & & & & & & & & & 1,0 & 1 & 18,6 \\
\hline 29 & 19,1 & 18,1 & 18,7 & 18,6 & 16,8 & 16,9 & 16,9 & 16,6 & 16,8 & 18,7 & 20,6 & 21 & 21,9 & 22,2 & 23,2 & 23,0 & 23,0 & 2 & 21,6 & 20,9 & 20,8 & 20,3 & $\begin{array}{r}19,8 \\
\end{array}$ & 19,3 \\
\hline 30 & 15,7 & 18,8 & 18,3 & 18,2 & 17,8 & 17,0 & 16,1 & 16,1 & 16,2 & 17,2 & 17,9 & 18 & 19,0 & 19,6 & 20,1 & 20,3 & 20,4 &, 2 & 19,2 & 18,0 & 17,3 & 16,3 & 16,2 & 16,0 \\
\hline & & 18.6 & 18.4 & 183 & & g & & 18. & & & 200 & 21. & 22,4 & 22 & 22 & & & & & 20. & 20.3 & 20. & 196 & \\
\hline
\end{tabular}

\section{- Abaixo de $18,9^{\circ} \mathrm{C}$, considerada como condição de desconforto ao frio;}

- Entre $19,0^{\circ} \mathrm{C}$ a $25,5^{\circ} \mathrm{C}$, faixa de conforto térmico:

- Acima de 25,6드, significa desconforto ao calor. 
Tabela B.5: Resultados da Temperatura Efetiva (TE), para o dia e hora: janeiro de 2007.

\begin{tabular}{|c|c|c|c|c|c|c|c|c|c|c|c|c|c|c|c|c|c|c|c|c|c|c|c|c|}
\hline$\overline{D I A}$ & Oh & $\overline{1 h}$ & $2 h$ & $\overline{3 h}$ & $4 h$ & $5 h$ & $6 h$ & $7 h$ & $8 h$ & $9 h$ & $10 h$ & $11 h$ & $12 h$ & $13 h$ & $14 h$ & $15 h$ & $16 h$ & $17 h$ & $18 \mathrm{~h}$ & $19 h$ & $20 h$ & $21 h$ & $22 h$ & $23 h$ \\
\hline 1 & 23,4 & 22,6 & 22,4 & 22,1 & 21,8 & 21,6 & 21,4 & 22,3 & 23,1 & 23,6 & 23,8 & 24,2 & 25,0 & 25,0 & 25,1 & 24,6 & 24,9 & 25,0 & 24,7 & 24,6 & 24,4 & 24,2 & 23,6 & 23,6 \\
\hline 2 & 22,4 & 23,3 & 23,2 & 22,6 & 22,6 & 22,4 & 22,4 & 22,3 & 22,8 & 23,1 & 23,7 & 23,2 & 22,1 & 23,6 & 23,6 & 24,6 & 25,4 & 24,6 & 24,8 & 24,4 & 23,4 & 22,8 & 22,5 & 22,4 \\
\hline 3 & 22,1 & 2,4 & 22,4 & 22,4 & 22,4 & 2,4 & 22,4 & 22,6 & 23,0 & 23,4 & 24,3 & 24,6 & 24,5 & 24,4 & 24,3 & 23,9 & 24,2 & 23,2 & 22,6 & 22,3 & 22,0 & 22,1 & 22,0 & 22,2 \\
\hline 4 & 22,7 & 23,0 & 23,0 & 23,0 & 23,0 & 23,0 & 23,0 & 22,1 & 22,4 & 22,8 & 23,4 & 24,0 & 25,4 & 25,8 & 25,3 & 24,3 & 23,7 & 22,7 & 22,6 & 22,5 & 22,5 & 22,5 & 22,5 & 22,8 \\
\hline 5 & 23,1 & 22,6 & 22,7 & 22,7 & 22,7 & 22,7 & 22,7 & 22,7 & 22,7 & 23,4 & 24,4 & 24,6 & 24,5 & 24,4 & 24,2 & 24,8 & 24,5 & 25,0 & 24,6 & 24,4 & 23,8 & 23,0 & 22,4 & 23,0 \\
\hline 6 & 23,6 & 3,0 & 22,8 & 2,9 & 22,9 & 2,9 & 22,9 & 23,2 & 23,7 & 24,4 & 25,3 & 25,5 & 24,5 & 24,4 & 24,2 & 24,8 & 26,6 & 26,7 & 27,0 & 26,6 & 23,4 & 23,4 & 23,3 & 23,6 \\
\hline 7 & 23,3 & 3,7 & 23,6 & 3,3 & 22,8 & 22,6 & 22,9 & 23,0 & 23,6 & 24,0 & 24,4 & 24,8 & 25,4 & 25,9 & 25,7 & 25,2 & 24,8 & 24,8 & 24,7 & 22,5 & 22,6 & 22,7 & 22,6 & 23,4 \\
\hline 8 & 24,8 & 3,4 & 23,4 & 3,2 & 23,2 & 22,4 & 21,9 & 21,7 & 22,0 & 22,5 & 23,2 & 23,6 & 24,5 & 25,4 & 25,8 & 26,1 & 26,2 & 25,8 & 25,2 & 25,0 & 24,8 & 24,4 & 23,8 & 24,8 \\
\hline 9 & 22,2 & 4,8 & 24,8 & 4,0 & 22,5 & 22,4 & 22,4 & 21,9 & 22,2 & 22,5 & 24,0 & 24,8 & 25,8 & 25,9 & 26,0 & 25,8 & 25,1 & 24,5 & 24,1 & 23,9 & 23,7 & 23,3 & 23,1 & 22,2 \\
\hline 10 & 23,4 & 1,9 & 21,9 & 1,3 & 21,0 & 20,8 & 20,8 & 22,3 & 24,4 & 25,0 & 25,4 & 26,1 & 26,5 & 26,7 & 27,1 & 26,5 & 26,6 & 26,3 & 26,8 & 26,0 & 25,4 & 25,0 & 24,7 & 23,5 \\
\hline 11 & 21,6 & 3,2 & 23,0 & 22,4 & 22,4 & 22,4 & 22,5 & 23,9 & 24,2 & 24,9 & 24,9 & 26,2 & 26,6 & 26,4 & 23,8 & 23,8 & 23,8 & 23,8 & 23,4 & 22,9 & 22,6 & 22,6 & 22,6 & 21,6 \\
\hline 12 & 20,7 & 1,6 & 21,4 & 0,8 & 20,8 & 20,6 & 20,6 & 22,2 & 23,2 & 24,2 & 25,4 & 25,9 & 26,5 & 24,8 & 23,8 & 24,9 & 23,8 & 22,7 & 22,2 & 22,2 & 22,2 & 22,1 & 21,8 & 20,7 \\
\hline 13 & 20,9 & 0,8 & 20,8 & 1,3 & 21,4 & 1,6 & 21,9 & 22,6 & 22,5 & 22,8 & 23,3 & 23,9 & 25,0 & 24,8 & 25,0 & 25,4 & 22,5 & 22,6 & 23,2 & 23,8 & 23,0 & 22,6 & 22,5 & 20,9 \\
\hline 14 & 22,5 &, 8 & 20,9 & 9 & 20,9 & 0,9 & 21,2 & 22,4 & 23,7 & 24,0 & 24,8 & 25,2 & 26,2 & 26,6 & 26,9 & 26,6 & 25,1 & 26,0 & 26,2 & 25,4 & 8,3 & 23,0 & 21,9 & 22,8 \\
\hline 15 & 21,5 & 2,6 & 22,7 & 1,4 & 20,6 & 19,8 & 19,6 & 21,4 & 21,7 & 22,5 & 24,0 & 24,8 & 25,2 & 26,2 & 26,6 & 26,9 & 26,6 & 24,5 & 24,3 & 24,2 & 24,2 & 23,5 & 22,8 & 21,5 \\
\hline 16 & 21,6 & 21,1 & 21,1 & 21,1 & 21,0 & 20,4 & 19,9 & 21,0 & 21,8 & 22,6 & 22,6 & 23,4 & 24,0 & 24,6 & 25,4 & 26,0 & 25,9 & 25,6 & 25,2 & 24,8 & 23,8 & 23,0 & 22,6 & 21,5 \\
\hline 17 & 22,2 &, 8 & 20,4 & 0,1 & 20,0 & 19,8 & 19,8 & 20,2 & 21,0 & 21,1 & 20,9 & 21,5 & 22,3 & 23,2 & 22,9 & 23,5 & 24,6 & 24,0 & 23,4 & 22,9 & 22,6 & 22,5 & 22,3 & 22,2 \\
\hline 18 & 24,0 & 22,2 & 22,2 & 22,2 & 22,2 & 22,2 & 22,2 & 22,9 & 23,5 & 24,3 & 25,4 & 25,7 & 25,9 & 26,2 & 26,3 & 26,7 & 26,4 & 26,0 & 26,0 & 25,4 & 24,9 & 24,8 & 24,5 & 24,2 \\
\hline 19 & 25,2 & 3,8 & 23,8 & 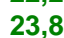 & & 22,8 & 22,2 & 22,2 & 23 & 24,0 & & 26,3 & & & & & & & & & & & & 25,3 \\
\hline 20 & 21,6 & 6,4 & 23,2 & 2,6 & 22,4 & 20,8 & 20,8 & 21,4 & 21,8 & 22,4 & 23,5 & 23,4 & 24,6 & 24 & 23,8 & 23 & 23 & 23,4 & 23,3 & 22,7 & 22,6 & 22,2 & 22,3 & 21,6 \\
\hline 21 & 22,8 & 1,6 & 21,6 & 0,6 & 20,6 & 20,4 & 20,4 & 21,4 & 21,9 & 23,2 & 24 & 25 & 25,8 & 25 & 26,0 & 2 & 26 & 26,2 & 25,2 & 24,6 & 24,6 & 24,3 & 23,9 & 23,2 \\
\hline 22 & 21,1 & 2,8 & 22,9 & 1,7 & 21,5 & 0,2 & 20,7 & 21,5 & 22,1 & 22,6 & 23,6 & 23,7 & 23,7 & 24 & 24,4 & 26,5 & 24,8 & 24,4 & 24,0 & 23,7 & 23,4 & 22,3 & 23,8 & 21,1 \\
\hline 23 & 22,6 & 21,1 & 21,1 & 20,1 & 19,6 & 19,2 & 18,8 & 20,2 & 21,5 & 22,4 & 23,5 & 24,2 & 25,0 & 25,4 & 25,4 & 26,2 & 25,6 & 26,0 & 25,4 & 5 & 24,5 & 24,1 & 23,8 & 22,6 \\
\hline 24 & 22,4 & 2,4 & 22,2 & & & & & 21,0 & 2 & 23,0 & 2 & 24,1 & U & & 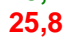 & & & & & & & & 3 & 22,6 \\
\hline 25 & 24,2 & 22,4 & 22,2 & 21,8 & 21,6 & 21,8 & 21,7 & 22,4 & 23,2 & 24,4 & 26,1 & 26,1 & 26,0 & 26 & 26,9 & 24,6 & 26,8 & 27,2 & 25,3 & 25,1 & 24,6 & 23,8 & 23,7 & 24,1 \\
\hline 26 & 22,0 & 3,6 & 23,4 & 22,6 & 22,4 & 22,6 & 0 & 22,3 & 22,9 & 23 & 2 & 26,1 & - & 26 & - & 24,6 & & 24,2 & & 2,8 & 22,8 & 8 & 22,8 & 22,0 \\
\hline 27 & 22,4 & 22,0 & 22,0 & ת & 22,0 & 018 & & 22,9 & & 23 & & 25,8 & 2 & 26 & & & 26,8 & 25,8 & & & 220 & 23,3 & 23,2 & 22,4 \\
\hline 28 & 21,7 & 22,4 & 22,2 & 22,2 & 22,0 & 21,8 & 21,6 & 22,3 & 22,2 & 22,3 & 22,6 & 23,9 & 25,3 & 24 & 25,1 & 23,9 & 22,8 & 22,8 & 22,6 & 22,6 & 22,4 & 22,2 & 22,2 & 21,7 \\
\hline 29 & 22,6 & . & 21,6 & 1,6 & 21,6 & 21,6 & 21,1 & 22 & 2 & 23 & 24 & 23 & 24 & & 24,3 & & & & & & 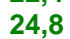 & 4,2 & 24,2 & 23,0 \\
\hline 30 & 23,2 & 22,0 & 21,8 & 21,4 & 21,4 & 21,4 & 21,4 & 22,4 & 23,5 & 24,7 & 26,1 & 26,6 & 26,7 & 26,9 & 27,1 & 22,8 & 27,2 & 27,4 & 26,2 & 26,2 & 24,5 & 24,0 & 23,9 & 23,4 \\
\hline 31 & 22,0 & 22,0 & 22,6 & 3,0 & 22,4 & 22,4 & 22,4 & 21,8 & 22,7 & 23,6 & 24,6 & 25,0 & 25,3 & 26,1 & 26,4 & 23,6 & 26,0 & 26,1 & 26,2 & 25,9 & 25,4 & 24,9 & 24,7 & 21,9 \\
\hline Médi & 22,6 & 22,5 & 22,4 & 22,0 & 21,8 & 21,6 & 21,5 & 22,1 & 22,7 & 23,4 & 24,2 & 24,7 & 25,2 & 25,4 & 25,4 & 25,3 & 25,3 & 25,1 & 24,7 & 24,3 & 23,9 & 23,4 & 23,2 & 22,6 \\
\hline
\end{tabular}

- Abaixo de $18,9^{\circ} \mathrm{C}$, considerada como condição de desconforto ao frio;

- Entre 19,0ㄷ a 25,5ㄷ , faixa de conforto térmico:

- Acima de 25,6드, significa desconforto ao calor. 
Tabela B.6: Resultados da Temperatura Efetiva (TE), para o dia e hora: junho de 2007.

\begin{tabular}{|c|c|c|c|c|c|c|c|c|c|c|c|c|c|c|c|c|c|c|c|c|c|c|c|c|}
\hline$D I A$ & $\bar{h}$ & $1 \mathrm{~h}$ & $2 h$ & $\bar{h}$ & $\overline{4 h}$ & $\bar{h}$ & $6 h$ & $7 h$ & $8 \mathrm{~h}$ & $9 h$ & $10 \mathrm{~h}$ & $11 h$ & $12 h$ & $13 \mathrm{~h}$ & $14 h$ & $15 h$ & $16 \mathrm{~h}$ & $17 h$ & $18 \mathrm{~h}$ & $19 h$ & $20 h$ & $21 h$ & $22 h$ & $23 h$ \\
\hline 1 & 0,5 & 16,3 & 6 & 2,7 & 2,4 & & 12,3 & 164 & 16,8 & 17,3 & 186 & 9,1 & 198 & 06 & 214 & 22,0 & 19 & 21,8 & 21,2 & 200 & 20,4 & 203 & 200 & 19,8 \\
\hline 2 & & 19,9 &, 7 &, 4 & 8 & & 18,2 & & 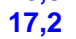 & 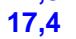 & & & & & 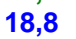 & 8,9 & r & & & & ,2 & & . & 16,9 \\
\hline 3 &, 3 & 16,6 & 16,1 & 5,5 & 14,9 & 2,7 & 14,3 & 12,4 & 2,7 & 12,8 & 13,9 & 4,6 & 15,0 & 7,4 & 18,4 & 18,7 & 0,8 & 16,4 & 5,4 & 4,5 & 4,0 & 3,4 & 2,8 & 2,8 \\
\hline 4 & & 11,0 & 7 & 0 & 9,8 & 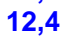 & 104 & 10,2 & 7 & 124 & 0 & 10 & $=0$ & $\therefore 0$ & 77 & $18 ?$ & 0 & 81 & 50 & 54 & 4,9 & 46 & 3,6 & 3,6 \\
\hline 5 & & 11,4 & 11,2 & 0,3 & 9,8 & 9,4 & 9,4 & 11 & 3,0 & 15,0 & 17,3 & 9,0 & 19,3 & , , & 20,1 & 100 & & 19,8 & & 8,2 & 0,4 & & 0 & 5,0 \\
\hline 6 & 8 & 12,8 & 12,7 & 33 & & 4 & 13,4 & & 5 & 15,5 & 17,7 & & 19,0 & 0,2 & 20,5 & 21,0 & 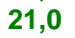 & 01 & 0,0 & 0. & ,8 & 9 & 18,4 & 18,8 \\
\hline 7 & & 18,0 & & & & 4 & 12,8 & & 8,9 & & 0,7 & 4 & 22,5 & 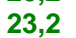 & 23,9 & 24,0 & & 23,8 & & 4 & & & 20,0 & 19,7 \\
\hline 8 & 0 & & 18,8 & & & 8 & 100 & & & & 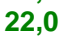 & & & & & & & & 3 & & & & & 0,6 \\
\hline 9 & , & & 3,2 & 3,7 & & (0 & & & , 2 & & 0 & 2,7 & & & 24,3 & & & & & & & & & 0,6 \\
\hline 10 & 6 & 18,4 & 8,2 & 3,0 & 17,9 &, 7 & 17,7 & 18,8 & 9,4 & 20,5 & 2,0 & 2,9 & & 3,8 & 24,0 & 3 & & & & 2,0 & & &, 5 & 19,4 \\
\hline 11 & & & & & & & & & & & & & & & & & & & ,4 & & 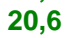 & &, 1 & 9,0 \\
\hline 13 & & & . & & & & & & & & & & & & 23 & & & & & & & & 19,2 & 9,1 \\
\hline 14 &, 5 & 18 & 4 & & & 1 & & & & & & & & & 24,0 & & & & & & & & 19,9 & 19,6 \\
\hline 15 & & & & & & & & & & & & & & & & & & & & & & & & 0 \\
\hline 16 & 8 & & 4 & ,8 & & 8,0 & & &, $\mathrm{f}$ & & & & & & & & & & & & & & 9,5 & 9,4 \\
\hline 17 & & & 17 & & & 7, & & 18 & & & & & & & & & & & & & & & 4 & \\
\hline 18 & & & & & & & & & & & & & & & & & & & & & & & & 6 \\
\hline 19 & 1 & & 18,7 & & & 18,2 & & 19 & & & & & & & & & & & & & & &, 7 & 0,6 \\
\hline 20 & & & & & & & & & & & & & & & & & & & & & & & & \\
\hline 21 & 3,1 & & 18 , & & & & & & & & & & & & & & & & & & & & & 9,2 \\
\hline 22 & 2 & & & & & & & & & & & & & & & & & & & & & & & \\
\hline 23 & & & & & & & & & & & & & & & & & & & & & & & & \\
\hline 25 & & & & & & & & & & & & & & & & & & & & & & & & \\
\hline 26 & & & & & & & & & & & & & & & & & & & & & & & & \\
\hline 27 & & & & & & & & & & & & & & & & & & & & & & & 4 & \\
\hline 28 & & & & & & & & 14 & & & & & & & & & & & & & & & & 4 \\
\hline 29 & & 14 & & & & & & & & & & & & & & & & & & & & & 9 & 16,7 \\
\hline a &,$f$ & & 14,9 & 6 & 14 & 4, & 1 & 3, & 4 & 14 & 17 & 20 & & , & 0 & & 20 & & & 8 & 2 & & 18,8 & 17,0 \\
\hline & $(.5$ & 6, & & 6.5 & & & 5,8 & & 2 & 18,3 & 19,6 & 20,7 & 21,4 & 2,0 & 22,4 & 22,5 & 22,4 & 22,1 & 21,2 & 20,2 & 9,7 & 19,2 & 18,9 & 18,1 \\
\hline
\end{tabular}

- Abaixo de $18,9^{\circ} \mathrm{C}$, considerada como condição de desconforto ao frio;

- Entre 19,0ㄷ a 25,5ㄷ $\mathrm{C}$, faixa de conforto térmico:

- Acima de 25,6드, significa desconforto ao calor. 